LIME PLASTER USE AT LBA KALAVASOS-AYIOS DHIMITRIOS (CYPRUS) 


\section{LIME PLASTER USE AT LATE BRONZE AGE KALAVASOS-AYIOS DHIMITRIOS (CYPRUS): EVIDENCE FOR APPLICATION-SPECIFIC RECIPES AND THE CREATION OF SOCIAL SPACE}

\section{By PETER TATSUO WALLACE, B.A}

A Thesis Submitted to the School of Graduate Studies in Partial Fulfillment of the Requirements for the Degree Master of Arts

McMaster University (C) Copyright by Peter Wallace, October 2017 
Master's Thesis - P Wallace; McMaster University - Anthropology

McMaster University MASTER OF ARTS (2017) Hamilton, Ontario (Anthropology)

TITLE: Lime Plaster Use at Late Bronze Age Kalavasos-Ayios Dhimitrios (Cyprus): Evidence for Application-Specific Recipes and the Creation of Social Space AUTHOR:

Peter Tatsuo Wallace, B.A. (Simon Fraser University). SUPERVISOR: Associate Professor Tristan Carter. NUMBER OF PAGES: xv, 184. 


\section{Lay Abstract}

Craft specialization is a core feature of urban life but the process of specialization is not perfectly understood. This thesis seeks to explore the use of lime plaster for constructing surfaces at the Late Bronze Age (LBA) site of Kalavasos-Ayios Dhimitrios (K-AD) on the island of Cyprus. Previous research has revealed a central, monumental complex, among the first of its kind on the island, surrounded by an early city. How did the LBA people create their living environment in this new setting? This thesis has shown, through the analysis of lime plaster features, floors and walls that the LBA inhabitants of K-AD were able to create diverse, specialized surfaces with a specialized lime plaster tradition in a scale and complexity that went beyond structural requirements, suggesting these surfaces were constructed with the explicit intent for creating space imbued with social meaning. 


\section{Abstract}

Kalavasos-Ayios Dhimitrios (K-AD; Figure 1) is a Late Bronze Age (LBA) settlement on Cyprus. It is notable for having among the earliest examples of urbanism and monumental architecture on the island along side the sites of, for example, Kition, Alassa, Enkomi, and Maroni (Philokyprou 2011; Fisher et al. in press; Figure 1). The LBA on Cyprus marked the beginning of urban society, economy and architecture in Cyprus (Fisher et al. in press). This study explores the social processes associated with the transition to urbanism represented by the entangled relationship between the architectural creation of social spaces and the use of these spaces as platforms for the creation and negotiation of power and influence (Fisher 2009a, 2009b; Fisher et al. in press). Specifically this study will concentrate on the construction of plaster surfaces, the immobile architecture of these social spaces, as indexes of the social development at KAD during the LBA.

Analysis of pyrogenic lime and gypsum plasters was carried out using highresolution microscopic methods based on the integration of petrography and soil micromorphology. These techniques are employed to optically examine in-situ and oriented plaster samples in laboratory thin section. Laboratory Fourier-transform infrared spectroscopy (FT-IR) analysis was applied to loose sediments to obtain spectroscopic data when necessary.

Following the findings that lime plaster recipe variation is the result of human choice (Kingery et al. 1988; Love 2011, 2013a) the results of this analysis shows that the LBA architects at K-AD produced different recipes for different utilitarian uses and also 
that the construction of elite spaces demanded complex recipes that extend beyond utilitarian requirements, which can be classified as more "expensive," resource-draining procedures (Kingery et al. 1988; Love 2011). Plaster is used at K-AD for both functional purposes and as an active component in societal creation and transformation.

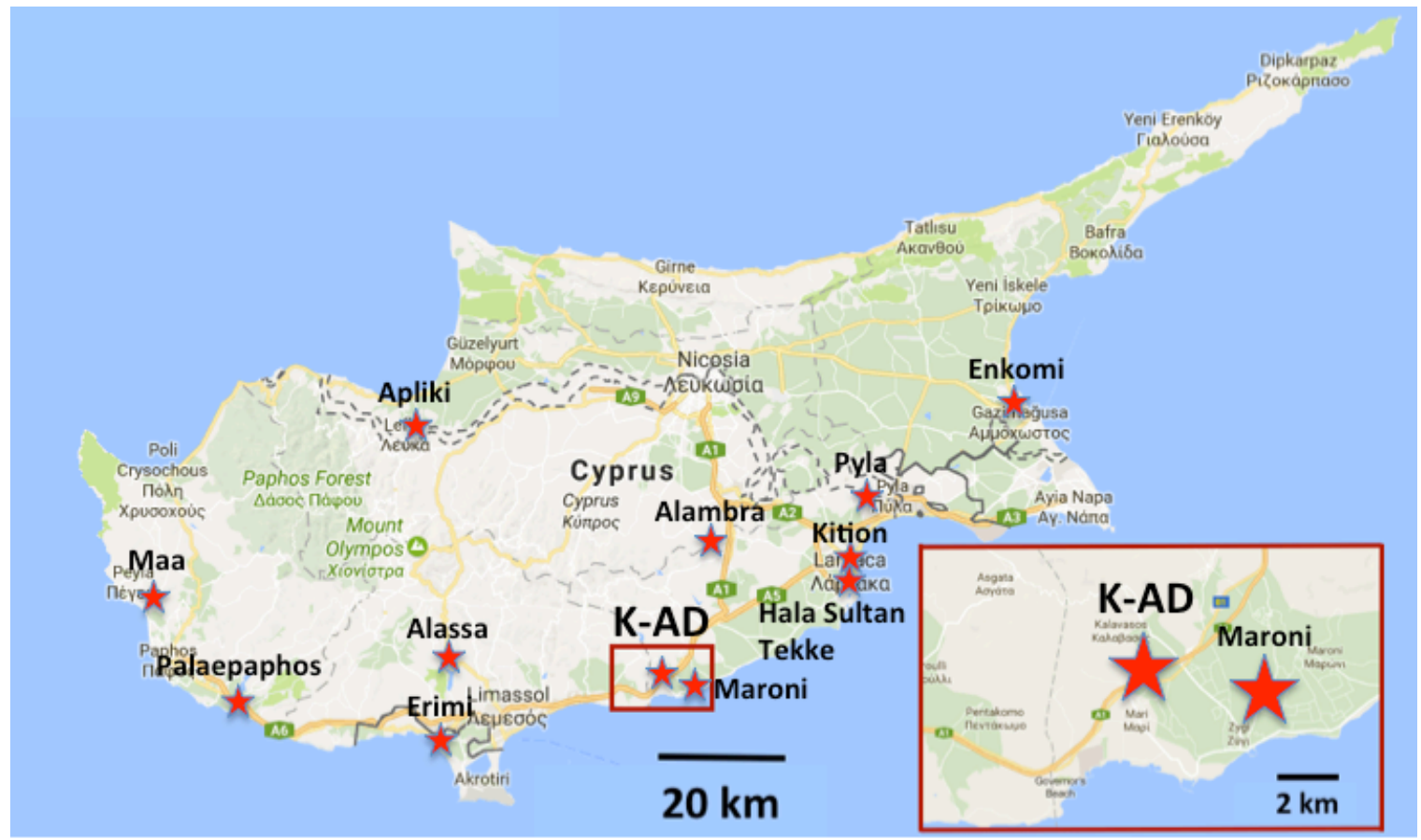

Figure 1. Map of Cyprus with K-AD as an insert and a selection of LBA sites. Credit: Google Maps, edited by the Author. 
Master's Thesis - P Wallace; McMaster University - Anthropology

\section{Keywords}

Urbanization, social space, place, social interaction, construction traditions, practice, plaster, technology, Cyprus, Late Bronze Age, micromorphology, FT-IR 


\section{Acknowledgements}

I would like to thank my committee first and foremost for the education I received in the process of compiling this body of work. Thank you to my supervisor Dr. Tristan Carter for the time you spent helping me structure this thesis in a coherent fashion and for pushing my focus towards the bigger anthropological picture beyond the scientific archaeology details of my work. I want to express my gratitude to you for your work in making this project a success. A big thank you goes out to my committee member Dr. Francesco Berna, my maestro of soil micromorphology and FT-IR ho taught me everything over the last four years. This project would have never happened without you. A special thank you to my third reader Dr. Maria Philokyprou for your advice on how to develop my thesis and encouragement during the defense that the last two years produced a good project! I am very appreciative for the encouragement for future research.

A special thank you to Dr. Kevin Fisher, co-director of the KAMBE Project that oversees the new research at K-AD. This project all began with your presentation at Simon Fraser University. A special thank you to Dr. Alison South for your introduction to $\mathrm{K}-\mathrm{AD}$ on site and for your correspondence and encouragement with the project. I hope I have helped you and many others to understand the people of K-AD. A special thank you to Dr. Alan Dickin for lending me one of your personal petrographic microscopes to use for my research! A special thank you to Dr. Dongya Yang for all the hours you spent discussing academics with me, and always without any hesitation. A special thank you to 
Dr. Barbara Winter who once told me to "JUST WRITE IT!" You should know how helpful those words have been over the last six months.

I would also like to thank my mom, Paige Yano, for raising me, sending me care packages from B.C. when I first moved to Ontario, the incessant support and asking me "when are finishing?" ad nauseum! I appreciate it all very much.

Finally I thank my fellow graduate students Senior Master Tyler Murchie, recently-minted Master Éloi Bérubé, and soon-to-be Master Miriam Karrel. The struggle would not have been as much fun without you! I will miss the whisky, French, board games, travelling, and all our joking around! I will miss you guys cringing ay my jokes already do.

An overall thank you to the members of the Department of Anthropology for the last two years, with a special thank you to John Silva for you wonderful help answering all my questions regarding administration and Portuguese food! 


\section{Table of Contents}

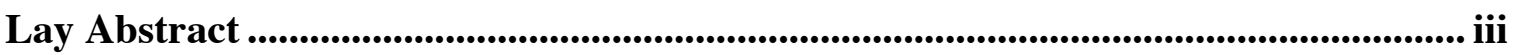

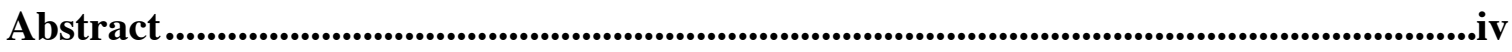

Keywords ................................................................................................................................vi

Acknowledgements .................................................................................................... vii

Table of Contents ....................................................................................................................ix

List of Figures........................................................................................................................................

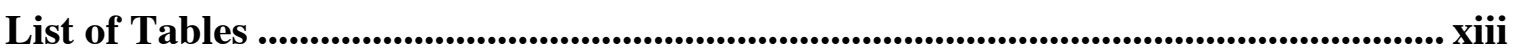

List of Abbreviations ...........................................................................................................xiv

Declaration of Academic Achievement ......................................................................................xv

1. Introduction to the Project.......................................................................................................1

1.1 Urbanization and its Consequences for Socio-Technical Practices ...................................6

2. Background to Kalavasos-Ayios Dhimitrios and Cyprus................................................16

2.1 Climate and Flora ...........................................................................................................................17

2.2 An Overview of Cypriot Geology ……………………...............................................................18

2.2.1 The Geological Context of Kalavasos-Ayios Dhimitrios ……………………………....19

2.3 Human Occupation of Cyprus......................................................................................................20

2.4 The Cypriot Late Bronze Age and the Rise of Urbanization/Alašiya ...............................21

2.5 Vasilikos Valley Project: Settlement Dynamics in the Vasilikos Valley (Cyprus) from

the Pre-Pottery Neolithic - Late Cypriot IIC ..........................................................................25

2.5.1 Neolithic Kalavasos-Tenta …………………………………………………......27

2.6 Late Cypriot II Kalavasos-Ayios Dhimitrios................................................................................28

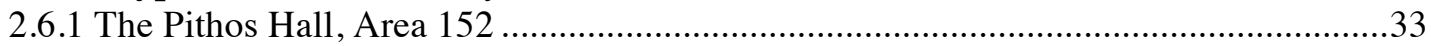

2.6.2 Other areas within Building X................................................................................37

2.7 KAMBE Excavations...................................................................................................................38

3. Technical traditions in the context of urbanization / 'social complexity' ................41

4. Plaster Chemistry and Identification .................................................................................46

4.1 Identification and Analysis of Plaster ................................................................................50

4.1.1 Identification and Analysis of Plaster Using Optical Microscopy (Petrography and Soil

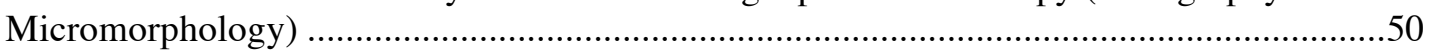

4.1.2 The Identification and Analysis of Plaster Using FT-IR.............................................53

5. Samples, Materials and Methods..........................................................................................54

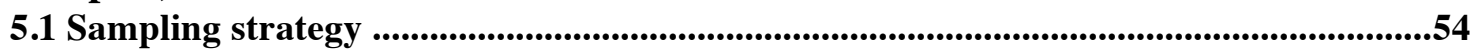

5.2 Collecting and Processing Samples ............................................................................................57

5.3 Optical Microscopy (Petrography and Soil Micromorphology) ........................................61

5.4 FT-IR .......................................................................................................................................66

6. Results of the Microscopic Analysis (Petrography and Soil Micromorphology) ...69 


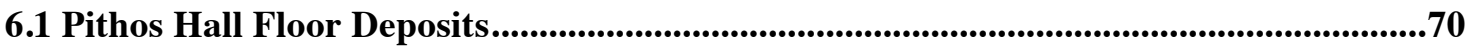

6.1.1 Pithos Hall Floor Deposits from Central Column Sequence .......................................70

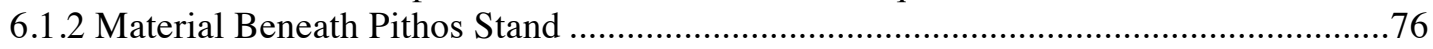

6.2 Plaster-Covered Steps.....................................................................................................................77

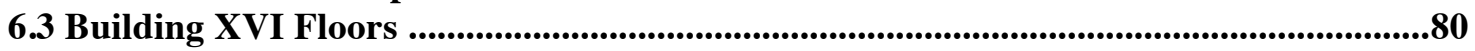

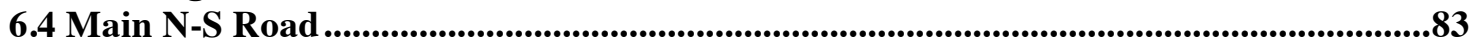

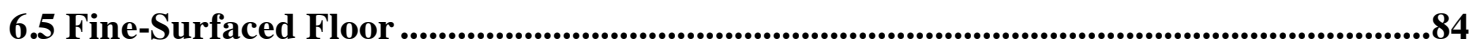

6.6 Pebble Floor in B.X Northern Pithos Storage Area ............................................................86

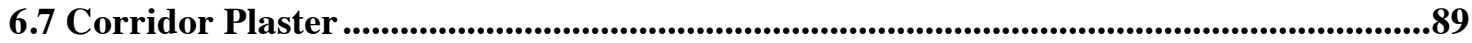

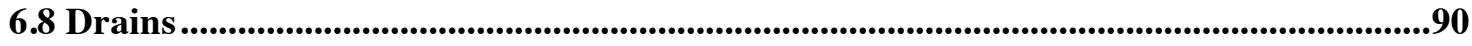

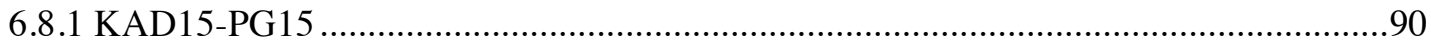

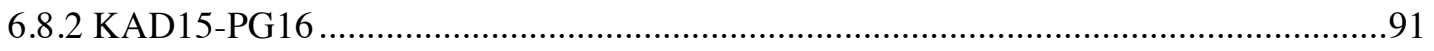

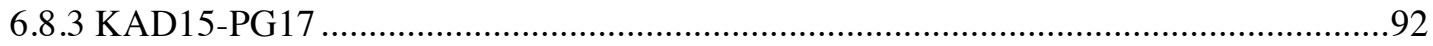

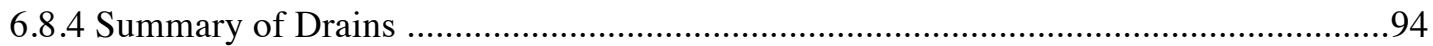

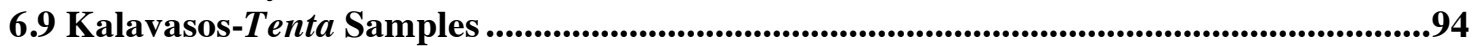

6.10 Pithos Hall Mudbrick-Adhered Fragments from the Storage Facility .........................95

6.11 Subterranean Plaster Chunk from Pre-LCIIC Context .................................................98

6.12 Area 174 Samples from 1994 .................................................................................................99

6.13 Summary of the Microscopic Analysis ......................................................................100

7. Results of the FT-IR Analyses............................................................................102

7.1 Archaeological Samples of the Red Sediment from Area 152 .........................................102

7.2 Drapia Geological Samples and Experiment ......................................................................103

7.3 Terra Rossa Samples from Kalavasos Village and Farmer's Field ..............................105

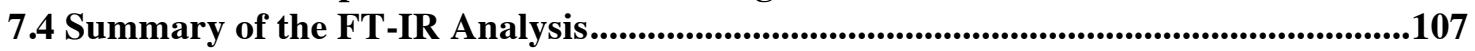

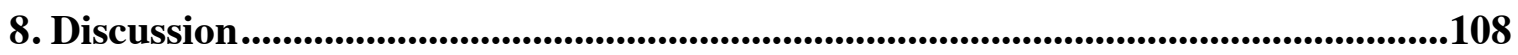

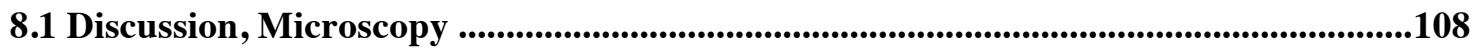

8.2 Discussion, FT-IR .............................................................................................................................119

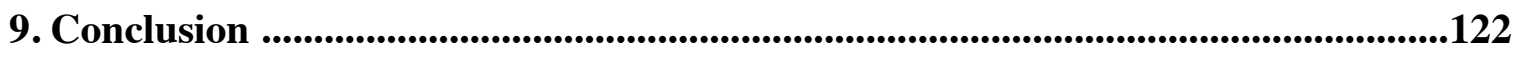

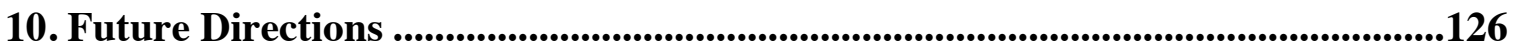

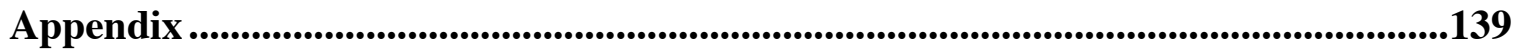




\section{List of Figures}

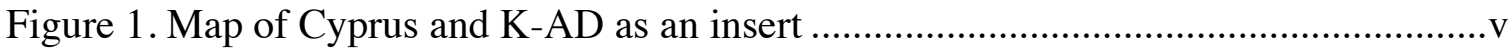

Figure 2. Map of Cyprus in the eastern Mediterranean ............................................. 16

Figure 3. Map of the geological zones of Cyprus .......................................................... 18

Figure 4. Map of the lithology, with radii, around K-AD ..........................................20

Figure 5. Map of the Vasilikos dam, valley and surrounding regions ............................26

Figure 6. Image of the Pithos Hall with Kalavasos-Tenta located in the top center

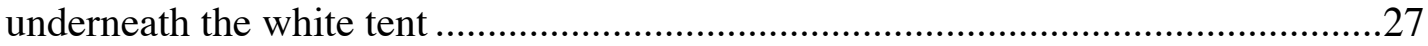

Figure 7. Map of the extent of K-AD based on surface finds and location of the A1

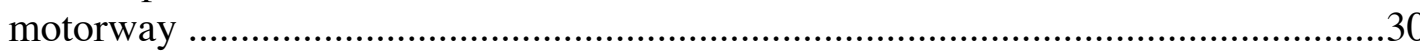

Figure 8. Pithos Hall facing northwest with pithos stone bases and plaster-covered stairs

9. Provenience of thin section samples....

Figure 10. Front view of intact block sample KAD15-MM23, Area 161, before wrapping

Figure 11. Front view of intact block sample KAD15-MM23, Area 161 wrapped in

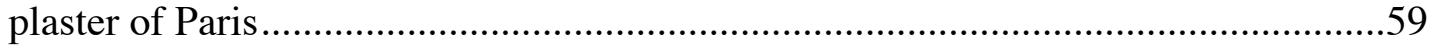

Figure 12. Top view of intact block sample KAD15-MM23, Area 161, wrapped in plaster of Paris.

Figure 13. Sample KAD15-MM15-1, the main N-S road, in a plastic container with packing in preparation for imbedding with polyester resin after drying it in an over for two days.

Figure 14. Sample KAD15-MM14, Unit 7, Building XVI sondage, after imbedding and cutting

Figure 15. Example of microscopic analysis of thin section KAD15-PG05-1. Multiple images

Figure 16. Infrared spectra comparing pure calcite (a), a calcite and quartz mixture (b), and a calcite and clay mixture.

Figure 17. Pithos Hall Samples. Multiple images.......................................................... 71

Figure 18. Micritic calcite units KAD15-MM21-L3 (A) and KAD15-MM15-1 (B) with dendritic mineral stains. Multiple images ........................................................... 72

Figure 19. Microscan detail of artificial pozzolanic material within KAD15-MM22 layers. Multiple images

Figure 20. Building XVI sondage block sample, KAD15-MM14, with five areas traced out for processing into thin sections a-e with thin section -MM14b and microscan detail of two microstratigraphic units M7 and L7. Multiple images ....

Figure 21. Thicknesses of KAD15-MM14 units grouped as Layers and Matrixes...........81

Figure 22. KAD15-MM14 units arranged from top to bottom displaying fine mass ........82

Figure 23. KAD15-MM15-1c. Secondary calcium carbonate void coating, $400 \mu \mathrm{m}$ thick 84 Figure 24. Unit 3 facing north. Fine-surfaced floor sampling locations. Multiple images 85 Figure 25. Northern Building X samples. Multiple images ........................................ 87

Figure 26. Plaster drain samples, Area 191 
Master's Thesis - P Wallace; McMaster University - Anthropology

Figure 27. KAD15-IR64 and -IR105 compared to a library reference spectral curve of

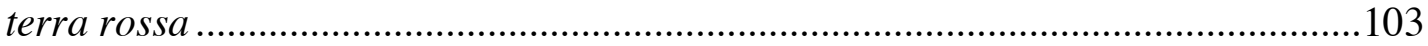

Figure 28. Spectral curve of terra rossa undergoing heat transformation .......................103

Figure 29. Spectral curve of umber soil near Drapia undergoing heat transformation....105 Figure 30. Spectral curves of sediment from a farmer's field (KAD15-IRD07) and two geological samples (KAD15-MM26-1 and -MM27-1) ........................................106

Figure 31. Resource volume of Pithos Hall floor units ..................................................112 
Master's Thesis - P Wallace; McMaster University - Anthropology

\section{List of Tables}

Table 1. B.X, A.152 Pithos Hall floor sequence ………….........................................112 


\section{List of Abbreviations}

$\begin{array}{ll}\text { B.C.E } & \text { Before Common Era } \\ \text { FT-IR } & \text { Fourier-transform infrared spectroscopy } \\ \text { K-AD } & \text { Kalavasos-Ayios Dhimitrios } \\ \text { KAD15 } & \text { "KAD" = K-AD site designation; "15" = 2015 (year of excavation) } \\ \text { KAMBE } & \text { Kalavasos and Maroni Built Environments Project } \\ \text { LBA } & \text { Late Bronze Age } \\ \text { LCII } & \text { Late Cypriot II } \\ \text { Ma } & \text { million years ago } \\ \text { MM } & \text { micromorphology } \\ \text { PG } & \text { petrographic } \\ \text { PPL } & \text { plane polarized light } \\ \text { SEM } & \text { scanning electron microscope } \\ \text { VWC } & \text { volumetric water content } \\ \text { XPL } & \text { crossed polarizers }\end{array}$




\section{Declaration of Academic Achievement}

Previous laboratory-based analyses of plasters from Cyprus are limited (Philokyprou 2012: 172). Indeed the analysis of the relatively abundant assemblage of earthen-based construction materials, as outline above, is rare. In this study I will contribute to this section of the literature with an explicitly social analysis of plaster technology. This study will contribute to the archaeological literature on urbanism, Cypriot and eastern Mediterranean by exploring our understanding of conscious design and the creation of social space at an early urban site on Cyprus, K-AD through the study of a ubiquitous and everyday material, plaster. This is an innovative study that exploits the potential of these overlooked data-sets. 


\section{Introduction to the Project}

Lime and gypsum plasters are common construction materials globally whose history of manufacture and use spans over ten thousand years (e.g. Kingery et al. 1988; Philokyprou 2012). Plaster, as the term is used in this study, is a product of pyrotechnology that exploits the chemical reduction of fired rock (limestone or gypsum) that when mixed with water forms a paste that dries back into the original rock (see section 4). This technology enables people to essentially mold liquid rock with three ingredients: a 'parent' raw material of limestone (calcium carbonate) or gypsum (calcium sulphate), fire and water.

The history of plaster use on the eastern Mediterranean island of Cyprus can be traced back at least nine thousand years ( $7^{\text {th }}$ millennium B.C.E.) to the Pre-Pottery Neolithic site Kalavasos-Tenta where it was used as a floor surface and to coat walls (South and Todd 1997; Philokyprou 2012). Some 5000 years later tonnes of plaster were used to create floors, roads and wall surfaces at K-AD (Figure 1), a Late Cypriot IIA-IIC settlement (LCIIA-IIC, during the Cypriot LBA; South 1984a).

Radiocarbon calendar dates place the LCIIC occupation of K-AD to 13251200BCE (Manning 2013 in Knapp 2013a: 521), a period of increased contact with eastern Mediterranean mainland and ever increasing local social stratification (see South 1995; South and Todd 1997; Fisher 2009a; Knapp 2013a: 348-358). These shifts are impressive and rapid - in part demonstrated by new architectural forms and the observed array of plasters across the site area as floors, wall surfaces and roads (South 1982, 1983, 
1984a, 1995). This project subjected samples of these surfaces to formal laboratory analysis in order to more fully understand the ways in which this common construction material was used during this period of social change.

In this thesis it is argued that the changing social processes witnessed at K-AD can be investigated through a contextual analysis of the site's plaster walls and floors. This hypothesis follows Fisher (2009a) and Fisher et al. (in press) who suggest the architectural developments at K-AD were not a strict product of an urbanizing social fabric. Rather these structures played an integral and active role in forming place in which roles were continually negotiated. Specific application traditions were socially integral components of monumental structures in this emerging urban socioeconomic society.

The archaeological assemblage of plaster is particularly well suited for this analysis. It is a recipe-based pyrotechnology that varies in composition as a result of the choices made by people rather than by geologic determinism (Love 2011, 2013a) and its use follows a conservative tradition of skilled and deliberate application (Kingery et al. 1988). The observed variations revealed in this study are the deliberate result of the skilled architects and decision-makers of K-AD. All variation - microscopically, macroscopically, and spectrographically - among the samples studied in this research project can and will be viewed as the result of social decisions with extra-utilitarian (social) implications. That is to say that variation among the samples will not be random, nor will all surfaces have the same method of construction. The variations observed should reflect a conservation of tradition between similar surfaces and a differentiation 
among surfaces according to their placement within or without the monumental complex at $\mathrm{K}-\mathrm{AD}$.

The fragmentary archaeological record and the restrictions it places on this field of inquiry should be familiar to many researchers. Ceramic wares and stone tools are among the few material assemblages that preserve in the archaeological record magnificently well and have been favourite media of analyses over the long term (e.g. Childe 1925). More importantly than preservation, however, researchers have been able to hypothesize the connection ceramics or lithics had to human society by their variation perceivable to the unaided eye - be it decoration, dimensions or choice of raw material. Plaster is also a common technology that has become abundant in the archaeological record over its thousands of years of use by human societies. It is specifically abundant at LBA Cypriot sites, among others, but it has not been 'visible' or theoretically connected to social processes in the same way ceramics or lithics have been, until recently.

Modern advances in microarchaeological research (see Weiner 2010 for a volume on microarchaeology) and theory (see Section 1 [below], Section 3) have opened the door to studying the abundant earthen-based construction materials (e.g. mudbrick, plaster, mortar) as products of social processes. With the help of high-resolution analyses these material assemblages that in certain contexts vastly outnumber in volume other archaeological assemblages (Love 2011) yield to the researcher their unique variations and adornments. Earthen-based construction materials can be seen as socially imbued artifacts, along side ceramics and lithics. 
Recent high-resolution archaeological studies have explored sediments (Pauketat and Alt 2005; Jusseret 2010; Bauer in press), mudbricks (Matthews 2005; Love 2011, 2013a) and plasters (Theodoridou et al. 2013; Turco et al. 2016) among others. The repertoire of techniques employed to study the microscopic record (following Wright 1992, in Turco et al. 2016; Weiner 2010) include micromorphology (Goldberg 1979; Berna et al. 2007; Shahack-Gross and Finkelstein 2007; Philokyprou 2012; Goshen et al. 2017), X-ray fluorescence and X-ray diffraction (Berna et al. 2007; Nodarou et al. 2008; Love 2011; Miriello et al 2013), FT-IR (Weiner 2010; Anderson et al 2014; Goshen et al. 2017), Raman spectroscopy (Martinez-Ramirez et al. 2003), loss on ignition (Love 2011), and geophysical analysis (Manning et al. 2014). These techniques occupy a wide range of technical capabilities and are not all financially practical for most researchers, with FT-IR being among the cheapest and most practical techniques to identify mineral components and micromorphology providing the capability to study materials in a preserved, in-situ state that may also be further analyzed in the future.

The above inquiries have developed alongside a body of theory that connects geologic technologies to the social world (e.g. Bauer in press; Pauketat and Alt 2005). It has been argued persuasively that earthen-based construction materials are thoughtful products of cultural traditions. These traditions can be viewed in terms of cultural reproduction through active engagement by society with the tradition in a living system. Traditions become active components that are created and recreated by (often conservative) reproduction, otherwise known as habitus (Bourdieu 1977) enabling geologic materials to be approached as appropriate media with which to engage with 
social questions (e.g. Kingery et al. 1988; Pauketat and Alt 2005; Love 2011; Bauer in press). By understanding the processes involved in geological material culture construction we can ask questions about societal organization (Love 2011), unintended consequences (Bauer in press), and social change (Pauketat and Alt 2005; Dobres 2010).

The questions this project addresses are: what were the effects of urbanism with regards to lime and gypsum plaster surface construction at K-AD? Did plaster technology change over time and across different social spaces at $\mathrm{K}-\mathrm{AD}$, according to the dialectic relationship of population density, socioeconomics and craft specialization? And, can we use the 'mundane' archaeological record of pyrogenic plaster technology as an index to view social and economic capital at K-AD? Samples (see Figure 9 and Appendix Image 45 for locations) will be compared in an intra-site analysis that will compare and quantify constituent material to address compositional, and therefore recipe variations between key areas and features.

Analytically the research questions are addressed by means of micromorphological analysis, a high-resolution visual method that allows in-situ samples to be viewed under the microscope. This is a process that will enable the distinction of constituent materials such as lime or gypsum plaster, as well as microstratigraphic fabric units (see section 5.3 for details) that are not visible with the naked eye. Fourier-transform infrared spectroscopy (FT-IR) is also employed. This is a chemical analysis where discrete spectral curves from covalent chemical bonds are used to determine constituent chemical compounds and crystalline phases, the aim being to identify material crystalline 
phases where optical means are not sufficient, such as in the case of sediments or other mixed material.

Concerning data sets employed for this study, dozens of plastered surfaces have been exposed from large-scale excavations at K-AD with many displaying unique visual characteristics, which appear to be the result of the disparate application of plaster recipes across the site. Individual surfaces appear to be homogeneous in composition indicating the observed changes are intentional, not least between the monumental center and outside areas.

\subsection{Urbanization and its Consequences for Socio-Technical Practices}

In this section I will discuss the academic inquiry into the phenomenon of urbanism more broadly and discuss how researchers have sought to understand and explain the transformations of social roles involved in the navigating of lives in an urban environment. I then introduce the expected changes at K-AD during an urban transformation with particular reference to craft traditions, specifically plastering technology. The specific context of K-AD's urbanism will be further explored in section 2.4 of this thesis.

Childe (1950) hypothesized that urban societies can be identified cross-culturally by ten common characteristics. These include, among others, craft specialization, centralization of power among ruling elites, and the proliferation of created monumental public spaces (Childe 1950: 9-16). These common characteristics provide a means to label societies, modern and (pre)historic alike, as "urban" or not. They do not, however, enable the inquiry into the process of urbanization or the relationship between urbanism 
and the aforementioned ten static factors. The use of the term "revolution" to describe the changes a society undergoes from pre-urbanism to urban lifeways also implies a sudden large-scale shift between socio-economic processes, whereby a "progressive change" in organization provides the impetus or shock for other changes to follow suit. In this thesis it is argued that developments in technology and social organization are continuous processes that cannot be simplified to imagine a defined shift from one established predetermined state to another (e.g. Pauketat 2001: 85). In the case of K-AD specifically the evidence from the results of this study suggests, in part, in the affirmative this dialectic relationship and of the differentiation of plaster recipes according to both function and social space.

Craft specialization can be generally understood as the diversification and optimization of a task that are arrived at though trial, thought and practice by designated individuals on a (near) daily basis (i.e. specialists), within a cultural framework that imbues meaning into the craft and dialectically the craft influences the culture. While in certain instances such crafts might involve song, dance, navigation, etcetera (see Helms 1993: 14) this thesis is exclusively concerned with the tangible, specifically the production of plaster and its application to surfaces.

Craft specialization creates a wide range of possibilities to enhance a craft, from sourcing specialized raw materials to the final design on a product. These alterations can manifest at different stages of manufacture. For example, all crafts begin with the selection of materials from which to create the desired object; materials are ranked in value according to the established mode of exchange in the respective society. The value 
of the raw material selected at this stage will have direct effect on the value of the final product. This recurring pattern of the possibility to add value into a product is present at all steps in the manufacture of a craft. Resource scarcity and acquisition, the preparation of the material to make it suitable to use, and in the final execution of the craft by a tradesperson summarize additional moments where value can be added into the final product. In some cases a product can be commissioned, perhaps by an elite individual, who chooses a particular craftsperson for the task. Specific craftspeople with specific skillsets may also add value to the final product. To quote Helms (1993: 54), “...artisans themselves contain, exhibit, and control special powers that may harm as well as help society; that they evidence exceptional knowledge and intelligence and hence may be harmful magicians or adept at the occult and the demonic as well as being helpful bards, diviners, curers, and crafters of beneficial materials and activities." With various stages of specialization available the resting question is how does craft specialization permeate society and which crafts, at what levels, become specialized? Before we explore these questions let us first let us explore innovation.

When people come together or when there are challenges (in whatever form) to overcome, ideas proliferate. The following is an illustration to demonstrate the potential. Imagine there are two people $(a, b)$. They have their own ideas $(a, b)$ and they can form one pairing and have a discussion or a conversation. Two people can share their respective knowledge $(a+b)$. If you add a third person $(a, b, c)$ you create the potential for three unique conversational pairs $(\mathrm{a}+\mathrm{b}, \mathrm{a}+\mathrm{c}, \mathrm{b}+\mathrm{c})$. This follows the general patter that $n$ people have a network of $\frac{n^{2}-n}{2}$ possible paired relationships. Ten individuals have a 
network of $\frac{10^{2}-10}{2}=45$ unique pairings. If you include the potential for groups of three or more individuals the possibilities for discussion follow the formula $2^{n}-(n+1)$, which approximate $2^{n}$ when $n$ is large. What is evident in both equations is that potential groupings are related exponentially to the number of people. Urban centers are places where innovation and development can thrive on the understanding that a group on $n$ individuals have an exponentially greater potential than the sum of their respective beings (roughly $2^{n} \gg n$ ). The ten individuals mentioned previously can be arranged into $2^{10}-(10+1)=1013$ unique groupings of size 2 to 10 people. The more people there are, the more potential there is, but these people have to be in contact with one another and that is the environment an urban setting provides. Of course these equations do not necessitate the number of interactions taking place, nor do they assume all interactions share or generate knowledge. These merely serve to illustrate that when a population grows linearly potential increases exponentially.

Population increase is an important factor in urban societies but where these populations come from can have more of an effect than the number itself. Populations vary according to three general factors. The first is the number of births as the number of babies per woman can have a dramatic effect on a population. Think of China's infamous 'One-Child Policy' or the 'Baby Boomers' of the postwar years. The same effects on population can be seen with the second factor: mortality rates. The number of births will not have an effect on a population if the mortality rate remains high, especially among newborns. If life expectancy increases (i.e. rates of mortality decrease) and child mortality decreases a population will grow. This has been a general trend over the last 
100 years worldwide (www.gapminder.org/data). The final factor to consider for urban populations is migration, the movement of people in and out of an urban setting. Unlike births and deaths, which only effect one population, migrations reduce the population of emigration and increase the population of immigration. The three aforementioned factors of birth, mortality and transience all contribute to innovation and diversity.

A final consideration in the link between people, urbanism and innovation is the necessary ability of members of a society to engage with crafts. In Childe's (1950) work, The Urban Revolution he suggests categorizing human societies, past and present, in three "stages" of evolution-oriented social development that are defined by the inhabitants' means of procuring food. "Savages," the first of three progressive stages, collect their food while "barbarians" engage in some form of agriculture and occasionally animal husbandry. "Civilized people" are more complex to define but in keeping with our viewscape concerning subsistence it is clear that in the eyes of Childe civilized people have an urban social system that regulates the production, and distribution of food by a limited sector of the population to everyone else (Childe 1950: 3-4). Urban societies are centered on cities, permanent habitation areas of high population density with an emancipated sector of the workforce that is free from producing food to sustain their needs. Rather than working in food production they were free to dedicate their time to the specialization of other tasks (i.e. crafts) in order to solve the demands and problems that arise in communities with increased population densities and demanded sophisticated infrastructure (Childe 1950: 6-9). Urban societies are therefore associated directly with 
the appearance of a numerous and ever-expanding set of specialized groups including: potters, metalsmiths, administrators, architects, weavers, butchers inter alia.

Urban centers are bigger, denser, and have more public settings than non-urban settings. These large centers of permanent structures for habitation, employment and reproduction introduce new problems for their inhabitants to consider with large-scale construction. These new problems are on a larger scale than in non-urban settings, but the differences can be visualized as being a strict result of the size of a habitation center. More people demand in a sedentary society more roads to traverse, more homes to live, more pipes for water and sewage, etcetera. The scale of problems grow, although they scale sub-linearly to population (Cesaretti et al. 2016), the larger problems necessitate specialists with training and experience.

While a population grows linearly, problems increase sub-linearly while the potential to approach new problems scales exponentially. Individuals who grow up in an urban setting and those who arrive later in life can both apply their respective skills to new problems as they arise and contribute to task specialization. Having grown up in a non-urban setting individuals would likely have been introduced to a wide array of experiences unknown to urban people, and the converse is equally true. If individuals have migrated to an urban center they may be able to approach new problems in different ways according to their respective habitus. With different ways of thinking and creating between dense arrays of individuals innovation, social stratification and craft specialization grow. Entirely distinct communities can form from those dominated from transience over those with birth-dominated growth (Birch 2013: 1-16), most notably 
owing to the idea that individuals from disparate areas coming together may preclude an absence of precedent regarding community identity, leadership, and dispositions, allowing the new group to negotiate amongst themselves a potentially new identity and system(s) of innovation and specialization.

Work has been carried out to explain the reasons why people would choose to migrate to an urban center, or to migrate at all. So-called "push-pull" forces create a binomial situation where migration is dictated by "push" forces, unfavourable circumstances encouraging emigration, and "pull" forces, desired features of a new location that encourage immigration (see Anthony 1990).

Anthropologists have attempted to use several models to explain the observed changes in the organization of human societies and development of technologies and geography as seen through material culture. Among many theories of change are the 'diffusion' model that explains change through the movement of ideas from one (advanced) society to another (lesser) one, 'invasion' to explain social change through physical movement of peoples, and 'evolution' to suggest technologies follow developmental procedures and can be compared from one culture to the next (Renfrew 1969). All these 'modes' of cultural change seek to explain the phenomena of a change in observable, tangible material culture; their introduction to academic anthropology stems often from theories of the day from outside disciplines: e.g. history and biology (e.g. Meskell 2002:282). What is of interest in this project is if the changes observed in architecture and the sixe of $\mathrm{K}-\mathrm{AD}$ permeate the fabric of this early urban site into the plaster surfaces, and to what extent these hitherto unstudied crafts at K-AD are 
specialized. The aforementioned specific models of change and discussions on specific topics such as identity and ethnicity can be further explored elsewhere (Childe 1925, 1950; Smith 1929; Renfrew 1969; Anthony 1990; Jones 1997, 2007; Dietler and Herbich 1998; Knapp and Antoniadou 1998; Meskell 2002, 2007).

The preceding paragraphs argue that cities promote the specialization of tasks. What is less clear, and will be argued with this thesis, is the idea that each step in craft specialization furthers the idea of the 'city' or 'urban area' in a dialectic living cycle. People are the key components in a city that may be overlooked in archaeological assemblages. Without individuals working, living, creating and innovating the dense collection of structures known as a city is nothing more than a collection of structures. It is therefore argued that step-by-step craft specialization promotes the idea of the city while the city enables and necessitates the specialization of crafts. In conjunction with the fact that the potential within a city can be exploited for, for example, the ability for socioeconomic rifts and 'classes' of people to emerge it is argues that these elites were able to harness the epitome of specialized crafts in the creation of a monumental structure at various levels of construction. Elite individuals are those in a society who derive political and economic power through the preferential access and distribution of goods, particularly those produced by specialists (Helms 1993: 4).

We can ask ourselves when did a city come into being? Where is the threshold where we can begin to look at the effects that the 'city' had on craft specialization? The words of Timothy Pauketat (2001: 86), "Cahokia was always in a state of becoming," suggest succinctly we can visualize the 'city' or any urban/non-urban habitation setting as 
a living, changing collection of humans and their materials with no start time and date. Sites are not created: they exist as a complex living system. Pauketat's suggestion is that archaeological sites were dynamic environments in the past and will continue to develop in the modern day so long as people continue to react to them in different ways (Pauketat 2001). We can follow this line of reasoning to re-assert that craft specialization, the development of craft diversity and the growth of urban centers are created in conjunction.

This is not to say developments of crafts do not occur in non-urban settings. Only that that the difference between the rate of innovation in urban and non-urban setting is scaled with fewer individuals in non-urban settings and a more confined level of 'necessity' that dampens 'invention.' The result is that in comparison to an urban setting in peripheral and previous regions craft specialization occurs at a slower temporal rate but arguably innovation proceeds at a rate proportional not to population over time (scalar growth to population) but to the number of interactions occurring over time (exponential growth to population). All artifacts can vary significantly and each is a highly personal creation (Dobres 2010). Personal innovation on artifacts has previously been described as isochrestic variation and is a result of an the interplay between an individual's dispositions, or habitus (Sackett 1990; Jones 1997) and a societies' shared doxa the deeper dispositions that are not altered that are characterized as uncritically and inadvertently accepted truths of a system that are continuously self-reified by that system (Bourdieu 1977: 164). Personal innovation can also occur by accident, which is then accepted and integrated into the mainstream tradition. In this way personal variation can 
be seen as non-deterministic (Gosden 2006) to a further degree than isochrestic variation can, which is constrained by personal (habitus) and societal (doxa) dispositions.

All societies can experience craft innovation, but large-scale society-wide changes in an urban society are more apparent as they occur more rapidly in time under the experienced hands of craft specialists. Specialists are able to dedicate their lives to creating their craft to a high standard. This thesis explores how this dialectic relationship between plaster surface constructions relates to the Northeast Area at K-AD, which likely wielded comparatively large social and economic capital over the site and region during the LBA. This is discussed in detail in the following section (2). 


\section{Background to Kalavasos-Ayios Dhimitrios and Cyprus}

Cyprus occupies a strategic and central location in the Eastern Mediterranean (Figure 2) and has been visited by settlers and traders for over ten thousand years. For most of the occupation of this island, however, life has been resigned to simple village economies. For two thousand years before the LBA the circum-Mediterranean region saw kingdoms and empires rise and fall without any such centralization of community, let alone an urban state, ever developing on Cyprus.

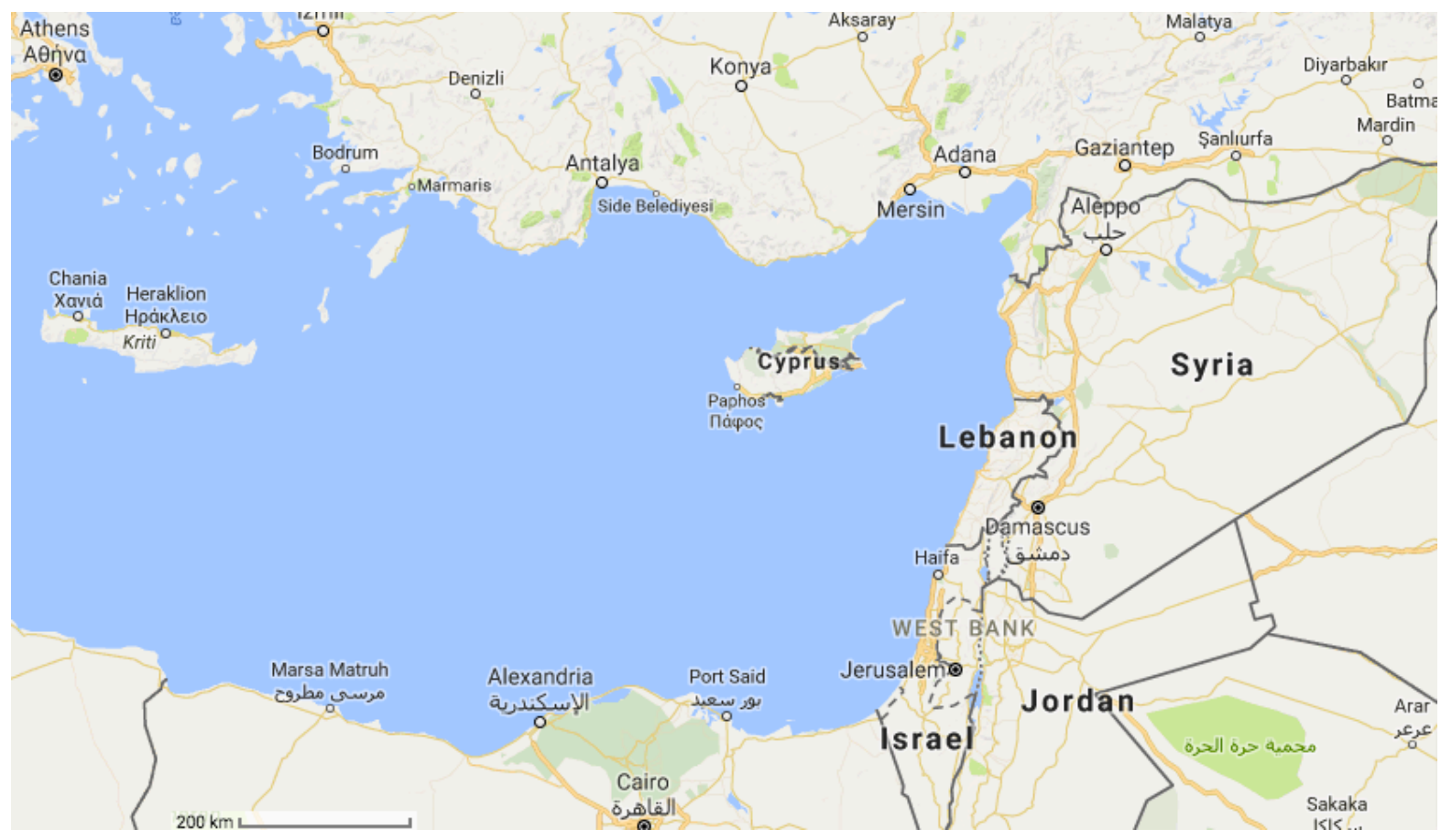

Figure 2. Cyprus (center) in the eastern Mediterranean. Credit: Google Maps.

In this chapter a summary Cypriot geography is provided to contextualize the 10,000 years of human occupation up to the LBA. Particular attention is placed on the south-central Vasilikos Valley, where the study site K-AD resides. This area of Cyprus has been the focus of a series of archaeological projects from the 1970's onward, most 
recently by the 2015 Kalavasos and Maroni Built Environments (KAMBE) excavation, material from which forms the basis of this research project.

\subsection{Climate and Flora}

Plaster is a pyrotechnology that requires an abundance of fuel and an available source of water. In this section I will bring the reader's attention to the climate and vegetation of Cyprus and the Vasilikos Valley as data pertinent to the manufacture of plaster.

The Vasilikos Valley and most of Cyprus experience a "Mediterranean" climate (shorthand "Csa") according to the Köppen-Geiger climate classification system (Kottek et al. 2006; Peel et al. 2007). The island thus has warm, temperate, wet winters with dry, hot summers. All rivers on Cyprus have intermittent flows that variably run dry in the summer months as a direct result of the winter rainfall received in a given year. According to Given and Knapp (2003: 132 in Jones 2007: 129) a practice of water management has been in place since the Roman period, although pre-Roman farming practices and aggregated settlements dating back to Neolithic times indicate prehistoric Cypriots have always a sophisticated capacity to manage their resources effectively. A system of water management has always been a vital part of Cypriot life.

LBA texts regarding the island's flora are limited owing to a general lack of available records, both translated (e.g. Akkadian) and untranslated (e.g. Cypro-Minoan) during this period (Keswani 1993). Most of the known written evidence from this period deals with financial and political matters between the Kingdom of Alašiya (an economic power on Cyprus; Goren 2003) and the surrounding kingdoms in Ugarit and Egypt 
(Goren 2003). The earliest surviving documents concerning Cypriot flora are those of the $1^{\text {st }}$ century CE Greek historian and geographer Strabo, over 1200 years after the occupation and abandonment of K-AD. He writes that Cyprus is a land rich with lush forests that impeded cultivation of the land (Geographica 14.6.5, in Knapp et al. 1990; in Jones 2007; in Government of Cyprus 2008; in Harris 2012). Among direct evidence of Late Cypriot flora from K-AD are the preserved charred wood roofing beams from Area 152 (A.152) and a "significant" deposit of botanical material in Area 173 that includes "lentils, grapes, pears, figs, olives, and members of the squash/cucumber/gourd family," (South 1991: 131). The flora available at K-AD during the LBA was diverse and human settlements we able to thrive unimpeded by the forests (contra Strabo).

\subsection{An Overview of Cypriot Geology}

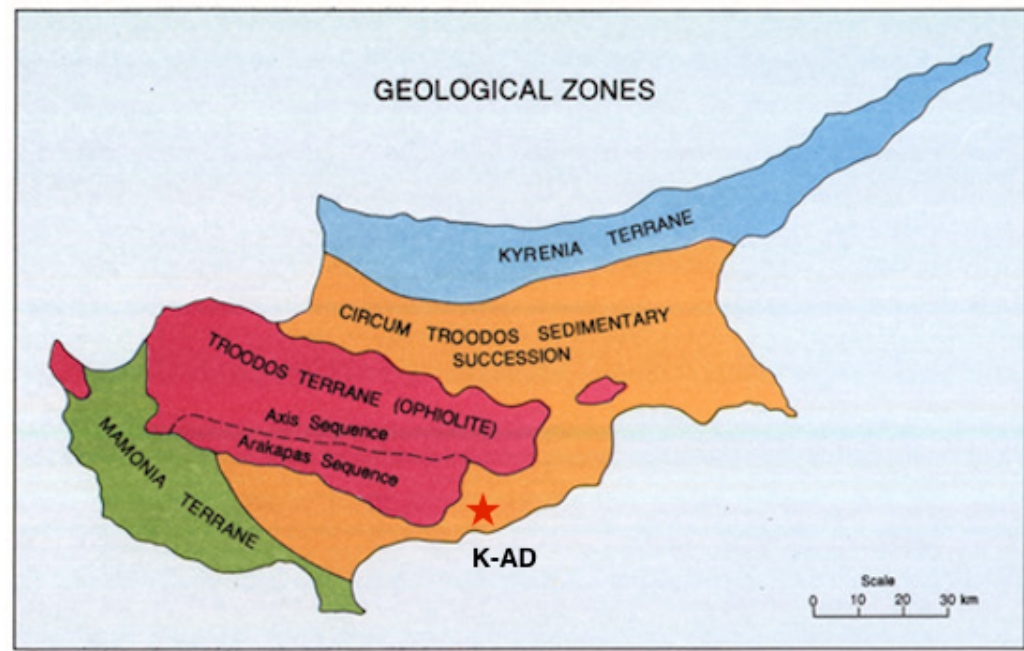

Figure 3. Geological zones of Cyprus. Credit: Government of Cyprus (1995).

Cypriot bedrock geology is a combination of sedimentary seafloor deposits, volcanic material, and continental crust that spans some 90 million years $(90 \mathrm{Ma})$ to a final tectonic uplift event 2 million years ago resulting in the Cyprus we see today (for details see 
Government of Cyprus 2002; Roveri et al. 2014). These geological processes have resulted in the formation of massive deposits of gypsum, limestone, chalk and marl evaporates $1 \mathrm{~m}$ to over $10 \mathrm{~m}$ thick, abundant raw resources that are scattered across the island (see Rouchy et al. 2001; Broodbank 2002: 63-82; Roveri et al. 2014). Limestone, chalk and marl are all calcium carbonate materials.

In addition to island-wide deposits of carbonates and gypsum Cyprus is in possession of a copper ores that have been mined since prehistory. The influence copper had on Cypriot history and identity is reflected in both its name being derived from the Greek "Kyprios" (copper), and copper-yellow being a main colour of its modern national flag. Copper deposits are found in the upper and lower pillow lavas that circumscribe the Troodos Mountains (Figure 3). K-AD is some $7 \mathrm{~km}$ south of the of these ore deposits in the Troodos foothills and $3 \mathrm{~km}$ north of the sea, a location that is believed to have been ideal for controlling regional trade (South 1980).

\subsubsection{The Geological Context of Kalavasos-Ayios Dhimitrios}

Today the LBA site of K-AD - where unexcavated - is covered in a white to beige silty-clay soil. Excavations at K-AD uncovered havara bedrock, a local carbonate marl (South 1984a; Schirmer 1998 for details on havara), although geological maps indicate the full $>10 \mathrm{Ha}$ site is constructed on variable geologies from Holocene alluvium to Pleistocene biocalcarenite and sandy marls (Figure 4). A series of alluvial terrace deposits and river cuts over the last $2 \mathrm{Ma}$ along the Vasilikos River has exposed four terraces from sea level of over 80m lateral elevation (Gomez 1987: 349). All constituent materials required to make lime plaster, gypsum plaster, or packed mud mortars are 


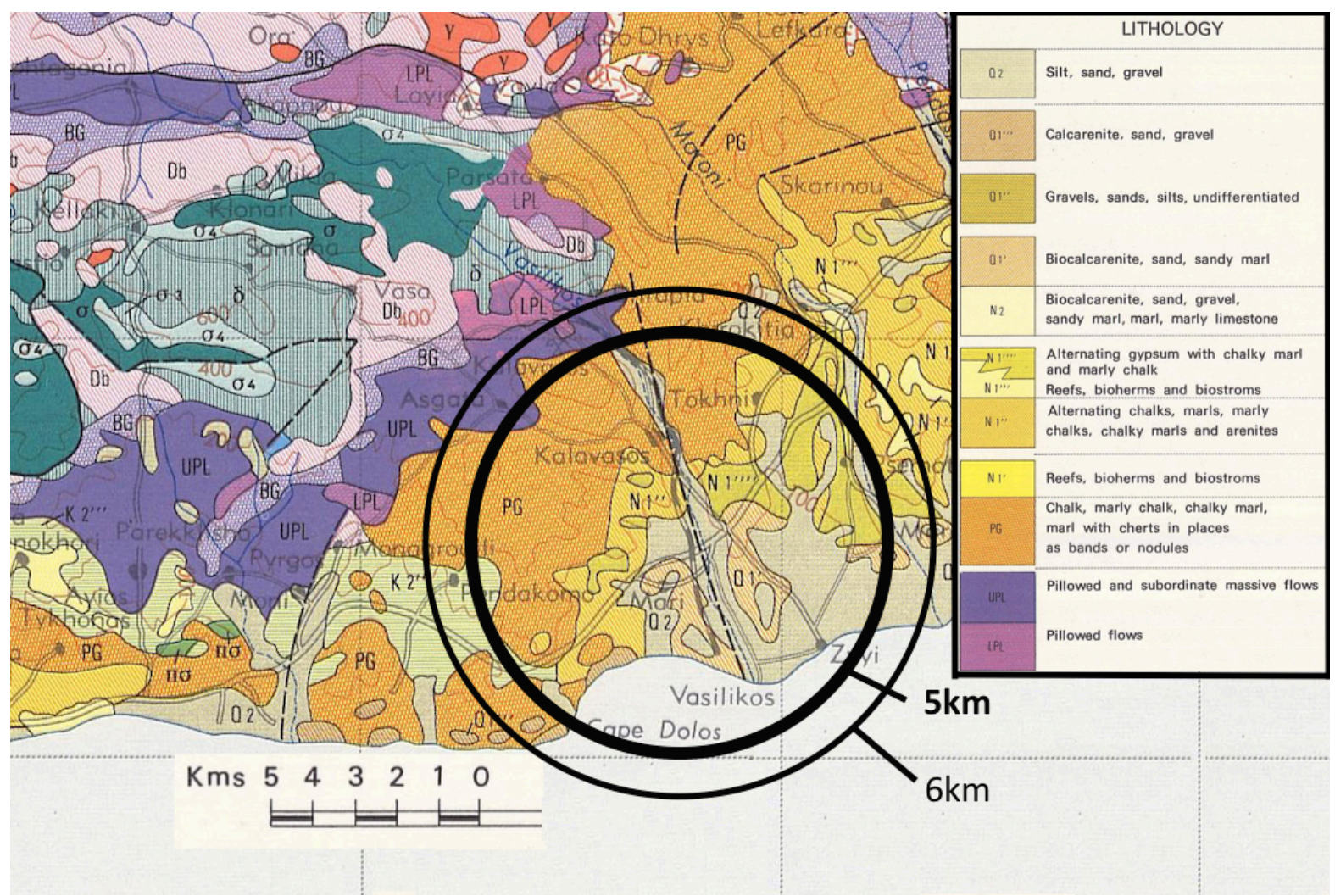

Figure 4. Lithology with radii around K-AD. Credit: Government of Cyprus (1979).

available within a $3 \mathrm{~km}$ radius around $\mathrm{K}-\mathrm{AD}$, and in substantial quantities (Figure 4). Tests of volumetric water content (VWC) during the dry summer months found a range from $5 \%$ at the surface to $24 \%$.3-.5m at deep (Urban et al. 2014: Fig. 4).

\subsection{Human Occupation of Cyprus}

Cyprus is an island located in the Eastern Mediterranean (Figure 2), some $100 \mathrm{~km}$ south of continental Anatolia, $200 \mathrm{~km}$ west of the Levant, $400 \mathrm{~km}$ north of Egypt, and $600 \mathrm{~km}$ east of Crete and the Aegean world.

The earliest archaeological site currently known on Cyprus is AkrotiriAetokremnos, a seasonally occupied rock shelter dated to the Epi-Paleolithic, c. 11,700 years before present (Knapp 2013a: 45-55). Despite recent claims for earlier activity on 
the island (Strasser et al. 2016) there is as of yet no concrete evidence to suggest that humans had the technological capabilities to reach Cyprus during the Early or Middle Paleolithic periods (Cherry and Leppard 2015).

The Epi-Paleolithic, Neolithic and Chalcolithic occupation preceding the LBA societies of Cyprus witnessed fluctuations in population size, settlement growth, and socio-economic complexity, the eras of fluorescence appearing to correlate with increased connectivity to the surrounding Eastern Mediterranean mainland. For example, a close connection between Cyprus and the Eastern Mediterranean mainland during the Early Aceramic Neolithic period is believed from the introduction of cattle and obsidian in the archaeological record; a connection that ends in the Late Aceramic Neolithic with the extinction of cattle, intensification in the use of deer the simplification of farming technologies and the replacement of obsidian with local chert in the archaeological record (Knapp 2013a: 77-194). The reintroduction of cattle following the Late Aceramic Neolithic and Chalcolithic periods is evidence of a re-established connection with the Eastern Mediterranean mainland and is paralleled with the introduction of the spindle whorl, the plough, and an eightfold increase in the number of sites to 345 (Knapp 2013a: 195-297). For a thorough introduction to Cypriot prehistory see Knapp 2013a.

\subsection{The Cypriot Late Bronze Age and the Rise of Urbanization/Alašiya}

The LBA on Cyprus is defined by structural, hierarchical, and material changes that have been associated with the development of greater sociopolitical complexity (Knapp 2013a: 348-358). The relatively isolated village economies of previous periods were replaced with at least part of Cyprus becoming a major political-economic power 
engaging in interregional socio-economic relations with state-level societies across the eastern Mediterranean (Goren et al. 2003). Knapp (2013a: 348) is his magnificent synthesis of Cypriot prehistory regards this LBA transition to be "an entirely different level and scale" than preceding alterations to social structure on the island. Innovations in copper casting, craft specialization and the first town centers with monumental architecture are among the significant changes that occurred at this time (Knapp 2013a: $348)$.

Urbanism is a major feature of many eastern Mediterranean LBA societies more generally (Crete, the Greek mainland, Anatolia, the Levant, Mesopotamia and Egypt) and in some cases an urban lifestyle was present for millennia before the first traces of urban life appears on Cyprus. From the Pre-Dynastic Egyptians to the Sumerians in Mesopotamia, urban life flourished for two thousand years on Cyprus' doorstep without, somewhat perplexedly, ever taking root on the island.

The first cities appear on Cyprus in the LBA, or Late Cypriot Period, approximately 1680/1650-1200 BCE in absolute dates (Manning 2013 in Knapp 2013a: 521). An important insight to the nature of LBA Cypriot socio-economic structure comes from a series of clay tablets from the Egyptian site of Amarna that details diplomatic correspondence with a political-geographic entity known as Alašiya (Goren et al 2004: 48-75). The letters illustrate a $14^{\text {th }}-13^{\text {th }}$ century independent kingly state that was rich in copper resources and an equal to the Mediterranean powers of Egypt and Ugarit (northern Syria) (Goren et al., 2004: 48-75; Peltenburg 2012; Knapp 2013a: 438). For example, Alašiya and was responsible for the export of $25,000 \mathrm{~kg}$ of pure copper ingots over the 
duration of the 50-year Amarna correspondence (Goren et al. 2004:49-51; Knapp 2013b). Petrographic analysis on the tablets has suggested the clay used in their manufacture originates from south central Cyprus along the eastern foothills of the Troodos mountain range (Goren et al 2003, 2004: 57-69). The political arrangement of Alašiya as a local city-state or Cyprus-wide empire is debated (see Keswani 1993; Manning and De Mita 1997; Goren et al. 2003; Peltenburg 2012; Knapp 2013a: 432-447), but if we assume the center of power for Alašiya are centralized near the source of the clay tablets then two LBA archaeological sites have been suggested (Goren et al. 2003, 2004: 48-75), namely K-AD and Alassa-Paleotaverna/Pano Manadilaris (30km west of K-AD, see Figure 93 in Knapp 2013a: 350). Both are known to have been of local prominence at the time of the Amarna and Ugarit letters and are within the source area for not only the clay used to make the original tablets, but also the copper mines that would have been able to meet the demand from Egypt and Ugarit outlined in the letters. As of yet, however, neither site has produced a corresponding collection of diplomatic clay tablets to identify and secure the administrative center of the first Cypriot state.

The very emergence of Alašiya has been suggested to be the direct result of the need for state-level control over an intensifying trade in Troodos copper with LBA circum-Mediterranean state level societies such as Egypt and Ugarit in the $14^{\text {th }}$ and $13^{\text {th }}$ centuries (Peltenburg 2012). The Troodos Mountains are an ophiolite complex with a historically known abundance of copper ore. K-AD's centralized position between the Troodos copper mines and the Mediterranean, its monumental architecture and centralization of wealth are suggestive of K-AD's executive role in LCIIC society (South 
1995: 192-194). Recently, however, the specific role K-AD played in LBA copper trade has been brought into question (South 2012). The site is well positioned to take control over any production of copper from the Kalavasos mines, a correlating feature that has been used to suggest LBA inhabitants across Cyprus did engage in industrial copper production to the end of supplying the Eastern Mediterranean demand (see Davies 1930; South 2012; Knapp 2013b). South (2012) argues the isotopic analysis performed on copper tablets (Gale et al. 1997) demonstrates Kalavasos ores were not used in the production of LBA copper oxhide ingots (so named because they resemble a stretched hides of oxen; see Gale and Stos-Gale 1986; Stos-Gale and Gale 2009 for details on their specifications and distributions) found across the eastern Mediterranean. The circumstantial evidence of a mine with rich copper ores, evidence of industrial copper trade and an urban community does not demonstrate what role, if any, K-AD directly played in the copper trade (South 2012). The urban setting and administrative role of K$\mathrm{AD}$ is established independently of any potential role in the production and distribution of copper, as evidenced by the icentralized storage of olive oil, cylinder seals for administration and record keeping, Cypro-Minoan tablets (not yet translated), monumental architecture, and other characteristics to be detailed below (e.g. South 2012: $35)$.

$\mathrm{K}-\mathrm{AD}$ has been dated to the Late Cypriot II on the basis of its ceramic assemblage (South 1982), and radiocarbon dating, broadly equating to 1450-1200 BCE (Manning 2013 in Knapp 2013a: 514). The minimum/maximum extent of the site has recently been refined to 8.5 and 11.5ha (South 2014). South (2013) notes that the concentration of 
structures at LBA K-AD is on a scale not previously seen in the Vasilikos Valley (nor in Cyprus more generally), well in line with Knapp's (2013a: 348-358) general changes seen at the LBA transition. South (2014: 74) has estimated K-AD's population at a value of 1000-1500 people or 118-130 people per hectare, a considerable amount of people in one city considering modern population numbers for the entire Vasilikos Valley (Kalavasos village, Drapia, Zygi, and Mari) peaked at 2220 people in 1960 during an immigration influx with increasing production at the Vasilikos Copper mines (South 2014: 76). South (2014: 76) suggests that the first census carried out by the British in 1881 of 936 people may be the most representative sustainable population for a basic farming economy. The conclusion of this work suggests the urban population of LBA K-AD totals $100 \%-150 \%$ the population of the agricultural villages Kalavasos, Drapia, Zygi and Mari combined, a considerable consolidation of a single community.

This chapter looked at the known changes in socio-economics, administration and interregional trade that appeared on Cyprus in the LBA with the appearance of a kingly state known as Alašiya. The site of K-AD reflects these changes very closely. Although the prestige and power attributed to Alašiya stems from its control over copper resources confirming K-AD specifically engaged in the trade is not essential to further out study on craft specialization. K-AD demonstrates the general trend of a socio-economic system becoming more complex and population growth in an urban center (see section 2.6). 
A comprehensive study by the Vasilikos Valley Project led to the documentation of over 135 sites from the modern Vasilikos dam to the Mediterranean coast (Figure 5; Todd 2004: 51), reflecting an occupation history that goes back to the Pre-Pottery Neolithic B, as attested by the site of Kalavasos-Tenta (South 1995; South and Todd 1997).

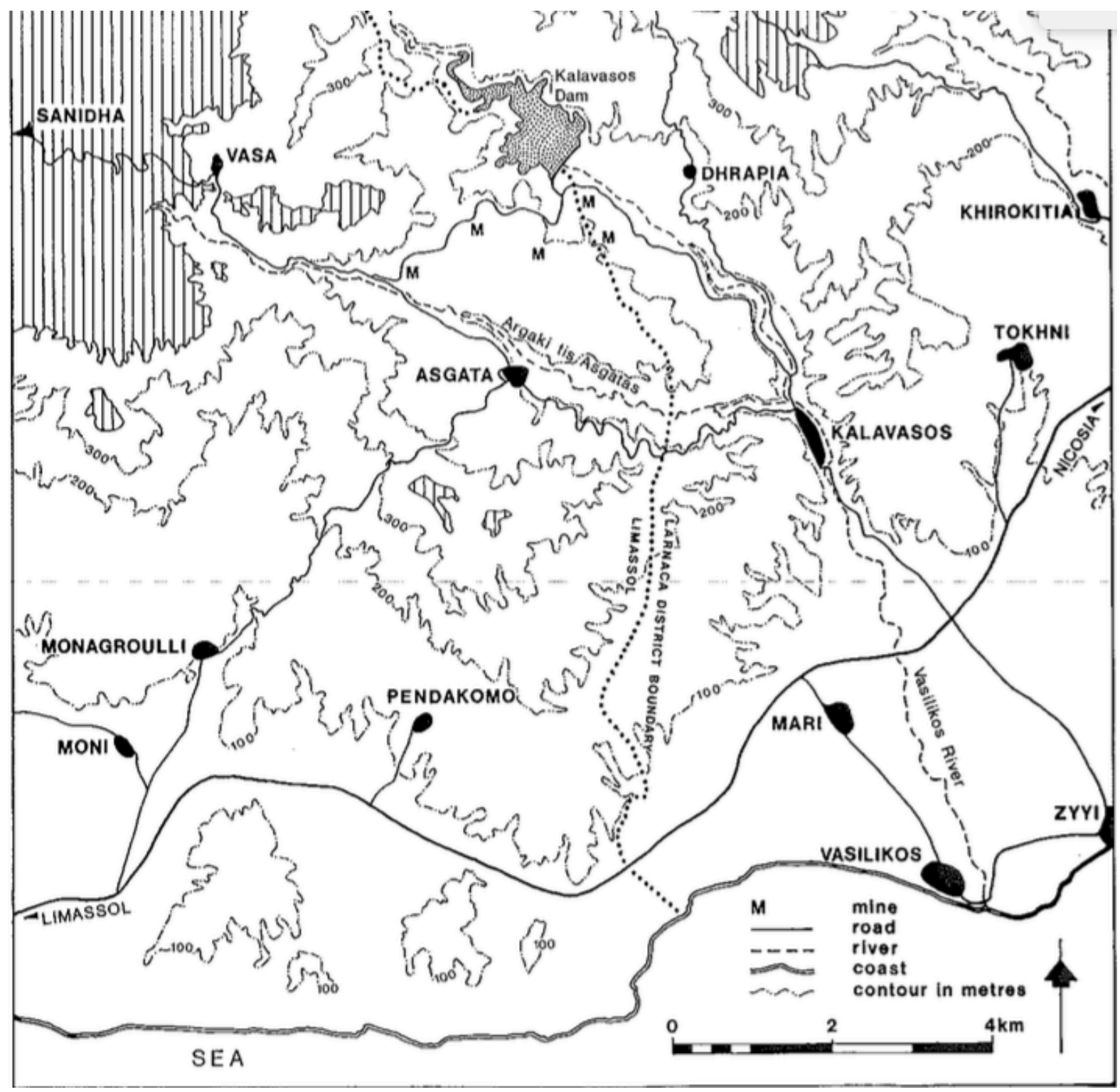

Figure 5. Vasilikos dam, valley and surrounding regions. Credit: Todd and South 1992. 
Master's Thesis - P Wallace; McMaster University - Anthropology

\subsubsection{Neolithic Kalavasos-Tenta}

The Pre-Pottery Neolithic B village site of Kalavasos-Tenta sits atop a slight prominence in a commanding position over the landscape approximately $100 \mathrm{~m}$ north of $\mathrm{K}$-AD (Figure 6). It is pertinent to this thesis for providing a sample of plaster surfaces with which to contrast the LBA K-AD materials.

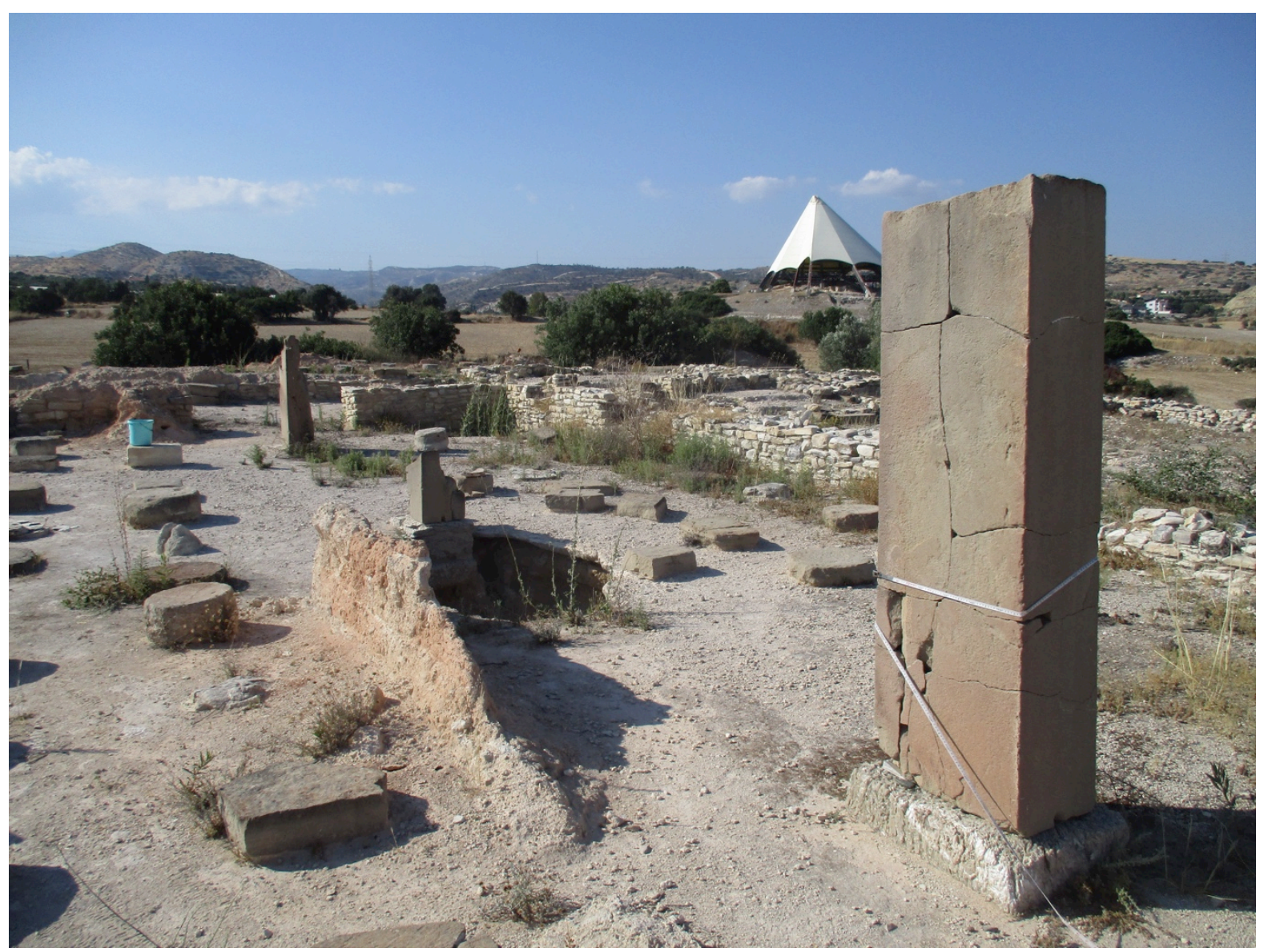

Figure 6. Pithos Hall. Kalavasos-Tenta located in the top center underneath the white tent. Credit: Author's image.

Tenta dates from approximately 8400 to $5600 \mathrm{cal} \mathrm{BCE}$, a range of ca. $2500-3100$ years covering five periods of occupation (Manning 2013 in Knapp 2013a: 504-505, 524525). The site consists of a palimpsest of circular and oval housing units, most of which 
are located within the circumference of a defensive wall and ditch (South 1995). The houses were constructed using mudbrick and uncut stones, which were held together with mortar. Surfaces were coated with among the oldest plaster on Cyprus (Philokyprou 2012: 172). The excavation of the superimposed central structures S.14, S.17 and S.36 revealed the only two red coloured plaster floors at Tenta among many white ones. These red floors appear once in S.17 and once in S.36 and are a significant find. For a detailed discussion of Kalavasos-Tenta see the research of Todd $(1987,1998,2001)$. KalavasosTenta offers a point-of-comparison between plaster traditions of the Neolithic and LBA periods, i.e. a contrast of pre-urban and urban contexts. The fact that the two sites are located in the same geographic and ecological setting is important theoretically the same physical resources would have been available to both populations. As such, it should follow that any distinctions in the manner in which these sites' plasters were manufactured and used should reflect distinct socio-political/cultural traditions, rather than differences in resource availability.

\subsection{Late Cypriot II Kalavasos-Ayios Dhimitrios}

In this section the Vasilikos Valley Project's excavations and findings at K-AD will be outlined. First, a general overview of K-AD will be given followed by the specific mentions of Area 152 (section 2.6.1) and the rest of the monumental complex of Building $\mathrm{X}$ that were sampled for this research project (section 2.6.2).

In 1976 Dr. Ian Todd of Brandeis University and director of the Vasilikos Valley Project began conducting archaeological survey in southern Cyprus along the Vasilikos River where the modern village of Kalavasos sits (South 1995: 187). The LC IIA-IIC site 
of K-AD (South 1997: 171-173) was excavated between the years 1979 and 1998 as part of the Vasilikos Valley Project (Fisher and Manning in press). K-AD's earliest levels of occupation appear in localized areas, such as tombs in the Northeast Area that date from the LCIIA:1 period (South 1997: 171). After reaching the zenith of its influence in the $13^{\text {th }}$ century BCE K-AD was peacefully abandoned (South 1984b: 14; Todd and South 1992: 195), with evidence of Building X being, at some point, destroyed by fire (South 1984a: 22-23, 1988: 225; Todd and South 1992: 195).

Surface survey carried out by the Vasilikos Valley Project indicates a total size of 10-11.5ha for K-AD (Figure 7, South 1984b: 11, 1991: 131; Todd and South 1992: 195). This figure has since (South 2012) been revised to a minimum site size of 8.5ha and a maximum of $11.5 \mathrm{ha}$, reflecting the acknowledgement that although surface finds suggest the maximum extent could well be along the dashed and dotted line seen above (Figure 7) there has of yet been not concrete evidence of LBA structures across the entire suggested site area (South 2014: 69-72). The monumental structure of Building X, its surrounding structures, and the Southeast Area were nearly completely excavated by the Vasilikos Valley Project with many of the excavated materials having since been stored in a facility, nicknamed "the quarry," for temporary curation and future study in Kalavasos. The Northeast and Southeast excavation areas were enclosed by a fence and left open to the elements (i.e. sun, wind rain, local biology). These natural processes may have contributed to the present degraded state of many surfaces and must be taken into account when analyzing in-situ materials. 


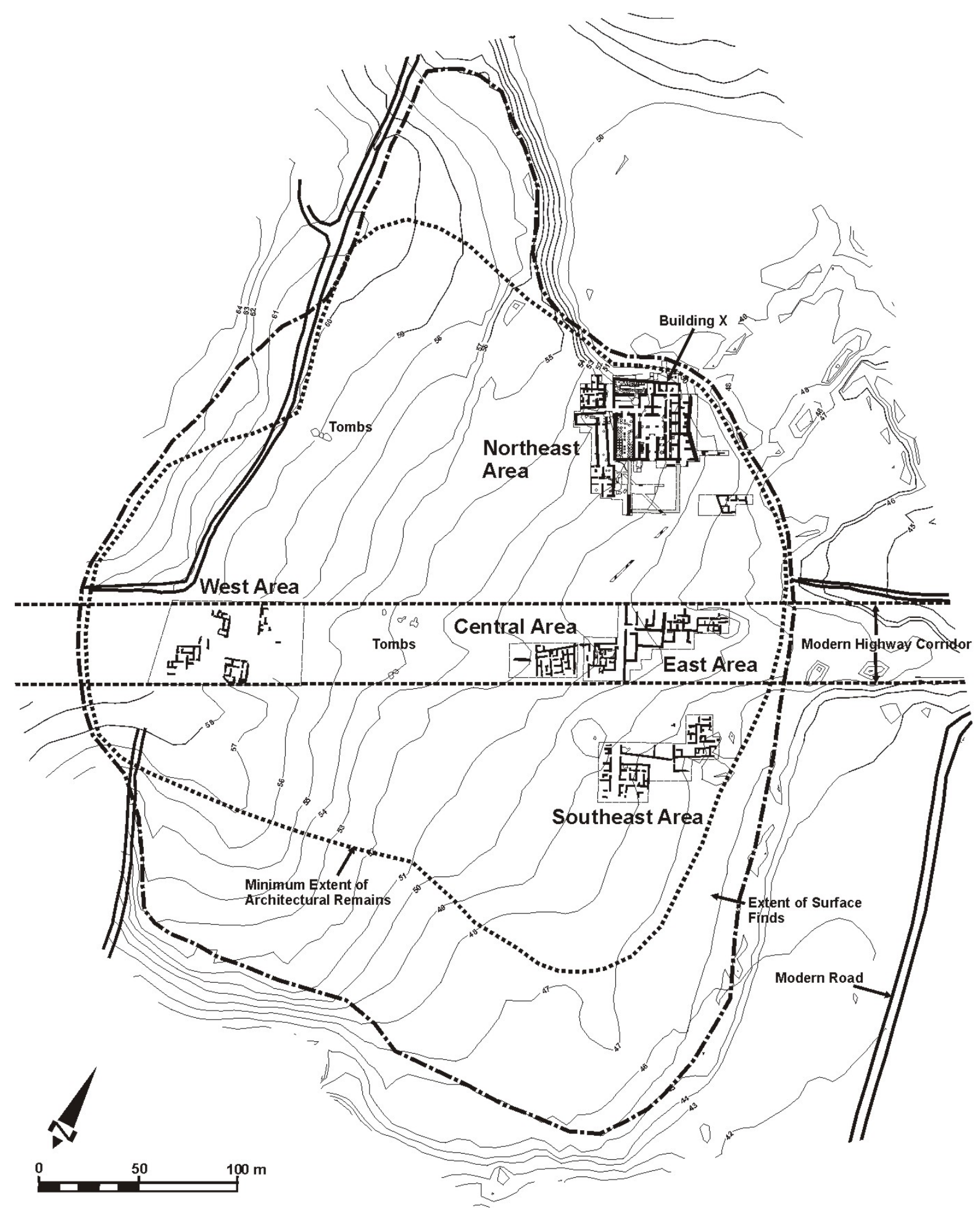

Figure 7. The extent of K-AD based on surface finds and location of the A1 motorway. Credit: Alison South and Team (creator), Kevin Fisher (editor). 
Excavations of K-AD began in 1979 and followed the planned construction route of the A1 highway from Nicosia to Limassol (South 1997: 151). The construction of the highway commenced the following year in 1980 putting an end to excavations along its path (South 1984a). From 1980 Todd, South, and members of the Vasilikos Valley Project opened excavations to the south and north of the construction path, revealing parts of a large Bronze Age settlement on both sides (e.g. South 1984a). The Southeast Area revealed several rooms floored with plaster and pebble-surfaced road (South 1982). Subsequent excavations in the Northeast Area, Central Area, and West Areas uncovered more rooms and another section of a road (Northeast Area) with all architecture on the same set orientation, suggesting K-AD was constructed on a plan (South 1984a: 12-13; Todd and South 1992: 195).

Excavations of K-AD during the mid to late 1980's focused on the Northeast Area (Figure 8, Figure 9), located one kilometer north of the A1 Motorway. Building X (ten) is interpreted as a massive court-centered administrative building, a product of its size, use of ashlar masonry, storage capacity and overall structure (South 1988: 228, 1997: 151), and sits on the northeastern edge of K-AD (South and Todd 1997; Fisher 2009a). It is among the earliest monumental structures on Cyprus, along with structures at nearby Maroni, both of which were the first to use ashlar masonry (Philokyprou 2011: 39).

Building $\mathrm{X}$ was central to this research project, the study analyzing a number of plaster samples from the structure (Figure 9). A basic premise in these analyses was that following long-standing arguments concerning the correlation between urbanism, elites and craft specialists, it might follow that distinctions would have existed in the kind of 
plaster employed in (elite) Building X, compared to some of the more quotidian structures within the community. Such distinctions have already been noted with regard to Building X's size, architectural elaboration, raw materials, and energy expenditure; can differences in plastering traditions also be documented?

Building X was excavated to LCIIC levels in the 1980's and then expanded to uncover most of the structure through the early 1990's (South 1997). Building $X$ is believed to have originally been two-storied on the basis of the staircase located to the west of the main south-facing entrance, the structure's fortuitous architecture, and pillar foundation stones in the central court (South 1984a: 14, 1984b: 15, Fisher 2009a). The structure is square and measures $30.5 \mathrm{~m} \times 30.5 \mathrm{~m}$. It was partially constructed with dressed stone ashlar masonry, i.e. hand cut and prepared stones with flat surfaces that are laid without mortar binding.

LBA architects used a wide variety of raw materials in the construction of K-AD in general, and Building X specifically. Cut sparitic gypsum slabs, or gyphomarmara (Philokyprou 2012), were used for pillar bases in Area 152 and used in the foundations of parts of the northern and eastern enclosure walls; rounded river or beach pebbles of ophiolite origin were used to make pebble floors; and limestone was used in its raw form as pillar bases and building stones for walls.

Sandstone was quarried from the local sedimentary deposit known as the Pachna formation (Philokyprou 2011), most likely from the nearby modern village of Tochni (South 1997: 154). Ashlar masonry reflects a change in social organization where previously unseen construction materials are sought out from specific locations (South 
1984a, Philokyprou 2011). Instead of picking up conveniently shaped stones for rubble walls the sandstone had to be quarried, transported, flattened and finished. Alongside a quantifiable rise in the number of "elite" ceramic, stone and metallic objects found at KAD (South 1984a, 1997) the unequal distribution of these materials, and the greater-thannormal elaboration and expenditure of energy required by this building (South 1984a, 1997; South and Russell 1993), reinforces the theory that (a) we are dealing with a stratified social structure at $\mathrm{K}-\mathrm{AD}$, and that (b) Building $\mathrm{X}$ is a socio-economically important building.

Use of the area of K-AD before the current monumental LCIIC layers have been dated to the LCIIA:1 period (South 1997: 171). Numerous graves (see South 1997) have been excavated both within and surrounding Building X since 1979. Notably, tombs 11, 13 and 14 appear to have been integrated within the monumental complex of K-AD having been kept visible along the roadway with four stone corner markers. All three of these tombs contain elite individuals and the tombs date from the LC IIA:2/IIB (tomb 11) to the LC IIB/IIC (South 1997: 171). Tombs 11, 13 and 14 are located next to a preLCIIC stone wall S.450 (South 1988, 1997). The incorporation of these graves into the construction of LCIIC layers suggests that these tombs were of known individuals to LCIIC inhabitants and the high socioeconomic status of the individuals suggests their incorporation is intentional and a possible means to legitimize authority (South 1997: 171). For a description of the tombs at K-AD see South (1997: 159-171).

\subsubsection{The Pithos Hall, Area 152}


Area 152 is the largest room in Building X $(19 \times 7.5 \mathrm{~m}$, Todd and South 1992: 195; Figure 6) and is among the reasons Building $\mathrm{X}$ is believed to be an administrative center (South 1988: 228, 1997: 151). The excavation of Area 152 revealed dozens of smashed ceramic storage vessels (pithoi) leading to its alternative name the "Pithos Hall," (South 1984a: 22, 1988: 225, 1997: 154). It is estimated that originally some 50 pithoi would have been stored in Area 152 alone, including six subterranean vessels (South 1988: 225, 1995: 194; Todd and South 1992: 195), one of which was excavated from the center of the room the Vasilikos Valley Project team leaving a large hole with a visible profile of the floor stratigraphy in the middle of the room. When the Pithos Hall and the smaller storage magazine to the north, Area 161, are viewed together the storage capacity Building $X$ is estimated to have been a minimum of 50,000 liters (South 1995: 194). Gas chromatography revealed the vessel bases had been in contact with olive oil (South 1991: 132, 1995: 194) leading South and Todd to suggest the primary happenings in the LCIIC at Building X were the production and centralized storage of olive oil (South 1992: 144).

The Pithos Hall was constructed with ashlar wall based and a second layer of (Roman-robbed) orthostats on its western and southern edge (South 1984a: 22, 1988: 225). There is a partial mudbrick separation wall in the south-central area of the room between the two western rows of pithoi stands and the central ashlar pillars. Four plaster coated pisé (pressed mud) steps are on the north wall, deteriorating from exposure to the wind and rain since being excavated two decades ago (Figure 8).

Finally there are three reconstructed ashlar pillars on cut sparitic gypsum bases. There were six ashlar pillars that supported a wooden roof, as suggested by the spacing of 


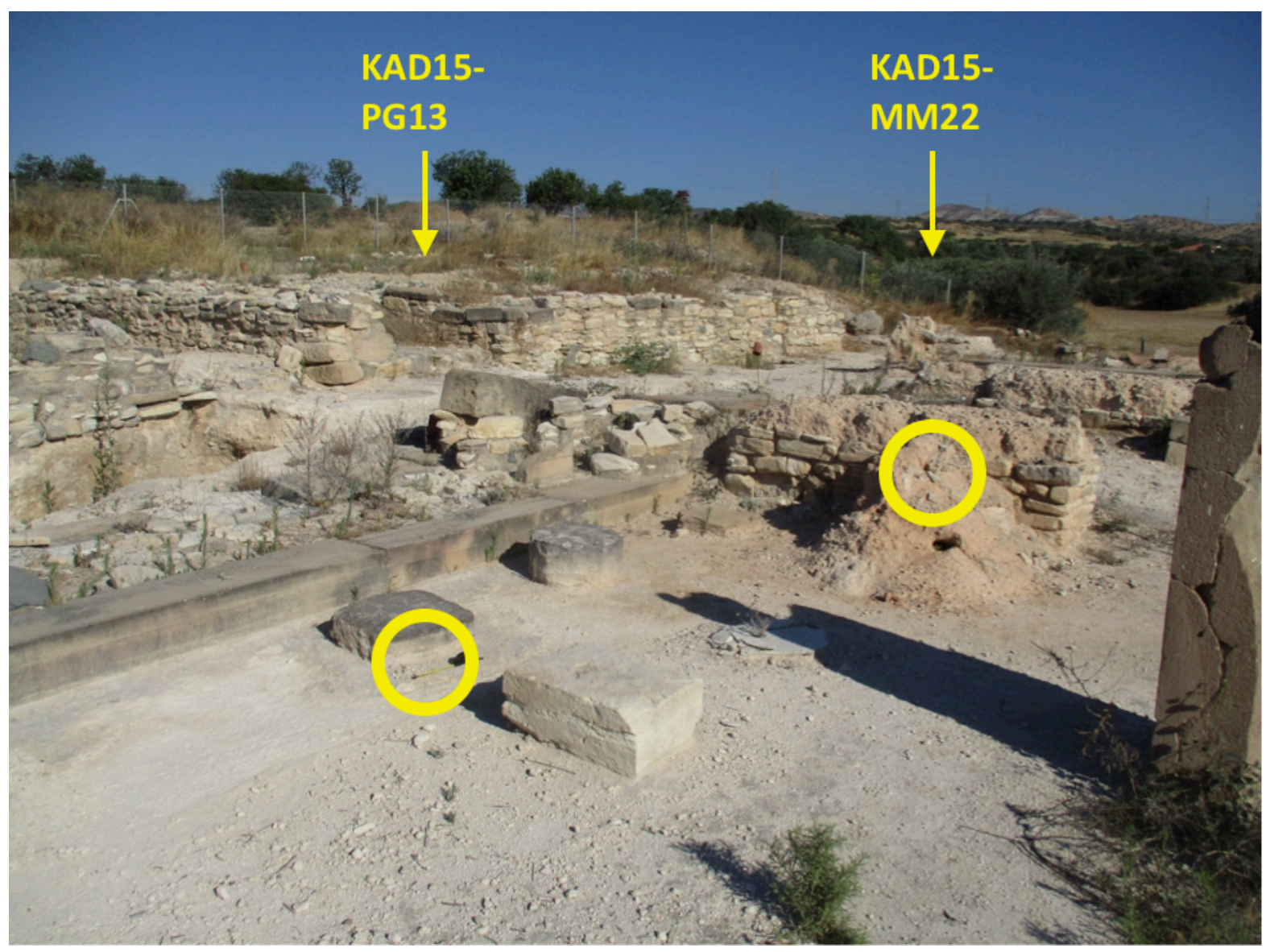

Figure 8. Pithos Hall (Area 152) facing northwest with the sampling locations for KAD15-PG13 and KAD15-MM22 circled. Credit: Author's image.

the present gypsum bases and the wood charcoal that was found during the original excavations (South 1984: 22-23, 1988: 225). There are also three pits, one in the northeast corner of the Pithos Hall, one in the center (Figure 6, center), and a smaller third in the southwest corner. This pithos was approximately $1.8 \mathrm{~m}$ in height and during the excavation of this pithos the project discovered an earlier plaster floor that had been cut through by the LCIIC people in order to set this pithos in place (South 1997: 154).

The earlier constructed plaster floor in the Pithos Hall, was one numerous earlier occupation levels found at K-AD since 1992; most of the site as we see it today was (re)constructed in the LCIIC period (South 1997: 155). The orientation of the previous 
layer in the Pithos Hall was exactly, or very nearly exactly aligned to the LCIIC level (South 1997: 155). The excavation pit in the center of the floor revealed a sandstone pillar base stone atop of which a gypsum pillar base was set, which is visible on the current surface of the Pithos Hall, suggesting that the previous room had a very similar construction. The two floors visible in the Pithos Hall profile appear, to the naked eye, to have been constructed following a similar procedure including the application of a red sediment layer underneath the thick plaster surface layer.

Given the importance of this room as the central storage space for wealth, and the large exposed floor profile in the middle of the room, it made sense to collect numerous plaster samples from the Pithos Hall. A 350mm micromorphological column sequence was taken from the central hole (KAD15-MM21) in order to study the floor construction process and the constituent materials. At least two floor construction phases were apparent from the profile, and each floor was considerably thick. Sample KAD15-PG13, a plaster-like chip, was taken from the base of a pithos stone base as the relationship between the current surface and the original surface is unknown (the original surface may have eroded). The pithos stone bases, however, would have preserved the original surface very well into the modern day.

Inside the Pithos Hall there were also plaster-covered steps that were along the north wall and to the west of the doorway. Sample KAD15-MM22 was taken from these steps to compare this thin plaster with the drain plasters and the fine floor uncovered in Unit 3 (Figure 9). 


\subsubsection{Other areas within Building $X$}

Area 161 (Appendix Image 45), to the north of the Pithos Hall, is the second largest storage area within the monumental complex at $\mathrm{K}-\mathrm{AD}$ and has a similar arrangement of pithoi stands. Following Area 152 this area also has the remains of an interior, central mudbrick wall (Appendix Image 45). Area 161 has a pebble floor and was sample as KAD15-MM23.

Area 176 (Appendix Image 45) is located between the Pithos Hall and Area 161 (Appendix Image 45) and has a sloping pebbled floor that tilts downward toward the east, ending with a large robber's trench that likely housed a sandstone basin in antiquity (South 1997: 154). The floor's history of construction is divided into two phases. The first was prepared by laying flat, irregular stones on an earthen surface (original floor). The second phase was prepared by covering the flat stones with a mudbrick-like/pisé earthen mixture approximately $10 \mathrm{~cm}$ thick then applying a capping of plaster/pebbled mixture (South 1997: 154). A tilted, durable plaster floor ending with a large basin suggests this room was for processing and collecting olive oil. An in-situ sandstone basin of similar size to the robber's trench in Area 176 was discovered in Building XI to the west of Building X (South 1992: 135-139, 1997: 154). Area 176 was not sampled.

The eastern side of Building X is composed of a N-S corridor (A.158) (Appendix Image 45) from which six rooms are accessible (A.169-174, inclusive). These rooms are relatively small, approximately $3 \times 4 \mathrm{~m}$ each and separated by stonewall; the southernmost room is largest of the six at $3 \times 5 \mathrm{~m}$. The corridor connecting the rooms were excavated in sections labeled Area 158A, B, and C from north to south. At the northeast end of Area 
158A a preserved section of surfaces is visible that alternates between carbonate-based and pebbled, in total approximately $30 \mathrm{~cm}$ thick. The floor composition at this northern extremity is smoothed plaster while the surfaces for the six rooms and the corridor are variably pebbled and eroded. At the northern extreme of this corridor (Area 158A) a block sample was taken, KAD15-MM25, of a pebble floor sandwiched between two calcite layers. Samples -PG08a and -PG08b were retrieved from the storage facility and originally come from the well located in Area 174.

\subsection{KAMBE Excavations}

The KAMBE Project held two field seasons in 2008 and 2010 at K-AD and Maroni-Vournes, -Tsaroukkas, and-Aspres under the co-directorship of Kevin D. Fisher, Sturt W. Manning, and Michael Rogers (Fisher et al. in press for details). The KAMBE project's mission was to "investigate the relationships between architecture, social interaction and social change" that accompanied the first transition to urban life on Cyprus (Fisher et al. in press) by conducting high-resolution scientific and spatial analyses at the aforementioned sites (see Manning et al. 2014 for details on Maroni). Preliminary survey at K-AD included the use of geophysical magnetometry, resistivity and ground penetrating radar (GPR) (see Urban et al. 2014, Fisher and Manning in press). Drone-assisted photogrammetry and 3-D modeling were employed to create spatial plans (Fisher and Manning in press). Further survey has compiled a collection of GPR data across much of the 10-11.5ha site that lies north of the highway (Fisher and Manning in press) allowing a highly accurate plan of the site to be mapped effectively without complete excavation, reducing costs and preserving archaeological material. 
Limited excavations were carried out following remote mapping for a more detailed investigations into the built environment at K-AD. The excavations provided new surfaces from antiquity in contrast to the material that has been exposed to the elements since the Vasilikos Valley Project excavations in the 1980's and 1990's. In 2012 a $3 \times 10 \mathrm{~m}$ trench was opened to the south of Building $\mathrm{X}$ and was called Unit 3 (Figure 9). It was widened a meter on either side to $5 \times 10 \mathrm{~m}$ in the 2015 field season. The Unit 3 excavations revealed another section of the main N-S plaster road, several dividing stone walls, Roman-age robber trenches, a room with an extremely hard fine plaster floor that continues up the walls, and a thick plaster surface on the eastern end (Fisher and Manning in press). Unit 7 was excavated in a similar manner with a 2015 extension and is located on the west side on the monumental complex (Fisher and Manning in press).

Work by Fisher (e.g. 2009a, 2009b) sought to assess the role the monumental structure played in facilitating social interaction by freely allowing or restricting access to different areas within a structure. Fisher assessed the placement of ashlar masonry within doorways and the connections between rooms within the monumental Building $X$ in an access and threshold analysis (Fisher 2009a). By considering "thresholds" throughout Building X marked by two small ashlar stones and their relationship with access "depth" Fisher viewed the structure as having been constructed with a set purpose of facilitating interactions centrally within the site of K-AD in this newly urban society (Fisher 2009a, 2009b). Using this analysis some areas could be considered more "public" and others more "private," with respective levels of social dialogue taking place in their respective areas. Fisher's analysis has implications for the construction of plaster floors and walls 
Master's Thesis - P Wallace; McMaster University - Anthropology

between rooms and structures when we consider that plaster technology recipes vary as a result of human choice and not access to raw materials (Love 2011: 142). K-AD's construction is evidence of the intentional design to construct an urban site and an elite complex from the uniform grid that connects the site to the ashlar base stones found at the base of supporting walls. The analysis of plaster recipes can speak to the relationship between the social processes of using plaster and the resources that went into creating that plaster. 


\section{Technical traditions in the context of urbanization / 'social complexity'}

In this chapter I will offer a cross-cultural literature review as to how scholars have considered the relationship between mundane crafts (specifically geological technologies) and complex socioeconomic structures. Specifically I engage with the viewpoint that these crafts are not simply "mundane" but rather they are technologies created by people who were living, innovating and embracing their specific craft while being influenced by their surroundings, histories and ontologies (Dobres 2010: 103-110). These technical traditions, and specifically plaster in regard to this thesis, are traditions with intentional designs that are steeped in history, socially produced and socially imbued.

Advances have been made in establishing theoretical frameworks that link the relatively large and historically overlooked assemblages of earthen construction materials to social processes. Research has typically tended to focus on a specific set of earthen technology, i.e. plasters or mudbrick, but not both at once, not least because the size of the assemblages involved. Some of these new earthen technologies include sediments (Pauketat and Alt 2005; Jusseret 2010; Bauer in press), mudbricks (Matthews 2005; Love 2011, 2013a, 2013b) and plasters (Theodoridou et al. 2013; Turco et al. 2016). Microscopic analysis and chemical techniques that go beyond visual assessment (following Wright 1992, in Turco et al. 2016) have been employed within theoretically informed research projects (e.g. Bauer in press; Pauketat and Alt 2005). New theoretical perspectives attempt to demonstrate earthen-based materials are encultured resources, 
made by individuals who have a living history behind them influencing their work from which their society and social practices can been interpreted (Dobres 2010; Love 2011). In the same way, synchronic and diachronic variation can be accessed from these architectural technologies (Pauketat and Alt 2005; Dobres 2010).

Earthen construction materials are distinct from other commonly researched artifact assemblages because they are immobile features of construction and architecture (as opposed to ceramics or lithics; i.e. transportable artifacts). It has been argued previously that architecture plays a fundamental role in the creation of social identities and boundaries, and that a change in architecture will have a direct effect on the people living in its midst (Wilson 1988). The design is not the only social function of space, however, as the unseen design components hidden behind the walls or under the floor surface can convey cultural-social meaning through a network of shared knowledge in the community, much like how we all know a church that has been consecrated is spiritually imbued with meaning that would not be afforded to a building that simply looks like a church.

Love (2013b) has argued that variation in mudbrick technology at Çatalhöyük is directly reflective of variation in social identity despite the mudbricks being subsequently covered with plaster and remaining unseen. Love (2013a) suggests this earth-based material culture is reflective of human behaviour and can be used as indices of the relationship between people and their social environment. Love (2011) related irregularities in mudbrick composition to individual households, and that these distinct recipes reflected specific choices and traditions of particular social groups at Çatalhöyük, 
rather than being a reflection of differential access to sedimentary raw materials around the site. Her analysis revealed that mudbrick composition varied more between houses than within a single house indicating small-scale, household manufacture with a large degree of individual variation across the site. Individuals constructed their own homes. Both the process of manufacture (Love 2013b) and the subsequently created social spaces (Wilson 1988) are linked closely to the creation, maintenance and expression of social identity.

A theoretical underpinning of this thesis is the claim that technological traditions can be linked to social identity and social processes through people and their habitus. They are dynamic processes with which individuals engage and redefine through active practice (Bourdieu 1977; Bauer in press). Craftspeople are guided by their respective histories, training and social obligations to complete a task appropriately, while simultaneously being capable of making their own decisions, all of which leads to variability between individual and/or group technical traditions. Sackett (1990) refers to the intra-ethnic range in material culture style among same-function objects as 'isochrestic variation,' (Dietler and Herbich 1998, Sackett 1990 in Dietler and Herbich 1998). Each event of creation, therefore, is an active event by which the craftsperson uses their unique history to manufacture their craft (Dobres 2010: 103). Additional considerations arise when within the monumental center of an urban city tonnes of plaster are being laid. The craftsperson is now engaging with profound social changes that accompany construction in a city. The nature of the event, the private/public format, the craftsperson's personal histories and the directed purpose of creating all influence the 
final outcome leaving each event a unique act of creation. The consideration of each event as unique moment where traditions are created and altered relinquishes the need for an explanation of who harbors the knowledge of plaster manufacturing techniques before an innovation is made, such as is the case with construction in an urban area that requires an industry on an industrial scale. Rather than following a set written recipe for each specific purpose a shared knowledge of the historic practices involving plaster technology can be innovated upon in order to meet the challenge of monumentalizing a city center in what can be seen as a "mutual becoming" of craftsperson and craft (Dobres 2010: 108). Likewise, each event can inform the subsequent projects from a floor surface to a road, and so forth, following the theory of practice (e.g. Bordieu 1977; Dobres 2010).

Earthen-based archaeological remains have been studied following the theory of practice to explore the human condition. These materials are situated in secured provenience and function (i.e. as construction materials) in contrast to portable ceramics, and can often constitute a considerable percentage of the material record and one that has rarely been maximized with regard to its interpretive potential. Plaster and mudbrick are recipe-based materials that have been shown to vary with individual manufacturing rather than the availability of materials. The continuous interaction between human and nonhuman social actors is the mechanism for both change within the material record and also the stage for conservative dispositions to be renegotiated and readopted. Settlement aggregation is a process that brings groups together and can increase the variability of interactions that can take place between individuals of different dispositions. The possibility for an individual to alter a technology by diffusion, emulation, innovation, or 
otherwise, therefore increases, however, individual change of materials through practice remains the mechanism for change.

The use of plaster at K-AD within the monumental complex of Building $\mathrm{X}$ is suggested to be of the highest quality. Alongside calcareous sandstone ashlar blocks, open-court architecture and construction on a monumental scale (thick walls, second story, non-residential structure) it is suggested that high-quality components used in the construction of Building $\mathrm{X}$ were key elements in creating and reinforcing space for the negotiation of social roles and were specifically selected for this purpose (Fisher 2009a). Plaster itself has not historically been a material used to study social dynamics at archaeological sites. Previous researchers have preferred objects that could be studied visually, such as ceramics, architectural plans and grave goods. The accessibility of petrographic techniques, however, opens the door for the analysis of this technology in one of the first studies of its kind on Cyprus. This thesis asks the question: 'did plaster technology changes over time and across different social spaces at $\mathrm{K}-\mathrm{AD}$, according to the dialectic relationship of population density, socioeconomics and craft specialization?' 


\section{Plaster Chemistry and Identification}

In this chapter I first define plaster and then offer a literature review on studies that have enabled the successful identification of plasters in antiquity using micromorphology and FT-IR, i.e. the two analytical techniques employed in this thesis.

"Plaster" is used in this thesis exclusively to refer to lime plaster, a hard, white material that is the product of the lime $\left(\mathrm{Ca}(\mathrm{OH})_{2(a q)}\right)$ reacting with atmospheric carbon dioxide to form micritic calcite $\left(\mathrm{CaCO}_{3}\right)$. Lime dries to form a hard protective surface. This thesis also deals with gypsum plaster, also known as plaster of Paris, a similar yet functionally softer product that is produced through the hydration of dehydrated gypsum. Lime and gypsum plasters are common materials familiar to most people in their everyday lives. The plastered white walls of homes in Guatemala or Greece (lime), the artistic surface of a fresco painting (lime), intricate stucco crown molding (lime) and medical casts holding together broken bones (gypsum) are examples of some of the common modern uses of plaster.

In her original excavation reports South (1997: 155) uses "the term 'plaster' to refer to a variety of materials, mostly used for floors, including the type of thick white floors made from what appears to be pulverized chalk." This definition is helpful when attempting to visualize the site of $\mathrm{K}-\mathrm{AD}$ from a written or spoken source but it is too broad for the current study; one aim of my study has been to generate a more detailed characterization of the plasters being produced and employed by this LBA community. Wherever there is plaster on the ground, specifically, we can identify a created floor, not 
a "simple" surface that was merely used as a floor. This is an important distinction to recognize the engineering and technology behind these intentionally created surfaces.

To make plaster one has to crush and thermally reduce the parent material: either calcium carbonate (e.g. limestone, chalk, marl, havara) or calcium sulphate (e.g. gypsum). During the firing process the parent material undergoes chemical and structural transformations. The resulting powdery material is then mixed with water to create a paste that will crystalize back into the parent rock. The chemical reaction for lime plaster is as follows:

1. Calcination (burning): $\mathbf{C a C O}_{3(s)}+$ heat $\rightarrow \mathrm{CaO}+\mathrm{CO}_{2(g)}$

2. Slaking (mixing with water): $\mathrm{CaO}_{(s)}+\mathrm{H}_{2} \mathrm{O}_{(l)} \rightarrow \mathrm{Ca}(\mathrm{OH})_{2(a q)}+$ heat

3. Setting (turning back into stone): $\mathrm{Ca}(\mathrm{OH})_{2(a q)}+\mathrm{CO}_{2(g)} \rightarrow \mathbf{C a C O}_{3(s)}+\mathrm{H}_{2} \mathrm{O}_{(g)}+$ heat

The reaction of gypsum plaster, or plaster of Paris, is very similar:

1. Dehydration (burning): $\mathbf{C a S O}_{4(s)} \cdot \mathbf{2} \mathbf{H}_{2} \mathbf{O}+$ heat $\rightarrow \mathrm{CaSO}_{4(s)} \cdot 0.5 \mathrm{H}_{2} \mathrm{O}+1.5 \mathrm{H}_{2} \mathrm{O}_{(g)}$

2. Hydration (mixing with water): $\mathrm{CaSO}_{4(s)} \cdot 0.5 \mathrm{H}_{2} \mathrm{O}+1.5 \mathrm{H}_{2} \mathrm{O}_{(l)} \rightarrow \mathbf{C a S O}_{4(s)} \cdot \mathbf{2} \mathbf{H}_{2} \mathbf{O}+$ heat

Legend: $(\mathrm{s})=$ solid,$(\mathrm{l})=$ liquid,$(\mathrm{aq})=$ aqueous,$(\mathrm{g})=$ gas, heat=energy

In both reactions the "daughter" material has the same chemical formula as the "parent" source. Concrete is an innovation on this ancient tradition and is used today in lieu of plaster for the same reason lime plaster is used over gypsum plaster; the resulting material is more resilient, upon setting, to chemical and physical weathering (Kingery et al. 1988; Philokyprou 2012). To compare their hardness, gypsum is the defining material 
for a value of " 2 " on the relative Mohs mineral hardness scale while calcite, a polymorph of calcium carbonate, is coincidentally the defining material for a value of " 3 ."

Another key difference between gypsum and lime plasters is the amount of energy required during firing for dehydration and calcination to occur, respectively. Gypsum requires a heat source at a minimum of $100-190^{\circ} \mathrm{C}$ to drive off the chemically bound water molecules (Kingery et al. 1988; Philokyprou 2012). Calcium carbonate, on the other hand, requires a temperature greater than $800^{\circ} \mathrm{C}$ for calcination to take place (Karkanas 2007, Philokyprou 2012). The additional thermal energy and technical knowledge required to manufacture lime plaster makes it more energetically expensive than gypsum plaster (Kingery et al. 1988). There are significant additional resources required in the creation of lime plaster, for example, to crush and prepare the harder rock, in maintaining a longer and hotter burn, and the greater investment of time during the setting process. There are necessary considerations to make when choosing what kind of plaster to use. Gypsum plaster requires much less fuel than lime plaster to manufacture and is quicker to produce but it would yield a physically and chemically inferior product. Lime plaster requires more energy to produce but in the end provides a lower maintenance, more durable surface than gypsum plaster.

Prehistoric plaster use on Cyprus has recently been thoroughly researched by Philokyprou (2012). Use of the substance for floors and walls coincides with some of the first permanent settlements on the island, an unsurprising correlation according to Philokyprou (2012: 172) because plaster technology was already a common part of the construction practices of Central Anatolia and the Near East before the first permanent 
settlements on Cyprus arose in the Pre-Pottery Neolithic. Philokyprou (2012: 173) also summarizes a consistent trend across Mediterranean-Near Eastern regions, and especially within individual sites, of societies having a strict preference for lime-based or gypsumcentered plasters from the Neolithic period through the LBA. Populations of the Aegean, Anatolia, and the Levant all had lime-based plaster traditions, suggesting the plaster on Cyprus should also be lime-based (Philokyprou 2012). This hypothesis was confirmed by Philokyprou, as far as post-Neolithic sites were concerned, which came at a bit of a surprise considering the abundance of easily accessible gypsum deposits scattered throughout the island. Cyprus has abundant deposits of both limestone and gypsum that are many meters thick (Orszag-Sperber et al. 2009; Rouchy et al. 2001) and both limestone and gypsum rocks were used at K-AD as raw building materials (South 1984a: 19, 1988: 225; 1997: 155; Philokyprou 1998). According to Philokyprou (2012), however, the likelihood of finding both lime- and gypsum-based plasters at one site is unlikely as Cypriots from the Chalcolithic period onward followed a tradition of choosing lime plaster. In other words, plaster production at K-AD should be viewed as primarily in terms of conscious design and tradition, rather than of environmental determinism.

With the addition of what are known as "pozzolanic" materials lime plaster can be transformed into hydraulic plaster. Pozzolanic materials are those whose active silicate particles react with lime in the presence of water, creating what is known as hydraulic plaster or plasters that have hydraulic properties. Natural pozzolans (i.e. volcanic ash) are differentiated from so-called artificial pozzolans. Where there is an absence of their 
volcanic counterparts, such as is the case on Cyprus, fired ceramics can be crushed and used as artificial pozzolans (Theodordou et al. 2013).

Hydraulic plaster, when compared to pure lime plaster, is more resistant to weathering. Hydraulic plasters incorporate liquid water as they set into a solid material and are the able to harden under water. They bypass the need for carbon dioxide by using active silicates to react with lime to form calcium silicate in lieu of calcium carbonate (Philokyprou 2012). Pure lime plasters, on the other hand require atmospheric carbon dioxide to set into a solid and will dissolve in water (Regev et al. 2010; Philokyprou 2012). Volcanic ash is a common form of natural pozzolanic material. The use of pozzolanic additions in lime plasters is rare before the Roman Period (Regev et al. 2010); however, previous research by Philokyprou has found evidence for the creation of hydraulic plaster at LBA K-AD (2012).

\subsection{Identification and Analysis of Plaster}

The identification of pyrogenic lime and gypsum plasters is outlined below. Methods employed for microscopic analysis (4.1.1) are explained separately from a detailed overview of FT-IR techniques (4.1.2).

\subsubsection{Identification and Analysis of Plaster Using Optical Microscopy (Petrography and Soil Micromorphology)}

Degraded anthropogenic plaster surfaces can look very similar to compacted carbonate surfaces. Indeed the mineralogy and chemical signature of lime plasters, in contrast to spectroscopic data, are indistinguishable from their parent raw materials, i.e. limestone (Karkanas 2007, Goshen et al. 2017) and so the question of differentiating 
between the two materials is paramount. Petrography and soil micromorphology allow the description and assessment of microstructure and mineralogy concurrently and are found to be a reliable method of distinguishing between burnt lime calcite and compacted geogenic calcite (Karkanas 2007).

Petrography and soil micromorphology are based on the analysis of $30 \mu \mathrm{m}$-thick thin sections. Samples are collected as intact blocks, dried in an oven and impregnated with a liquid transparent resin that sets into a solid. The impregnation preserves a sample's internal morphology by replacing the air and voidspace with a transparent medium. The sample is then cut, mounted on a microscope slide, and polished for analysis. Thin section analyses have allowed researchers to assess a sample's internal morphology, stratigraphic relationships between constituent materials and mineral crystal arrangements. Prehistoric plaster analysis using micromorphology has an established history that includes, but is not limited to the following studies. Goren and Goldberg's (1991) analysis of plaster products at a variety of Neolithic sites in northern Israel that revealed a varied approach to manufacturing plaster within a limited site area. Karkanas (2006, 2007) studied Neolithic floor production and use of space in the Kouveleiki caves in Greece that revealing the division of space between an area with a trampled surface and another with a plaster surface. The microstructure and microstratigraphy of the trampled surface at the front of the cave was interpreted to be a seasonal pen for animals whereas areas with plaster surfaces were interpreted to be the main area for human habitation. Matthews et al. (1997) conducted a study on site formation processes that spanned three early urban sites in the Near East, Their study included lime plaster 
surfaces among surfaces of non-pyrogenic origin, mortar, mudbrick obsidian and other artifact assemblages. The use of lime plaster was found to be not as common as pressed earth prepared floors and lime plaster use was restricted to unroofed settings. Goshen et al. (2017) studied surfaces at Middle Bronze Age Canaanite palace called Tel Kabri, Israel. They found lime plaster was limited in its application, being restricted to special buildings and that the lime plaster was applied in coats.

Pyrogenic lime plaster can be identified by microscopy, in part, by determining the presence of portlandite (crystallized calcium hydroxide), the absence of foraminifera (fossils), the abundance of micritic calcite, and the presence of shrinkage fissures (Kingery et al. 1988; Karkanas 2007). Gypsum plaster can be identified by the unique appearance of orderly arranged gypsum crystals when viewed between two light polarizers set at right-angles to each other known as "cross-polarized light" (XPL, see section 5.3 for details), in contrast to the random arrangement of crystals found in natural gypsum rock (Philokyprou 2012). Thermal alteration of calcite can more robustly be determined from fabric (see section 5.3) analysis (Karkanas 2007). Where optical microscopy cannot determine the origin of calcite deposits, FT-IR peak ratios, as outlined by $\mathrm{Chu}$ et al. (2008), can be employed to determine if the material has been thermally altered.

Philokyprou's research (2012) was the first comprehensive study of early pyrotechnology on Cyprus and among the first to use laboratory analysis on prehistoric Cypriot plasters, spanning the Neolithic to the end of the LBA. Their methodologies included on-site observation, on-site testing of mechanical strength, laboratory chemical 
analysis and select SEM (scanning electron microscope) analysis to define the composition of plasters (Philokyprou 2012). Philokyprou found there was an association between physical properties and chemical composition; the surfaces that appeared friable and crumbly materials were mud-based mortars while physically tough floor surfaces were lime plaster (Philokyprou 2012). The pyrogenic component of the plasters had been mixed with aggregates, to extend and strengthen the material (Philokyprou 2012). The addition of aggregates is necessary to strengthen the resulting plaster, but it also allows the pyrogenic component of the technology to be extended over a greater volume (Kingery et al. 1988, Karkanas 2007).

\subsubsection{The Identification and Analysis of Plaster Using FT-IR}

Fourier Transform Infrared Spectroscopy (FT-IR) is an expedient method of ascertaining a pyrogenic origin of the calcite composing the lime plaster while micromorphology is the best means of studying the plaster's composition or recipe (Goshen et al. 2017). Chu et al. (2008) and Regev et al. (2010) have employed the use of FT-IR to differentiate pyrogenic calcite from geological calcite when testing archaeological surfaces with much success. Their method, provided in more detail below (section 5.4) involves measuring the intensity ratio between absorption peak values of calcite on an FT-IR spectrum. Goshen et al. (2017) approached the issue of researching the use of plaster technology at Tel Kabri with both micromorphology and FT-IR used in conjunction. 


\section{Samples, Materials and Methods}

In this chapter the sampling strategy is outlined (5.1) followed by sample collection and sample processing (5.2). The two methods of analyses, soil micromorphology (5.3) and FT-IR spectroscopy (5.4), are then described. For full scans of all thin sections used in this study, see Appendix Images 5-43.

\subsection{Sampling strategy}

In 2015 Dr. Francesco Berna and the author, Peter Wallace, collected earthenbased samples at K-AD (Figure 9). Collected materials were assessed and collected with the helpful guidance of KAMBE project directors Kevin Fisher and Sturt Manning. Archaeological samples were collected in-situ from the excavated monumental complex in the Northeast Area and from Units 3 and 7 that were undergoing excavation. Additional samples from previous excavations were collected from a long-term storage facility.

Sampling was guided by an understanding of what would be required to create a suitable collection for a study project and was limited by our capabilities to sample all the necessary material in time. For example, the main $\mathrm{N}-\mathrm{S}$ road located within the "monumental" northeast area and uncovered in Unit 3 is a visually homogenous (Appendix Images 11-13), 200mm thick layer of coarse white plaster that has an irregular and undulating surface. Meanwhile, also in Unit 3, a structure next to the N-S road has a thin $8 \mathrm{~mm}$ plaster floor that is carried up the wall (a moderately common occurrence in Cyprus [Philokyprou 2012: 179]) and is also visually homogenous (Appendix Image 14, 15, and 43). The plaster here is very tough, despite its thin composition and covers a soft 

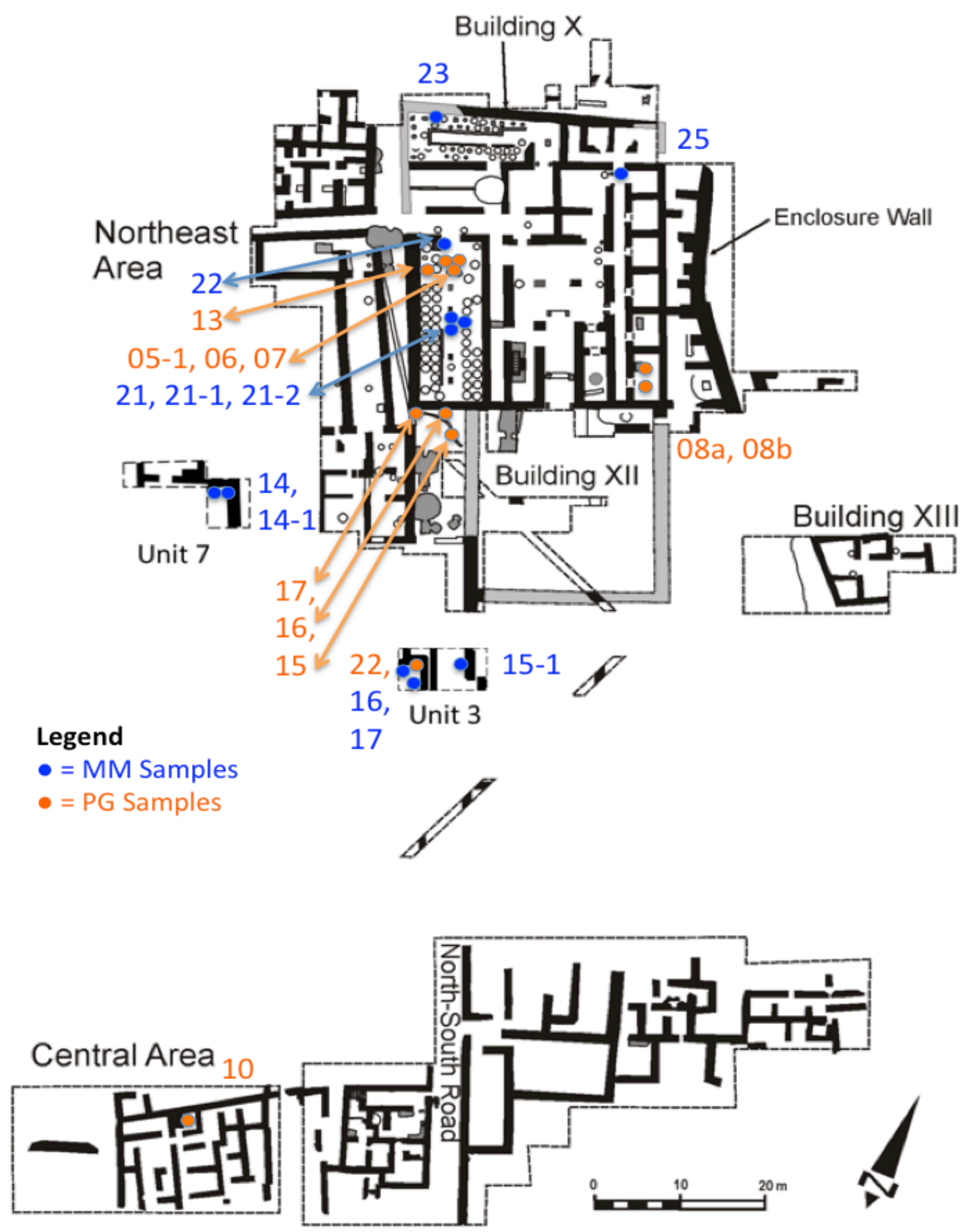

Figure 9. Provenience of thin section samples from K-AD. Credit: Alison South (creator), S Pak (reference images), the Author (editor). MM blocks are sampled in a column (e.g. Figure 10) while PG samples are usually smaller (e.g. Figure 17c). 
calcareous ground matrix. These two plaster surfaces were sampled to get a better understanding of their individual characters and how they were best suited for their respective roles.

Our attention was also drawn to the main storage room, nicknamed the "Pithos Hall," as the largest room in Building X (South 1997: 154). The Pithos Hall appeared to have a LCIIC-period floor constructed on top of an older floor. Both floors have a visually similar construction pattern with at least three constituent "steps" with as many visually identifiable layers creating two superimposed $150 \mathrm{~mm}$ thick floors. With on-site observations alone it was clear the northeast areas of $\mathrm{K}-\mathrm{AD}$ was constructed with a multiplicity of plaster traditions in use. The recipes for the plasters in the Pithos Hall appear to be selected for a particular function as they vary in thickness, composition and colour. A complete column sequence of the two floors was taken in three micromorphological blocks to have an intact series of strata in sequence for study (Appendix Images 16-22).

As a final example the Neolithic Kalavasos-Tenta samples will be mentioned. The author, Francesco Berna and Alison South visited the site to have a better understanding of ancient architecture on the LBA landscape (in its variable state of ruin) and also to witness the technical traditions that may have been passed down to the LBA people from the Neolithic Period as the Vasilikos Valley is one area on Cyprus with evidence of occupation from the Neolithic to the modern day (South 1995; South and Todd 1997). At Kalavasos-Tenta alternating red and white plaster flooring was observed with red plaster 
on the surface. Two plaster samples (Appendix Images 41, 42) were taken from Tenta for a point-of-comparison study with the plaster at K-AD.

Micromorphological block samples were collected from Units 7 and 3, the only two areas undergoing current excavation in 2015, from areas within the main monumental complex currently enclosed by a fence in the northeast end of the site area, and from the storage facility that houses excavated material from the Vasilikos Valley Project excavations. FT-IR samples, rarely more than one gram of loose material, were collected in small bags from all areas of the site and surrounding area. In total over 180 unique samples including 138 loose sediment samples for FT-IR analysis were collected.

Following the field season work was done to identify all the materials pertinent to this thesis. It was decided that the study of plaster floors and walls provided more than enough material for a thesis.

\subsection{Collecting and Processing Samples}

In order to assess the relationship between urban organization and construction practices at $\mathrm{K}-\mathrm{AD}$ in the Late Cypriot IIC period thirty-seven petrographic thin sections of archaeological surfaces were prepared from fourteen distinct locations at K-AD (Figure 9, Appendix Images 5-40, 43). Archaeological samples were collected from their original context at K-AD in intact, oriented blocks (Figures 10-12) following standard micromorphological procedure (e.g. Karkanas and Efstratiou 2009; Matthews 2010). Additional plaster samples collected during the 1979-1990's excavations (South 1980, 1984a) were also retrieved from a long-term storage facility to be processed into thin sections. The collection and analysis of plaster samples from the Vasilikos Valley Project 
Master's Thesis - P Wallace; McMaster University - Anthropology

excavations provided access to material that is no longer present on site. The complete excavation of areas within the monumental complex left no loose in-situ materials for field collection.

The internal morphology of samples is preserved during transportation from the site to the laboratory by wrapping them in plaster of Paris bandage to create a form-fitting hard cast. Samples were then tightly wrapped with packing tape to prevent any loose sediment from moving or pouring out. Each sample was labeled with the sample number, the top of the sample and a north arrow to indicate its original orientation (Figure 11, 12).

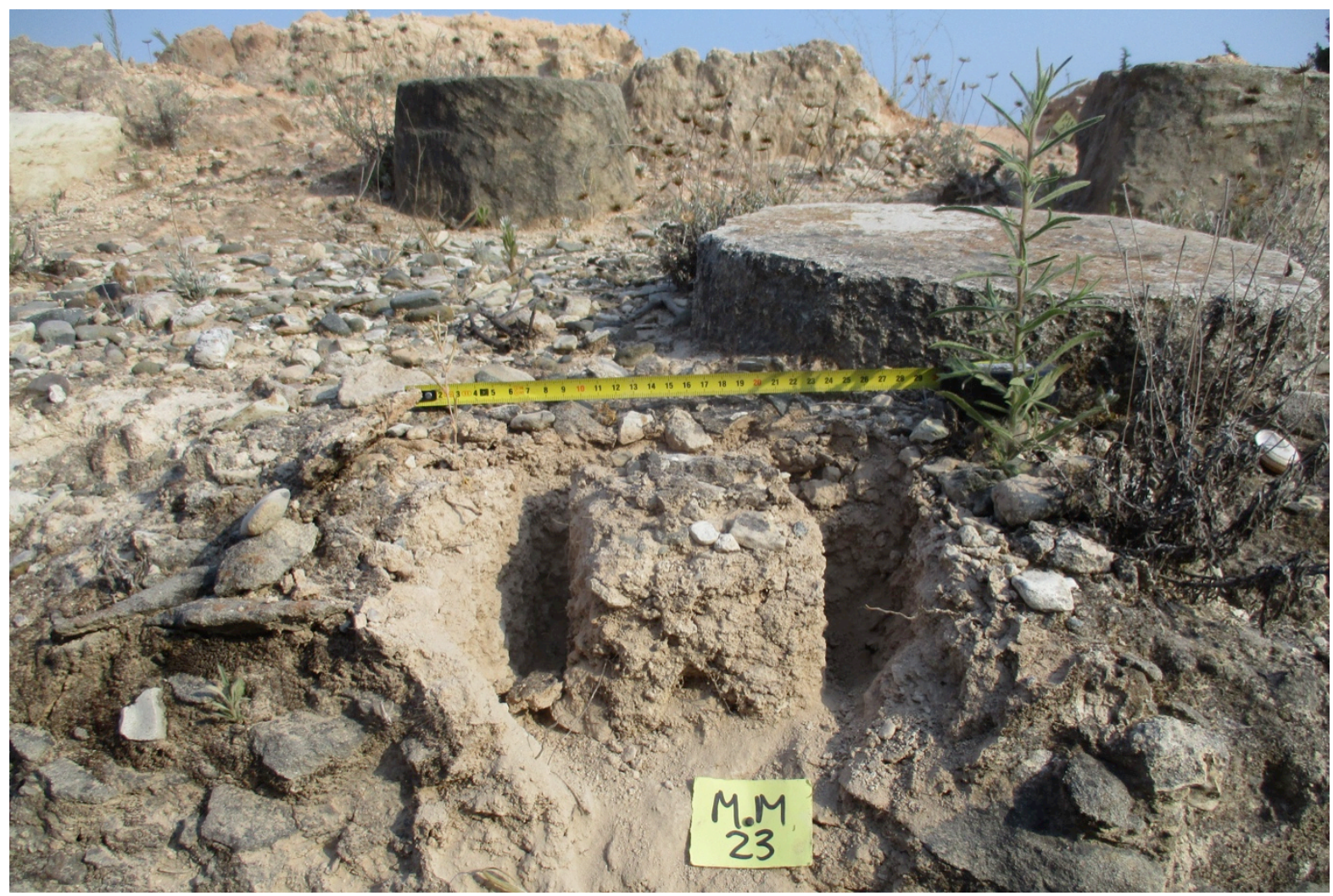

Figure 10. Front view of intact block sample KAD15-MM23, Area 161, before wrapping. Credit: Author's image. 
Master's Thesis - P Wallace; McMaster University - Anthropology

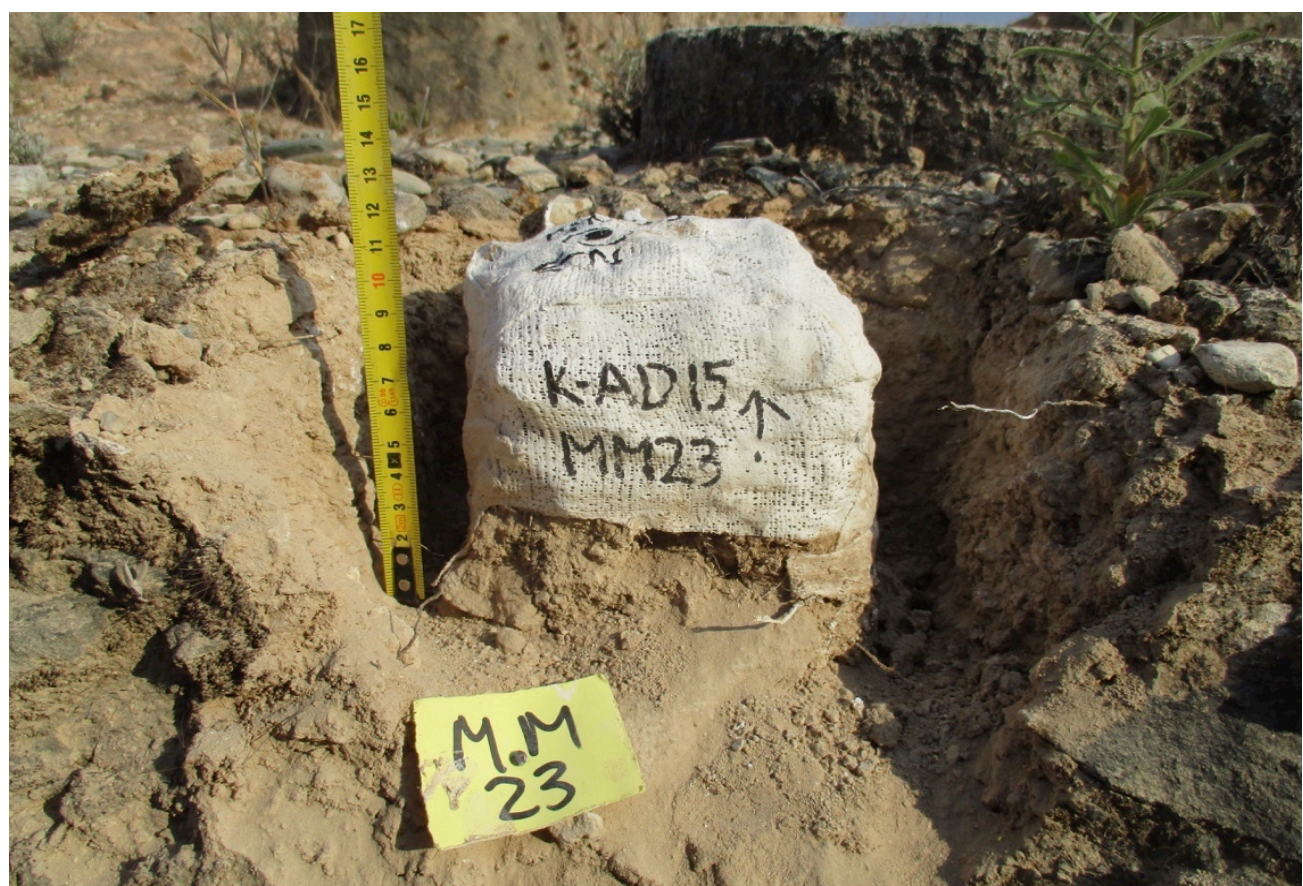

Figure 11. Front view of intact block sample KAD15-MM23, Area 161 wrapped in plaster of Paris. Credit: Author's image.

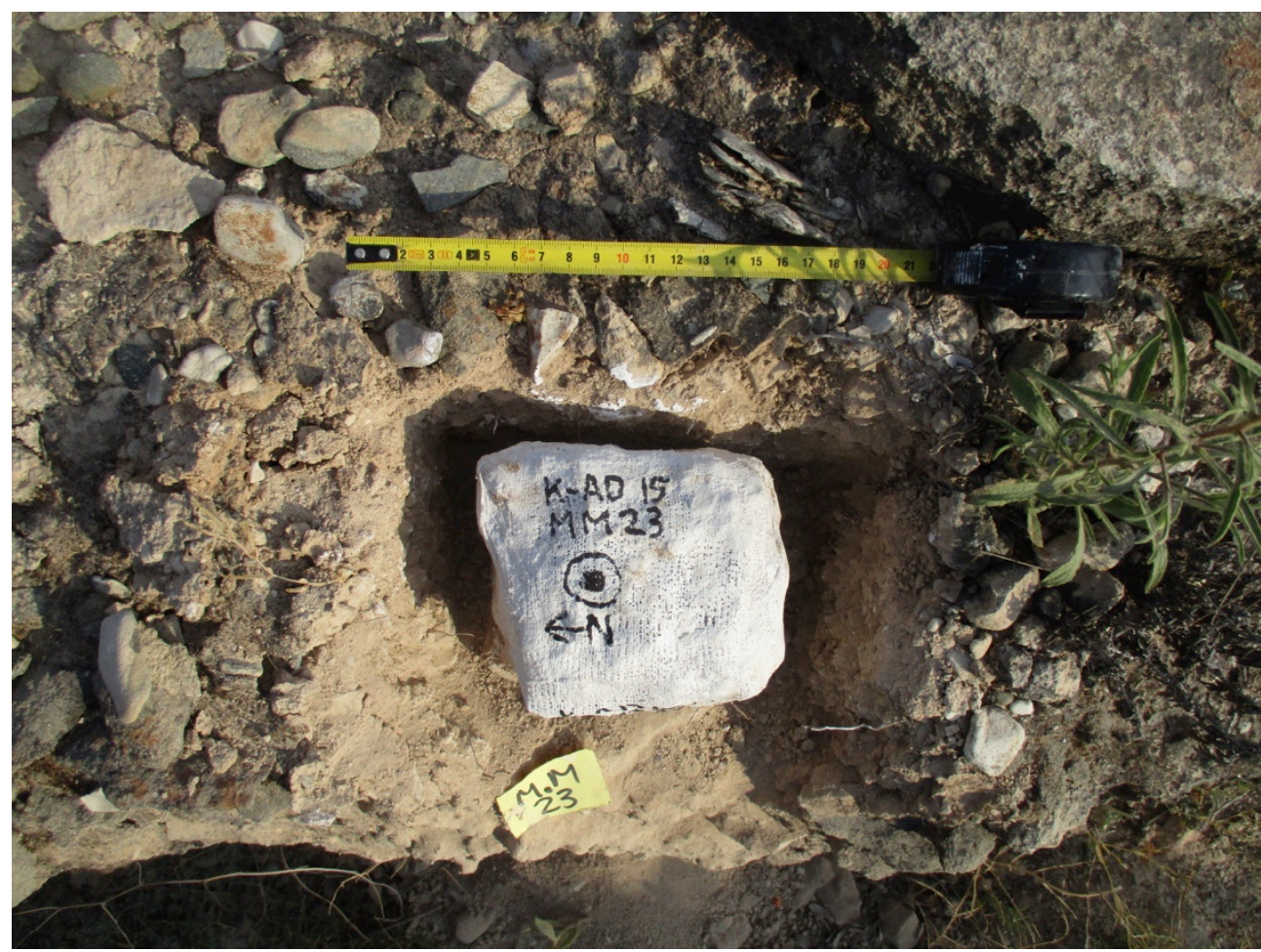

Figure 12. Top view of intact block sample KAD15-MM23, Area 161, wrapped in plaster of Paris. Notice the narrow excavation of the back of the block sample. Credit: Author's image. 


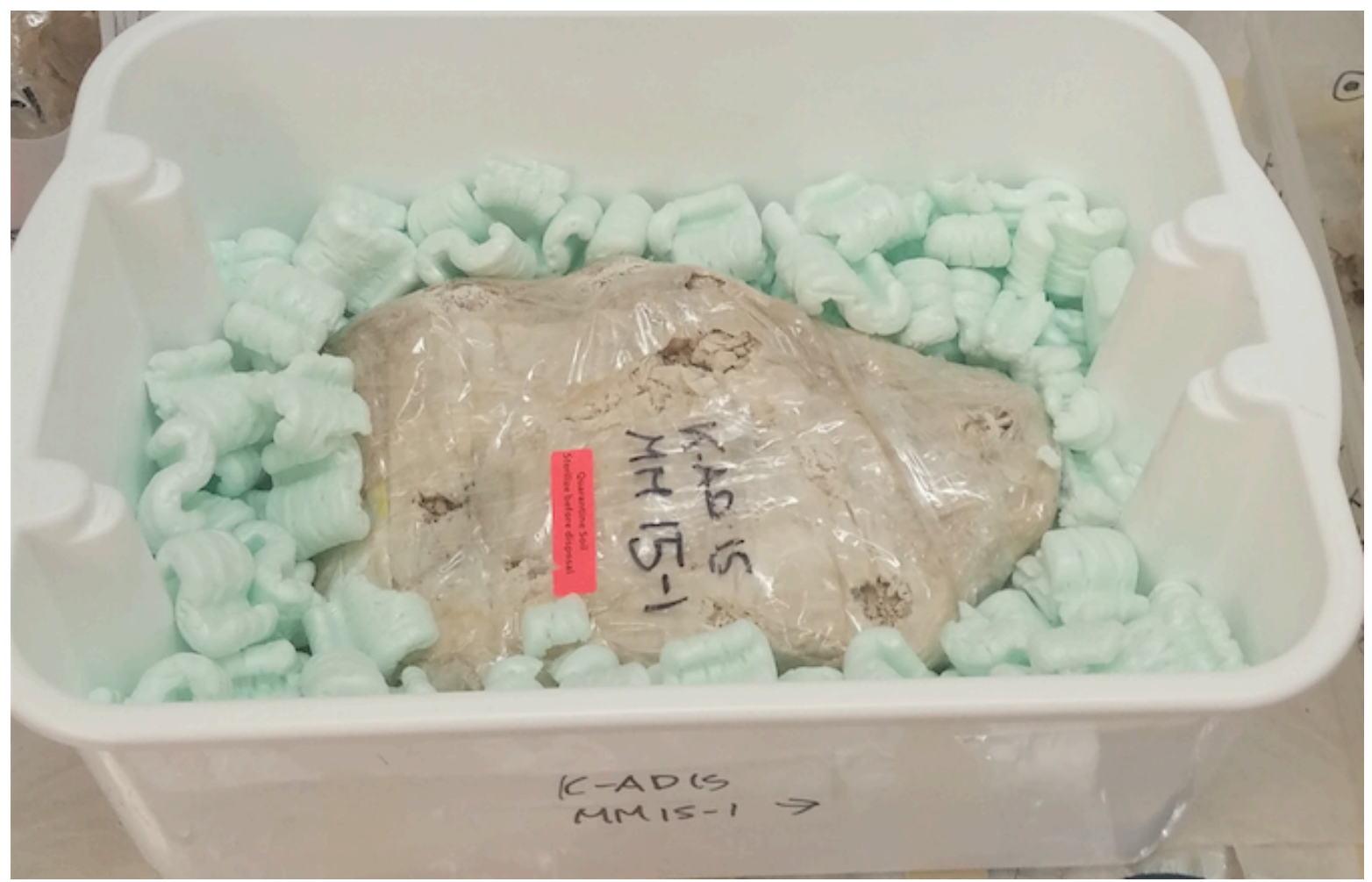

Figure 13. Sample KAD15-MM15-1, the main N-S road, in a plastic container with packing in preparation for imbedding with polyester resin after drying it in an oven for two days. Credit: Author's image.

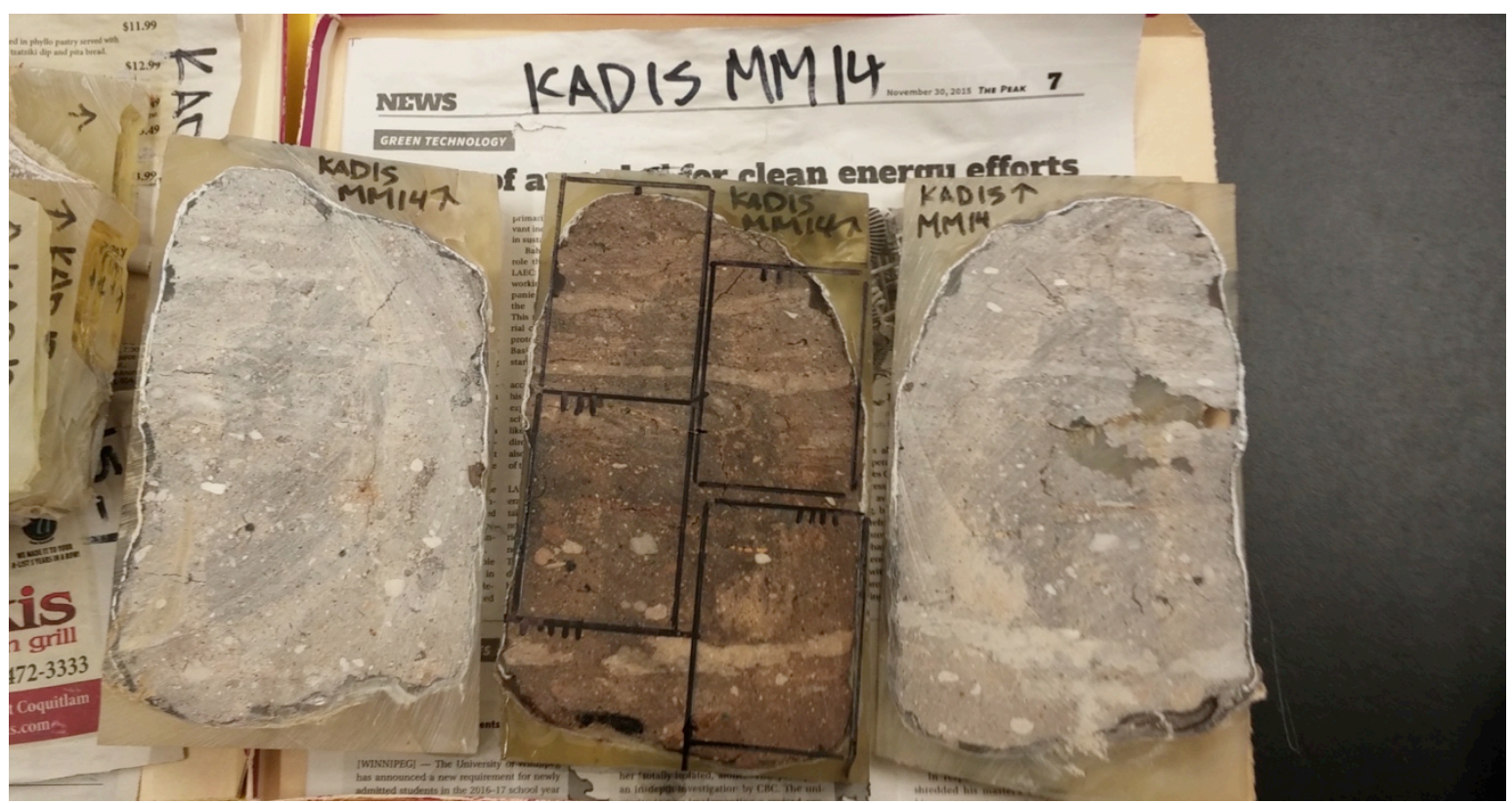

Figure 14. Sample KAD15-MM14, Unit 7, Building XVI sondage, after imbedding and cutting. Five slides have been measured and will be processed into thin sections. Credit: Author's image. 
These samples were transported to Simon Fraser University where they were dried in an oven for a minimum of 48 hours at $50^{\circ} \mathrm{C}$ to remove all non-chemically bound water. The samples were impregnated in a plastic container (Figure 13) under vacuum with a polyester resin (Goren and Goldberg 1991). They were then sliced into $51 \times 76 \mathrm{~mm}$ "tiles" and processed into $30 \mu \mathrm{m}$ thick petrographic thin sections by Quality Thin Section in Arizona, USA. Ten samples were cut into smaller, $25 \times 45 \mathrm{~mm}$ "tiles" and processed in the same manner. The preparation procedures described here were executed under the supervision of Dr. Francesco Berna (e.g. Berna et al. 2012; Goldberg and Berna 2010) in the Geoarchaeology Lab at Simon Fraser University, Burnaby, British Columbia, Canada.

In tandem with the petrographic thin sections loose sediment samples of plaster and reference geological samples were collected from K-AD for Fourier-transform infrared spectrographic analysis (FT-IR). The amount of sediment varied between light scrapings of $50 \mathrm{mg}$ to small pebbles several grams in weight. All of the sediment scrapings, despite being of relatively small abundance, provide enough material to be tested for consistency dozens of times if necessary (Berna et al. 2007; Albert et al. 2008).

\subsection{Optical Microscopy (Petrography and Soil Micromorphology)}

Soil Micromorphological analysis enables fabric studies and the identification of microstratigraphic units of intact, oriented archaeological samples. When analyzing petrographic thin sections identified changes in material constitutions designates a boundary between discrete fabrics. An identified fabric will most often be of self-similar constitution throughout, although some fabrics may have graded distributions. Neighboring fabrics will be visually distinct in composition and meet at a contact surface 
that grade from clear to diffuse. Optical microscopy provides valuable tools in the study of recipe-based plaster technology by allowing composition and material distribution patterns to be analyzed concurrently. The procedure of micromorphological analysis is outlined in this section.

Micromorphological analysis was carried out in plane polarized light (PPL), and crossed polarized light (XPL) using a Leitz petrographic microscope equipped with $3.2 \times$ to $40 \times$ Zeiss lenses, a rotating stage, a gypsum $1 \lambda$-retardation filter. PPL is the default setting on a petrographic microscope and for most purposes does not have a noticeable effect on microscopic analysis. It consists of the microscope's transmission lighting passing through a single polarizing filter restricting the transmission of light waves to a single vibrating plane perpendicular to the path of the light. XPL is a process where a sample is placed between two polarizing filters that are set at right angles to one another. Light exiting the initial polarizing filter is unable to pass through the second, orthogonally oriented filter effectively blocking all light from transmitting through the microscope. When a sample is placed between these two filters anisotropic material (e.g. quartz, Figure 15, Image F) bend the incoming light allowing it to pass through the second polarizer. The sample becomes illuminated to an observer looking through the microscope eyepiece. The rotation of the microscope stage can result in an array of colours (e.g. pyroxene, Figure 15, Image F and G) that change and disappear (become extinct) at regular intervals diagnostic to individual minerals, known as birefringence. The identification and analysis the birefringent patterns among the fine mass of a fabric 


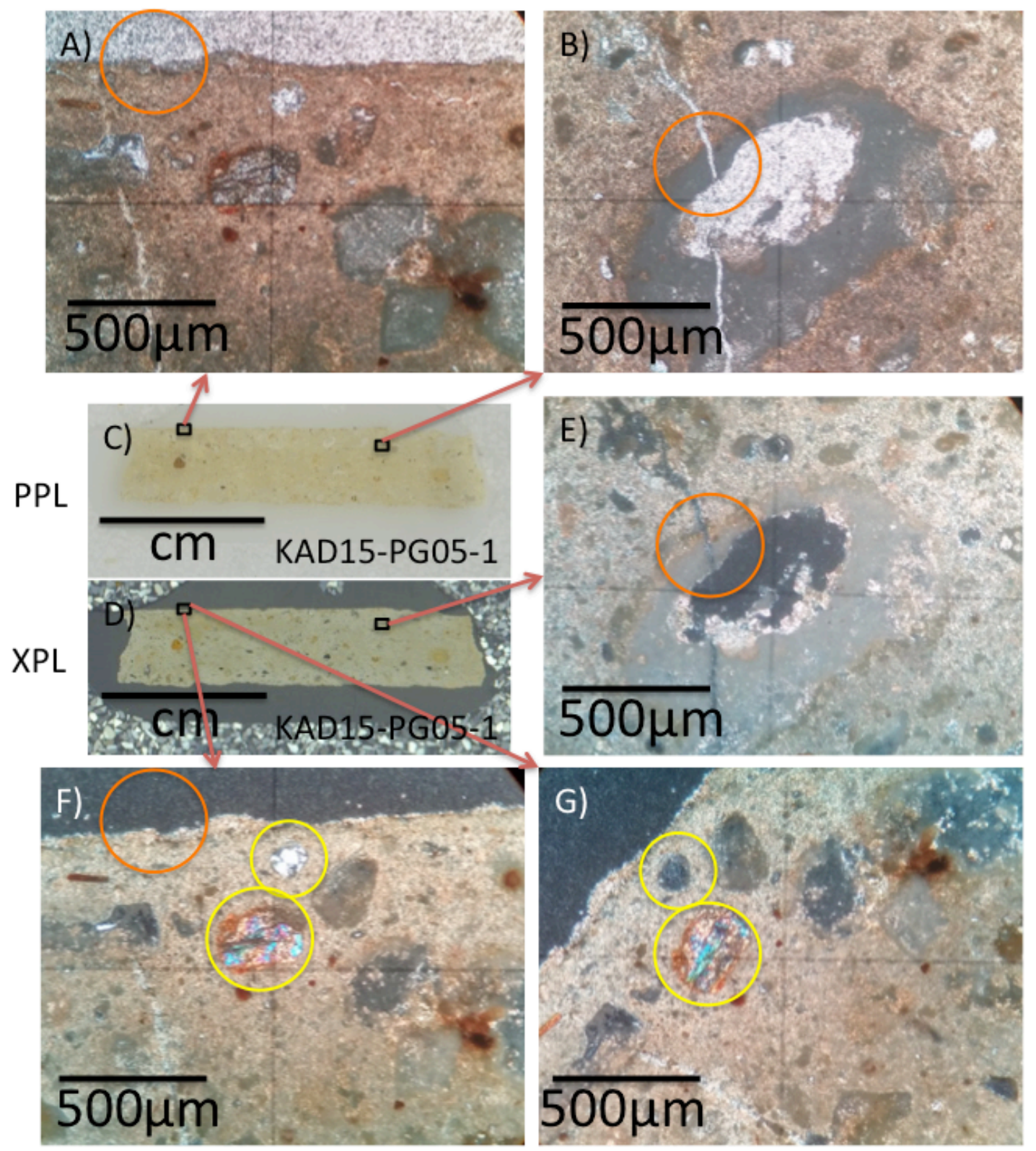

Figure 15. Example of microscopic analysis of thin section KAD15-PG05-1. A) Circled portion, in PPL, covers the border between the anisotropic calcite groundmass of sample KAD15-PG05-1 and the isotropic polyester resin. In comparison the corresponding region in Image F, in XPL, the upper polyester resin becomes extinct while the calcite becomes illuminated. B) Chamber void feature, in PPL. The region circled in orange can be compared with the same region in Image E, in XPL, the planar void becomes extinct, the micritic calcite slightly illuminates while the secondary calcite just below the circled area displays a brightly illuminated crystallitic b-fabric. C) Image of KAD15-PG05-1 in thin section, PPL. D) Image of KAD15-PG05-1 in thin section, XPL. E) See description of Image B. F) A comparison of the orange-circled region is found above in the write-up 
for Image A. A quartz grain and a pyroxene grain have been circled in yellow. Notice how their colours change when the microscope stage is rotated in Image G, also in XPL. G) See description of Image F. Credit: Author's images.

are known as b-fabric. These properties of petrography and soil micromorphology and the following analyses follow Stoops (2003).

The soils at K-AD are diffusely carbonatic due to the abundance of marls and limestone across Cyprus, and in the Vasilikos Valley (Gomez et al. 2004) (see Appendix, Images 1-4). This situation makes distinguishing between the archaeological white-to-tan sediment layers difficult in the field. In the laboratory with the aid of magnification and controlled lighting undisturbed sediments and plasters can be discriminated into distinguishable layers (e.g. Karkanas and Efstratiou 2009). Petrographic samples were divided into any observed fabric units. The noted quantifiable changes in composition and the microscopic arrangement, or microstructure, between lateral spreads will shed light on preparation techniques and replastering events, some of which can be only millimeters thick (Matthews 2005; Philokyprou 2012). The surfaces observed in sequences will be measured for thickness and assessed for composition. Multiple surfaces superimposed on one another will be assessed for compositional consistency and inter-plaster (preparation) deposits.

A coarse/fine limit set for all samples at $2 \mu \mathrm{m}$. This measure is a ratio of material larger and smaller than a set limit. In this case the limit is set at $2 \mu \mathrm{m}$, the approximate limit of resolving a fine silt particle under a petrographic microscope. With this measure all resolvable particles are larger than clay. 
Individual material abundances were recorded for materials that composed at least $10 \%$ of a unit in thin section. Materials that did not meet this threshold were recorded as trace amounts.

Slides were assessed for the presence and amount of $\mathrm{CaCO}_{3}$ (calcite) or $\mathrm{CaSO}_{4}$ (gypsum) optically. Pyrogenic calcite is a grey mass of unresolvable micritic crystals in PPL and XPL. Sections of the grey mass may contain or be bordered by larger calcite crystals that display a crystallitic b-fabric in XPL. Unreacted calcite in the form of limestone appears as larger, blocky crystals, while unreacted chalk is composed of tiny calcite shells in a close packing arrangement. Gypsum plaster, on the other hand, forms resolvable but short needle-like spars when viewed in XPL (e.g. Philokyprou 2012). The interference colours of gypsum spars under cross-polarization are also of a lower-order magnitude (grey and white) than calcite of any size, which displays a greater range interference colours (yellows and pinks) making the two easily and quickly distinguishable (Stoops 2003).

Identified calcite abundances are differentiated according to the abundance of micritic calcite. The micritic, burnt and reacted calcite component represents a different level of socioeconomic technology use than crushed and unreacted carbonates. Higherquality plasters are expected to derive from fully reacted lime, which is more costly to produce than plasters that have aggregates to extend the range of the cementing component. The terms "robustness" and "fineness" will be used to reflect a plaster's comparative durability and percentage of micritic components, respectively. 
Minor aggregate components will also be recorded. This information will be used to hypothesize about potential recipes of manufacture at K-AD. Minor inclusions can also be applied to sourcing studies, for example, Anderson et al. (2014) distinguished between softlime sources based on the inclusion of clay particles in the analyzed plaster. Present clay particles can be assessed with FT-IR to reveal if they were present during raw material firing or if they were subsequently added (Berna et al. 2007).

Burnishing can be applied to the outer surface of plasters while drying, resulting in a smooth, compacted outer surface (Philokyprou 2012). This both homogenizes particle side and hardens the outer layer increasing preservation and use durability. Surfaces will be examined closely to distinguish between plaster samples with evidence of burnishing versus finishing layers. Burnished samples will have gradual changes between the body of the matrix and the exterior whereas finishing layers will be distinct fabric units.

\subsection{FT-IR}

FT-IR can be used to identify minerals by matching a sample's absorption spectrum with the absorption spectra of known minerals. It provides a second means, beyond visual analysis, to identify constituent materials and crystalline phases and is particularly useful for the analysis of loose sediments.

Select loose sediment samples have been analyzed using a Thermo Fisher Scientific Nicolet IS5 FT-IR spectrometer and petrographic thin sections have been analyzed with a Thermo Fisher Scientific Nicolet iN10 MX FT-IR microspectrometer. 
The spectrometers were programmed to take the average of 32 repeat scans at $4 \mathrm{~cm}^{-1}$ resolution. Spectral readings were collected over $4000-400 \mathrm{~cm}^{-1}$ (wavenumbers).

Sediment samples were prepared using standard FT-IR procedure (Berna et al. 2007; Shahack-Gross et al. 2005) by first homogenizing and dehydrating a few tens of micrograms of sample with an agate mortar and pestle in a hot environment provided by a hot plate or under an incandescent light bulb. Approximately $0.1 \mathrm{mg}$ of sample was then mixed with $50 \mathrm{mg}$ of FT-IR grade $\mathrm{KBr}$ (potassium bromide). The two are mixed to suspend the sample in the $\mathrm{KBr}$ and then compacted into a $7 \mathrm{~mm}$ pellet with a Pike hand press. Under pressure the white $\mathrm{KBr}$ salt turns into a glass that is transparent in both the visible spectrum and infrared (IR) light, which allows the FT-IR radiation to interact with the samples' valence electrons. Different covalent bonds absorb energy at consistent and discrete energy levels (wavenumbers) revealing the components suspended in the potassium bromide. Micromorphology slides were placed directly under the FT-IR microspectrometer, after being wiped clean of any dust or oil, and processed.

Spectrographic information obtained with FT-IR can also be used to independently identify pyrogenic calcite, as described by Chu et al. (2008) and Regev et al (2010). Their method compares the intensity of spectral peaks in calcite, $v_{2}\left(874 \mathrm{~cm}^{-1}\right)$ and $v_{4}\left(713 \mathrm{~cm}^{-1}\right)$ within a sample of calcite (figure 16). This method was not used for this study due to technical problems but can be used in future research (see section 10).

Materials that cannot be identified through optical means will also be subject to FT-IR analysis as necessary for identification. Reference samples from K-AD and the vicinity will be compiled as a reference library of spectral peaks. All materials will be 


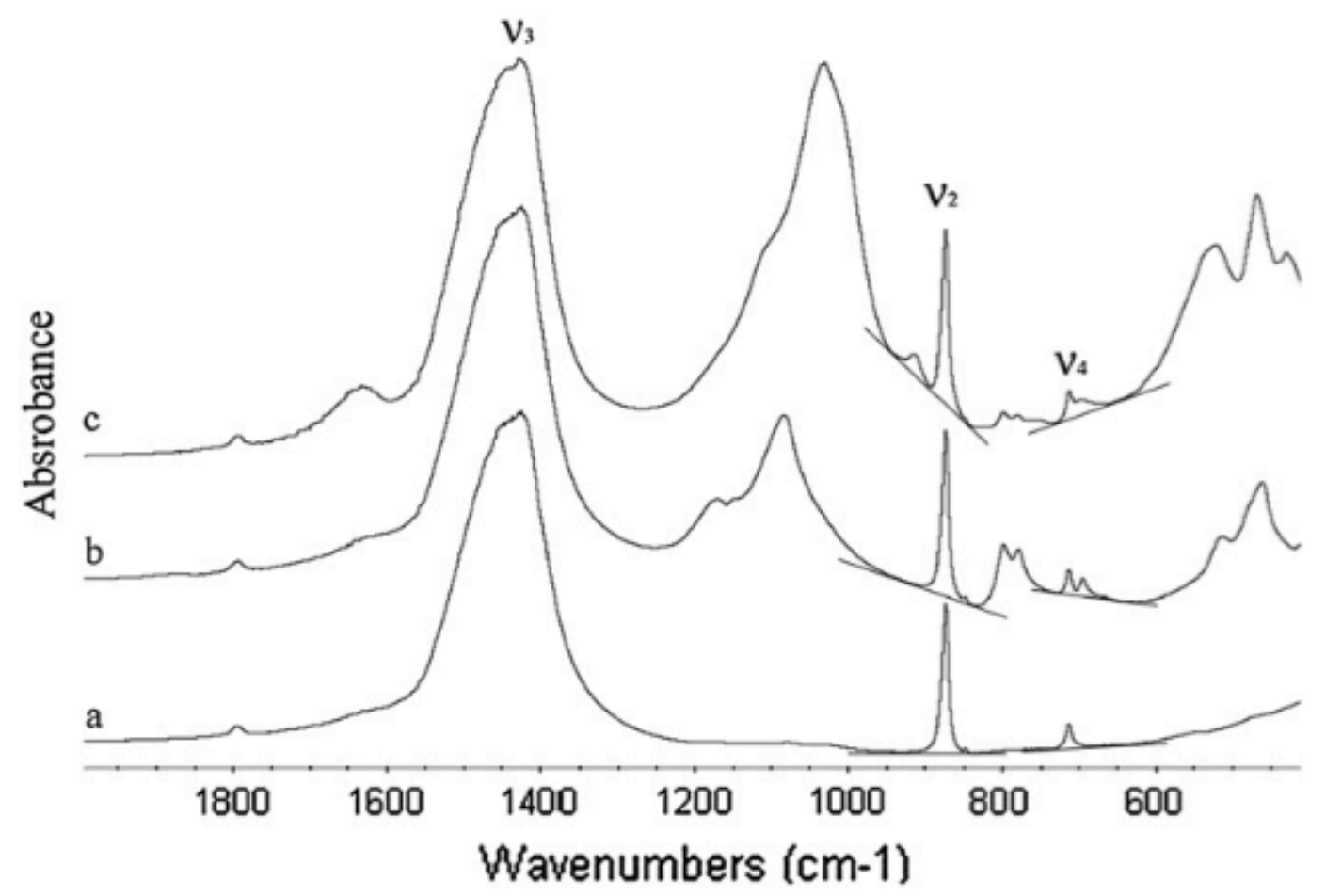

Figure 16. Infrared spectra comparing a) pure calcite, b) a calcite and quartz mixture, and c) a calcite and clay mixture. Credit: Chu et al. (2008).

compared against this library. The Weizmann Institute of Science's Kimmel Center for Archaeological Science provides an online collection of FT-IR spectra, which will be used for both a comparative reference with collected materials, and to help identify any materials that remain unidentified (http://www.weizmann.ac.il/kimmel-arch/infraredspectra-library). 


\section{Results of the Microscopic Analysis (Petrography and Soil Micromorphology)}

In the previous chapter this study's sampling strategy and methods of analyses were provided. In this chapter we turn to the results of the micromorphological analyses. This chapter details the data collected from all analyzed petrographic thin sections. In the following chapter the data from FT-IR analyses are provided, which is then followed by a discussion of these results in the context of the research questions.

There are two notable general findings. First, all samples examined from K-AD were completely free of any traces of gypsum. The significance of this discovery, discussed in greater detail below, is that LBA architects consciously chose lime over gypsum to create plaster despite both materials being plentiful and used in their raw form at K-AD. One of the two Neolithic samples from Kalavasos-Tenta, sample KAD15PG20, is a gypsum plaster while KAD15-PG21 is a lime plaster.

The second general finding is that the fine fractions of all microstratigraphic units were composed of a calcite base and to a large extent the fine mass was dominated by calcite. The calcite matrixes include both pyrogenic and geogenic material, which will be separated in more detail below. Of the coarse fraction limestone pebbles are dominant except in the case of pebble floors in which case the dominant coarse fraction components were pebbles, which vary between limestone aggregates and igneous river pebbles.

Individual samples and their constituent units are presented below and are grouped by sampling area and architectural purpose (e.g. Pithos Hall floor samples, plaster drain samples, etcetera). Layers are labeled from the top (youngest) to bottom 
(oldest) and unless otherwise stated all layers (e.g. L1, L2) are unique in composition to the sample they relate to. In other word KAD15-MM21-L1 (Pithos Hall floor surface) is a distinct microstratigraphic layer from KAD15-MM22-L1 (Pithos Hall step surface). All observed layers are homogenous in composition unless stated otherwise.

\subsection{Pithos Hall Floor Deposits}

B.X, A.152, N50B, KAD15-MM21 (a, b, c), KAD15-MM21-1, KAD15-MM21-2 (a, b, c), KAD15-PG13

The Pithos Hall, Area 152, is located in the southwestern area of Building X (Figures 9, 17). It takes its name from the abundant pithoi stands, sherds, and complete vessels found in-situ during the original excavation (South 1988: 225). The pithos hall was the largest storage area and overall the largest room at K-AD.

Area 152 has generated and sustained much interest as the main storage area (along with Area 161) for a vast, 50,000 liter-minimum deposit of olive oil (South 1995: 194). The double-occupation floor that the pithoi stood on was sampled in three intact micromorphological blocks that yielded seven thin sections Appendix Images 16-22). The samples were taken from the excavation pit in the middle of the room. Sample KAD15PG13 was taken from the base of a sandstone pithos stand (Figure 17, Image C; Appendix Image 37 ) on the hypothesis that if the original surface of the Pithos Hall has been eroded the pithos stand would have preserved its underlying portion.

\subsubsection{Pithos Hall Floor Deposits from Central Column Sequence}

B.X, A.152, N50B, KAD15-MM21 (a, b, c), KAD15-MM21-1, KAD15-MM21-2 (a, b, c)

The floor sequence consists of two construction sequences with a discontinuity between the two events at Layers 6, 7 and 8, which upon closer inspection appear to be 
Master's Thesis - P Wallace; McMaster University - Anthropology

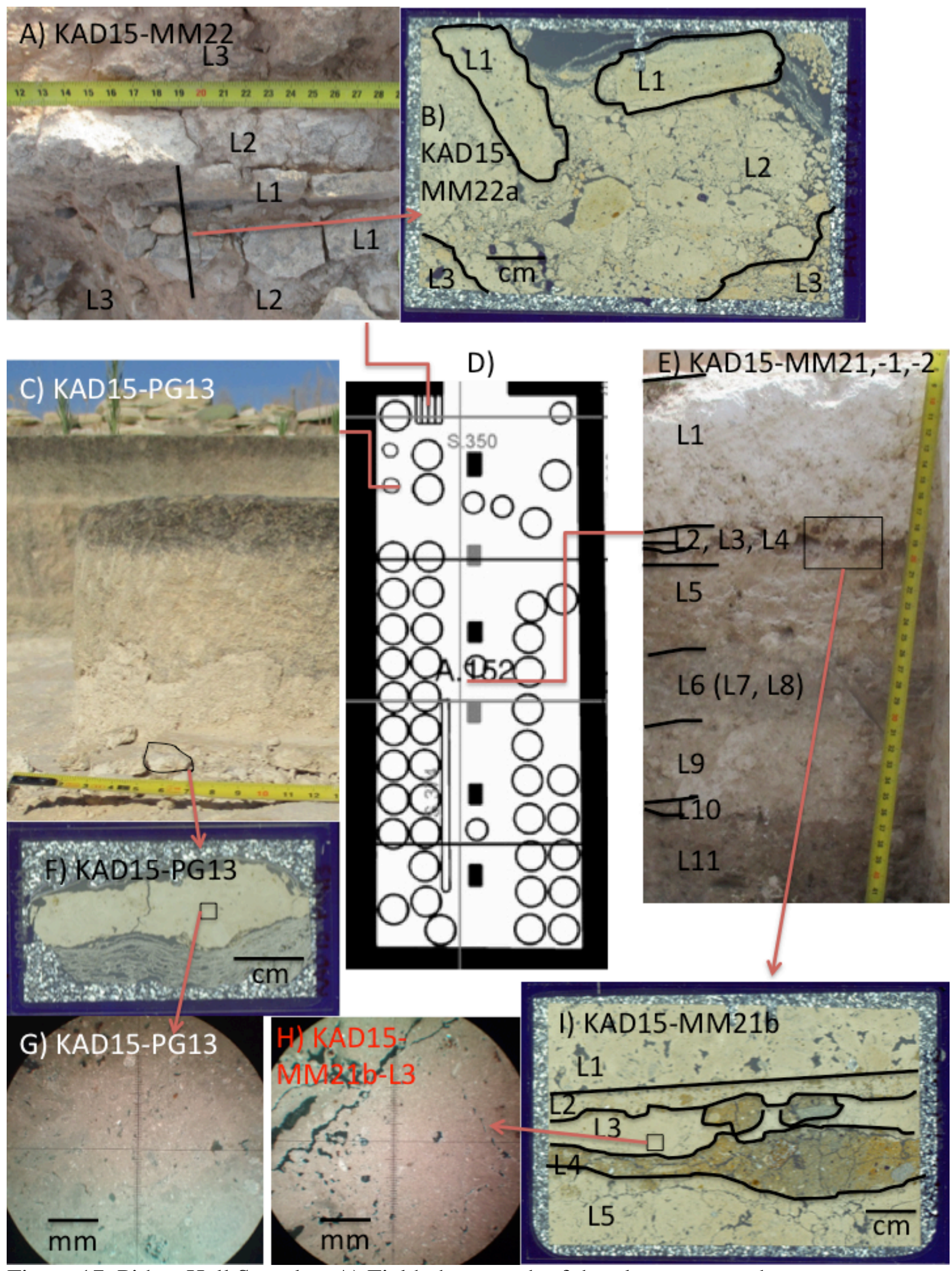

Figure 17. Pithos Hall Samples. A) Field photograph of the plaster covered steps, top 
view, sample KAD15-MM22. B) KAD15-MM22a, XPL, in thin section $(51 \times 76 \mathrm{~mm})$ with microstratigraphic units KAD15-MM22-L1, -L2 and -L3. C) Sandstone pithos stand. KAD15-PG13 was sampled from the circled location. D) Detail of the Pithos Hall from the site plan of K-AD. E) Field photograph of the Pithos Hall floor sequence in profile. Samples KAD15-MM21, KAD15-MM21-1, and KAD15-MM21-2 have been removed. F) KAD15-PG13, XPL, in thin section $(27 \times 46 \mathrm{~mm})$. The homogenous composition of this sample forgoes the need for a unit designation (i.e. -PG13a). G) Microscan, XPL, in 3.2X of KAD15-PG13: Groundmass. H) Microscan, XPL, in 3.2x of KAD15-MM21-L3: Groundmass. I) KAD15-MM21b in thin section $(51 \times 76 \mathrm{~mm})$ with microstratigraphic units KAD15-MM21-L1, -L2, -L3, -L4, -L5. Credit: Author's images A-C, E-I; Alison South, Image D.

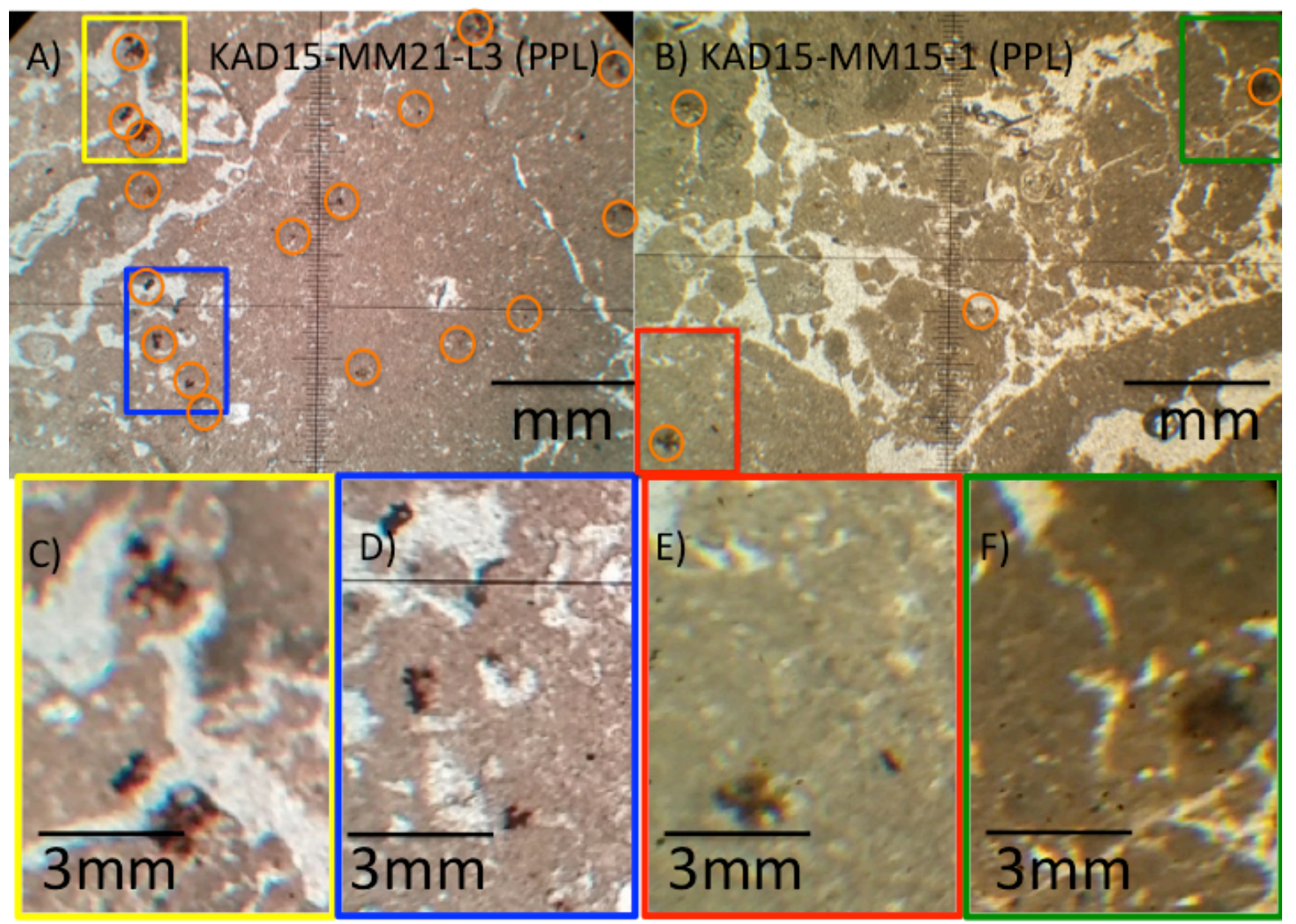

Figure 18. Micritic calcite units KAD15-MM21-L3 (A) and KAD15-MM15-1 (B) with details of among the largest observed dendritic mineral stains (C-F). The magnified inserts correspond in colour with the location indicated on the two microscans. Dendritic stains circled in orange (A, B). All images are in PPL. Credit: Author's images.

sections of the same unit labeled Layer 6 (L7, L8). The top construction event took place with the expansion of K-AD in the Late Cypriot IIC. The two floors appear to have been 
constructed using the same procedure: base carbonate layer (Figure 17, Image E; Layers 5 and 11), thin red clay layer (Figure 17, Image E; Layers $2+3+4$ and 10), thick top micritic calcite layer (Figure 17, Image E; Layers 1 and 9). Layer 1 (Figure 17, Images E and I) is $100 \mathrm{~mm}$ thick and composed of a fine-grained, hard plaster. The coarse materials amount to $10 \%$ of the sampled section and include quartz, chert, and fossils. Voids and shrinkage fissures (lateral partially accommodating planar voids) have secondary calcite layers up to $250 \mu \mathrm{m}$ thick. There are scattered brown dendritic stains (Figure 18) averaging $100 \mu \mathrm{m}$ throughout the unit. Voids have a distinct white, pale hypocoating.

The thin orange layer beneath the main plaster surface was revealed to be composed of two red mm-thick strata (L2, L4) that encased a dense lime plaster layer (L3). L2 is an average of $3 \mathrm{~mm}$ thick and L4 is an average of $7 \mathrm{~mm}$ thick. L2 and L4 are identical in composition but vary in compositional texture across the sampled portion. L4 in this slide revealed a coarse fraction of $33 \%$ while L2 has a coarse fraction of $20 \%$. The major coarse component in both L2 and L4 at 10\% for each layer is quartz and quartzite grains with the remaining coarse fraction including pyroxene, sediment inclusions and igneous minerals. Sediments have a crystallitic b-fabric and there are no pedofeatures within the L2 and L4 strata.

L3 is a fine grey calcite layer, 9mm thick, with undulating upper and lower boundaries. It is a very fine (95\%) micritic calcite matrix with a crystallitic b-fabric. A 5\% coarse fraction includes quartz and scattered fossils. Dendritic mineral stains are present. 
L5 is a $50 \mathrm{~mm}$-thick layer of $20 \%$ coarse material suspended in a calcite matrix. It is tan and grey in colour. The coarse fraction consists of $8 \%$ fossils and varying trace amounts of unburnt limestone, quartz, shell, igneous materials, sediment aggregates, and opaque punctuations. There are no pedofeatures in this layer and the b-fabric remains crystallitic.

L6, L7, and L8, upon closer inspection, are parts of the same unit and will be described as "L6 $(7,8)$ ”. L6 $(7,8)$ is a 40mm, grey to dark grey heterogeneously mixed layer. It has an average $25 \%$ coarse fraction with $15 \%$ of the sample being composed of fossils $100-150 \mu \mathrm{m}$ in size. The balance of the coarse fraction is composed of pyroxene, shell, quartz, igneous minerals and sediment inclusions, which are found concentrated in seperate areas of the unit as both depositional layering and cut infills. The fine mass includes grey and white calcite, plaster nodules, and scattered red clay. Pedofeatures are concentrated to diagenesis in the plaster inclusions, void hypocoatings and some staining.

Layers 6, 7, and 8 were initially defined to be separate units based on perceived change between thin sections. L6 $(7,8)$ marks the discontinuity between the lower and upper floors. It is a natural fill with miscellaneous aggregates, fossils and other geogenic material, and plaster chunks that presumably rolled in. The top of Layer $6(7,8)$ also has a clear cut-feature, $2 \times 17 \mathrm{~mm}$, that is filled with brown sediment, which suggests this layer accumulated over time. There now appears to be a pause in activity between the disuse of the bottom floor and preparation of the top floor sequence, as suggested by the gradual accumulation of Layer $6(7,8)$ on top of the bottom floor surface. There are no dendritic stains in this layer. The micromass b-fabric is overall crystallitic. 
The bottom right corner of L6 $(7,8)$ is a clear dark $5 \mathrm{~mm}$ thick localized area with a coarse mass of $50 \% .4 / 5$ is composed of calcite aggregates $70-400 \mu \mathrm{m}$ in size in a chitonic arrangement with the calcite fine mass. The remaining 1/5 coarse mass is composed of quartz and igneous minerals.

L9 is grey, 60mm thick, and composed of a fine, hard plaster. The coarse materials amount to $14 \%$ of the unit with fossil inclusions $30-200 \mu \mathrm{m}$ in size taking the majority of the space (10\%) and quartz filling the balance. The fine fraction is composed of micritic calcite. There is grey and dark grey clay throughout the matrix; all voids have dark grey hypocoatings. There are a few instances of dendritic mineral staining. The fine fraction has an undifferentiated b-fabric.

L10 is a red-brown layer, $10 \mathrm{~mm}$ thick, and $16 \%$ coarse material that is $10 \%$ quartz. The remaining coarse fraction is composed of punctuations, sediment aggregates, and pyroxene. The arrangement is double-spaced porphyric. There are no pedofeatures and the b-fabric is crystallitic. This is a preparation layer similar to the orange L2 and L4 layers in colour, thickness, provenance, composition, and lack of pedofeatures.

L11 is a dark grey calcite layer with $20 \%$ coarse fabric in a double-spaced porphyric distribution pattern. The coarse material is $15 \%$ quartz and $5 \%$ igneous minerals to a maximum $700 \mu \mathrm{m}$. There is a single ceramic sherd within this layer, $25 \mathrm{~mm}$ long and $8 \mathrm{~mm}$ wide. The sherd is brown on its external surfaces with an inward reduction gradient that has left the center black. It was not analyzed further. There are no granostriations or other pedofeatures present among fabric constituent materials. The bfabric is crystallitic. 
L12 is very different from all preceding layers. It is composed of coarse aggregates amounting to $95 \%$ of the slide. Igneous aggregates $300 \mu \mathrm{m}$ to $1.5 \mathrm{~mm}$ compose $40 \%$ of the stratum and fossiliferous limestone aggregates $3-5 \mathrm{~mm}$ take up $10 \%$ of the stratum. A single $3.5 \mathrm{~cm}$-long fossiliferous limestone aggregate with a reaction rim covers $40 \%$ of the visible area. Chalk is the only fine mass present and most minerals are granostriated. The layer is $22 \mathrm{~mm}$ thick but likely extends past the base of this terminus sample. It is also likely that this layer is geogenic.

To summarize, it appears this column sequence from the Pithos Hall represents two events of floor construction separated by Layer $6(7,8)$. Both floor construction events represent three basic steps: laying a base layer, the application of a thin, red sediment layer, and topping off the floor with a layer of lime plaster that is thicker than the previous two layers. This tradition, or construction recipe, was altered for the second construction event with the thickening of each layer with its corresponding part in the bottom floor. Additionally, Layer 10, the red sediment layer in the bottom floor, was rendered as three distinct layers (L2, L3, L4) with pure lime plaster as the central layer (L3). This floor thus appears to represent the diachronic development of a floor recipe.

\subsubsection{Material Beneath Pithos Stand B.X A.152, N51C, KAD15-PG13}

The material sampled beneath a calcareous sandstone pithos base had a measured thickness of $12 \mathrm{~mm}$ and forms one unit (Figure 17, Image F). This is possibly the original finishing layer of the Pithos Hall floor that has been preserved by the pithos base stone. The sample is white in colour and very fine with a $10 \%$ coarse-fine ratio. The coarse 
aggregates include $100 \mu \mathrm{m}$ quartz grains, calcite fragments, fossils and opaque punctuations. Voids and fissures are all coated with secondary calcite, indicating the movement of calcite crystals by water over time. The b-fabric is undifferentiated with a uniform low order birefringence present across the sample.

This sample is denser than KAD15-MM21-L1, the top of the upper Piths Hall floor. It has no corresponding component with the bottom Pithos Hall floor, however, and therefore may either be a new addition to the floor construction tradition, the product of diagenesis, or perhaps the lower floor's surface had been removed prior to the construction of the upper floor.

\subsection{Plaster-Covered Steps}

B.X, A.152, N51A/C, KAD15-MM22 (a, b)

On the north wall of Area 152 on the west side of the doorway leading to Area 175 there is a plaster-covered pisé staircase. There are four steps (that ascend to the west) in a deteriorating state of preservation. The junction between the top of step 3 and to edge of step 4 was sampled, preserving the angle and pressed mud composition onto which the plaster was originally laid (Appendix Images 23, 24). The analysis of this sample revealed three distinct units of construction: the capping structured and hard pyrogenic plaster material, underlying coarse carbonate material composed of packed plaster nodules and a fine, red clay material that supports the entire structure.

The top beige layer, the plaster, is $10 \mathrm{~mm}$ thick and densely packed. The plaster has a $20 \%$ coarse fraction of limestone aggregates, quartz, pyroxene, sediment aggregates, with trace amounts of artificial pozzolanic material with most aggregates 
measuring less than $200 \mu \mathrm{m}$. The fine fraction is calcite with a crystallitic b-fabric. Mineral staining is present as irregular oval speckles. Edges of the plaster have an internal quasicoating throughout the sample.

Layer two is $30 \mathrm{~mm}$ thick and composed of dense plaster chunks up to several centimeters in size in a matrix of double-spaced porphyric calcite groundmass. The fine fraction is calcite with a crystallitic b-fabric with dendritic mineral stains present predominantly within the white plaster aggregates. The coarse fraction comprises $20 \%$ of the material, $10 \%$ of which are fossils. The balance is made of quartz, pyroxene, sediment aggregates, shell, and artificial pozzolanic material, albeit in small amounts. There is no evidence of secondary chemical alteration and no reaction rims present. Shrinkage fractures are found within the plaster chunks.

The base red clay material is over $70 \mathrm{~mm}$ thick (as per the size of the thin section) and has a coarse fraction of $10 \%$, which includes quartz, chert, shell, and artificial pozzolanic material that greatly exceeds the abundance seen in L1 and L2 by several orders of magnitude (Figure 19). This layer has numerous included plaster chinks that have hypocoatings, reactions rims and dendritic mineral stains. The fine mass has a crystallitic b-fabric.

This feature appears to have been made in three steps. The first, basal layer of pressed mud acted as a rough form for the final steps. On top of this layer a mixture of slacked lime was mixed with recycled plaster aggregates. The slacked lime would have been extended by the plaster inclusions while creating a surface that would not shrink or degrade as easily as pressed mud, extending the period of use for the steps. The final layer 
Master's Thesis - P Wallace; McMaster University - Anthropology

is a pyrogenic plaster. The trace amount of artificial pozzolanic material do not indicate that this layer has hydraulic properties. Instead their limited abundance suggests they are unintentional inclusions, perhaps the result of the plaster being prepared in proximity to the pressed mud base, which has a much higher abundance of artificial pozzolans that serve no strengthening purpose in a mud-based mizture.

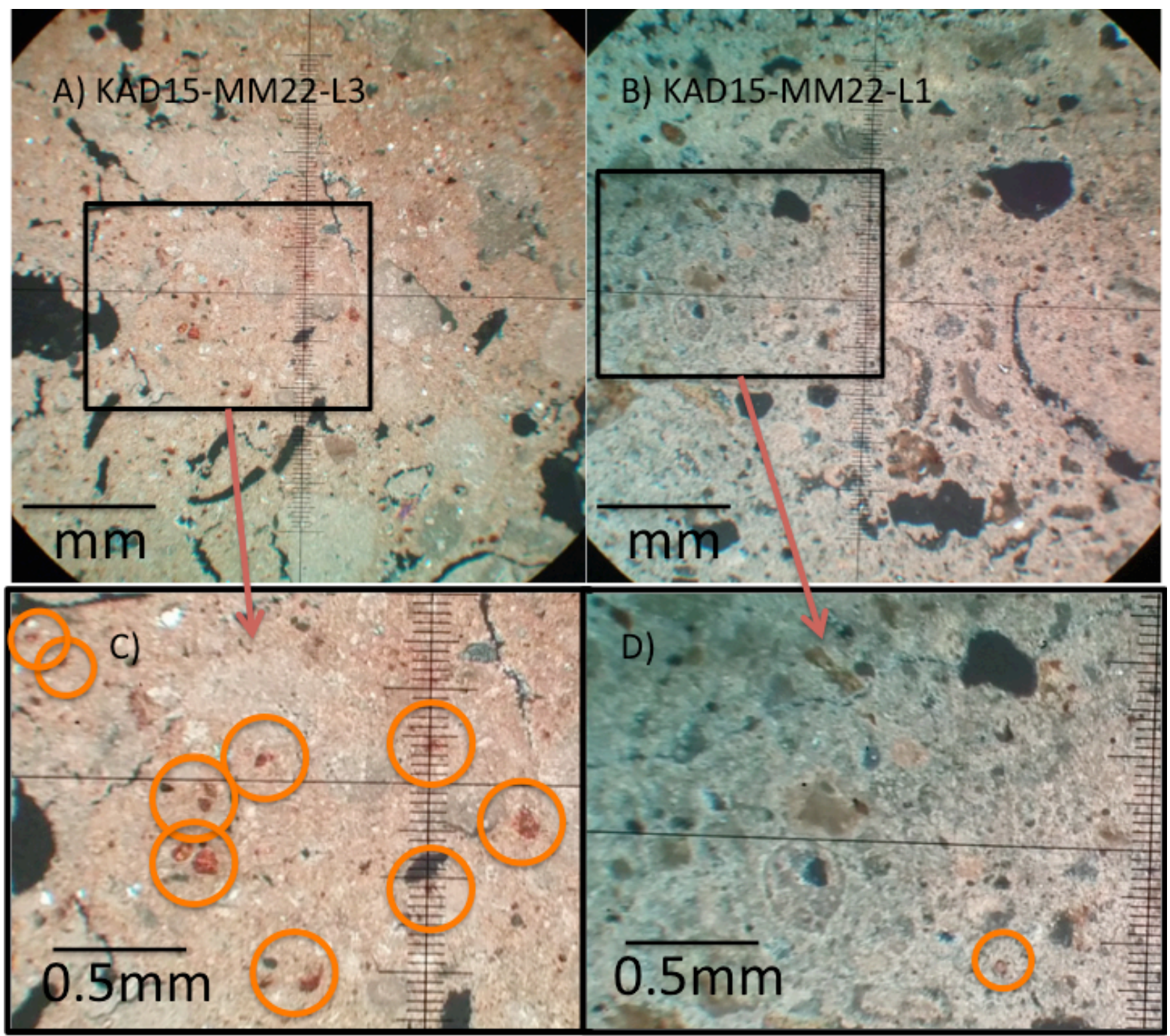

Figure 19. KAD15-MM22-L3 (A) and-MM22-L1 (B) from the steps in the Pithos Hall. Microscan detail of aggregate inclusions. C) Magnified detail of $-\mathrm{L} 3$. Notice the abundance of red artificial pozzolanic material in the pressed mud (pisé) structure in comparison with the surface layer (D). All images are XPL. Credit: Author's images. 


\subsection{Building XVI Floors}

B.XVI, Unit 7, KAD15-MM14 (a, b, c, d, e), KAD15-MM14-1

A sondage was dug along the north wall of Building XVI in Unit 7 at the end of the 2015 field season to explore the composition of the living floors located outside of the monumental complex. Two superimposed micromorphology blocks were taken, KAD15MM14 (Figure 20; Appendix Images 5-9) and KAD15-MM14-1 (Appendix image 10). In the lab eleven surface layers separated by twelve fill strata were quantified for a total of twenty-three units across five micromorphology thin sections.

Numerous stratigraphic units are represented across multiple slides (Figure 20). The thicknesses of the strata were averaged when possible. In the field thirteen layers in total were observed and measured, half as many that were identified after they had been processed into thin sections. Those field observations are inaccurate and have been disposed of. The underlying stratigraphic unit, MM14-1, was a massive, homogeneous unit.

Two groups of units were observed, labeled "M," for porous matrix and "L," for dense layers. Layers are clearly defined micritic calcite pyrogenic lime plaster units separated by non-pyrogenic, calcite-dominated matrixes. The layers are thinner on average (3.6mm, range 1.0-6.5mm; Figure 21), more compact (dominated by planar voids) and whiter in colour (naked eye)/grey (microscope) than the surrounding material (Figure 20). Voidspace also includes vesicular and partially accommodated planar shrinkage fractures. The twelve matrix units are thicker on average $(11.7 \mathrm{~mm}$, range 2.0 $34.5 \mathrm{~mm}$; Figure 21), less compact (dominated by packing voids) and are tan in colour 
A) KAD15-MM14

B) $-\mathrm{MM} 14 \mathrm{~b}$

C) -MM14-M7-L7
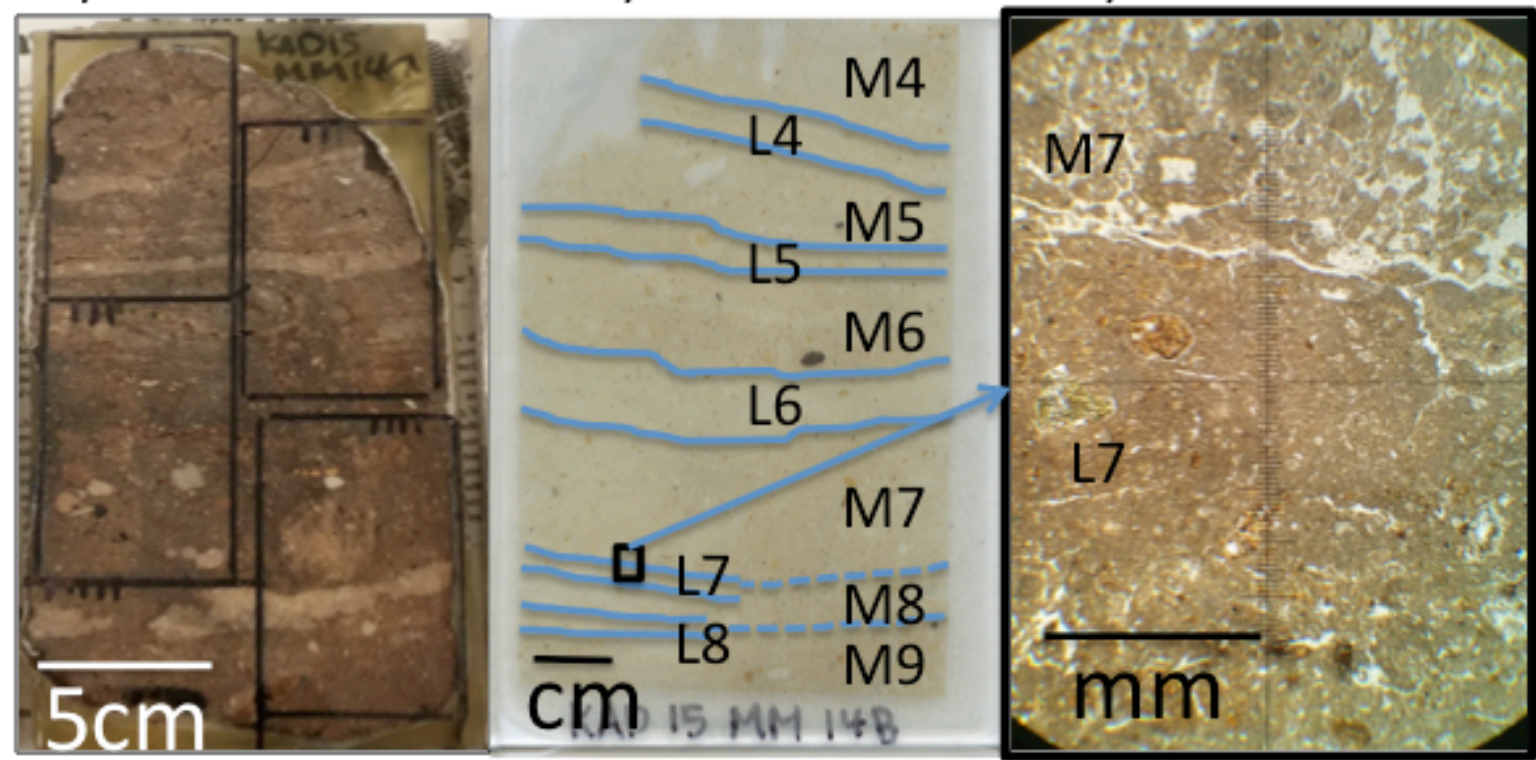

Figure 20. A) Embedded and cut block sample KAD15-MM14 with five areas traced out for processing into thin sections a-e, top to bottom (day lighting). B) Slide KAD15MM14b containing layers M4, L4, M5...L8, M9 (day lighting). C) Detail of M7 and L7 (PPL). Notice the abundance of pore space in M7 and shrinkage fractures in L7. Image has been corrected for optical inversion. Credit: Author's images.

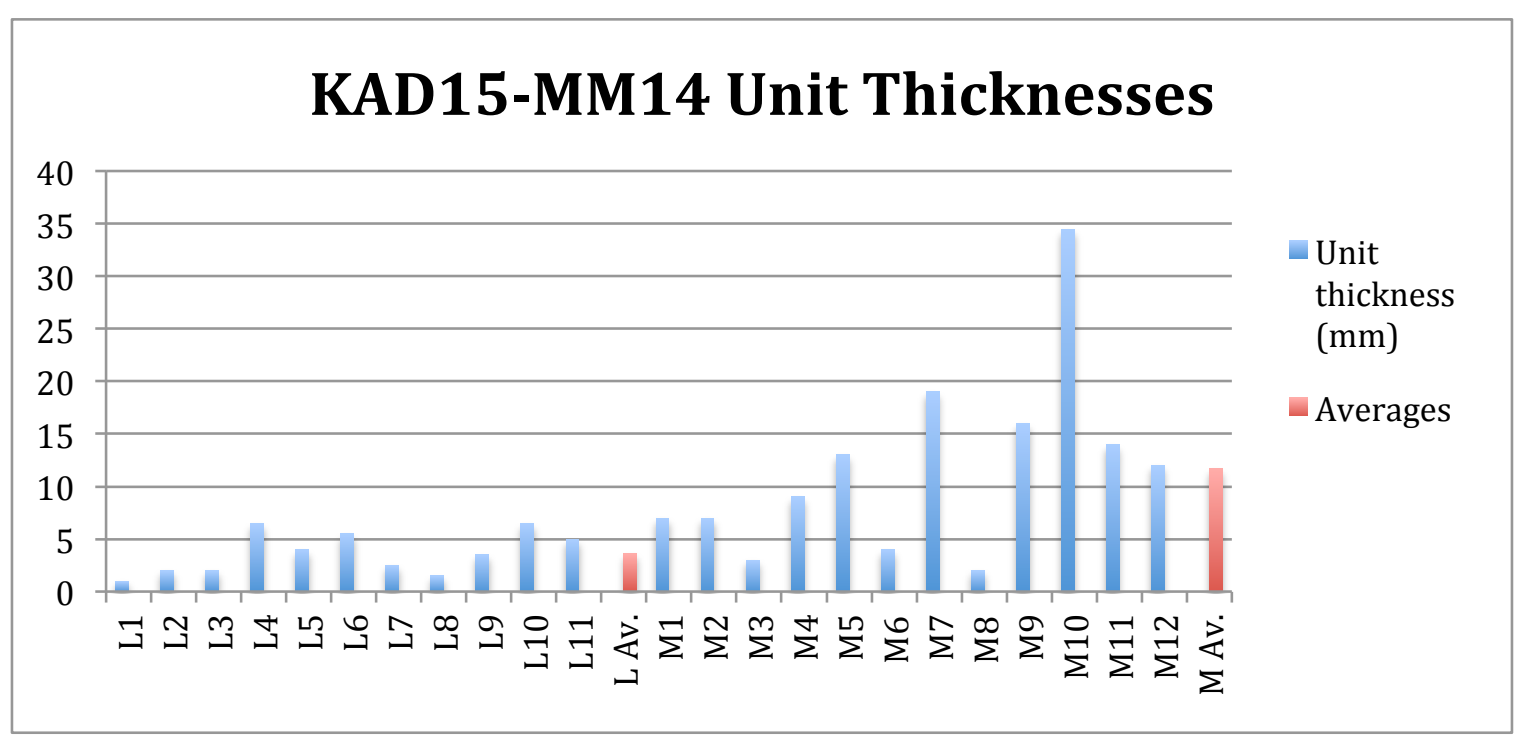

Figure 21. Thicknesses of KAD15-MM14 units grouped as Layers and Matrixes. Unit thicknesses are in blue. The average thickness of all Layers and Matrixes are in red. Credit: Author image. 


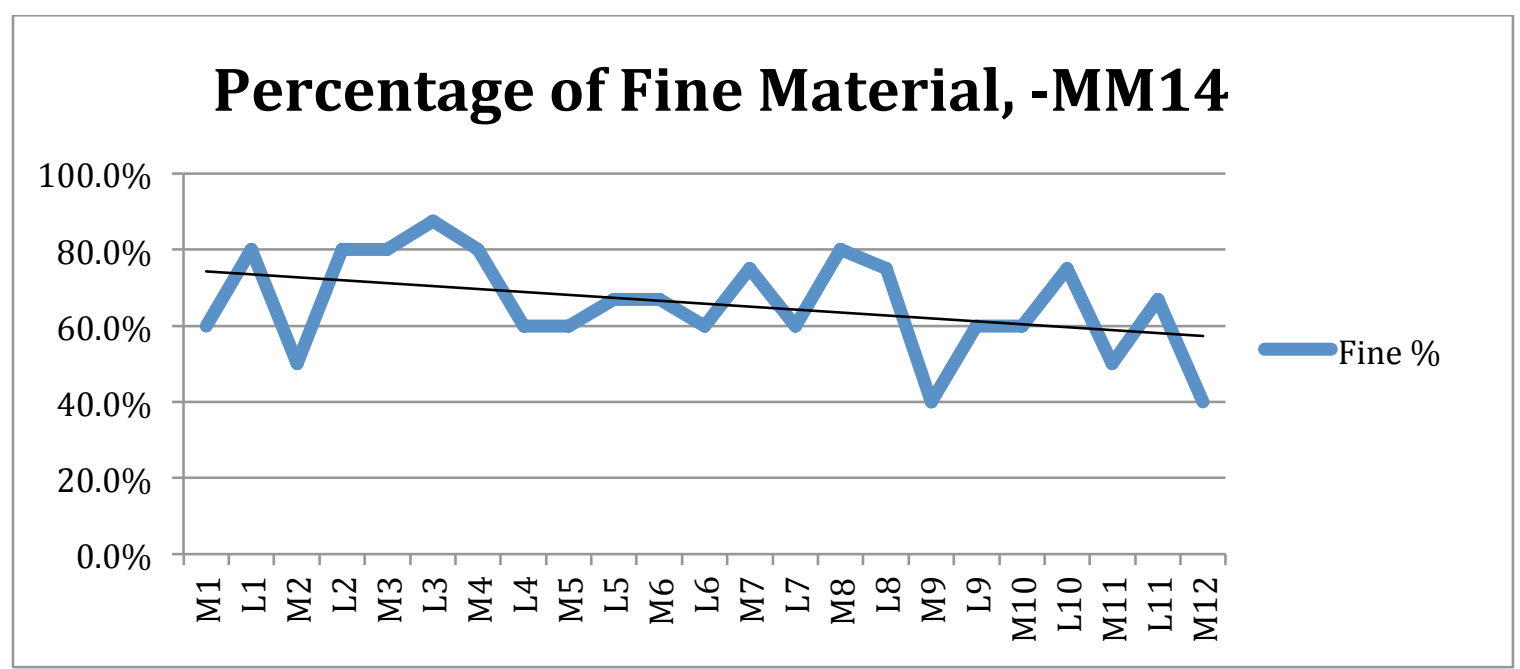

Figure 22. KAD15-MM14 units arranged from top to bottom displaying fine mass. Credit: Author's image.

(naked eye)/grey and tan (microscope). These units contain more sediment (and therefore less calcite) and are darker in colour.

Units L1-L4 have a speckled micromass and L9 has a dotted micromass. There is a noticed compositional dominance of calcite in the layers that is contrasted with the presence of sediment in the matrixes.

The underlying $75 \mathrm{~mm}$ block contained only one layer, tan colour, $67 \%$ coarse fraction, $33 \%$ fine fraction, and a speckled micromass. Its composition does not closely resemble the plaster surfaces or the matrix fill layers (see Figure 22). The coarse fraction includes $20 \%$ fossiliferous limestone, $20 \%$ sediment aggregates and $10 \%$ igneous rocks with quartz, pyroxene, chert and roots making the balance (17\%). Pedofeatures include the coating and infilling of voids, roots and fissures with secondary calcite and granostriated voids. As expected with the abundance of calcite the b-fabric is crystallitic.

These surfaces appear to have been constructed on a regular basis with the application of a crushed calcite and sediment layer followed by a thin layer of lime 
plaster. These surfaces appear to be a cheaper alternative than applying a thick lime plaster floor but at the same time their visual appearance would be similar to the lime plaster floors such as those seen in the monumental Northeast Area.

\subsection{Main N-S Road}

Unit 3, KAD15-MM15-1 (a, b, c)

A $20 \mathrm{~cm}$ thick block sample of the main $\mathrm{N}-\mathrm{S}$ road was taken from Unit 3 and processed into three thin sections (Appendix Images 11-13) that revealed a massive, homogenous and uniform microstructure. The sample has a micritic calcite groundmass with well-developed separated peds in a random arrangement. The coarse fraction comprises $10 \%$ of the material constituents and consists of chalk, quartz, sediment aggregates, shell, and igneous rocks. The unit appears coarse with a crumby microstructure from the included chunks. This sample has a crystallitic b-fabric and has scattered mineral dendritic stains. Micritic calcite nodules have white, pale pedofeatures as hypocoatings and quasicoatings as well as accommodating lateral planar voids (shrinkage fractures). There is also abundant secondary calcium carbonate within voids and impregnating groundmass at parts. These layers are up to $700 \mu \mathrm{m}$ thick.

This thick, pyrogenic lime road has a uniform composition, even distribution of voids, mineral dendrites and inclusions. It closely approximates the top lime plaster layers of the Pithos Hall floor deposits (KAD15-MM21-L1, -L9) with one major exception: the development of peds and the accompanying high volume of voids. There are fewer mineral dendrites in the road, but the abundance more closely resembles the amount in the Pithos Hall deposits when the high proportion of voids is considered. 


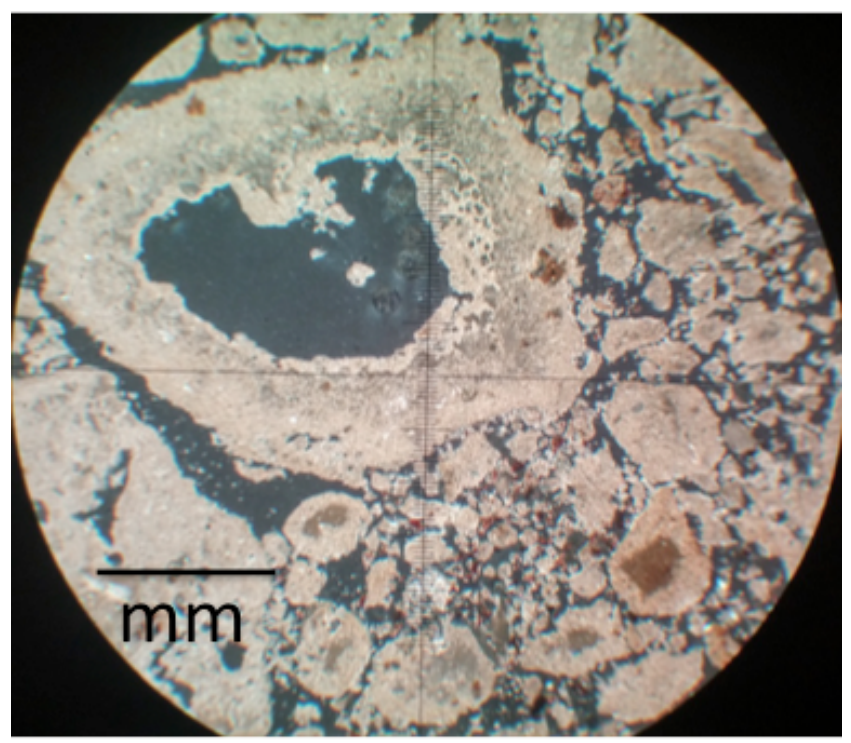

Figure 23. KAD15-MM15-1c.

Secondary calcium carbonate void coating, $400 \mu \mathrm{m}$ thick. Credit:

Author's image.

\subsection{Fine-Surfaced Floor}

Unit 3, KAD15-MM16 (floor), KAD15-MM17 (floor near wall), KAD15-PG22 (wall)

Three samples were taken from the smooth, thin, floor-to-wall surface that coats

the entire floor and continues up the wall (Figure 9, 24). The two floor samples, MM16 (Appendix Image 14) and MM17 (Appendix Image 17), have three shared microstratigraphic units that were found to be identical to each other, and also identical to the wall sample PG22 (Appendix Image 43). All samples are 8mm thick in total.

The top layer/outer surface (L1) in each sample is a tan/beige colour with a $10 \%$ coarse fraction that includes quartz, fossils, sediment inclusions, and chert aggregates with a maximum size of $30 \mu \mathrm{m}$ each. This top layer is $0.5-1 \mathrm{~mm}$ thick with a sharp, flat contact with L2. Samples MM16 and PG22 have an undulating, degraded surface portion while MM17's 


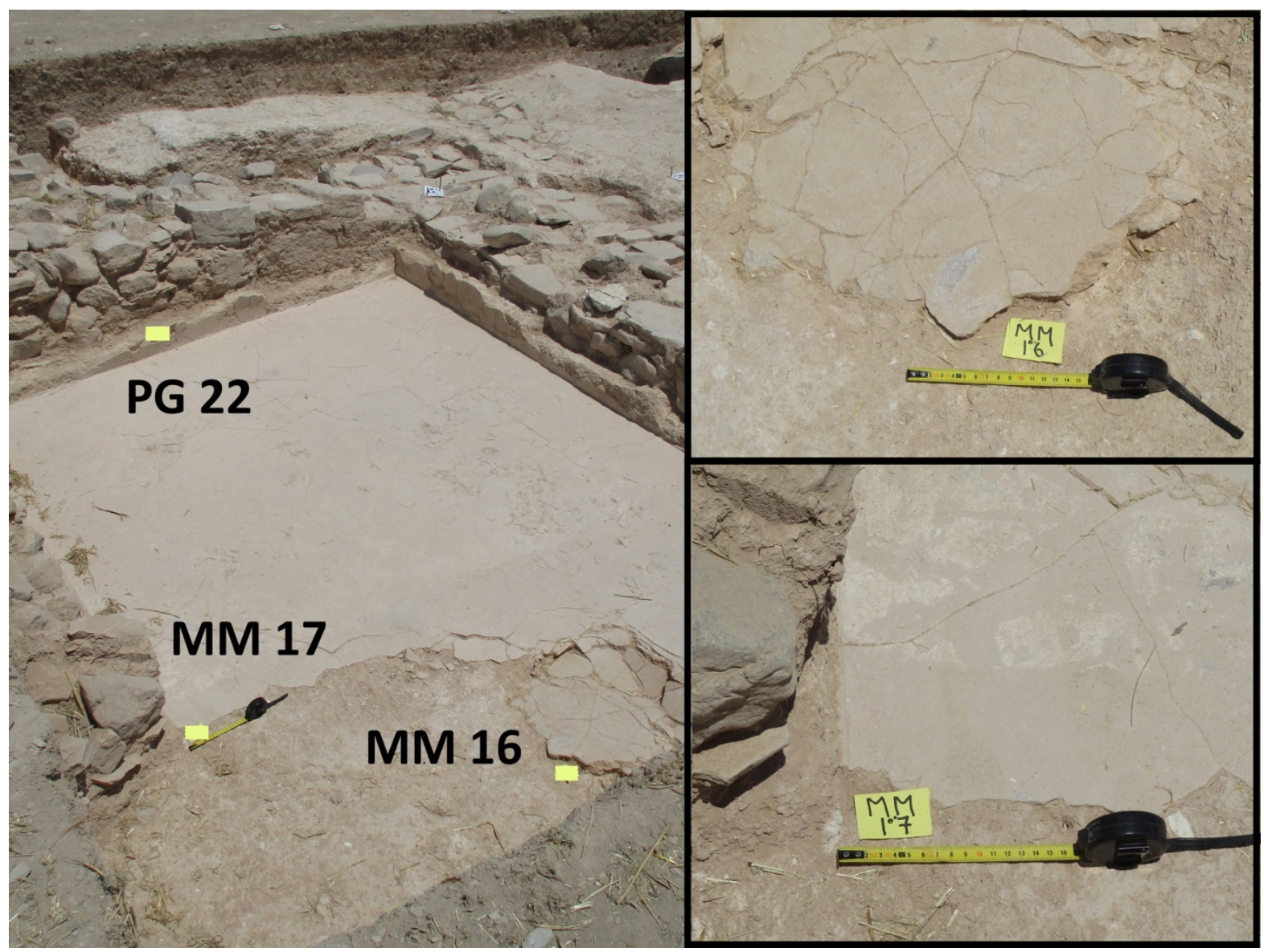

Figure 24. Unit 3 facing north. Fine-surfaced floor sampling locations. Main N-S road at top. Credit: Author's images.

surface is flat. Pedofeatures are limited to planar infillings of calcite. The b-fabric is crystallitic.

L2 in all samples is beige to grey in colour, a maximum $3-4 \mathrm{~mm}$ thick with an undulating basal contact. The appearance of two layers is clear in both PPL and XPL. The coarse fraction in L2 is $20 \%$, which includes $15 \%$ sediment inclusions and $5 \%$ quartz, pyroxene, and a small amount of artificial pozzolanic ceramic inclusions $20-150 \mu \mathrm{m}$.

L3 is grey to white in colour, $3-4 \mathrm{~mm}$ thick, has an undulating upper contact and a sharp, flat basal contact. The base contact with MM16 and the underlying matrix is apparent from a continuous lateral fissure at the $8 \mathrm{~mm}$ mark from the surface layer. The 
base contact of MM17 is clear from the transition to a single-spaced fine enaulic microstructure and red clay fine matrix. PG22 does not have a base contact to a new unit. This unit has secondary calcite permeation that is not seen in the previous two layers. Artificial pozzolanic materials are present in small quantities as small aggregates, 20$100 \mu \mathrm{m} . \mathrm{L} 3$ has a dotted micromass and crystallitic b-fabric.

These three layers appear to have been constructed and applied separately, as evidenced by their sharp, mostly flat lateral contacts. The use of pozzolanic inclusions for only the central layer is interesting, because the up-the-wall application of this lime plaster seemed to suggest the room stored liquid in antiquity.

\subsection{Pebble Floor in B.X Northern Pithos Storage Area B.X, A.161, N53C/D, KAD15-MM23 (a, b)}

One block sample from the north edge of Area 161 yielded two thin sections (Figure 25, Images A-H; Appendix Images 25, 26). Analysis revealed three stratigraphic units, all tan in colour, and differentiated on the abundance and size of their coarse fraction.

L1 contained a pebble aggregate groundmass of rounded chalk pebbles, chert, igneous minerals and fine calcite. Aggregates larger than $10 \mathrm{~mm}$ composed $50 \%$ of the stratum with smaller aggregates comprising $10 \%$ and fine mass filling the balance. The coarse fraction is highly variable including the sole instance of serpentine, multiple pieces of chert, along with the common quartz, fossils, artificial pozzolans $(50 \mu \mathrm{m})$ and pyroxene in an open porphyric distribution. $\mathrm{L} 1 \mathrm{is} 20 \mathrm{~mm}$ thick and has a crystallitic b-fabric, including the secondary calcite coatings on aggregates and a calcite-filled fine fraction. 
Master's Thesis - P Wallace; McMaster University - Anthropology

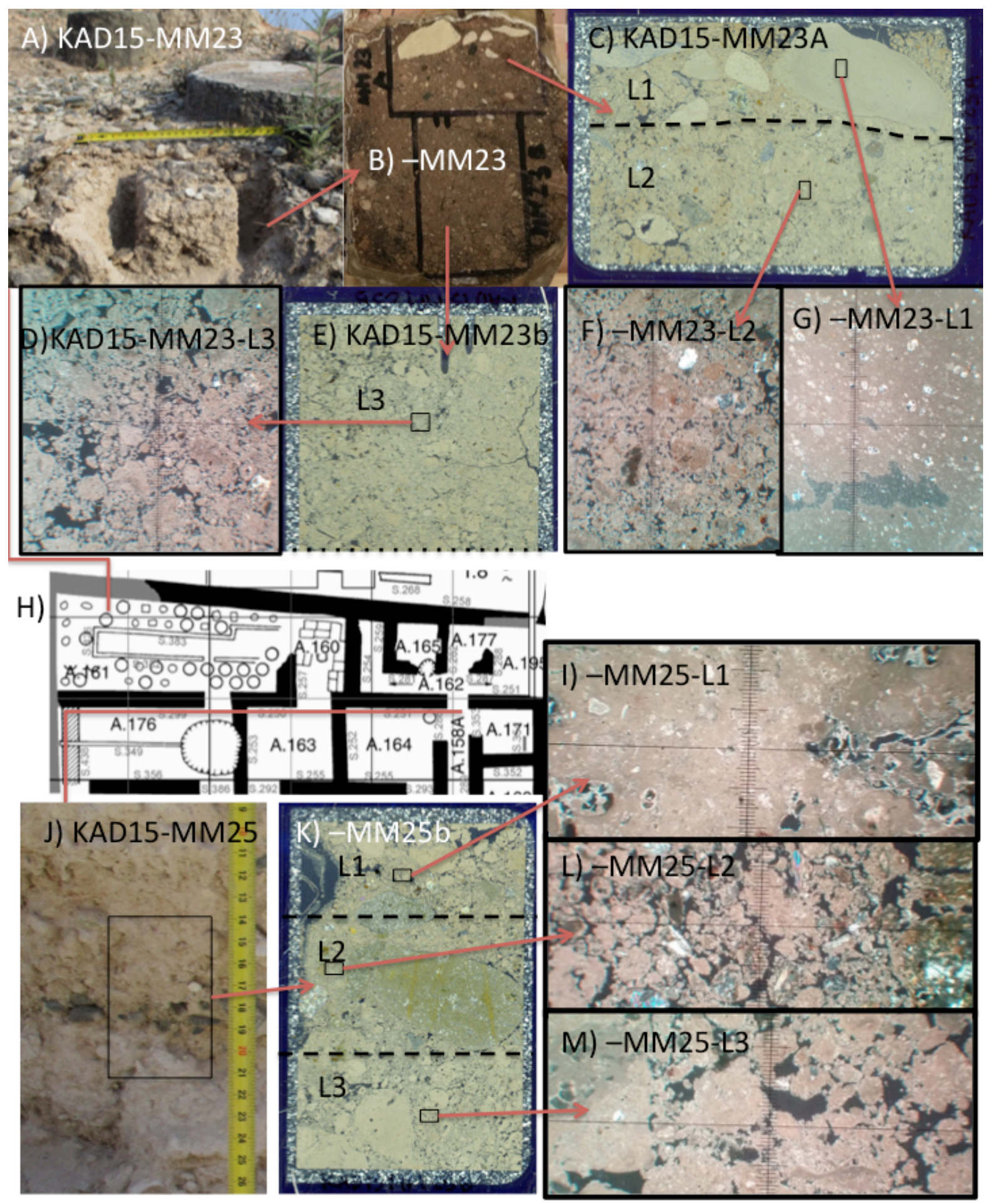

Figure 25. Northern Building X samples. A) Area 161, sampling location for KAD15MM23. B) Sample KAD15-MM23 imbedded with resin and prepared for thin sectioning. C) KAD15-MM23a, XPL, in thin section $(51 \times 76 \mathrm{~mm})$ with microstratigraphic units KAD15-MM23a-L1 and KAD15-MM23a-L2. D) Microscan, XPL, in 3.2x of KAD15- 
MM23-L3: Groundmass. E) KAD15-MM23b, XPL, in thin section $(51 \times 76 \mathrm{~mm})$ with microstratigraphic unit KAD15-MM23b-L3. F) Microscan, XPL, in 3.2x of KAD15MM23-L2: Groundmass. G) Microscan, XPL, in 3.2x of KAD15-MM23-L1: Chalk aggregate. H) Detail of the north half of Building X from the site plan of K-AD. I) Microscan, XPL, in 3.2x of KAD15-MM25-L1: Groundmass, fine calcite matrix. J) Field photograph on the eastern baulk on the north end of Area 158A, sampling location of KAD15-MM25. The composition of the baulk has a layer of pebbles between two white layers. K) KAD15-MM25b in thin section $(51 \times 76 \mathrm{~mm})$ with microstratigraphic units KAD15-MM25-L1, -L2, -L3. L) Microscan, XPL, in 3.2x of KAD15-MM25-L2:

Groundmass. Notice the birefringence of pyroxene, quarts inclusions not present in $-\mathrm{L} 1$ or -L3 of the same sample. M) Microscan, XPL, in 3.2x of KAD15-MM25-L3: Groundmass. Credit: Author's images A-G, I-M; Alison South, Image H.

Layer 2 had less coarse material, amounting to $20 \%$, down from $60 \%$, of the slide. There is no clear contact between the two layers, but rather a gradual grading into a finer and more porous matrix. L2 has the same artificial pozzolanic coarse material, chert, quartz and shell that are found in L1, and also an open porphyric distribution pattern. Of note are three unknown 3mm-wide igneous minerals of various colours (red, blue, green). The layer is $26 \mathrm{~mm}$ thick.

L2 also grades into L3 and is marked by the absence of mineral aggregates larger than a millimeter. There is a $10 \%$ coarse fraction and an absence of chert and unusual igneous aggregates, but apart from this the two sediment compositions and arrangements are more or less identical. L3 is at least $68 \mathrm{~mm}$ thick.

The graded boundaries between all three designated layers indicate that floor was constructed at a single time, most likely by a team of workers who were all using the same materials. The application of the coarse materials on top of the fine calcite mass could have been achieved by first applying slacked lime and then applying coarse aggregates directly on top of the wet mixture, creating the resulting pebble floor. 


\subsection{Corridor Plaster}

B.X, A.158a, P52D, KAD15-MM25 (a, b, c, d)

The analysis of four slides (Appendix Images 27-30) from this one block sample resulted in the identification of three layers (Figure 25, Image K). L1 is 44mm thick, 50\% micritic calcite (including well-developed round micritic calcite peds), $30 \%$ orange/red fine mass and $20 \%$ coarse material. Red/orange coarse aggregates larger than $500 \mu \mathrm{m}$ comprise $5 \%$ of the coarse fraction with the other $15 \%$ including smaller red/orange aggregates, chert, fossils, quartz, shell and pyroxene. There are no pedofeatures within the fine mass. There are dendritic mineral stains, reaction rims and calcite clay coatings within voids found within a central plaster aggregate only. It appears that this aggregate was a manufactured plaster surface that was broken up and added into a new mix. There are trace artificial pozzolans and organic material (plant roots) throughout.

Layer 2 is a pebble floor $42 \mathrm{~mm}$ thick and is only $40 \%$ fine calcite. $10 \%$ of the slide is coarse fraction quartz less than $10 \mathrm{~mm}$ in size. $10 \%$ is taken by rounded igneous aggregates less than $10 \mathrm{~mm}$. The remaining $40 \%$ of the slide is coarse fraction igneous material that exceeds $10 \mathrm{~mm}$. There are scattered irregular and dendritic mineral stains. The fine mass has a crystallitic b-fabric.

Layer 3 is $32 \mathrm{~mm}$ thick and $90 \%$ fine calcite mass that includes pure grey calcite plaster nodules, some of which are partially granostriated with beige clay and none of which show any mixing with beige clay. The plaster nodules have internal dendric mineral stains. None-nodules fine mass includes both grey calcite and beige clay sediment. The coarse fraction consists of quartz, pyroxene, shells, fossils and sediment inclusions. There are no pozzolans in this layer. For pedofeatures, half of the voids have 
calcite hypocoatings, coatings, and complete infillings. This is especially evident within well-developed round to subrounded micritic calcite peds (plaster nodules), which display a pale, white hypocoating.

The analysis of KAD15-MM25 revealed a unique sequence among the samples analyzed in this study. The existence of a middle pebble floor layer suggests that this was once the surface of a pebble floor. The overlying - L1 was then added at a later date and was extended with the inclusion of recycled plaster aggregates. The use of secondary lime plaster in this new mixture, a phenomenon not seen in the monumental Pithos Hall floors, suggests this new surface on top of the pebble floor demanded fewer resources in its construction.

\subsection{Drains}

B.X, A.191, S.392, N1C/N1D, KAD15-PG15, KAD15-PG16, KAD15-PG17

Three samples of drains (Appendix Images 38-40) were collected from Area 191, directly south of the Pithos Hall (Figure 9, 26, Appendix Image 45). Two samples were taken of structure 392, (S.392), KAD15-PG15 (in line with the Pithos Hall pillars) and KAD15-PG17 (directly south of the southwest corner of Area 152 and Building X). The third sample, KAD15-PG16, comes from an archaeologically discontinuous drain on the middle of the southern wall of Area 152.

\subsubsection{KAD15-PG15}

-PG15 is composed of two distinct microfabrics. Layer 1 is $15 \mathrm{~mm}$ thick, is whitish tan in colour and has a coarse percentage of $33 \%$. The coarse material is distributed in a uniform double-spaced porphyric arrangement. $20 \%$ of these coarse 
aggregates are grey, tan and red nodules, the red being ones being ceramic pozzolanic aggregates up to $750 \mu \mathrm{m}$. The remaining $13 \%$ includes quartz grains, isotropic glass, biological fossils and opaque punctuations. The remaining $67 \%$ of the sample is fine fraction with a crystallitic birefringence.

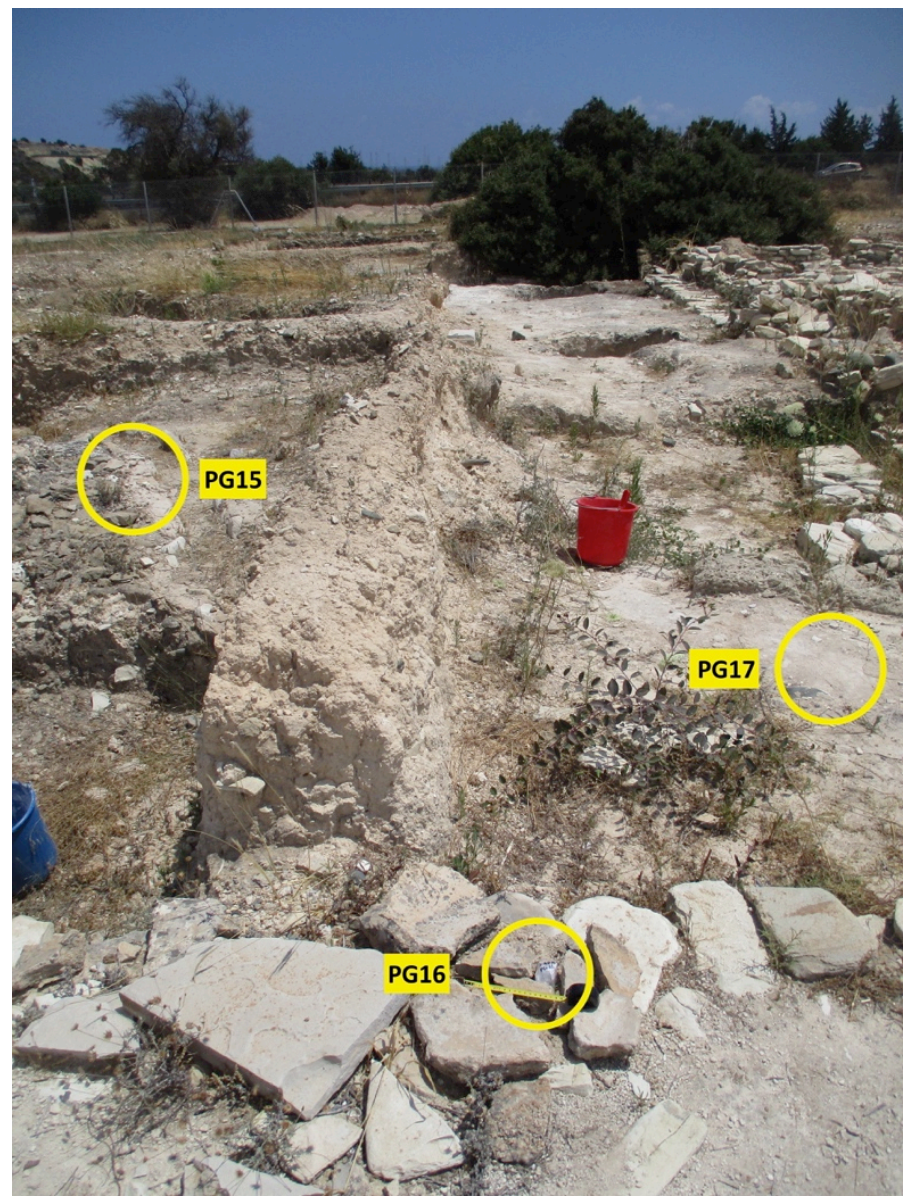

Figure 26. Pithos Hall (Area 152) and Area 191, facing south. Plaster drain samples KAD15PG15, -PG16, and -PG17 were sampled from the locations indicated. Credit: Author's image.

Layer 2 is $19 \mathrm{~mm}$ thick and shares and undulating diffuse boundary with L1. It has a similar material composition to Layer 1 , but with a coarse fraction is $50 \%$ with a close porphyric distribution pattern. Additional coarse materials include trace amounts of pyroxene and low-order

birefringence orthopyroxene. Voidspaces are coated with secondary calcium carbonate. There are no instances of re-used plaster aggregates or dendritic mineral stains.

\subsubsection{KAD15-PG16}

KAD15-PG16 has two main large constituent layers with the addition of five thin discontinuous microstratratigraphic varnishes on the top for a total of seven 
microstratigraphic units. The top five layered units are together $2 \mathrm{~mm}$ thick, averaging $0.4 \mathrm{~mm}$ thick each and have a range of $0.3 \mathrm{~mm}(\mathrm{~L} 1-\mathrm{L} 4)$ to $1.0 \mathrm{~mm}$ (L5). All have a crystallitic b-fabric and no evidence of pedofeatures. Layers 1-3 have coarse fractions of $20 \%$, are tan in colour and have a speckled micromass. The coarse aggregates all remain under $400 \mu \mathrm{m}$ and are mainly sediment aggregates. The three layers are distinguished from one another by the presence of thin grey bands of micritic calcite. Each band was interpreted as a discontinuity and designated the transition to a new layer.

L4 is light tan in colour, has $10 \%$ coarse fraction. Sediment inclusions also compose the majority of coarse fraction. L5 has the same composition as layers 1-3, but is three times as thick. The distinguishing feature that defines this as a new layer is again a thin, dark grey micritic calcite band. Trace coarse materials for all layers 1-5 are quartz and pyroxene grains and the distribution pattern is consistent as open porphyric.

Layer 6 and Layer 7 are each $28 \mathrm{~mm}$ thick and vary considerably in composition. L7 is an orange, tan and grey fine calcite layer with 5\% coarse materials. L6, on the other hand, is an aggregate laden layer with a $33 \%$ coarse fraction. $20 \%$ of L6 is composed of artificial pozzolans, calcite- and clay-filled sediment aggregates up to $2 \mathrm{~mm}$ across. The remaining coarse fraction includes quartz, pyroxene, olivine, and opaque punctuations. The layer is heterogeneous and has dark grey cloudy micrite interwoven with crystallitic calcite when viewed in XPL.

\subsubsection{KAD15-PG17}

The layers listed below follow an incredibly similar pattern to those seen in KAD15-PG16. The following descriptions follow the sequence set by my "top" marking 
on the sample and are in line with the data presented in my data collection table. After comparing these results with the data from KAD15-PG16 the sample KAD15-PG17 appears to be inverted.

Layer 1 is a half-millimeter thick dark grey micritic calcite band. It has a coarse component of $5 \%$ that includes opaque punctuations $10-30 \mu \mathrm{m}$. The distribution is fine monic. This layer has an undifferentiated $b$-fabric.

Layer 2 is $31 \mathrm{~mm}$ thick with a $33 \%$ coarse fraction. $20 \%$ of the slide is composed of tan and brown sediment aggregates $1 \mathrm{~mm}$ thick, including red artificial pozzolans. $50 \%$ of the layer is micritic calcite and $20 \%$ is dark grey calcite layers. The remaining coarse material is made up of quartz, quartzite, pyroxene, and olivine. Constituent materials in this slide are homogenously distributed.

Layer 3 is grey, $4 \mathrm{~mm}$ thick and composed of $20 \%$ coarse material, the majority of which are sediment aggregates with some quartz grains present. This layer was identified by a dark superior surface.

Layer 4 is grey, $1.5 \mathrm{~mm}$ thick and composed of $20 \%$ coarse material, the majority of which are sediment aggregates with some quartzite present. This is a thin sliver of a layer, identified by a discontinuous micritic calcite band $700 \mu \mathrm{m} \times 7000 \mu \mathrm{m}$ thick.

Layer 5 is grey, $1.5 \mathrm{~mm}$ thick and composed of $20 \%$ coarse material, the majority of which are sediment aggregates, with some quartz, pyroxene and quartzite present. This layer was identified by a dark superior surface.

Layer 6 is brown, $1 \mathrm{~mm}$ thick and composed of $20 \%$ coarse material including quartz, pyroxene, opaque punctuations $10-30 \mu \mathrm{m}$ in size. The fine mass is composed of 
micritic calcite and some dark grey areas. This is the only layer in the sample that has pedofeatures. Secondary calcium carbonate is present as void coatings, coatings in cracks and has strongly impregnated the sediment. The contact layer is smooth and clear.

\subsubsection{Summary of Drains}

The three drain samples, KAD15-PG15, -PG16, and -PG17, do not share many similarities besides the inclusions of artificial pozzolanic materials in the first thick unit in each sample (KAD15-PG15-L1, KAD15-PG16-L6, KAD15-PG17-L2). The pozzolanic layer is the body layer for the drains and what allows them to maintain their structural integrity while transporting liquids. -PG16 and -PG17 have additional and very thin units separated by bands of grey micritic calcite. These could be the result of water redistributing calcite within the sample, however, as these drains are hydraulic this may or may not be a possibility. This remains an open question.

\subsection{Kalavasos-Tenta Samples KAD15-PG20, KAD15-PG21}

The technological traditions of plaster production by an earlier (pre-urban) community living within broadly the same environment as the inhabitants of K-AD were obtained by examining two superimposed floor samples (Appendix Images 41-42) from Kalavasos-Tenta (Figure 6). KAD15-PG20 comes from Structure 17 dating to Tenta's Phase 2 and is the first of two superimposed floor samples. The sample appeared reddishbrown in macroscale, one of two floors from Tenta (i.e. the floor of underlying S.36) among many whites ones that is red, suggesting that this floor is special. Analysis revealed this sample is $4 \mathrm{~mm}$ thick and is composed of pyrogenic gypsum, the only 
sample in this study that is not composed of calcite. The coarse fraction accounts for $75 \%$ of the sample, a considerably higher percentage than other samples. Half of the material is composed of grey, beige, and brown sediment aggregates larger than $1 \mathrm{~mm}$ with a noticed concentration of brown sediment aggregates on the bottom edge of the sample. There are brown granostriations present on grey nodules. Minor coarse components include pyroxene, olivine and quartz.

Sample PG21, also from Tenta Phase 2, is from immediately beneath sample PG20. Upon analysis this layer was found to be $99 \%$ micritic calcite, an incredibly pure pyrogenic plaster. The scarce coarse fraction includes sediment aggregates, quartz and opaque punctuations all measuring less than $100 \mu \mathrm{m}$. The fine fraction is arranged in an enaulic pattern of dark grey and undifferentiated rounded plaster concentrations. The bfabric, where present, is crystallitic.

It appears that the construction of floors at Kalavasos-Tenta includes a tradition of gypsum plaster, and this may be restricted to red-coloured floors. The construction of these floors was first the application of a very pure lime plaster base layer, followed by a layer of gypsum mixed with red sediment to leave the surface with a red colour.

\subsection{Pithos Hall Mudbrick-Adhered Fragments from the Storage Facility B.X, A.152, N51C, 4.3, KAD87-PG05-1, KAD87-PG06, KAD87-PG07}

Samples of plaster were collected during the Vasilikos Valley Project excavations and stored for future reference and study. The following three thin sections (Appendix Images 31-33) were made from three samples of hard, plaster-like material adhered to mudbrick and initially suspected of being wall plaster. The Vasilikos Valley Project team 
collected them in 1987 from the eastern baulk of N51C, 4.3 in Area 152 (Appendix Image 45), just south of the mudbrick steps, which had yet to be excavated during the time of collection (Alison South, personal communication). The provenience of these samples therefore could be from the plaster staircase to the north, from the walls to the north and west, or perhaps neither. These samples were retrieved for analysis in 2015 from the storage facility in Kalavasos, Cyprus.

KAD87-PG05-1 has three layers. The three layers do no differ from one another very much in microscale and were distinguished with the naked eye from an observed change between the lighter tan exterior thirds and the darker grey interior. These colour changes have sharp lateral boundaries but are less apparent under the microscope. All three layers are all at least $90 \%$ calcite and at least $75 \%$ fine mass. The three layers range from 1.5 to $2.5 \mathrm{~mm}$ thick, with a total sample thickness of $5.8 \mathrm{~mm}$. L2 has the largest aggregates and L3 has the most aggregates. The b-fabric is undifferentiated for L1 and L2 and crystallitic for L3. None of the layers have mineral staining or a noticeable amount of ceramic pozzolanic material.

KAD87-PG06 has four distinct layers. L1 and L4 are similar in thickness, colour and composition and L2 and L3 are similar in the same respect. Layers 1 and 4 are both $4 \mathrm{~mm}$ thicker, tan and have a speckled micromass. They have a $10 \%$ coarse fraction composed of quartz and pyroxene $100-400 \mu \mathrm{m}$, with maximum values reaching $700 \mu \mathrm{m}$. These plaster layers are incredibly fine with a cloudy, undifferentiated micromass. Layers 2 and 3 are both $1 \mathrm{~mm}$ incredibly fine grey plaster layers with $5 \%$ coarse mass that includes quartz and olivine grains on the order of $100 \mu \mathrm{m}$. Layer 2 and 3 have a crystallitic 
b-fabric and can be differentiated from one another by a discontinuous beige band. None of the four layers displays any mineral staining or notable presence of artificial pozzolanic material.

KAD87-PG07 has four discernable layers. L1 is a grey band on the left sloping side of the sample. It has a depth measurement of $5 \mathrm{~mm}$ but is $1 \mathrm{~mm}$ thick when measured from the apparent surface to the clear, sharp contact with L2. It has a mildly speckled micromass and a $10 \%$ coarse fraction of red ceramic pozzolanic material, quartz and sediment aggregates. There are no pedofeatures in L1. L2 is grey in colour, $18 \mathrm{~mm}$ thick, and also has a mildly speckled micromass. Its $10 \%$ coarse fraction includes quartz, sediment aggregates but no pozzolans. L3 is a $2 \mathrm{~mm}$-thick dark grey lime plaster layer with a $5 \%$ coarse fraction consisting of quartz, other trace minerals, and no pozzolans. Pedofeatures include secondary calcite coatings in voids. L4 is an even finer plaster layer than L3 with a coarse percentage of $2 \%$. This layer is $1 \mathrm{~mm}$ thick and is grey to yellow in colour. Calcite coatings are present in voids. Layer four's homogeneous fabric is interrupted only by the odd quartz grain.

These three samples were collected from the same location at K-AD and all share the same context but they are not identical in composition and vary considerably, for example, -PG07 being curved in shape while the other two are perfectly flat (Appendix Images 31-33). It appears that samples -PG05-1 and -PG06 were surfaces constructed in phases with each new layer being applied directly on top of the previous layer. The construction of -PG05-1 consisted of three applications of the same plaster recipe. -PG06 is composed of two distinct recipes applied in a 1-2-2-1 pattern. There is an unknown 
amount of time between each application. It is less clear how the curved -PG07 was formed as a curved surface, but the application of four layers followed a clear gradient of coarse to fine.

\subsection{Subterranean Plaster Chunk from Pre-LCIIC Context}

Central Excavation Area (destroyed during the construction of the A1 Motorway) B.III, A.217, 6.1, KAD82-PG10

This sample (Appendix Image 36) was originally excavated in 1982 from the Central Area of K-AD (Figure 9) that now lies underneath the A1 motorway and has since been stored in the storage facility in Kalavasos village. It was sampled from the Central Area beneath the LCIIC layers in Building III (South 1983: 101-103) and originally given a description of "very solid gypsum plaster in large chunks," (Alison South, personal communication). The thin section analysis concluded this is a calcite sample homogenous in composition and at least $66 \mathrm{~mm}$ thick (the collected plaster chinks may be larger). Microscopic mineral stains up to $200 \mu \mathrm{m}$ and opaque punctuations averaging $30-50 \mu \mathrm{m}$ covered up to $50 \%$ of the fine fraction, more than any other sample. The specked micromass makes the sample appear darker in transmission light. However, this sample remains darker than any of the other samples at the site. The coarse fraction comprises $50 \%$ in this sample with quartz and quartzite aggregates up to $5 \mathrm{~mm}$ composing $30 \%$ of the sample. It is $50 \%$ coarse fraction, $30 \%$ gravel that is fine to very coarse. There are no pozzolanic materials present. Vesicle and chamber voids are coated and hypocoated with crystallitic secondary calcite. Planar voids have varied degrees of accommodation and some are completely coated with calcite and opaque punctuations. 
As this sample was from pre-LCIIC strata this material is one of the few samples that is separated in both time and space to the monumental contexts.

It appears that this sample was constructed in a single application. The context of this sample does not reveal any clues to the function of this material in antiquity.

\subsection{Area 174 Samples from 1994}

B.X, A.174, P1B, 23.2, KAD94-PG08a and P1B, 26.1, KAD94-PG08b

These two samples Appendix Images 34, 35) originate from within a well (subterranean cavity), located within A.174 on the southeastern side of Building X (Appendix Image 45). They were collected in 1994 by the Vasilikos Valley project team among an array other building material, broken stone, etc.

KAD94-PG08a has two layers. KAD15-PG08a has a dense first layer, L1, tan in colour and is $6 \mathrm{~mm}$ thick. $2-5 \%$ of the total unit was composed of voidspace (not taken into account when assessing coarse percentages). The layer, L1, has a speckled micromass and is $15 \%$ coarse material. Ten percent of the slide was composed of lime nodules up to $400 \mu \mathrm{m}$ thick, $5 \%$ sediment nodules up to $200 \mu \mathrm{m}$ thick and trace amounts of quartz, pyroxene and chert. Clay granostriations are present on grains and aggregates. L2 is $11 \mathrm{~mm}$ thick beige layer. It is much less dense with $10-20 \%$ voidspace and marginally coarser at $20 \%$. The majority of aggregates are sediment nodules with the largest reaching 1.5-2mm thick. Trace aggregates include quartz, quartzite, red nodules and opaque punctuations, creating a dotted micromass. Dark grey micritic plaster areas have an undifferentiated b-fabric while other fine-mass areas are crystallitic. 
KAD94-PG08b has fine layers that alternate in colour with Layers 1, 3 and 5 being grey and layers 2 and 4 being tan. The tan layers 2 and 4 are noticeably coarser than the grey layers. All layers have a dotted micromass and are porphyric in their coarse material distribution, single-spaced for coarser layers and single-spaced for finer layers. All physical aggregates are opaque punctuations and nodules up to $200 \mu \mathrm{m}$ in a calcite matrix. Trace coarse materials include quartz and pyroxene grains up to $700 \mu \mathrm{m}$ in size, except for L5, which has an upper size maximum of $150 \mu \mathrm{m}$ for these trace minerals.

It appears that these two surfaces were constructed over time with specific recipes that alternate. The recipes differ in overall colour and in composition and may have been applied as a pair. If this was the case the location of the material, being mixed with other artifacts in antiquity, removes the possibility of knowing which surface was exterior for PG08a. -PG08b, on the other hand, has an exterior surface of a grey, finer material on both sides (-08b-L1, L5). A fine material exterior follows many other samples in this study, including KAD15-PG13 as the potential surface of the Pithos Hall floors, KAD15MM22 having a plaster surface layer (-L1) on top of a coarser calcite base (-L2).

\subsection{Summary of the Microscopic Analysis}

In this chapter the results of the microscopic analysis of the 34 thin sections from $\mathrm{K}-\mathrm{AD}$ and two thin sections from Kalavasos-Tenta were presented. The results of this analysis have shown a clear synchronic variation among pyrogenic lime plaster recipes at K-AD. Diachronically, the two superimposed floors in Area 152 (the Pithos Hall) revealed an intensification of resource consumption in the construction of the upper floor 
Master's Thesis - P Wallace; McMaster University - Anthropology

while the overall method of construction and the composition of layers remained relatively consistent.

The analysis has also shown these surfaces have specific aggregates included in each recipe such as artificial pozzolans in the drain samples. Following the specific inclusion of aggregates in some samples there also appears to be the explicit exclusion of gypsum in any amount within all samples tested from K-AD. Between the sites of K-AD and Kalavasos-Tenta the tradition of using gypsum plaster surfaces is confined to the latter. Further details will be discussed in Section 8. 


\section{Results of the FT-IR Analyses}

The use of FT-IR spectra in this thesis is confined to the exploration of the red sediment layers, L2, 4 and 10 from the Pithos Hall floors (KAD15-MM21). This exploration revealed that the red material layers found in the Pithos Hall floor deposits (Figure 17, Images E and I; Layers 2, 4, and 10) are a spectrographic match for terra rossa and that no collected reference material was a match for this sediment. The source of the terra rossa remains unknown.

\subsection{Archaeological Samples of the Red Sediment from Area 152 B.X, A.152, N50B, KAD15-IR65, KAD15-IR105}

The loose sediment samples KAD15-IR65 and -IR105 were taken from the top red layer in the Pithos Hall floor sequence, provenience Building X, Area 152. These samples most likely contained material from KAD15-MM21-L2, -L3 and -L4 owing to the triparte construction of this $2 \mathrm{~cm}$ thick unit, which was unknown during sampling in the field. The collection from multiple points (-IR65 and -IR105) was done to ensure consistency of the sample. The following FT-IR spectral curves from -IR65 and -IR105 reveal only one difference with the absence of a small peak at 1438 wavenumbers $\left(\mathrm{cm}^{-1}\right)$ in sample -IR105 (Figure 27). This peak is a signature of carbonate.

Common peak values include $3437 \mathrm{~cm}^{-1}, 1640 \mathrm{~cm}^{-1}$, and $1036 \mathrm{~cm}^{-1}$, for basalt and $2513 \mathrm{~cm}^{-1}, 1441 \mathrm{~cm}^{-1}, 875 \mathrm{~cm}^{-1}$, and $712 \mathrm{~cm}^{-1}$ are indicative of carbonates (Weiner, FT-IR Library Database). Archaeological samples -IR65 and -IR105, however, fit within the definition of unheated, geogenic terra rossa (Figure 28). 


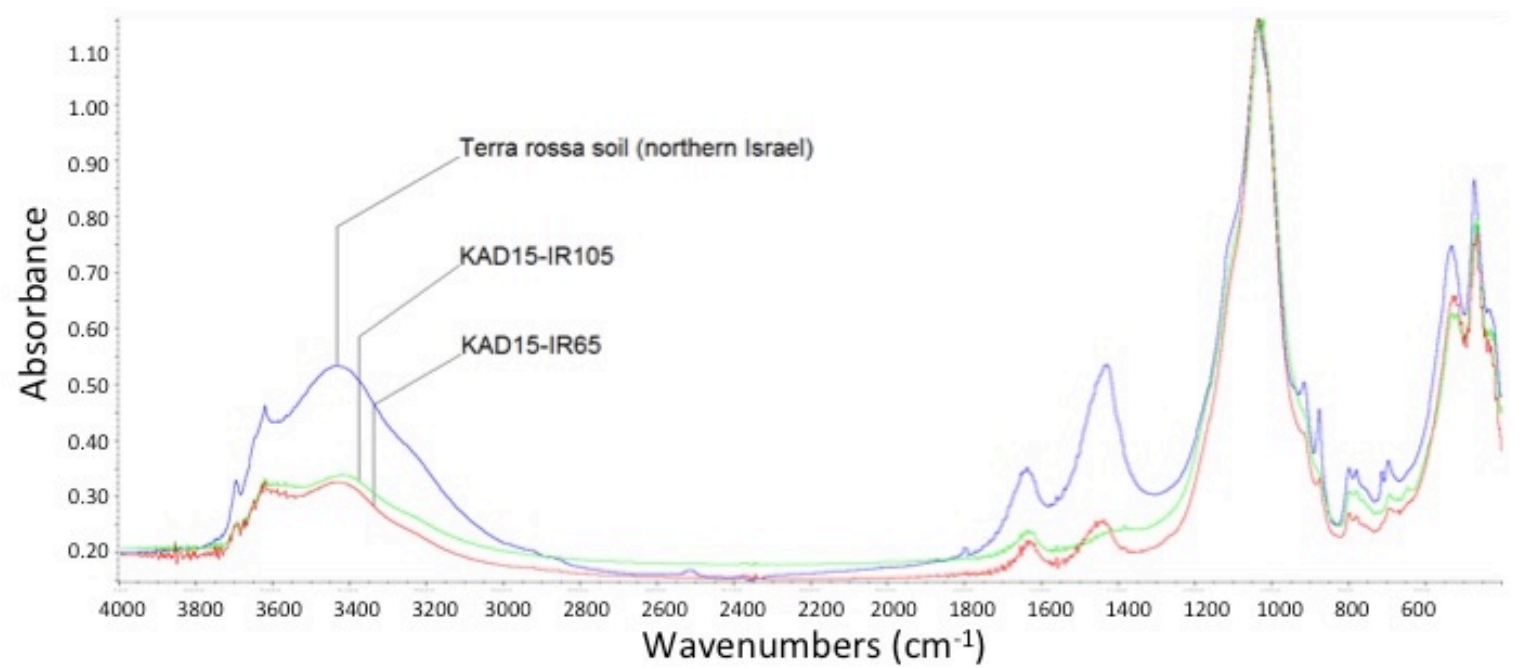

Figure 27. KAD15-IR64 and-IR105 compared to a library reference curve of Terra Rossa. Credit: Author's Image; Weiner and the FT-IR Library Database.

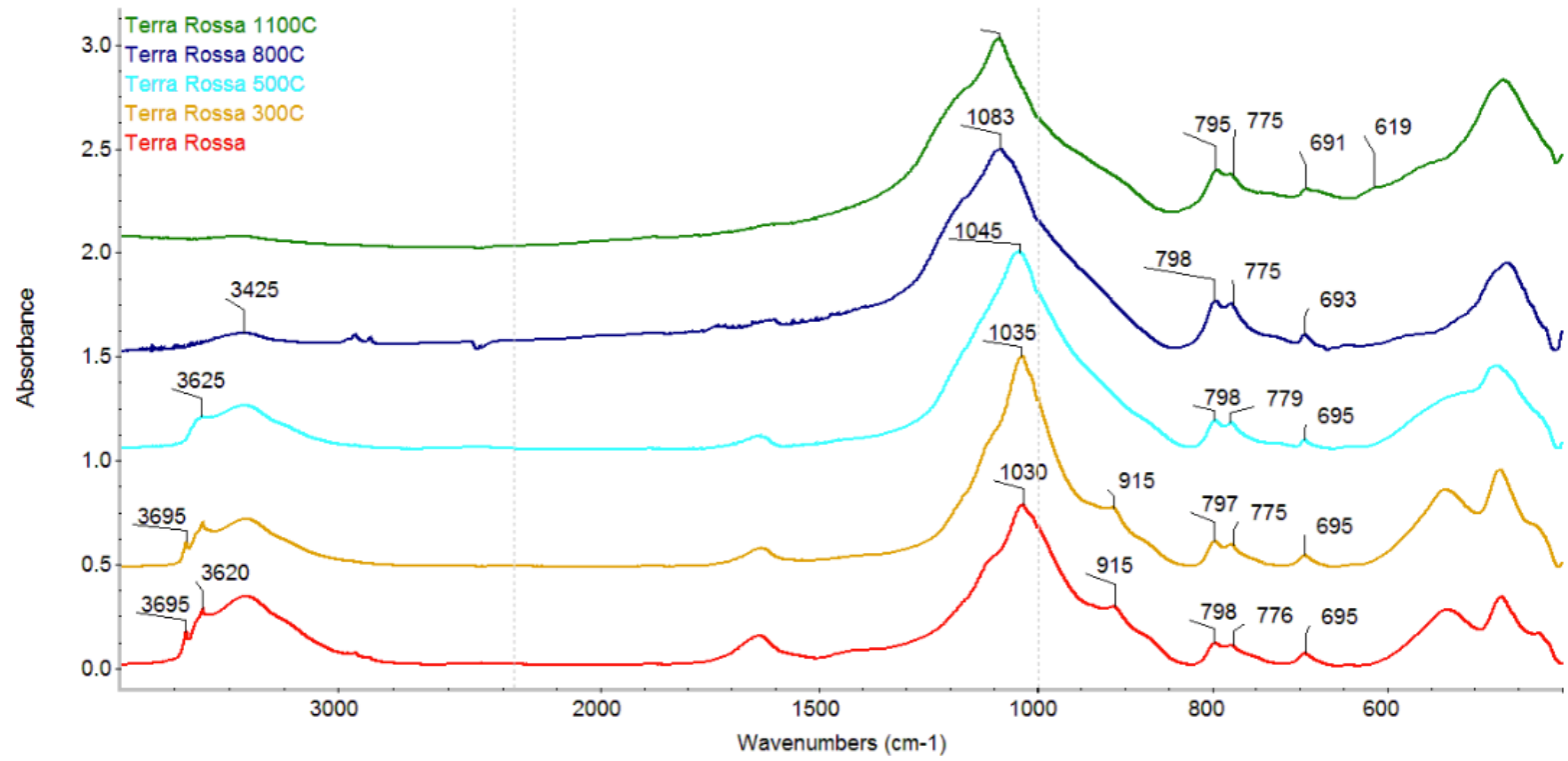

Figure 28. Terra Rossa undergoing heat transformation. Credit: Berna et al. 2007.

\subsection{Drapia Geological Samples and Experiment}

Drapia, 10km North of Kalavasos, KAD15-IRD04 (unheated, $300^{\circ} \mathrm{C}, 500^{\circ} \mathrm{C}, 800^{\circ} \mathrm{C}$ ), KAD15-IRD05. 
Geological samples were collected near the abandoned village of Drapia (Figure 5) in order to compare their composition to the archaeological samples from the Pithos Hall (KAD15-IR65 and -IR105). An outcrop of dark brown umber was identified and sampled along with the surrounding soil. KAD15-IRD04 (A-horizon soil near umber outcrop, unheated) and sample -IRD05 (umber) do not match any of the archaeological terra rossa samples: KAD15-IR65 (Pithos Hall terra rossa layer), KAD15-IR105 (Pithos Hall terra rossa layer); or any of the other geological samples: KAD15-MM26-1, KAD15-MM27-1, and KAD15-IRD07 (Figure 30; see section 7.3). -IRD04 (A-horizon soil near umber outcrop, unheated) and -IRD05 (umber) have peak absorption values at $3400 \mathrm{~cm}^{-1}, 3197 \mathrm{~cm}^{-1}$, a small bump at $1636 \mathrm{~cm}^{-1}$ and three absorption values with descending amplitudes at $1031 \mathrm{~cm}^{-1}, 893 \mathrm{~cm}^{-1}$ and $801 \mathrm{~cm}^{-1}$ (Figure 29). The peak at $3197 \mathrm{~cm}^{-1}$ discriminates the unheated umber samples, as it does not appear in any nonumber samples, archaeological or otherwise. When heated, the umber soils (Figure 29; KAD15-IRD04: $300^{\circ} \mathrm{C}, 500^{\circ} \mathrm{C}, 800^{\circ} \mathrm{C}$ ) lose the discriminating high peak at $3197 \mathrm{~cm}^{-1}$.

Close examination of the terra rossa heating experiment (Figure 28), however, reveals another means of discriminating the terra rossa samples (-IR65 and -IR105) from the heated umber soils (-IRD04: $\left.300^{\circ} \mathrm{C}, 500^{\circ} \mathrm{C}, 800^{\circ} \mathrm{C}\right)$. Two peaks at $798 \mathrm{~cm}^{-1}$ and $776 \mathrm{~cm}^{-1}$ can be seen on the right side for all five terra rossa (Figure 28) and both archaeological (Figure 27) curves to the noted exception of all three heated umber soils (Figure 29; -IRD04: $300^{\circ} \mathrm{C}, 500^{\circ} \mathrm{C}, 800^{\circ} \mathrm{C}$ ). In further detail, heating the A-horizon soil to $500^{\circ} \mathrm{C}$ dampens the intensity of the $3400-3440 \mathrm{~cm}^{-1}$ peak and raises the $1430 \mathrm{~cm}^{-1}$ peak to approximate KAD15-IR65 (Pithos Hall Layers 2, 3 and 4) closely. Heating this 
sample also causes the spectral curve to lose detail (e.g. shoulder at $910 \mathrm{~cm}^{-1}$ on -IR65) and definition (e.g. notice the widening of $1036 \mathrm{~cm}^{-1}$, exacerbated in sample heated to $800^{\circ} \mathrm{C}$ ). In the sample of the A-horizon soil that was heated to $800^{\circ} \mathrm{C}$ there is a complete loss of the peaks $874 \mathrm{~cm}^{-1}$ and $712 \mathrm{~cm}^{-1}$, signatures for carbonate, as a result of calcination and the release of carbon dioxide (See Chapter 3. Plaster; Philokyprou 2012). The geological samples and corresponding sediments that underwent experimental heating do no match the spectrographic signature of the archaeological terra rossa and are therefore rejected as possible sources of this material.

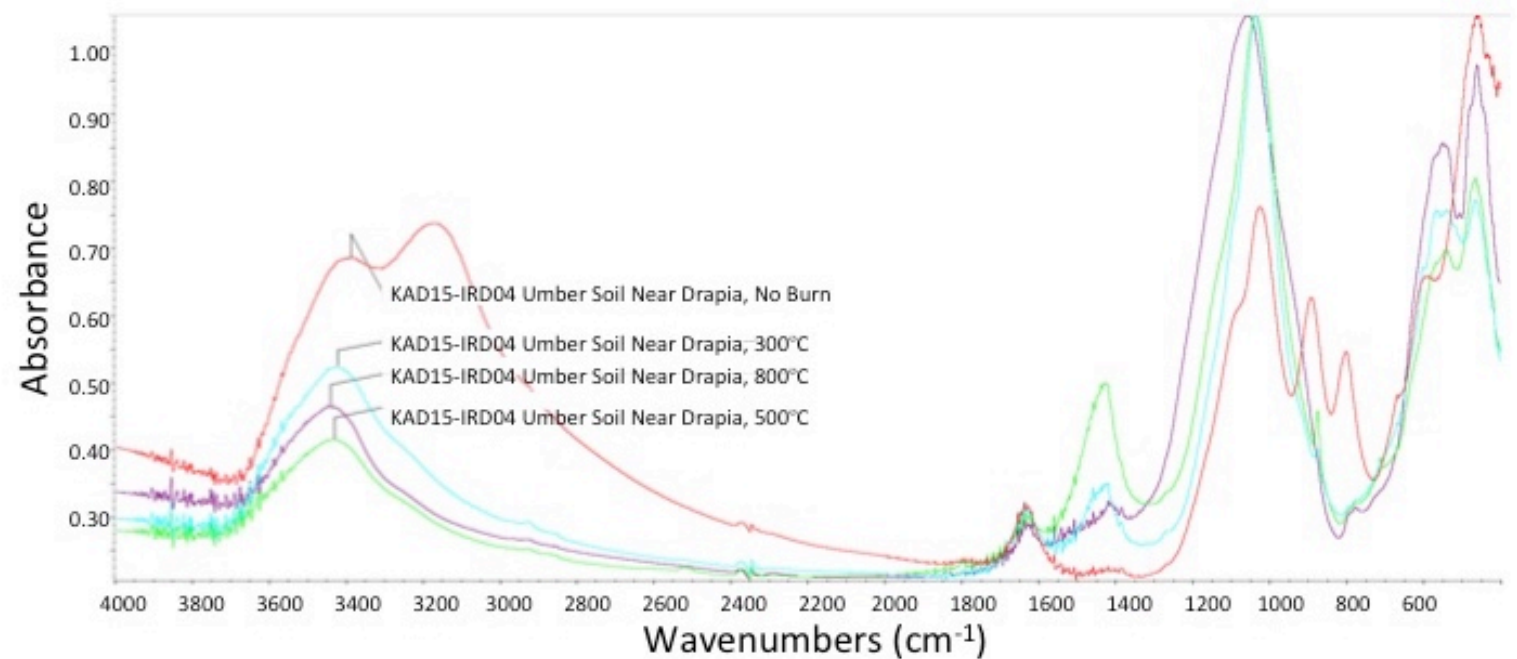

Figure 29. Sample KAD15-IRD04, "Umber Soil Near Drapia” undergoing heat transformation. Notice the difference between the unburnt A-horizon soil (red) and the burnt samples (blue $\left[300^{\circ} \mathrm{C}\right.$, two hours], purple $\left[800^{\circ} \mathrm{C}\right.$, two hours] and green $\left[500^{\circ} \mathrm{C}\right.$, two hours]). The second peak on the left and the descending intensity, triple peak on the right (red) and unique characteristics of samples -IRD04 (unburnt) and -IRD05 (umber). Credit: Author's image.

\subsection{Terra Rossa Samples from Kalavasos Village and Farmer's Field} Roadway Escarpment, KAD15-MM26-1, KAD15-MM27-1. Farmer's Field KAD15IRD07. 
Two intact sediment blocks were collected from two parallel red beds in a sedimentary outcrop that parallels the roadway on its eastern side heading into Kalavasos village from the A1 motorway. These red beds are visible in the vicinity of K-AD and slope upward towards the north. KAD-MM26-1 being sampled first from the lower band, and -MM27-1 sampled after from the upper band (unfortunately no image is available). The two samples have identical FT-IR signatures: calcite majority with a terra rossa component (Figure 30). This suggests that these units are currently undergoing standard geological transformation from limestone to terra rossa clay sediment. The higher component at peak 1032 $\mathrm{cm}^{-1}$ when MM26-1 (Figure 30) is compared with MM27-1 may

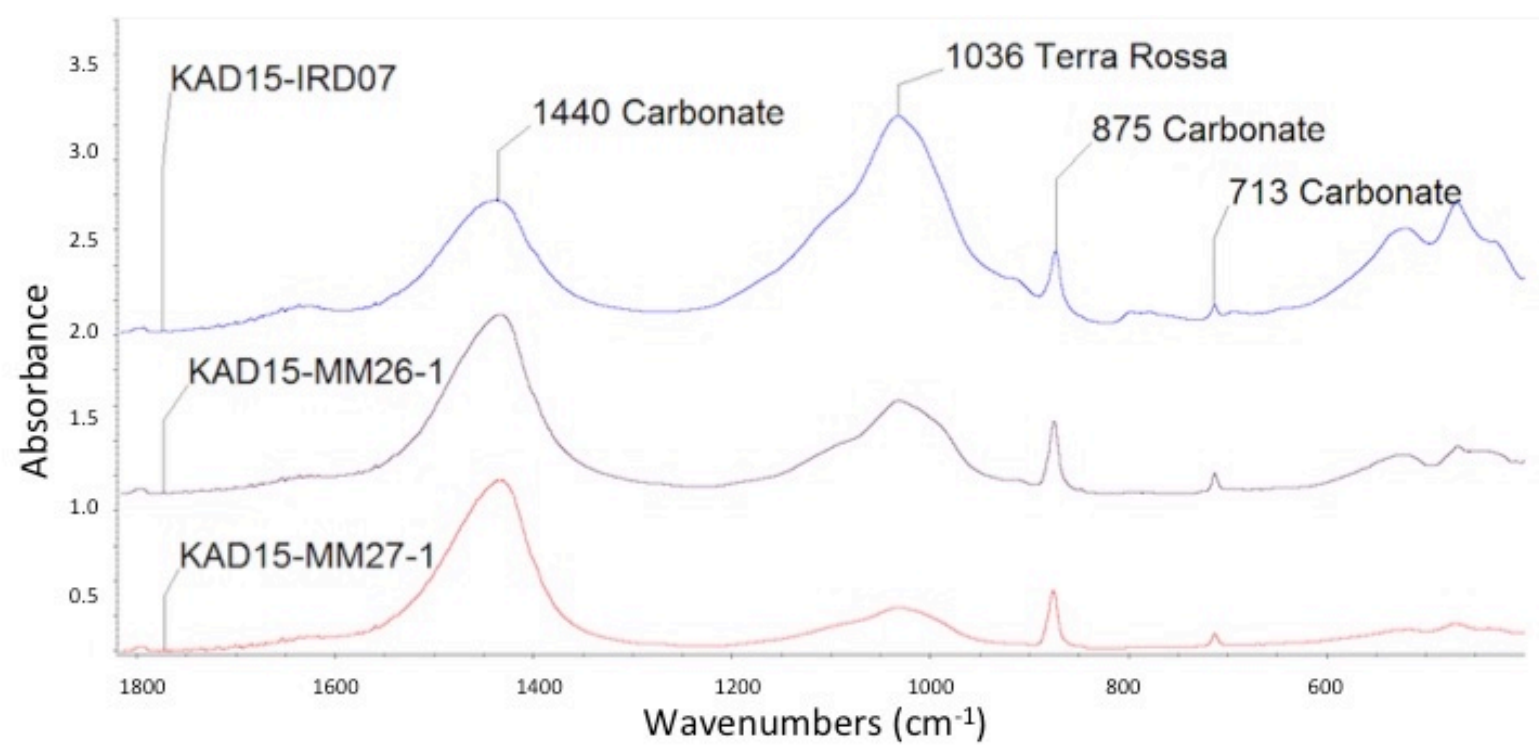

Figure 30. Spectral curves of sediment collected from a farmer's field (KAD15-IRD07) and two geological samples from two red-orange units found in an exposed profile $1 \mathrm{~km}$ south of Kalavasos Village (KAD15-MM26-1 and -MM27-1. Credit: Author's image. indicate the lower and older-MM26-1 is at a more progressive stage in transforming into terra rossa from limestone owing to its relatively earlier deposition. 
The reddish-brown sediment collected from a farmer's field on the southeastern edge of Kalavasos, sample KAD15-IRD07, has undergone more of a transformation from limestone into terra rossa than either -MM26-1 or -MM27-1 as seen from the relative depression of the carbonate peak at $1440 \mathrm{~cm}^{-1}, 875 \mathrm{~cm}^{-1}$ and $713 \mathrm{~cm}^{-1}$ when compared to terra rossa represented by peak $1036 \mathrm{~cm}^{-1}$ (Figure 30 ). The three samples shown in Figure 30 display a gradual transition of limestone to terra rossa, however, none of these samples closely approximates the archaeological samples from the Pithos Hall.

\subsection{Summary of the FT-IR Analysis}

In this chapter the results of the FT-IR analyses were described. There was only a single experiment and investigation conducted using FT-IR analysis revealing some significant results. Notably the red material that underlies both floor deposits in Area 152 is definitively terra rossa clay sediment. This FT-IR investigation could not locate the provenience of the terra rossa and future studies may start their search by looking at the purported red sediment that can be found at nearby Neolithic/Chalcolithic sites in the Vasilikos Valley following South's original hypothesis (1997: 171) of the terra rossa's origin. The terra rossa from K-AD was not compared with the red material within the Kalavasos-Tenta red gypsum sample, again citing technical issues for this shortcoming.

In the following discussion chapter the aforementioned results of the petrographic and FT-IR analyses are synthesized in conjunction with the project's research questions, that is to assess the results in light of the potential for plaster to be used at K-AD in the creation of social space, and to discuss the plaster traditions diachronically between $\mathrm{K}$ $\mathrm{AD}$ and Kalavasos-Tenta. 


\section{Discussion}

This chapter explores the implications of the results outlined in the previous chapter. The discussion is separated between micromorphological results (8.1) and the implications of the FT-IR analyses (8.2).

\subsection{Discussion, Microscopy}

This analysis has shown that there is a conservation of tradition according to plaster use among the monumental complex at $\mathrm{K}-\mathrm{AD}$ while there is a sophisticated level of specialization of plaster technology for specific functional and social purposes. The manufacture and application of plaster was careful and deliberate and the observable work put into some surfaces suggests a non-utilitarian, potentially symbolic level of preparation.

The first notable characteristic of plaster technology at K-AD to be evidenced from the analysis of these 39 thin sections is there is a complete absence of gypsum, or "plaster of Paris." These results reaffirm the overall preference for lime plaster observed by Philokyprou (2012) for LBA sites on Cyprus. There were no examples of gypsum being used in plaster as physical additions (either purposeful or accidental) or as a pyrogenic binding agent. The only instance of a gypsum plaster in this study came from the Neolithic site Kalavasos-Tenta sample KAD15-PG20, a 4mm-thick red top floor layer. Given that gypsum is readily available in the vicinity, and that micritic and sparitic gypsum rocks are both present at $\mathrm{K}-\mathrm{AD}$ in various forms serving numerous functions as workable geogenic material (pithoi lids, South 1988:225; pillar bases, etc.), this infers that the absence of gypsum plaster technology is clear evidence for raw material selection 
being underpinned by cultural choices rather than environmentally determined. We may go one step further and suggest gypsum was specifically avoided as an inappropriate contaminant during the manufacture of lime plaster, as gypsum does not constitute even trace abundances in any tested sample.

A second general point that can be taken from the results concerns two qualities shared between pyrogenic plaster samples from K-AD: the presence of dendritic mineral stains and white, pale hypocoating reaction zones. Dendritic mineral stains (Figure 18; Appendix Image 44) appeared exclusively in pyrogenic plaster and are similar in shape (by nature of being a fractal!) and colour to mineral stains that are present in limestone chunks. In geological limestone these fractals form along sedimentary bedding planes by means of mineral-rich water intrusion and mineral deposition. The fractal shape is a result of water forcing its way along the bedding plane and can be mistaken as a pseudofossil with an organized, organic structure. In thin section these dendritic stains do not have a clear source or origin. There are ubiquitous and each is isolated from the others. Most form an ovoid or a two-branch system but none develop further than this. As far as the literature is concerned these dendritic stains have not been discussed in plasters previously but may be the result of mineral precipitation in wet plaster slurries that have undergone long-term storage. The evidence for this hypothesis lies in the uniform distribution of these dendritic stains across the samples they appear in (e.g. Appendix Image 44). The stains are not concentrated along planar voids, nor do they concentrate along the surfaces of samples. The stains appear to be a direct feature of the material composition of the plasters themselves (Figure 18; Appendix Image 44). 
Among the Pithos Hall deposits dendritic mineral stains appeared across the strata KAD15-MM21-L1 (top floor surface), -L3 (fine plaster between two red layers, top floor) and -L9 (bottom floor surface) with appearances within plaster inclusions in -L2,L4, -L5, and -L11. All of the same instances also display white, pale hypo- and quasicoatings. The same pairing is present in all three thin sections of the plaster road KAD15-MM15-1 and KAD15-MM22's L2, but neither quality is present in KAD15MM22's Layer 1 or Layer 3. Both pedofeatures are again present in KAD15-MM23a, but only within plaster aggregate inclusions. The two largest plaster projects (the Pithos Hall and the main $\mathrm{N}-\mathrm{S}$ road) appear to have been made following the same basic recipe with some compositional changes that I believe relate to the specific function of each space. The Pithos Hall plaster was composed of a larger micritic calcite component per unit volume than other samples. This may have been a means to increase the social value of the room by using more resource-intensive pyrogenic lime, or perhaps the homogenous fabric constituted a belief that it entailed cleanliness, as olive oil was being store inside. The road's mixture, on the other hand, had a $30 \%$ coarse fraction limestone sand to gravel, which had the properties, if not the intended purpose, of extending the plaster over a larger area as well as creating a plaster surface with greater mechanical fortitude to compensate for the expected wear from daily transportation. Dendritic stains and white, pale hypocoatings are two features that do not appear in any other plaster layers, except a few examples in KAD15-MM14, which will be discussed below. It is also worth noting that KAD15-MM15-1 and KAD15-MM21-L1, and -L9 of the Pithos Hall are the thickest plaster layers that were sampled at K-AD. 
The long-term storage hypothesis and the fact that the dendritic stains only appear in the thickest layers, when looked at together, can be explained simply with the suggestion that it was never an intention to store plaster for any specific purpose except that the storage of large amounts of plaster for some time was necessary in order to produce enough material and transport it to the project area in order to complete these large, thick surfaces in one fluid operation. The plaster was likely not produced within the site of K-AD, but outside the urban area where a kiln could be built and fuel harvested to fire the raw material. From the kiln location (hitherto unknown) the quicklime could have been slacked and stored in a sealed container that has been filled with water to prevent the lime from setting into calcite (see section 4). This hypothesis would explain the similarities shared between the Pithos Hall and the N-S road plaster surfaces.

The Pithos Hall (Area 152) floor deposits are the clearest example of conscious design and the conservation of plaster manufacturing traditions at K-AD. A sunken and complete pithos was excavated from the center of the room during the Vasilikos Valley Project and it was from this hole three block samples were collected. Micromorphological analysis identified two sequences of floors that followed the same general construction method (See Table 1, Figure 31). The surface layers KAD15-MM21-L1 and -L9 are both thick, robust, white pyrogenic plasters with comparable traits. For example, their fine fraction contains white hypocoatings surrounding voids, and their coarse materials are the lowest for any KAD15-MM21 layers at $10 \%$ and $14 \%$ for $-\mathrm{L} 1$ and $-\mathrm{L} 9$, respectively. The material sampled from beneath the pithos stand, KAD15-PG13, also has a 10\% coarse 
fraction but a distinct recipe; it is differentiated from -L1 by its absence of dendritic mineral stains and its massive, void-free microstructure.

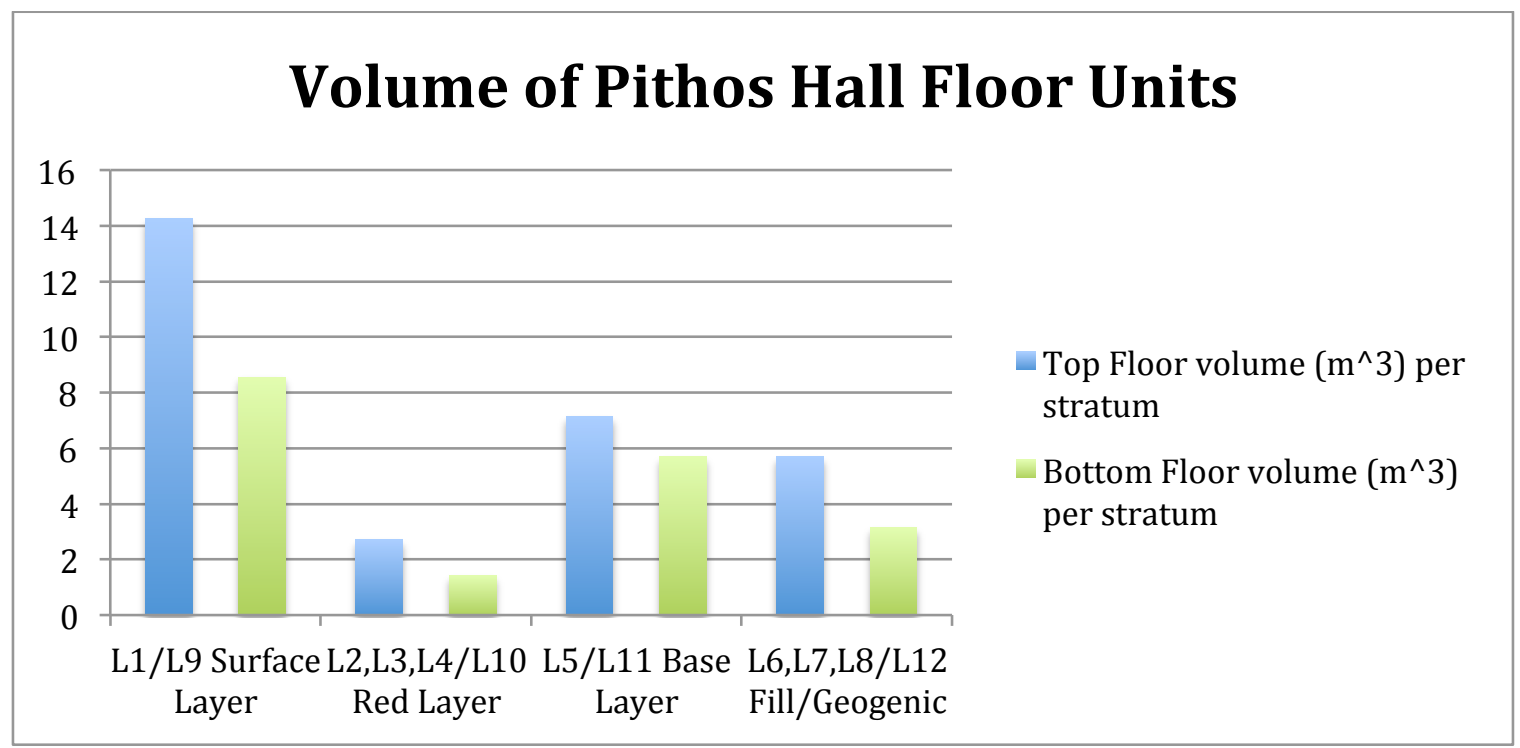

Figure 31. Calculated volume of Pithos Hall floor material per identified unit. Layers paired between the two floor construction sequences. Credit: Author's image.

\begin{tabular}{|l||l|l|l||l|l|l|}
\hline Pithos Hall Floor & Top Floor & $\begin{array}{l}\text { Thickness } \\
(\mathrm{mm})\end{array}$ & $\begin{array}{l}\text { Volume } \\
\left(\mathrm{m}^{3}\right)\end{array}$ & $\begin{array}{l}\text { Bottom } \\
\text { Floor }\end{array}$ & $\begin{array}{l}\text { Thickness } \\
(\mathrm{mm})\end{array}$ & $\begin{array}{l}\text { Volume } \\
\left(\mathrm{m}^{3}\right)\end{array}$ \\
\hline Plaster Surfaces & L1 & 100 & 14.2 & L9 & 60 & 8.6 \\
\hline $\begin{array}{l}\text { Anthropogenic } \\
\text { Red Layers }\end{array}$ & L2+L3+L4 & $\begin{array}{l}19 \\
(3+9+7)\end{array}$ & $\begin{array}{l}2.7 \\
(0.4+1.3 \\
+1.0)\end{array}$ & L10 & 10 & 1.4 \\
\hline $\begin{array}{l}\text { Carbonate } \\
\text { preparation layers }\end{array}$ & L5 & 50 & 7.1 & L11 & 40 & 5.7 \\
\hline Geogenic/fills & L6 $(\mathbf{L 7 , ~ L 8 ) ~}$ & 40 & 5.7 & L12 & $22+$ & $3.1+$ \\
\hline
\end{tabular}

Table 1. B.X, A.152 Pithos Hall floor sequence. Credit: Author's table.

Each of the compositional layers in the top floor required more resources to prepare when compared to the bottom floor. Most notably they are all physically thicker and require more raw material than their corresponding bottom floor units. The "red layer" in the top floor (Layers 2, 3 and 4) also required an additional two steps: an additional red layer (-L2) and an extremely fine plaster layer (-L3), which may not seem 
to be too arduous but it doubled the overall thickness of this level (19mm) when compared to the bottom floor's red layer $(10 \mathrm{~mm})$ and required three complete strata to be laid one after another. As Area 152 is the largest room at K-AD these additional steps represent a considerable additional investment of resources.

The floor sequence of the Pithos Hall has shown that the recipe and tradition of manufacturing a monumental floor was conserved at $\mathrm{K}-\mathrm{AD}$ between the two floor layering events. By the time of the second construction event several deliberate changes were added to the floor's creation, all of which made the second construction more labour intensive including the thickening the floor units and two terra rossa bands separated by a fine, pyrogenic layer. It is argued that the addition of these two additional layers, which were only identified in the laboratory with the aid of soil micromorphological techniques, does not invalidate the claim of the overall conservation of procedure between the two construction events. These additions were small in size but potentially carried great significance. They do not appear to have any structural benefit and are suggested to be a socioeconomic display of tradition and wealth, much like the construction of 'expensive' mudbricks that were only visible during the construction of homes in Çatalhöyük (Matthews 2005; Love 2013b).

The total volume of each constituent layer in the Pithos Hall has been calculated in $\mathrm{m}^{3}$ (Table 1). As the specific density of all the materials was not calculated mass estimates have been omitted. A future study would include using constituent materials and volume to estimate energy consumption per layer, which alongside the clear grandeur 
of the prepared floor sequence would further illustrate the central control of resources required for the construction of the edifice.

My research has indicated clearly that the urban community on Cyprus at K-AD employed clear context-specific recipes for manufacturing plaster that varied on the specific location the plaster was to be used. For example, plaster drains had the purposeful addition of artificial pozzolanic material, which created a material, upon setting, that was more physically and chemically resilient (possessed hydraulic properties making the plaster less soluble in water) than regular pyrogenic plasters. As such these plasters would be perfectly suited to drain liquid out of the site as regular plaster would dissolve with water and make a rather poor drain. Among the samples from K-AD artificial pozzolanic additions were restricted to plaster drains KAD15-PG15, -PG16 and -PG17 in dimensions varying up to $750 \mu \mathrm{m}$ in -PG15 and up to $1 \mathrm{~mm}$ for -PG16 and PG17. There are trace pozzolanic materials present in the fine plaster floor of Unit 3 (KAD15-MM16, -MM17, -PG22) measuring up to $150 \mu \mathrm{m}$, trace amounts in the plaster covering the steps in the Pithos Hall (KAD15-MM22a) measuring less than $200 \mu \mathrm{m}$, and $50 \mu \mathrm{m}$ trace amounts in Area 161's pebble floor sample-MM23, corridor plaster-MM25 and layer two of KAD87-PG07. No other samples contained pozzolanic additives, thus it can be argued pozzolanic properties were known to LBA architects and they explicitly exploited these properties for purpose-specific applications of plaster that dealt with fluids, i.e. to make drains.

Among the samples representing hydraulic plaster the drain samples (Figure 26; PG15, -PG16, and -PG17) have the largest and most plentiful artificial pozzolanic 
aggregates (Figure 19). The next largest abundance in a plaster sample is found in KAD15-MM22-L1: the plaster covering the steps in the Pithos Hall. Measuring up to $200 \mu \mathrm{m}$ in length the amount of artificial pozzolans present in -MM22 plaster surface (L1; Figure 19, Images B and D) increases by several orders of magnitude in the pisé base layer. The small amount of pozzolanic material in the plaster sample KAD15-MM22-L1 is greatly outnumbered by the amount of artificial pozzolans seen in the underlying pisé (KAD15-MM22-L3; Figure 19, Images $\mathrm{A}$ and C) and also by the amount of artificial pozzolans in the plaster drains. The small amount of artificial pozzolans do not give me the confidence to label the lime plaster -MM22-L1 as a hydraulic plaster. The volume of aggregates is not comparable with the comparatively overwhelming volumes of artificial pozzolans within the plaster drains samples (-PG15, -PG16, and -PG17), which are several orders of magnitude greater $(16 \mathrm{x}-32 \mathrm{x})$ than $-\mathrm{MM} 21-\mathrm{L} 1$. The remaining samples sampled in this study that contained trace pozzolanic material are likewise not hydraulic plasters.

Three pieces of micritic calcite "fine plaster" surfaces (KAD15-MM16, -MM17, and -PG22) from the west side of the main N-S road in Unit 3 (Figure 9, 24) revealed a uniform fabric between the three samples of three units, each with a smaller coarse fraction than the plaster drain samples and with the absence of pozzolanic material. These samples were noticeably hard and durable during sampling. The uniform constitution of the samples, which came from the floor and the lower wall of the room (Figure 24), indicate the plaster was applied up-the-wall during floor construction, decreasing the potential for the plaster to leak if it held liquid (Philokyprou 2012). The entire plaster wall 
sample was applied at the same time, in contrast to the method of successive thin applications known to prevent the material from potentially collapsing on its own weight (see Philokyprou 2012). Material from the upper wall was not preserved for analysis and a basal edge sample where the wall and floor meet in a curve was not taken to avoid damaging the site. When looking at the contact curve on site with the wall and floor it appears the plaster is continuous suggesting at least some, if not all, material was applied to the wall and floor contemporaneously.

Moving from a synchronic to a diachronic perspective, sample KAD15-MM14 from Building XVI (Unit 7; Figure 9) provided us with twenty-three successive micritic calcite units in $18 \mathrm{~cm}$ (Figure 20). These units alternate between thinner, massive "layers," (L) and thicker, well-separated ped "matrixes," (M). Matrix 1, the uppermost unit, to Layer 6 display a mostly consistent thickness pattern with matrixes varying between 3 and $13 \mathrm{~mm}$ thick, and layers varying between 1 and $6 \mathrm{~mm}$ thick (Figure 21). Using these widths as a baseline for normalcy $-\mathrm{L} 6,-\mathrm{M} 7,-\mathrm{M} 9,-\mathrm{M} 10$, and $-\mathrm{L} 10$ are large while $-\mathrm{L} 7$, $-\mathrm{M} 8,-\mathrm{L} 8$, and $-\mathrm{L} 9$, are thin. $-\mathrm{M} 11$ and $-\mathrm{L} 11$ return to an average thickness (See Figure 21). There is no possibility to estimate the amount of time between construction phases.

In addition to size variation there is limited conservation of material composition the apparent slope. The samples KAD15-MM14, MM14-1, were retrieved from the northern edge of Building XVI, next to a cobblestone wall, which may account for the angle and irregular thicknesses from sweeping or more intensive treading erosion further away from the wall. All the layers except for KAD15-MM14-L1, -L9 and -L11 have the same pale, white hypocoating seen in the Pithos Hall top plaster layers and the main N-S 
road. There are in these units, however, variations among mineral stains. The stains present in these plaster floors are round, smaller and not as regular as the dendritic stains seen throughout the previously mentioned monumental lime plasters. There were a few instances of mineral stains and micritic calcite nodules with pale white hypocoated margins within the twelve matrix units; however, these instances were concentrated to individual and isolated nodules not exceeding $300 \mu \mathrm{m}$ in size. These nodules within the "matrix" units are physically isolated in a packing void matrix.

This sequence of thin, irregular ephemeral surfaces is the antithesis of the large monumental features that were accessible along the LCIIC corridors not more than $70 \mathrm{~m}$ away (estimated from Figure 9). This sequence is the only series of floors from outside the monumental complex and therefore limited conclusions can be drawn. The floors are irregular, thin and numerous, in contrast to the surfaces within the monumental complex.

Additional variation is noted between the floor deposits from Areas 161 and 158a, samples KAD15-MM23 and-MM25 respectively. Area 161 is a smaller pithoi storage area in the northwest corner of the monumental complex. $-\mathrm{MM} 23$ is a pebble floor that becomes progressively finer with depth. It includes many igneous minerals that are unique to this sample that suggests the coarse fraction aggregates of KAD15-MM23 may not have been restricted to specific materials, in contrast to the lack of igneous aggregate inclusions in the Pithos Hall and the specific avoidance of gypsum overall. The entire sampled sequence of $-\mathrm{MM} 23$ is approximately $11 \mathrm{~cm}$ thick with the top $2 \mathrm{~cm}$ having a $60 \%$ coarse fraction. This floor serves a very similar purpose to Area 152, the Pithos Hall, however its floor construction is less labour intensive. Layers in -MM23 and -MM25 are 
both thinner than the Pithos Hall layers and coarser, requiring a smaller pyrogenic component per unit volume. The floor surface from Area 152 again appears to hold significance for LBA inhabitants at K-AD.

KAD15-MM25, the corridor plaster, (Figure 25, Images H-M) is a pebble floor that has been covered over with a layer of mixed plaster. In the center of KAD15-MM25$\mathrm{L} 1$ is a $40 \times 20 \mathrm{~mm}$ piece of pyrogenic white plaster, similar to KAD15-MM21-L1 and L9 of the Pithos Hall, being reused as an aggregate for a new mixture. The base layer, KAD15-MM25-L3, is of similar composition with plaster aggregates also showing granostriation by beige clay. These samples are being made with re-used, old plaster as an aggregate material, something that is not seen among thicker, or perhaps more important, plaster deposits.

Micromorphological evidence for the conscious and deliberate application of specific plaster mixtures at different areas of K-AD has been shown and interpreted as socially driven choices. Specifically, as an example of the conservation of tradition and purpose for a room the same a high-quality and robust pyrogenic plaster was used in the creation of the two thick (100mm and 60mm; Figure 31) floor phases in the Pithos Hall. A similar recipe with limestone aggregate extenders and additional voidspace was used in the manufacture of the main N-S road (KAD15-MM15-1), which is twice as thick at 200+ $\mathrm{mm}$ (see section 6.4) as the pithos hall floor surface. Plasters that were to form hard, thin surfaces (see section 6.5) up to $10 \mathrm{~mm}$ were constructed with a relatively abundant coarse fraction (20\%) (e.g. KAD15-MM16, -MM17, -PG22, -MM22), which may have increased the durability of such plasters to keep moisture from penetrating the surface. 
The disparate application of plaster recipes for seemingly similar uses such as the two superimposed Pithos Hall floors, or the floors between the two main pithoi storage areas - the Pithos Hall floors and the floor of Area 161 - are indicative of conscious design, social influence and tradition, rather than of environmental determinism. Among others these comparisons indicate plaster was used, at least in part, to illustrate the different social roles these areas played, and in the case of Area 152 how this role changed between the two construction events. The individual(s) in control of Area 152 and those who were permitted access to this storage facility would have been in a place of unique privilege beyond those in the central court or Area 161. The individual(s) in control of Building X would have similarly been in a place of prominence during the construction of Area 152's floor sequence, having witnessed the labourious steps taken to prepare the floor with sourced terra rossa and different plaster layers. The knowledge of the preparation would have also been a point of social dialogue. The construction sequences and material compositions were meaningfully employed in accordance with the intended social role Area 152 was to have. Different areas were designated with plasters of visible surface variation and compositional traits that were hidden from view; both of which contribute to the shared social perception - the doxa - of the exclusive spaces these surfaces adorned.

\subsection{Discussion, FT-IR}

FT-IR analysis has shown the red layers in the Pithos Hall are made from terra rossa: a reddish brown sediment that is rich in clay minerals and consolidates when compacted. The use of terra rossa as a means to consolidate the base of a surface, or its 
use as packing around sunken pithos is seen at K-AD. Its use as a functional material in the Pithos Hall, however, is called into question as the $60 \mathrm{~mm}$ and $100 \mathrm{~mm}$-thick lime plaster floors are incredibly hard even after 3000 years and one would not be incorrect in identifying the $40 \mathrm{~mm}$ and $50 \mathrm{~mm}$-thick, respectively, base layers would be more than sufficient to satisfy any and all utilitarian concerns by architects for material warping over time. The use of two layers of terra rossa in the upper sequence as well calls into question the function of the use of terra rossa. I argue that specifically in the case of Area 152 the procurement and application of terra rossa layers is more rooted in the tradition and culture of the act of constructing a surface by LBA Kalavasos elites than in its functional qualities as an exceptional packing material. Whether or not these cultural practices that were rooted in tradition had an additional metaphysical role it is currently not possible to say.

Preliminary exploration in the Vasilikos Valley in 2015 in the immediate area around K-AD yielded no examples of geologic terra rossa. South (1997: 171) hypothesized that archaeological terra rossa at K-AD may have been sourced from nearby (within 1km) "Neolithic/Chalcolithic sites Kalavasos-Kokkinoyia and Pamboules" by LBA people. It has been shown that the tested geogenic samples and sediments collected in the vicinity of K-AD were not fully transformed terra rossa by FT-IR analysis. These results are incompatible with the results of the material found beneath the floors in the Pithos Hall, which had an unobservable carbonate signature. The spectral curve from the red material that comprises L2 and L4 of the Pithos Hall floor sequence, sampled as KAD15-IR65 and KAD15-IR105, matches a library sample for unheated terra 
rossa (Figure 27). This finding also reveals that the terra rossa used in the construction of the Pithos Hall floors was not contaminated with any geogenic calcite or pyrogenic lime plaster during sourcing or during the construction of the floor suggesting individuals were conscious of material purity, much like the absence of trace gypsum in plasters.

The results of the FT-IR analysis has shown that the banded red strata outcrops that parallel the highway, collected as samples KAD15-MM26-1 (lower band) and KAD15-MM27-1 (upper band) are currently undergoing a geological transformation from calcite to terra rossa. The material from the farmer's field, KAD15-IRD07, revealed high carbonate signature (peaks $1437 \mathrm{~cm}^{-1}, 874 \mathrm{~cm}^{-1}$ and $713 \mathrm{~cm}^{-1}$ ) incompatible with the archaeological samples. It was similar to MM26-1 and MM27-1, but the latter two have a stronger carbonate signature suggesting that the material from the farmer's field was further along in its conversion to terra rossa. Samples collected near the abandoned village of Drapia have no similarities to the archaeological samples when tested unheated. The heated samples have a widening of spectral peaks (diagenesis of crystal structure) that is inconsistent with the archaeological samples.

Limited FT-IR analyses, the product of unforeseen circumstances, has been able to show that the red layers applied in sequence beneath each of the two floor surfaces in Area 152 are pure terra rossa. The provenience of this material, however, remains unknown, but may still be in nearby Neolithic/Chalcolithic sites (South 1997: 171). All reddish brown geological samples collected in the region surrounding $\mathrm{K}-\mathrm{AD}$ were shown to be calcareous material that was in the process of becoming terra rossa, but had not yet fully degraded into clay sediment. 


\section{Conclusion}

This research on the study of plaster construction practices at Kalavasos-Ayios Dhimitrios has demonstrated that plaster pyrotechnology and construction practices can be used as an index to explore the nuances of social organization. This study was undertaken to better understand the LCIIC people and their social dynamics during a period of political and economic change on the island of Cyprus. This thesis asked if plaster technology changes over time and across different social spaces at K-AD, according to the dialectic relationship of population density, socioeconomics and craft specialization. Plaster itself has not historically been a material used to study social dynamics at archaeological sites, especially not on Cyprus, due to the relatively new shifts in linking this geological technology with cultural practices. A theoretical underpinning of this thesis is the claim that plaster can be linked to social identity and social processes through people and their habitus. Under this framework a high-resolution plaster analysis involving micromorphology and FT-IR has examined over 90 distinct archaeological stratigraphic units at K-AD and ten infrared spectra of archaeological, geologic and experimental materials. The results of this analysis strongly suggest LCIIC people had purpose-specific recipes for the construction of plaster surfaces and implemented them across K-AD.

The main room at K-AD within the monumental Northeast Area, the Pithos Hall, which stored olive oil in antiquity, was the most heavily sampled area due to its accessibility and prominence. Among the samples was a sequence of two floor construction phases, KAD15-MM21, which exhibited conservative construction practices, 
i.e. the two floors were made in the same way, to the notable exception that the upper floor has physically more material used in each constituent layer. The additions in the upper floor are taken to be representative of the development of the socioeconomic importance of the Pithos Hall. Although the constituent terra rossa layers included in the floor and the overall thickness would not be visible to the population after completion the social impact of the floor would be preserved by those having witnessed the labourious steps taken to prepare the floor with sourced terra rossa and different plaster layers. The knowledge of the preparation would become a point of social dialogue. The construction sequences and material compositions were meaningfully employed in accordance with the intended social role Area 152 was to have. Different areas were designated with plasters of visible surface variation and compositional traits that were hidden from view; both of which contribute to the shared social perception - the doxa - of the exclusive spaces these surfaces adorned. A system of central organization/wealth accumulation/resource control developed between the lower and upper Pithos Hall construction phases as indicated by a thickening series of layers that were already monumental in size. The addition of two extra non-utilitarian construction steps in the top Pithos Hall floor when compared to the original floor (see section 8.1; Figure 31; Table 1) may also indicate a developing system of belief, tradition, superstition, or symbolism.

Analysis of different surfaces which were sampled largely within the Northeast Area due to time constraints and accessibility suggests there was an established knowledge of plaster manufacture and construction practices that on an urban scale included centralized resource control and a socioeconomic system that valued and 
demanded different materials for specific uses, including the use of limestone inclusions to extend an/or strengthen the main N-S road (KAD15-MM15-1) that connects the planned site and the complete moratorium on gypsum in any LBA plaster samples. One hypothesis that came from the micromorphological analysis is that the presence of dendritic stains in the thickest plaster layers, i.e. the Pithos Hall floors and the main N-S road, may be a product of slacked lime production. The need for large amounts of pyrogenic material may have demanded the manufacture and storage of large quantities of slacked lime in order for enough material to be made and applied to create the intended surface on one construction event. The time taken to prepare the necessary lime plaster could have allowed the dendritic stains to grow in an aqueous solution, which would then explain their even distribution (e.g. Appendix Image 44) across the thick samples they are present in.

The last result for the micromorphological analysis is that the LBA people at $\mathrm{K}$ AD employed the use of artificial pozzolanic material to create hydraulic plasters that were used exclusively in the creation of water-resistant plaster drains.

The main results from the FT-IR analysis is that the red layers in the Pithos Hall floor deposits, KAD15-MM21-L2, -L4, and -L10 (Table 1), are terra rossa and that the source of this terra rossa was not identified from any local samples in this analysis, however, these local samples were by no means exhaustive.

This analysis has shown that along with large-scale architecture, sophisticated plans, and ashlar masonry, plaster technology was regulated and implemented to build the new urban center from the ground-up both structurally and symbolically. My research has 
Master's Thesis - P Wallace; McMaster University - Anthropology

indicated clearly that the urban community on Cyprus at K-AD employed clear contextspecific recipes for manufacturing plaster that varied on the specific location the plaster was to be used, modes of preparation and consumption that both reflected and partconstituted social differences. 


\section{Future Directions}

This study has revealed some areas for future research. (1) Using petrography and soil micromorphology this project can be extended across the site of K-AD as for this study plaster samples were concentrated to the monumental complex. An intra-site analysis may be able to answer questions about the use of pyrotechnology in nonmonumental early urban residential structures and also if a tiered system was employed to create "higher-status" residential structures for the elites that facilitated the happenings within the Northeast Area. (2) A multi-site study can be carried out that includes the two other nearby monumental LBA sites at Alassa-Paleotaverna and Maoni. This study would explore the possibility of a shared tradition of plaster manufacture for monumental structures, or the possibility of skilled workers travelling between sites to apply their trade. These analyses would lend an understanding to the social arrangement on Cyprus during the Amarna correspondence (Goren et al. 2003) and further explore the depth of social division in this rapidly urbanizing society.

There are several questions that can be answered with FT-IR analysis, such as (3)

a further exploration into the source of the terra rossa, specifically by testing the potential Neolithic/Chalcolithic archaeological sites mentioned by South (1997: 171). (4) The only gypsum plaster found in this study came from the red floor of Kalavasos-Tenta's structure 17, the central building at the site. The underlying structure 36 also has a red floor, the only other instance of red floors at Tenta. An FT-IR sample would reveal if these are both gypsum plasters, and if so, further research could be undertaken to explore if the use of gypsum was restricted to these two red floors at Tenta. (5) A second question regarding 
these red floors that is quickly resolved with FT-IR is if the Pre-Pottery Neolithic B inhabitants utilized terra rossa as a red colouring agent.

The final future direction from this project is (6) conducting experimental limestone burns, both in the field and in the laboratory. This project would shed light on the environmental cost of producing the tonnes among tonnes of pyrogenic material demanded from the monumental complex at $\mathrm{K}-\mathrm{AD}$. The entire site extends for up to 11.5ha, but research into Building XVI revealed floor surfaces outside the monumental complex are significantly less resource intensive to construct. The top layer of plaster in the Pithos Hall requires a calculated $14.2 \mathrm{~m}^{3}$ of material to be applied in one event. What are the resources involved in producing this amount of material? Resources include trees for fuel, labour for collecting and crushing raw material, water for slacking, and a space to carry out this process and containers to transport plaster through the city and apply it.

The final research project in this list is by far the most labour intensive while some of the FT-IR projects can be carried out readily. 


\section{References}

Albert, Rosa Maria, Ruth Shahack-Gross, Dan Cabanes, Ayelet Gilboa, Simcha LevYadun, Marta Portillo, Ilan Sharon, Elisabetta Boaretto, and Steve Weiner

2008 Phytolith-rich layers from the Late Bronze Age and Iron Ages at Tel Dor (Israel): Mode of Formation and Archaeological Significance. Journal of Archaeological Science 35: 57-75.

Ames, Kenneth M.

2005 The Place of Ozette in Northwest Coast Archaeology. Ozette Archaeological Project Research Reports Volume III: Ethnobotany and Wood Technology. Seattle: WSU Department of Anthropology Reports of Research. Pp. 9-24.

Anderson, Emma, Matthew J. Almond, and Wendy Matthews

2014 Analysis of Wall Plasters and Natural Sediments from the Neolithic Town of Çatalhöyük (Turkey) by a Range of Analytical Techniques. Spectrochimica Acta Part A: Molecular and Biomolecular Spectroscopy 133: 326-334.

Anthony, David W.

1990 Migration in Archaeology: The Baby and the Bathwater. American Anthropologist 92(4): 895-914

Bauer, Andrew M.

(in press) Geoarchaeological Science and New Materialisms: Theorizing Analyses of Soils, Stones, and Social Landscapes.

Berna, Francesco, Adi Behar, Ruth Shahack-Gross, John Berg, Elisabetta Boaretto, Ayelet Gilboa, Ilan Sharon, Sariel Shalev, Sana Shilstein, Naama Yahalom-Mack, Jeffrey R. Zorn, and Steve Weiner.

2007 Sediments Exposed to High Temperatures: Reconstructing Pyrotechnological Processes in Late Bronze and Iron Age Strata at Tel Dor (Israel). Journal of Archaeological Science 34: 358-373.

Berna, Francesco, Paul Goldberg, Liora Kolska Horwitz, James Brink, Sharon Holt, Marion Bamford, and Michael Chazan.

2012 Microstratigraphic Evidence of in Situ Fire in the Acheulean Strata of Wonderwerk Cave, Northern Cape Province, South Africa. PNAS 109(20): E1215-E1220.

Birch, Jennifer

2013 Between Villages and Cities: Settlement Aggregation in Cross-Cultural Perspective. In. Jennifer Birch (ed.), From Prehistoric Villages to Cities: Settlement Aggregation and Community Transformation. Pp. 1-22. 
Bourdieu, Pierre

1977 Outline of a Theory of Practice. Cambridge: Cambridge University Press.

Broodbank, Cyprian

2013 The Making of the Middle Sea: A History of the Mediterranean from the Beginning to the Emergence of the Classical World. London: Thames and Hudson.

Cesaretti, Rudolf, José Lobo, Luís M. A. Bettencourt, Scott G. Ortman, and Michael E. Smith

2016 Population-Area Relationship for Medieval European Cities. PLoS One 11(10): e0162678

Cherry, John F., and Thomas P. Leppard

2015 Experimental Archaeology and the Earliest Seagoing: The Limitations of Inference. World Archaeology, DOI 10.1080/00438243.2015.1078739.

Childe, V. Gordon

1925 The Dawn of European Civilization. New York: Routledge.

1950 The Urban Revolution. The Town Planning Review 21(1): 3-17.

Chu, Vikki, Lior Regev, Steve Weiner, and Elisabetta Boaretto

2008 Differentiating Between Anthropogenic Calcite in Plaster, Ash and Natural Calcite Using Infrared Spectroscopy: Implications in Archaeology. Journal of Archaeological Science 35: 905-911.

Davies, O.

1930 The Copper Mines of Cyprus. The Annual of the British School at Athens 30 (1928/1929 - 1929/1930): 74-85.

Dietler, Michael and Ingrid Herbich

1998 Habitus, Techniques, Style: An Integrated Approach. In. Miriam T. Stark (ed.), The Archaeology of Social Boundaries. Washington DC: Smithsonian Institution Press. Pp. 232-263.

Dobres, Marcia-Anne

2010 Archaeologies of Technology. Cambridge Journal of Economics 34: 103-114.

Elliot Smith, Grafton

1929 The Migration of Early Cultures. Manchester: University of Manchester Press.

Fisher, Kevin D. 
2009a Elite Place-Making and Social Interaction in the Late Cypriot Bronze Age. Journal of Mediterranean Archaeology 22(2): 183-209.

2009b Placing Social Interaction: An Integrative Approach to Analyzing Past Built Environments. Journal of Anthropological Archaeology 28: 439-457.

Fisher, Kevin D., Jeffrey F. Leon, Sturt W. Manning, Michael Rogers, and David Sewell In press The Kalavasos and Maroni Built Environments Project: Introduction and Preliminary Report on the 2008 and 2010 Seasons. Report of the Department of Antiquities Cyprus.

Fisher, Kevin D., and Sturt W. Manning

In press Kalavasos and Maroni Built Environments (KAMBE) Project: Report on the 2016 Season at Kalavasos-Ayios Dhimitrios. Report of the Department of Antiquities Cyprus.

Gale, N. H., and Z. A. Stos-Gale

1986 Oxhide Copper Ingots in Crete and Cyprus and the Bronze Age Metals Trade. The Annual of the British School at Athens 81: 81-100.

Gale, N. H., Z. A. Stos-Gale, G. Maliotis, and N. Annetts

1997 Lead Isotope Data From the Isotrace Laboratory, Oxford: Archaeometry Data Base 4, Ores from Cyprus. Archaeometry 39(1): 237-246.

Gapminder Foundation

n.d. www.gapminder.org/data

Goldberg, Paul, and Francesco Berna

2010 Micromorphology and Context. Quaternary International 214: 56-62.

Gomez, Basil

1987 The Alluvial Terraces and Fills of the Lower Vasilikos Valley, in the Vicinity of Kalavasos, Cyprus. Transactions of the Institute of British Geographers 12(3): 345-359.

Gomez, Basil, Julie Hansen, and J. Malcolm Wagstaff

2004 Chapter II: The Vasilikos Valley. In. Ian A. Todd (ed.), Vasilikos Valley Project 9: The Field Survey of the Vasilikos Valley Vol. 1. Sävedalen: Paul Åströms Forlag. Pp. 6-16.

Goren, Yuval, and Paul Goldberg

1991 Petrographic Thin Sections and the Development of Neolithic Plaster Production in Northern Israel. Journal of Field Archaeology 18(1): 131-140. 
Goren, Yuval, Shlomo Bunimovitz, Israel Finkelstein, and Nadav Na'Aman

2003 The Location of Alashiya: New Evidence from Petrographic Investigations of Alashiyan Tablets from El-Amarna and Ugarit. American Journal of Archaeology 107(2): 233-255.

Goren, Yuval, Israel Finkelstein, and Nadav Na'aman

2004 Inscribed in Clay: Provenance Study of the Amarna Letters and Other Ancient Near Eastern Texts. Tel Aviv: Tel Aviv University.

Gosden, Chris

2006 Material Culture and Long-Term Change. In. Christopher Tilley, Webb Keane, Susanne Küchler, Michael Rowlands, and Patricia Spyer (eds.), Handbook of Material Culture. London: Sage Publications. Pp. 425-442.

Goshen, Nurith, Assaf Yasur-Landau, Eric H. Cline, and Ruth Shahack-Gross

2017 Palatial Architecture Under the Microscope: Production, Maintenance, and Spatiotemporal Changes Gleaned From Plastered Surfaces at a Canaanite Palace Complex, Tel Kabri, Israel. Journal of Archaeological Science: Reports 11: 189199.

Government of Cyprus

1979 Geological Map of Cyprus: Scale 1: 250,000. Geological Survey Department. Nicosia, Department of Lands and Surveys.

1995 Geological Map of Cyprus: Scale 1 : 250 000. Geological Survey Department. Nicosia, Ministry of Agriculture, Natural Resources and Environment.

2002 Geology of Cyprus. Lefkosia, Geological Survey Department.

2008 The Flora of the Forests of Cyprus. Department of Forests: Ministry of Agriculture, Natural Resources and Environment. Nicosia, Press and Information Office.

Harris, Sarah E.

2012 Cyprus as a Degraded Landscape or Resilient Environment in the Wake of Colonial Intrusion. PNAS 109(10): 3670-3675.

Helms, Mary W.

1993 Craft and the Kingly Ideal: Art, Trade, and Power. Austin: University of Texas Press.

Jones, Siân

1997 The Archaeology of Ethnicity: Constructing Identities in the Past and Present. London: Routledge. 
2007 Discourses of identity in the Interpretation of the Past. In. Timothy Insoll (ed.), The Archaeology of Identities. London: Routledge. Pp. 44-58.

Jusseret, Simon

2010 Socializing Geoarchaeology: Insights from Bourdieu's Theory of Practice Applied to Neolithic and Bronze Age Crete. Geoarchaeology: An International Journal 25(6): 675-708.

Karkanas, Panagiotis

2006 Late Neolithic Household Activities in Marginal Areas: The Micromorphological Evidence from the Kouveleiki Caves, Peloponnese, Greece. Journal of Archaeological Science 33: 1628-1641.

2007 Identification of Lime Plaster in Prehistory Using Petrographic Methods: A Review and Reconsideration of the Data on the Basis of Experimental and Case Studies. Geoarchaeology: An International Journal 22(7): 775-796.

Karkanas, Panagiotis, and Nikos Efstratiou

2009 Greece: Micromorphology Reveals Cycles of Renovation. Antiquity 83: 955-967.

Keswani, Priscilla S.

1993 Models of Local Exchange in Late Bronze Age Cyprus. Bulletin of the American Schools of Oriental Research 292: 73-83.

Kirk, Ruth, with Richard D. Daugherty

1978 Exploring Washington Archaeology. Seattle: University of Washington Press.

Kingery, W. David, Pamela B. Vandiver, and Martha Prickett

1988 The Beginnings of Pyrotechnology, Part II: Production and Use of Lime and Gypsum Plaster in the Pre-Pottery Neolithic Near East. Journal of Field Archaeology 15(2): 219-244.

Knapp, A. Bernard

2013a The Archaeology of Cyprus. Cambridge: Cambridge University Press.

2013b Revolution within Evolution: The Emergence of a 'Secondary State' on Protohistoric Bronze Age Cyprus. Levant 45(1): 19-44.

Knapp, A. Bernard, Jan Bouzek, David Frankel, Steve O. Held, Edgar Peltenburg and Alan H. Simmons

1990 Production, Location, and Integration in Bronze Age Cyprus. Current Anthropology 31(2): 147-176. 
Knapp, A. Bernard, and Sophia Antoniadou

1998 Archaeology, Politics and the Cultural Heritage of Cyprus. In. Lynn Meskell (ed.), Archaeology Under Fire: Nationalism, Politics and Heritage in the Eastern Mediterranean and Middle East. London: Routledge. Pp. 13-43.

Kottek, Markus, Jürgen Grieser, Christoph Beck, Bruno Rudolf and Franz Rubel

2006 World Map of the Köppen-Geiger Classification Updated. Meteorologische Zeitschrift 15(3): 259-263.

Love, Serena

2011 The Geoarcaheology of Mudbricks in Architecture: A Methodological Study from Çatalhöyük, Turkey. Geoarchaeology: An International Journal 27: 140-156.

2013a Architecture as Material Culture: Building Form and Materiality in the Pre-Pottery Neolithic of Anatolia and Levant. Journal of Anthropological Archaeology 32: 746-758.

$2013 \mathrm{~b}$ The Performance of Building and Technological Choice Made Visible in Mudbrick Architecture. Cambridge Archaeological Journal 23(2): 263-282.

Manning, Sturt W.

2013 Chronology for Prehistoric Cyprus, ca. 11,000-1050 Cal BC: Table A2. In. Bernard A. Knapp, The Archaeology of Cyprus. Cambridge: Cambridge University Press. Pp. 521.

Manning, Sturt W., and Francis A. De Mita Jr.

1997 Cyprus, the Aegean, and Maroni-Tsaroukkas. In. Dimos Christou (ed.), Cyprus and the Aegean in Antiquity. Nicosia: Department of Antiquities. Pp. 103-141.

Manning, Sturt W., Georgia-Marina Andreou, Kevin D. Fisher, Peregrine Gerard-Little, Catherine Kearns, Jeffrey F. Leon, David A. Sewell, and Thomas M. Urban

2014 Becoming urban: investigating the anatomy of the Late Bronze Age Complex, Maroni, Cyprus. Journal of Mediterranean Archaeology 27(1): 3-32.

Martinez-Ramirez, S., S. Sanchez-Cortes, J. V. Garcia-Ramos, C. Domingo, C. Fortes, and M. T. Blanco-Varela

2003 Micro-Raman Spectroscopy Applied to Depth Profiles of Carbonates Formed in Lime Mortar. Cement and Concrete Research 33: 2063-2068.

Matthews, Wendy

2005 Inhabiting Çatalhöyük: Reports from the 1995-99 Seasons: Supplementary Material. British Institute of Archaeology at Ankara 4(38): 553-71. 
2010 Geoarchaeology and Taphonomy of Plant Remains and Microarchaeological Residues in Early Urban Environments in the Ancient Near East. Quaternary International 214: 98-113.

Matthews, Wendy, C. A. I. French, T. Lawrence, D. F. Cutler, and M. K. Jones

1997 Microstratigraphic Traces of Site Formation Processes and Human Activities. World Archaeology 29(2): 281-308.

Meskell, Lynn

2002 The Intersection of Identity and Politics in Archaeology. Annual Review of Anthropology 31: 279-301.

2007 Archaeologies of Identity. In. Timothy Insoll (ed.), The Archaeology of Identities: A Reader. London: Routledge. Pp. 23-43.

Miriello, D., A. Bloise, and G. M. Crisci

2013 Compositional Analysis of Mortars from the Late Antique Site of Son Peretó (Mallorca, Balearic Islands, Spain): Archaeological Implications. Archaeometry 55(6): 1101-1121.

Nodarou, Eleni, Charles Frederick, and Anno Hein

2008 Another (Mud) Brick in the Wall: Scientific Analysis of Bronze Age Earthen Construction Materials from East Crete. Journal of Archaeological Science 35: 2997-3015.

Orszag-Sperber, Fabienne, Antonio Caruso, Marie-Madeleine Blanc-Valleron, Didier Merle, and Jean Marie Rouchy

2009 The Onset of the Messinian Salinity Crisis: Insights from Cyprus Sections. Sedimentary Geology 217: 52-64.

Pauketat, Timothy R.

2001 Practice and History in Archaeology: An Emerging Paradigm. Anthropological Theory 1(1): 73-98.

Pauketat, Timothy R., and Susan M. Alt

2005 Agency in a Postmold? Physicality and the Archaeology of Culture-Making. Journal of Archaeological Method and Theory 12(3): 213-236.

Peel, M. C., B. L. Finlayson, and T. A. McMahon

2007 Updated World Map of the Köppen-Geiger Climate Classification. Hydrological and Earth System Sciences 11: 1633-1644.

Peltenburg, Edgar 
2012 Text Meets Material in Late Bronze Age Cyprus. In. Artemis Georgiou (ed.), Cyprus: An Island Culture: Society and Social Relations from the Bronze Age to the Venetian Period. Oxford: Oxbow Books. Pp. 1-23.

Philokyprou, Maria

1998 Building Materials and Structures of the Architecture in Cyprus, from the Neolithic Period Until the Late Bronze Age. Nicosia: University of Cyprus, History and Archaeology Department.

2011 The Initial Appearance of Ashlar Stone in Cyprus: Issues of Provenance and Use. Mediterranean Archaeology and Archaeometry 2: 37-53.

2012 The Beginnings of Pyrotechnology in Cyprus. International Journal of Architectural Heritage 6: 172-199.

Regev, Lior, Alexander Zuckerman, Louise Hitchcock, Aren M. Maeir, Steve Weiner, and Elisabetta Boaretto

2010 Iron Age Hydraulic Plaster from Tell Es-Safi/Gather, Israel. Journal of Archaeological Science 37: 3000-3009.

Renfrew, Colin

1969 Trade and Cultural Processes in European Prehistory. Current Anthropology 10(2): 151-169.

Rouchy, J. M., F. Orszag-Sperber, M.-M. Blanc-Valleron, C. Pierre, M. Rivière, N. Combourieu-Nebout, and I. Panayides

2001 Paleoenvironmental Changes at the Messinian-Pliocene Boundary in the Eastern Mediterranean (Southern Cyprus Basins): Significance of the Messinian LagoMare. Sedimentary Geology 145: 93-117.

Roveri, Marco, Rachel Flecker, Wout Krijgsman, Johanna Lofi, Stefano Lugli, Vinicio Manzi, Francisco J. Sierro, Adele Bertini, Angelo Camerlenghi, Gert De Lange, Rob Govers, Frits J. Hilgen, Christian Hübscher, Paul Th. Meijer, and Marius Stoica

2014 The Messinian Salinity Crisis: Past and Future of a Great Challenge for Marine Sciences. Marine Geology 352: 25-58.

Sackett, James R.

1990 Style and Ethnicity in Archaeology: The Case for Isochrestism. In. Margaret W. Conkey and C. A. Hastorf (eds.), The Uses of Style in Archaeology. Cambridge: Cambridge University Press. Pp. 32-43.

Schirmer, Wolfgang

1998 Havara on Cyprus - A Surficial Calcareous Deposit. Eiszeitalter u. Gegenwart 48: 110-117. 
Shahack-Gross, Ruth, Rosa-Maria Albert, Ayelet Gilboa, Orna Nagar-Hilman, Ilan Sharon, and Steve Weiner

2005 Geoarchaeology in an Urban Context: The Uses of Space in a Phoenician Monumental Building at Tel Dor (Israel). Journal of Archaeological Science 32: $1417-1431$.

Shahack-Gross, Ruth, and Israel Finkelstein

2008 Subsistence Practices in an Arid Environment: A Geoarchaeological Investigation in an Iron Age Site, the Negev Highlands, Israel. Journal of Archaeological Science 35: 965-982.

South, Alison K.

1980 Kalavasos-Ayios Dhimitrios 1979: A Summary Report. Report of the Department of Antiquities, Cyprus. Pp. 22-53.

1982 Kalavasos-Ayios Dhimitrios 1980-1981. Report of the Department of Antiquities, Cyprus. Pp. 60-68.

1983 Kalavasos-Ayios Dhimitrios 1982. Report of the Department of Antiquities, Cyprus. Pp. 92-116.

1984a Kalavasos-Ayios Dhimitrios 1983. Report of the Department of Antiquities, Cyprus. Pp. 14-41.

1984b Kalavasos-Ayios Dhimitrios and the Late Bronze Age of Cyprus. In. Vassos Karageorghis and James D. Muhly (eds.), Cyprus at the Close of the Late Bronze Age. Nicosia: A. C. Levantis Foundation. Pp. 11-18.

1988 Kalavasos-Ayios Dhimitrios 1987: An Important Ceramic Group From Building X. Report of the Department of Antiquities, Cyprus. Pp. 223-228.

1991 Kalavasos-Ayios Dhimitrios 1990. Report of the Department of Antiquities, Cyprus. Pp. 131-139.

1995 Urbanism and Trade in the Vasilikos Valley in the Late Bronze Age. In. Stephen Bourke and Jean-Paul Descoeudres (eds.), Trade, Contact, and the Movement of Peoples in the Eastern Mediterranean: Studies in Honour of J. Basil Hennessy. Ann Arbour: University of Michigan. Pp. 187-197.

1997 Kalavasos-Ayios Dhimitrios 1992-1996. Report of the Department of Antiquities, Cyprus. Pp. 151-175. 
2012 Tinker, Tailor, Farmer, Miner: Metals in the Late Bronze Age Economy at Kalavasos. In. Vasiliki Kassianidou and George Papasavvas (eds.), Eastern Mediterranean Metallurgy and Metalwork in the Second Millennium BC. Oxford: Oxbow Books. Pp. 35-47.

2013 Moving Into the World: A Region of Southern Cyprus in the Late Bronze Age. In. A. Bernard Knapp, Jennifer M. Webb and Andrew McCarthy (eds.), J. R. B. Stewart: An Archaeological Legacy. Uppsala: Åströms Förlag. Pp. 149-160.

2014 From Pots to People: Estimating Population for Late Bronze Age Kalavasos. In. Jennifer M. Webb (ed.), Structure, Measurement and Meaning: Studies on Prehistoric Cyprus in Honour of David Frankel. Studies in Mediterranean Archaeology 143: 69-77. Uppsala: Äströms Förlag.

South, Alison K. and Pamela J. Russell

1993 Mycenaean Pottery and Social Hierarchy at Kalavasos-Ayios Dhimitrios, Cyprus. In. A. J. B. Wace and Carl W. Blegen (eds.), Pottery as Evidence for Trade in the Aegean Bronze Age, 1939-1989: Proceedings of the International Conference Held at the American School of Classical Studies at Athens, Athens, December 23 1989. Amsterdam: J. C. Gieben. Pp. 303-310.

South, Alison K. and Ian Todd

1997 The Vasilikos Valley and the Aegean from the Neolithic to the Late Bronze Age. In. Cyprus and the Aegean in Antiquity from the Prehistoric Period to the Seventh Century AD. Nicosia: Department of Antiquities.

Stoops, Georges

2003 Guidelines for Analysis and Description of Soil and Regolith Thin Sections. Madison: Soil Science Society of America, Inc.

Stos-Gale, Z. A., and N. H. Gale

2009 Metal Provenancing Using Lead Isotopes and the Oxford Archaeological Lead Isotope Database (OXALID). Archaeological Anthropological Science 1: 195213.

Strabo

24 CE Geographica.

Strasser Thomas F., Curtis Runnels, and Claudio Vita-Finzi

2016 A Possible Paleolithic Hand Axe from Cyprus. Antiquity Project Gallery 90, 350.

Theodoridou, Magdalini, Ioannis Ioannou, and Maria Philokyprou

2013 New Evidence of Early Use of Artificial Pozzolanic Material in Mortars. Journal of Archaeological Science 40: 3263-3269 
Todd, Ian A.

1987 Vasilikos Valley Project 6: Excavations at Kalavasos-Tenta Vol. 1 (SIMA LXXI:6). Götenborg: Paul Åströms Förlag.

1998 Kalavasos-Tenta. Nicosia: Bank of Cyprus Cultural Foundation.

2001 Kalavasos Tenta Revisited. In. S. Swiny (ed.), The Earliest Prehistory of Cyprus: From Colonization to Exploration (American Schools of Oriental Research, Archaeological Report 5). Boston: American Schools of Oriental Research. Pp. 95-107

2004 Field Survey in the Vasilikos Valley. British School at Athens Studies Vol. 11, Archaeological Field Survey in Cyprus: Past History, Future Potentials. Athens: British School at Athens. Pp. 43-54.

Todd, Ian, A. and Alison K. South

1992 The Late Bronze Age in the Vasilikos Valley: Recent Research. In. G. C. Ioannides (eds.), Studies in Honour of Vassos Karageorghis. Nicosia: Society of Cypriot Studies. Pp. 191-204.

Turco, F., P. Davit, F. Chelazzi, A. Borghi, L. Bombardieri, and L. Operti

2016 Characterization of Late Prehistoric Plasters and mortars from Erimi - Laonin, Tou Porakou (Limassol, Cyprus). Archaeometry 58(2): 284-296.

Urban, Thomas M., Jeffrey F. Leon, Sturt W. Manning, and Kevin D. Fisher

2014 High Resolution GPR Mapping of Late Bronze Age Architecture at KalavasosAyios Dhimitrios, Cyprus. Journal of Applied Geophysics 107: 129-136.

Weiner, Stephen

2010 Microarchaeology: Beyond the Visible Archaeological Record. Cambridge: Cambridge University Press.

Weizmann Institute of Science

n.d. Infrared Standards Library. Rehovot, Kimmel Center for Archaeological Science. Updated September 2014.

Wilson, P.

1988 Domestication of the Human Species. New Haven: Yale University Press.

Wright, George R. H.

1992 Ancient Buildings in Cyprus. Leiden: Brill. 
Master's Thesis - P Wallace; McMaster University - Anthropology

Appendix 
Master's Thesis - P Wallace; McMaster University - Anthropology

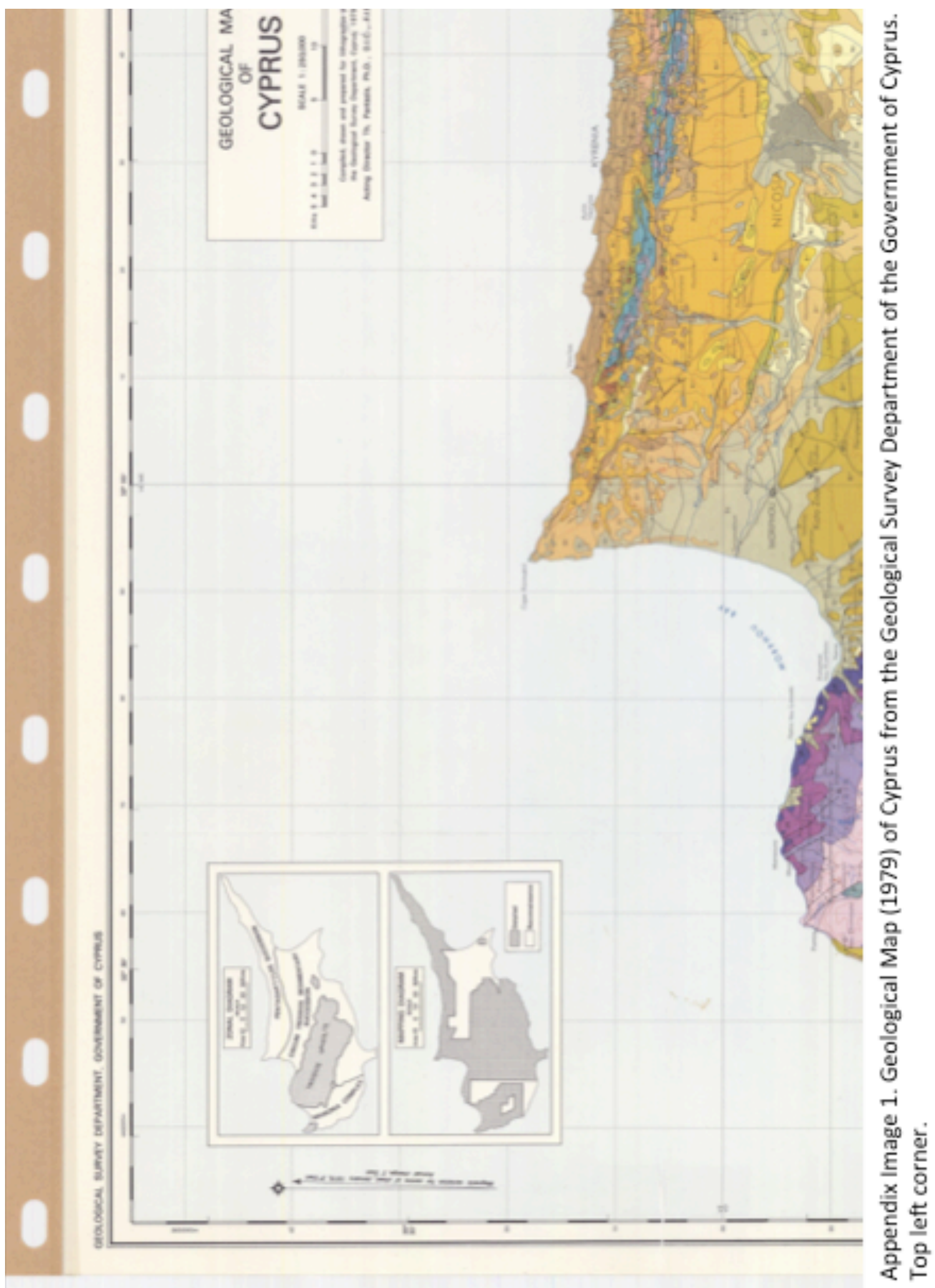


Master's Thesis - P Wallace; McMaster University - Anthropology

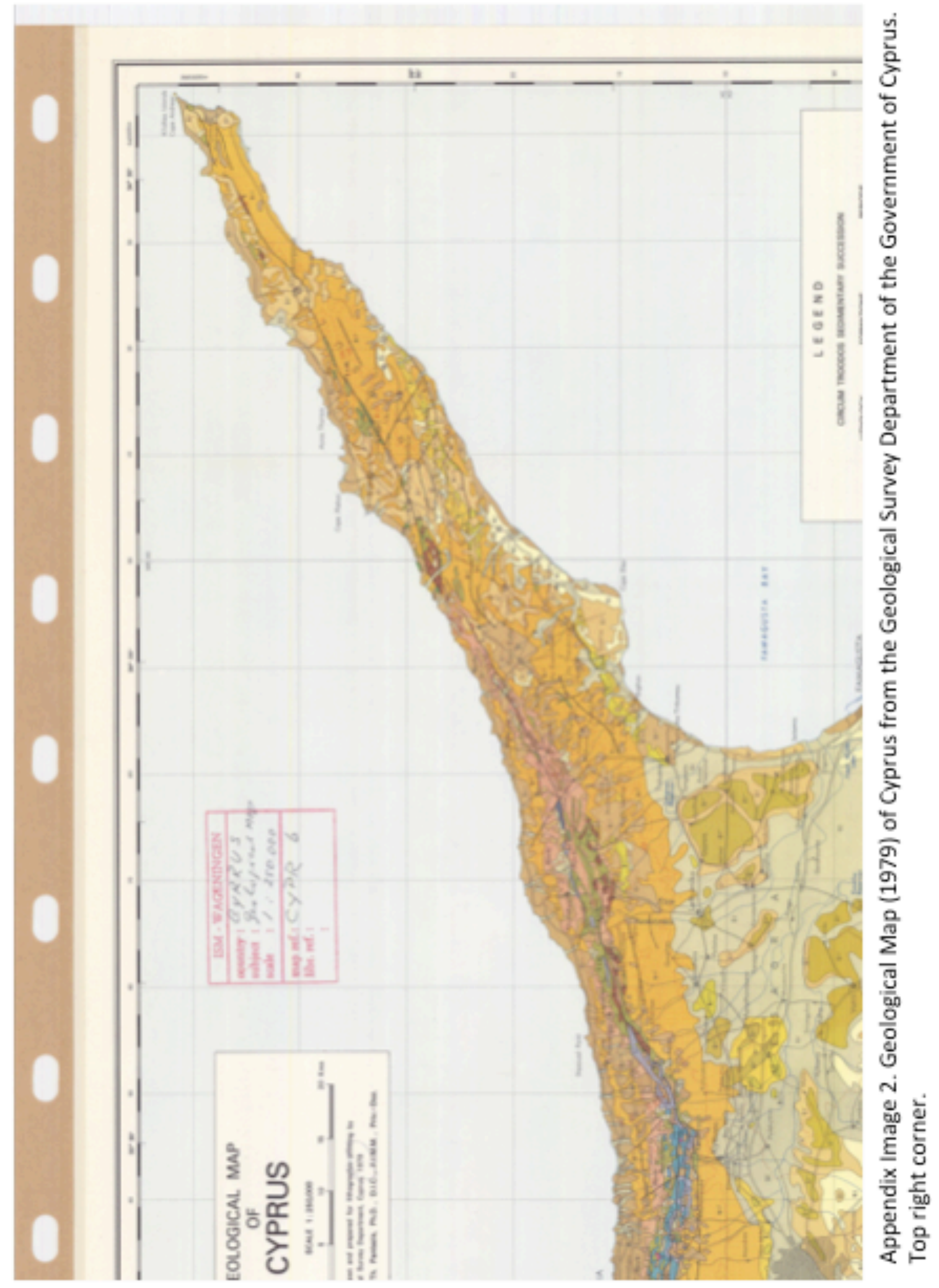


Master's Thesis - P Wallace; McMaster University - Anthropology

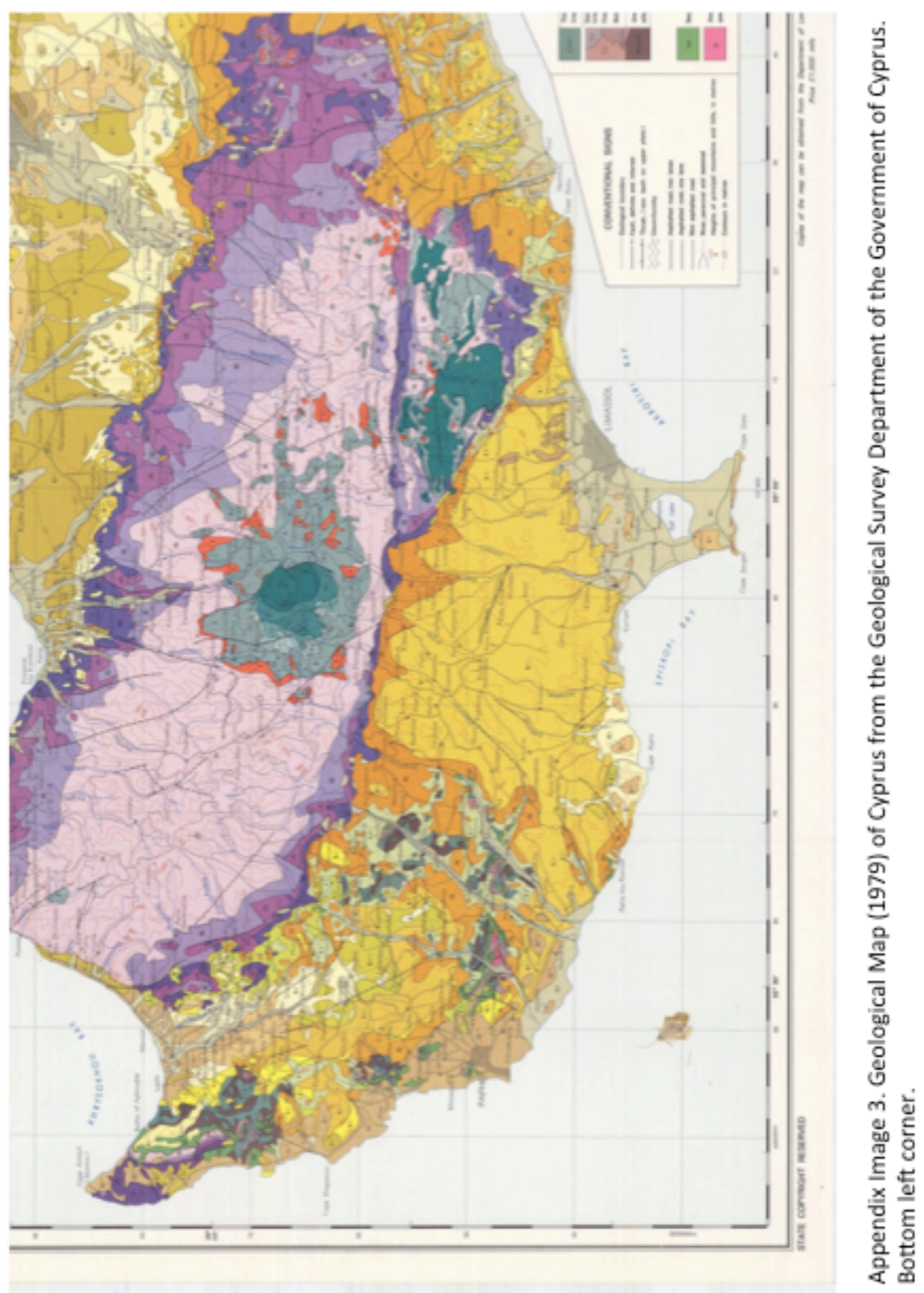


Master's Thesis - P Wallace; McMaster University - Anthropology

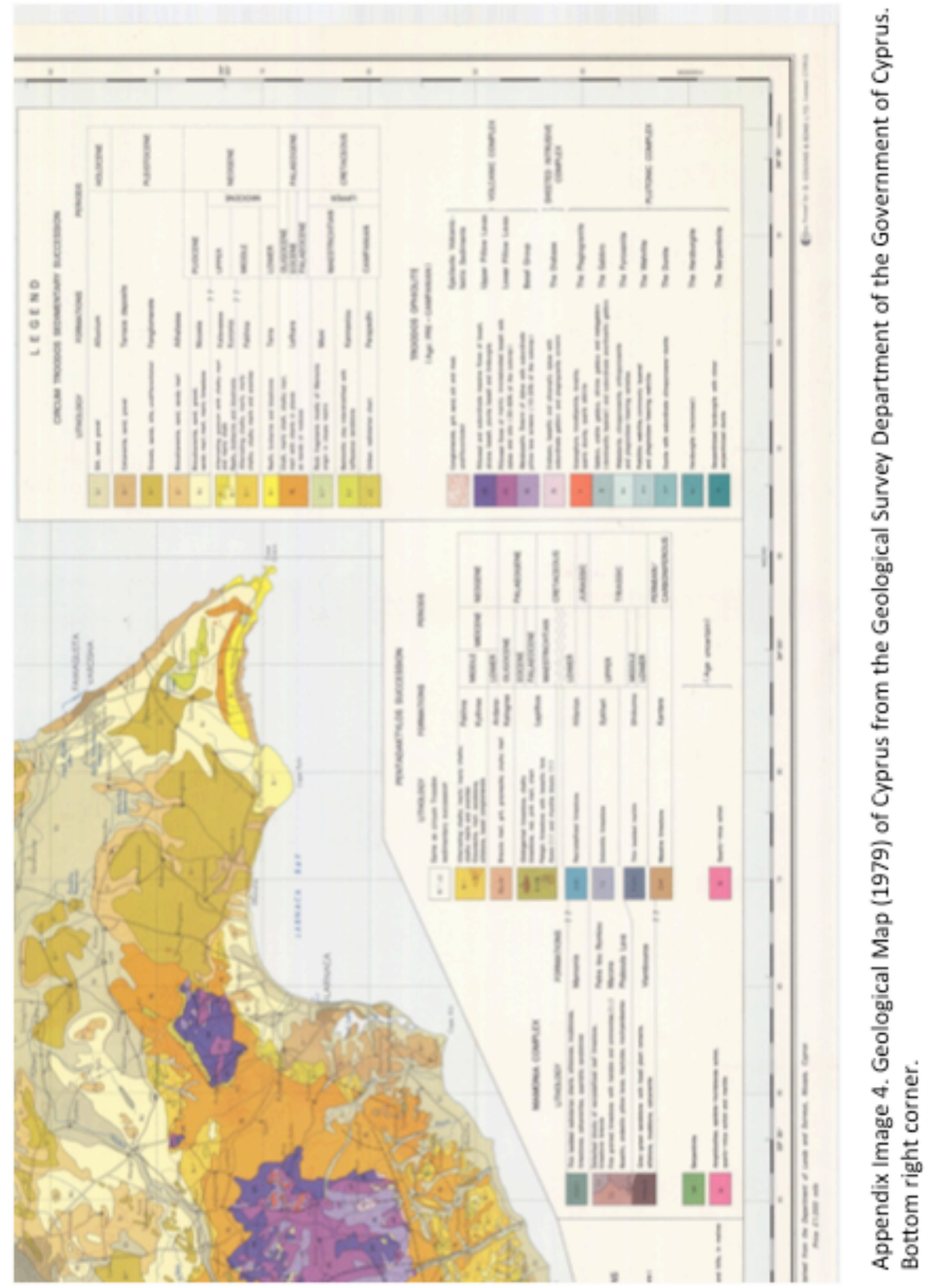


Master's Thesis - P Wallace; McMaster University - Anthropology

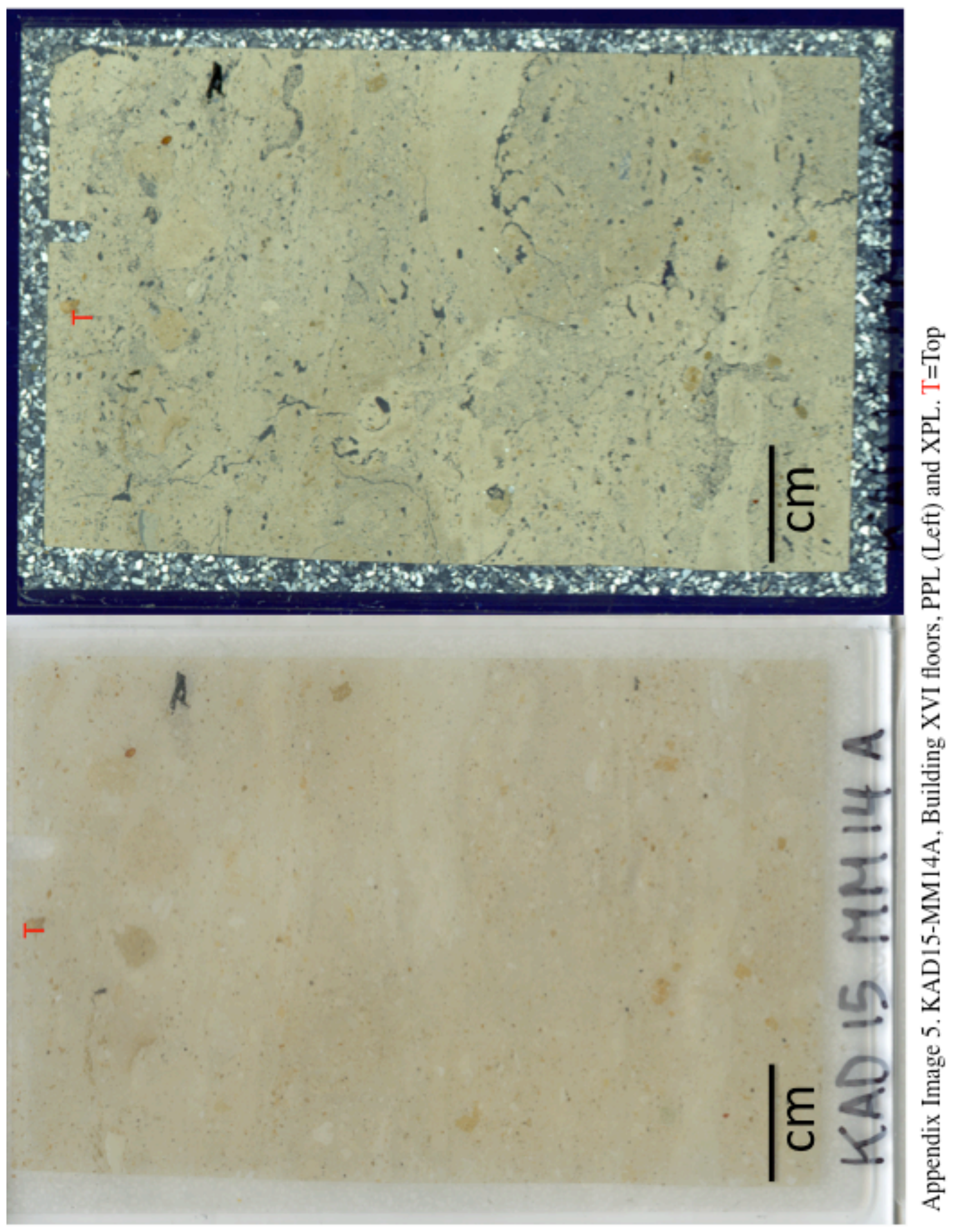


Master's Thesis - P Wallace; McMaster University - Anthropology

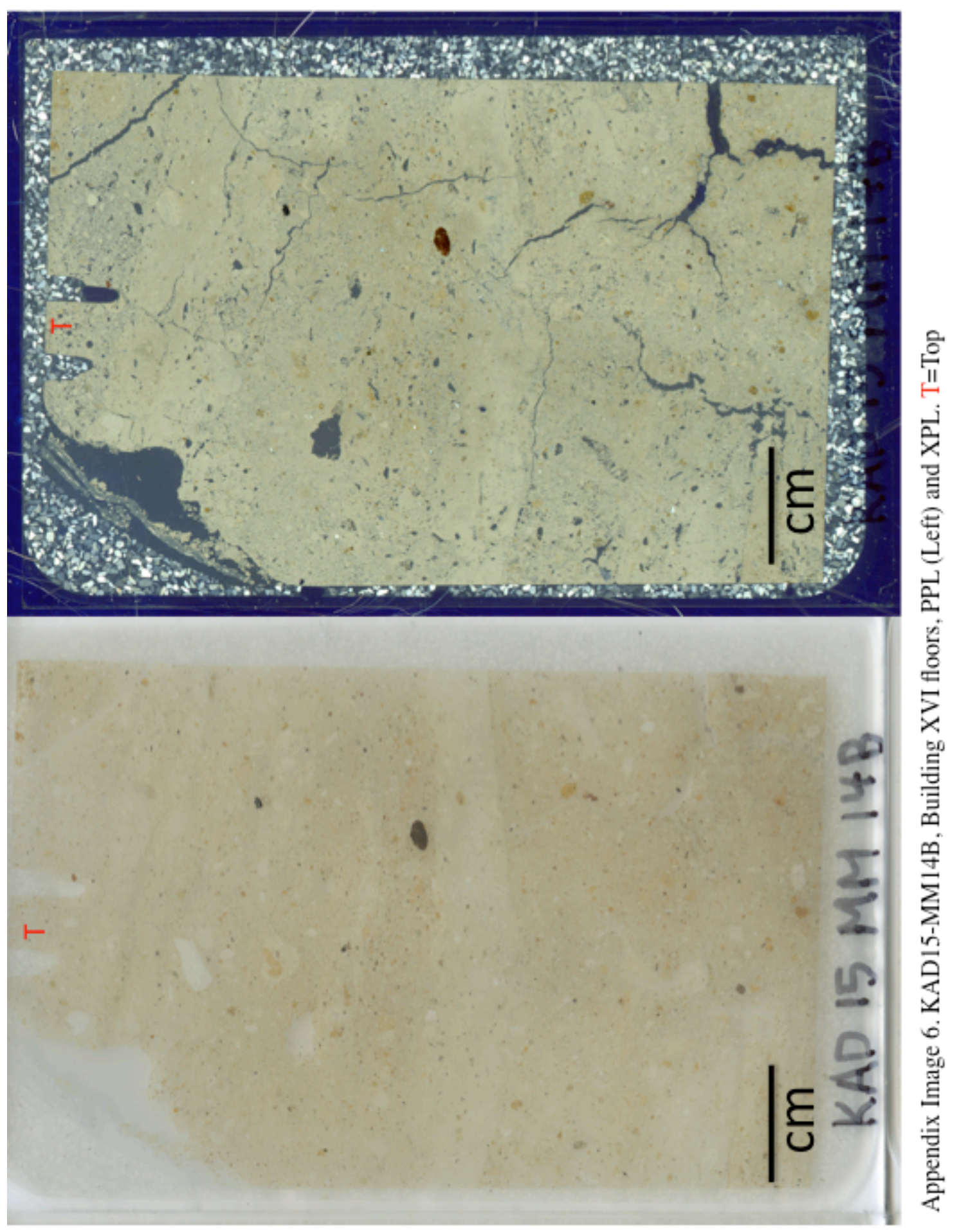


Master's Thesis - P Wallace; McMaster University - Anthropology

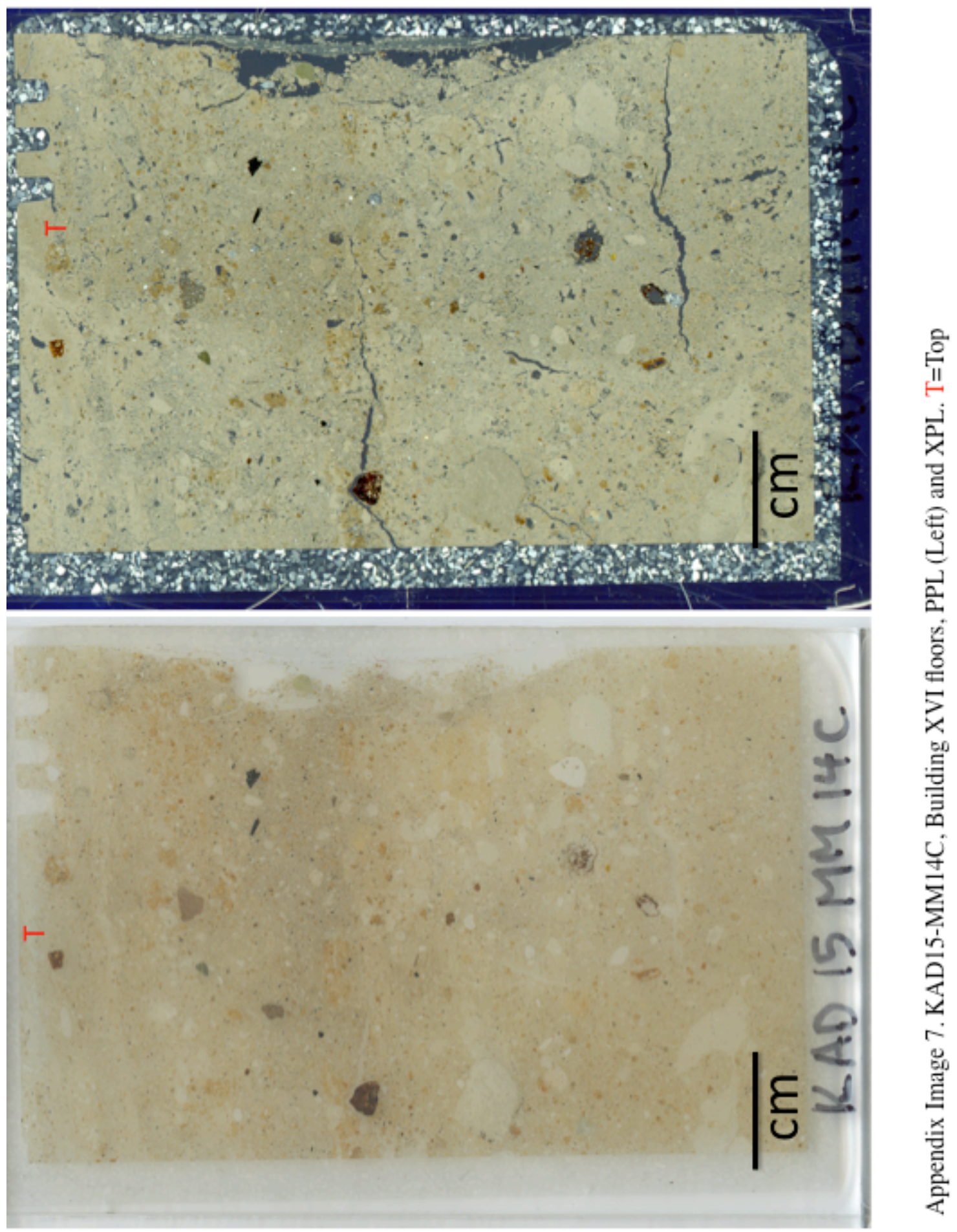




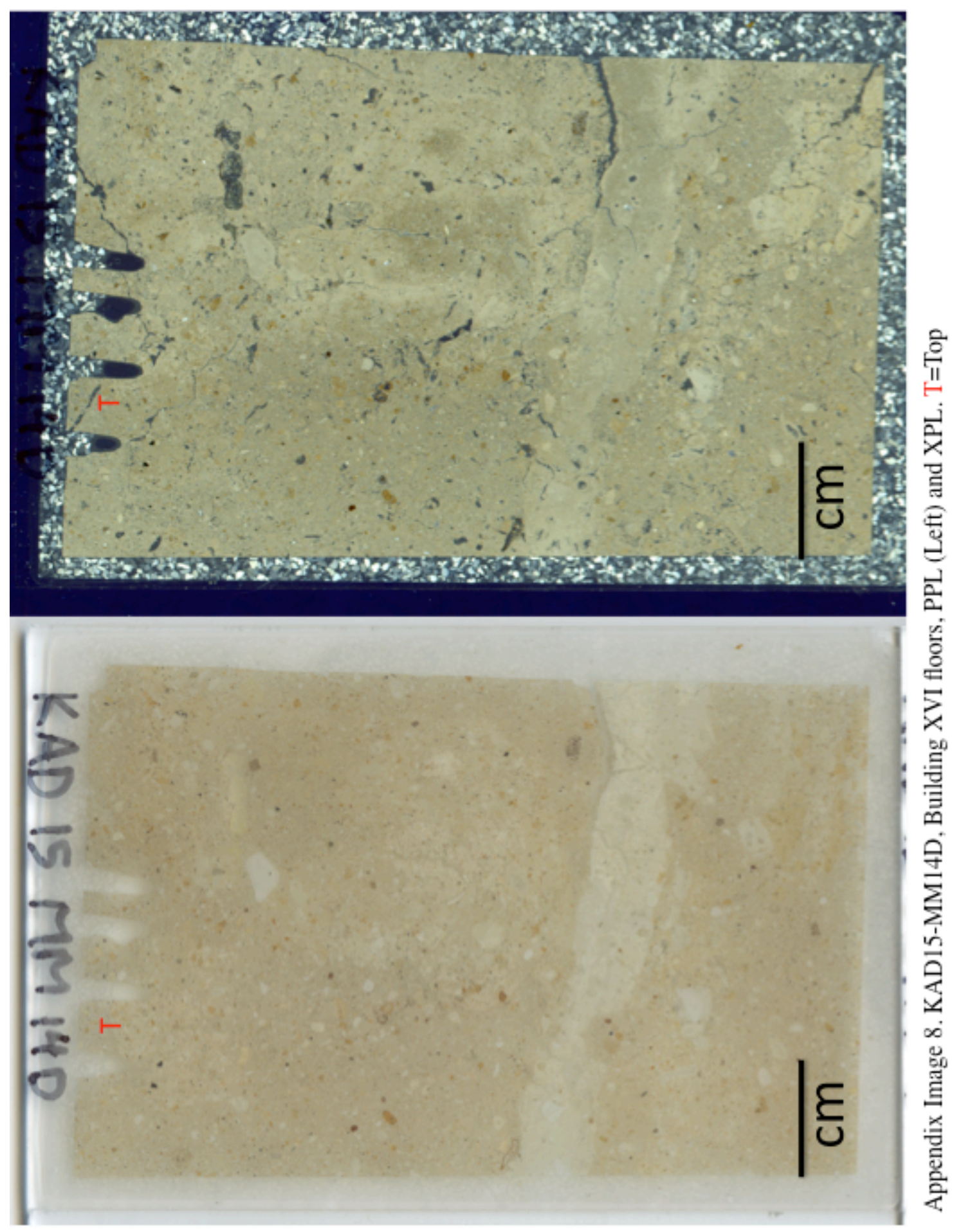


Master's Thesis - P Wallace; McMaster University - Anthropology

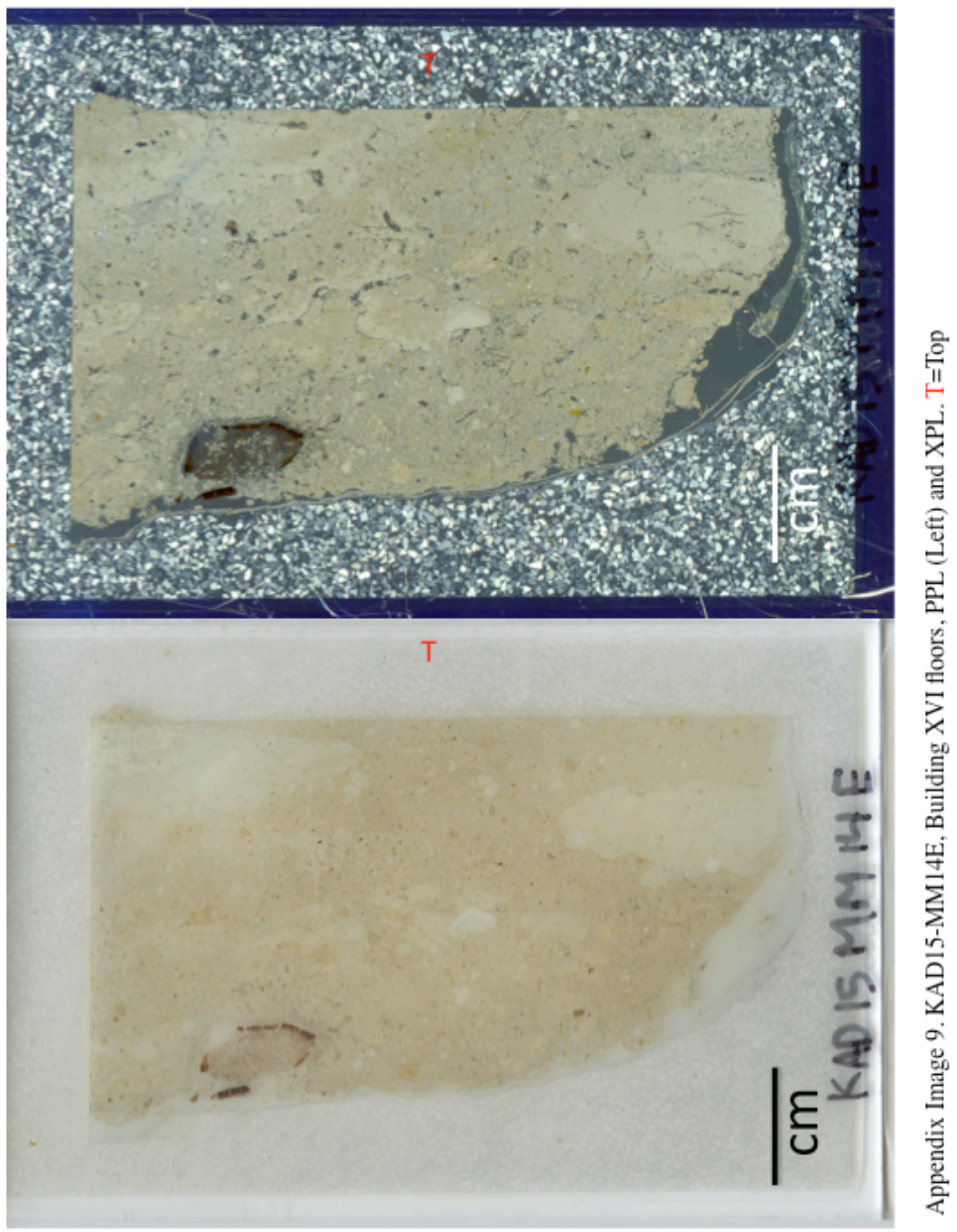


Master's Thesis - P Wallace; McMaster University - Anthropology

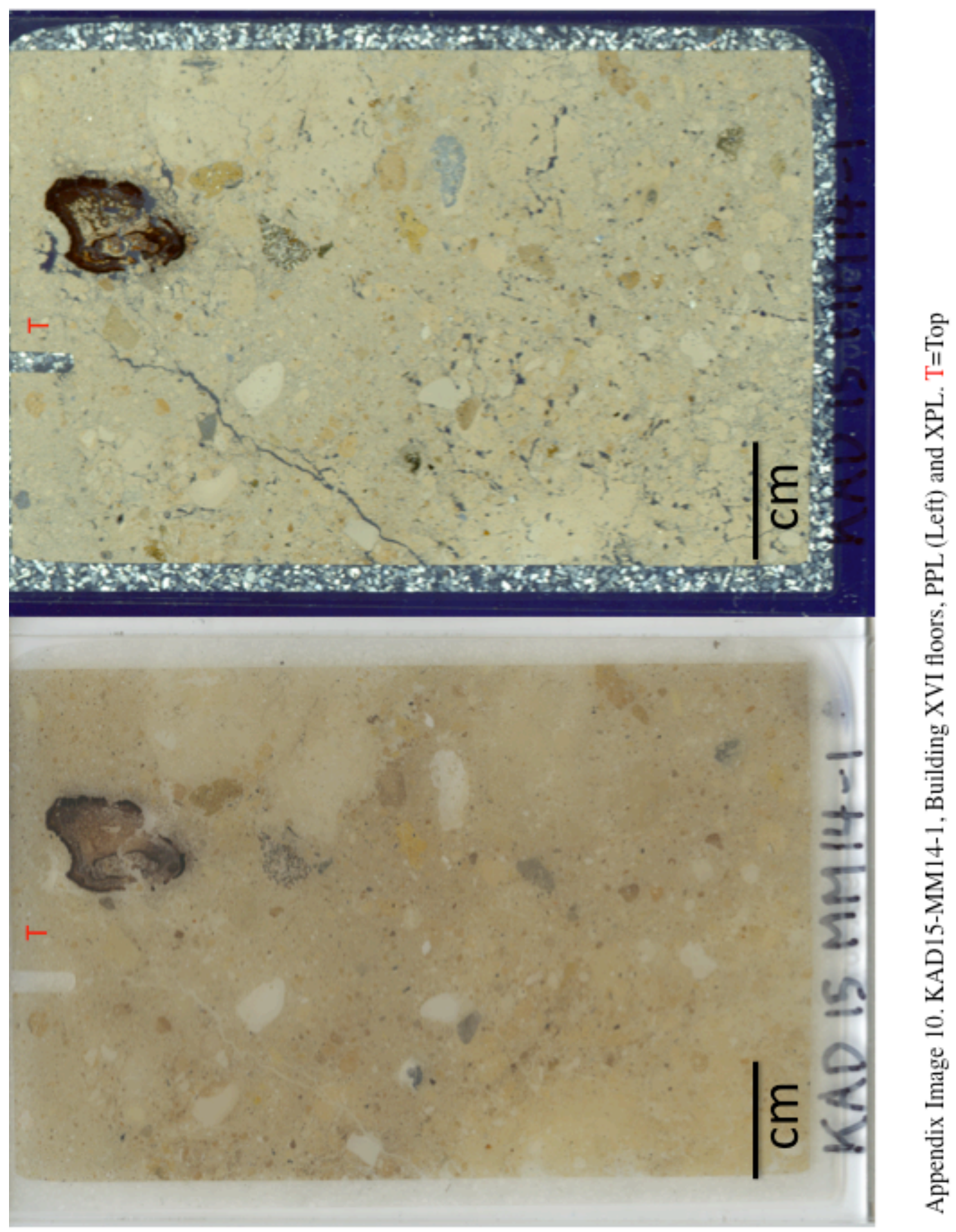


Master's Thesis - P Wallace; McMaster University - Anthropology

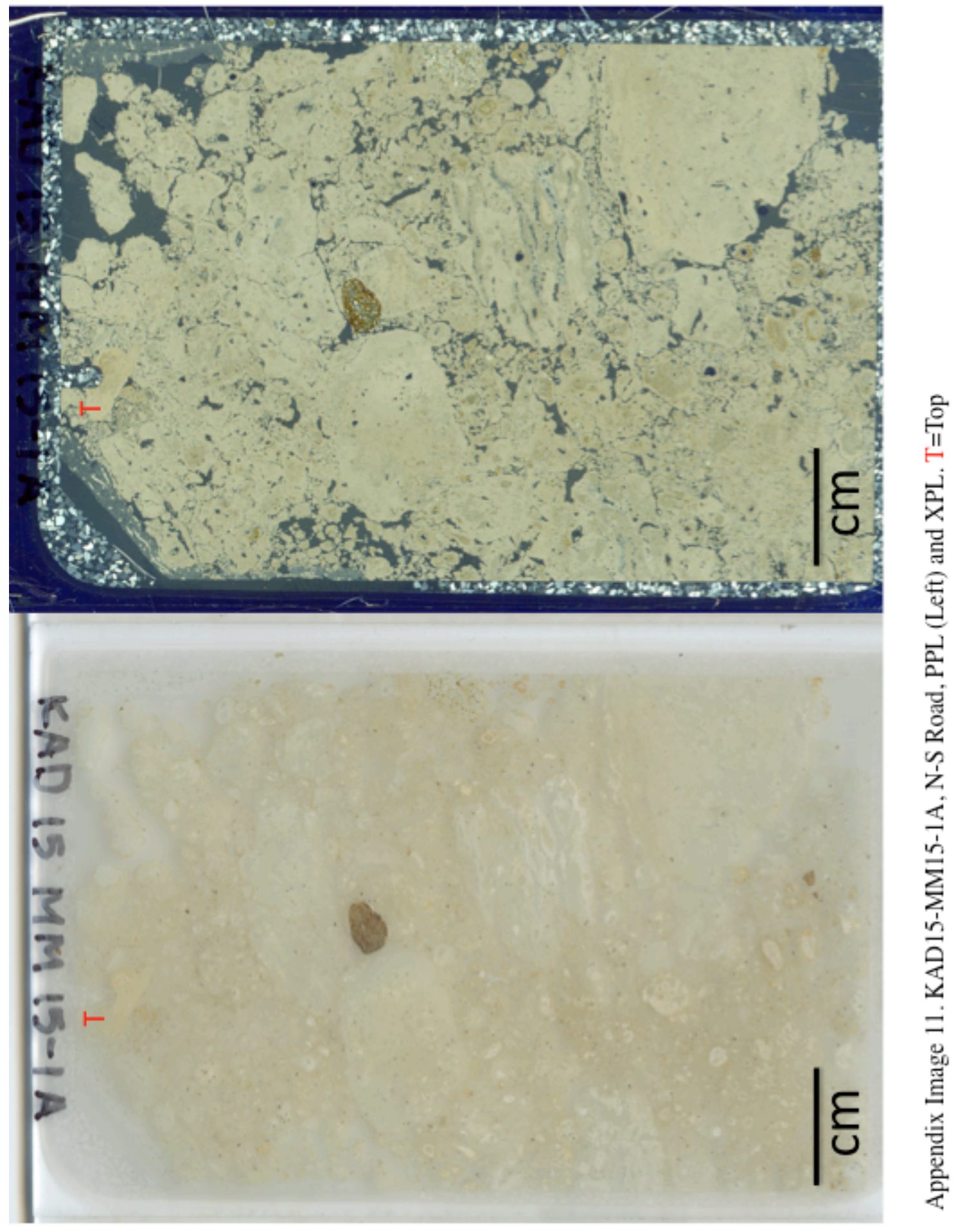


Master's Thesis - P Wallace; McMaster University - Anthropology

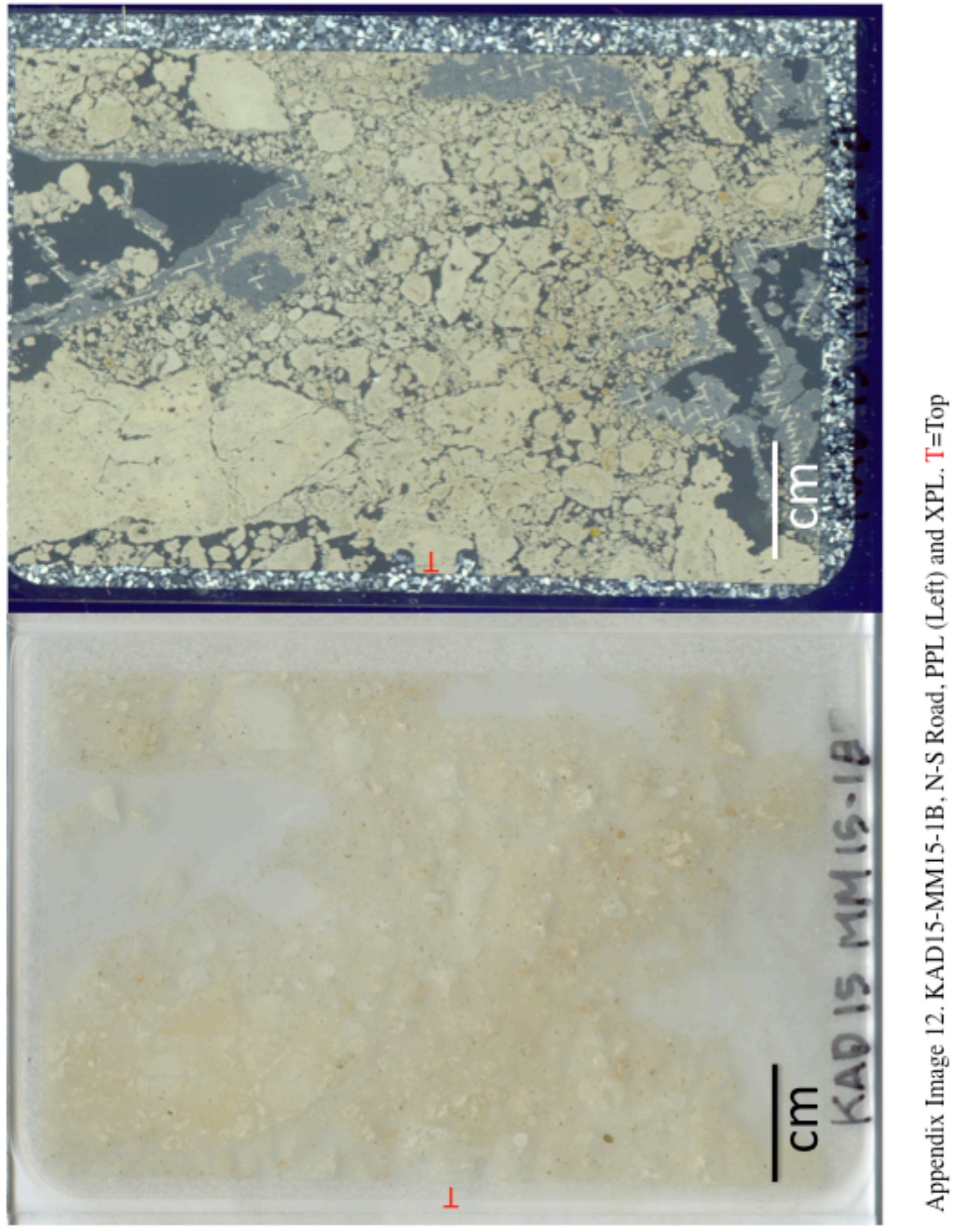


Master's Thesis - P Wallace; McMaster University - Anthropology

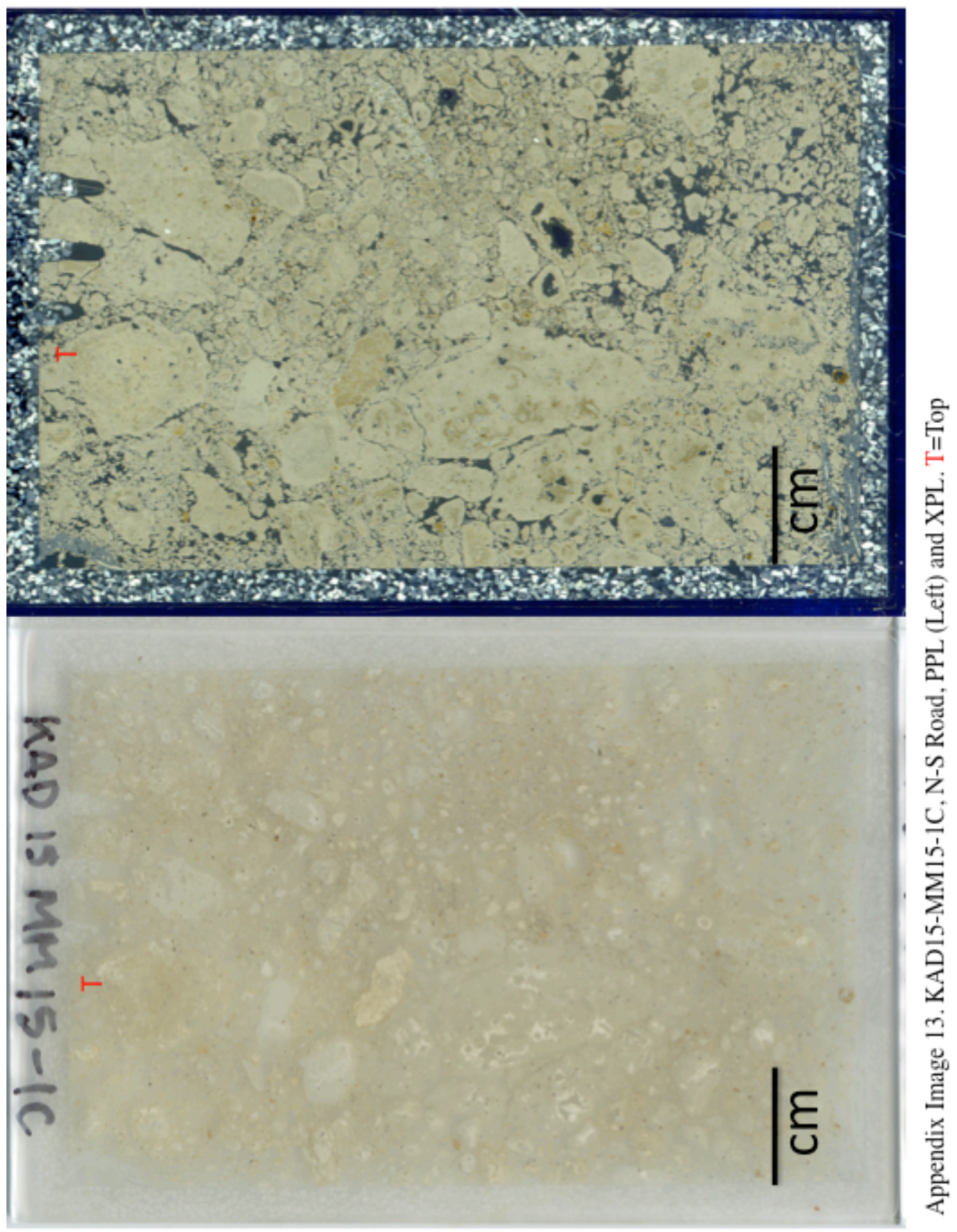


Master's Thesis - P Wallace; McMaster University - Anthropology

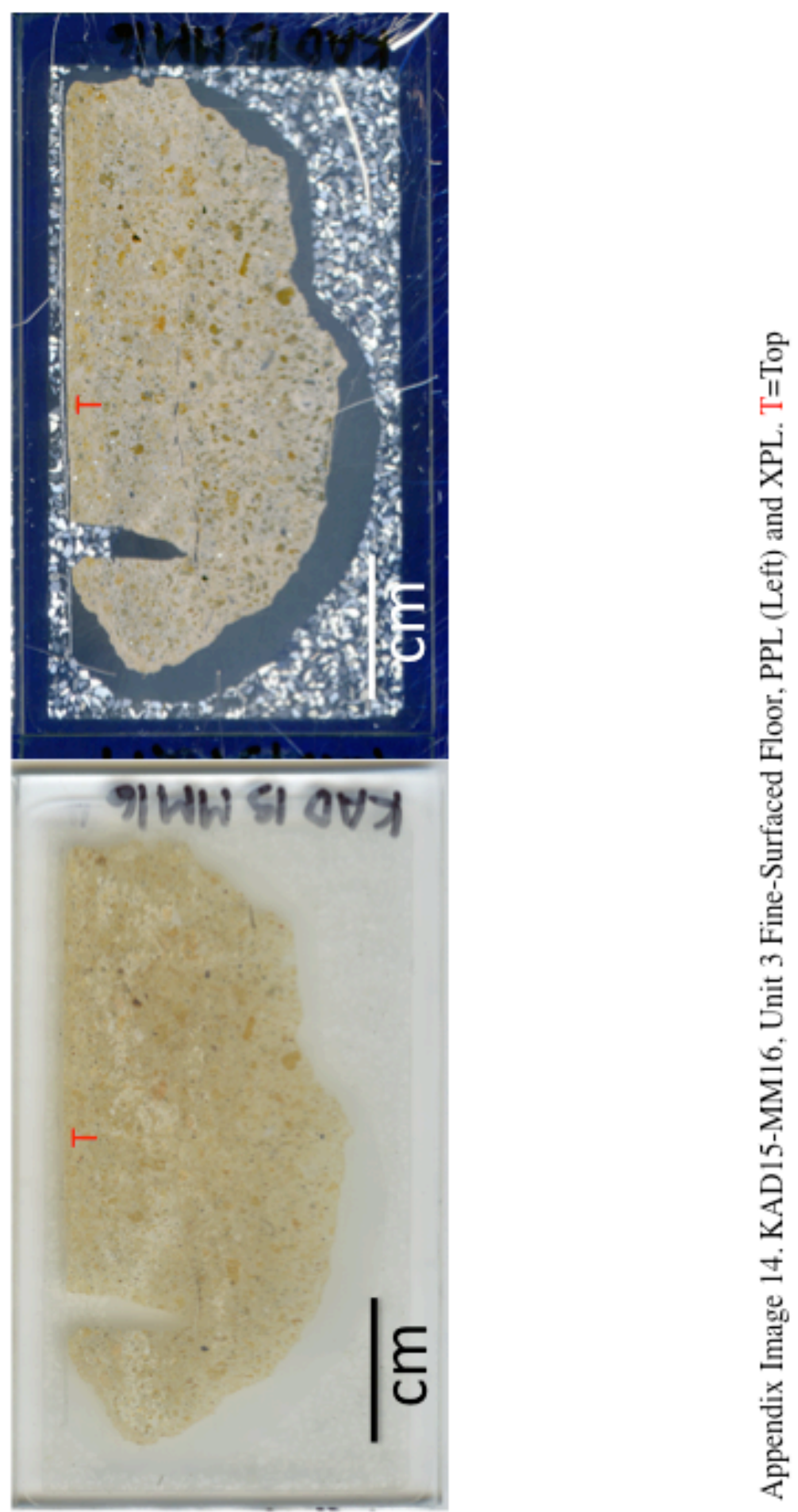


Master's Thesis - P Wallace; McMaster University - Anthropology

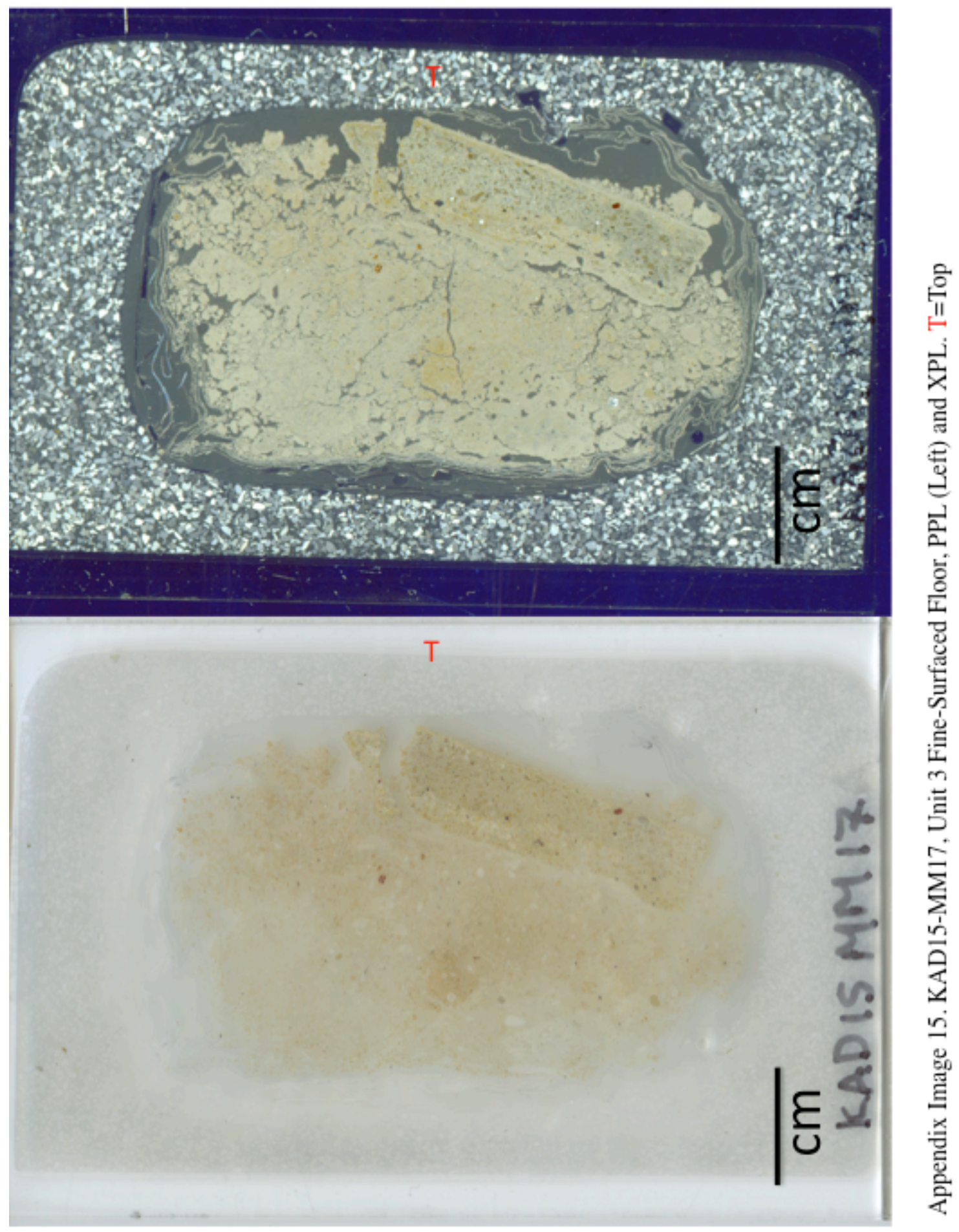


Master's Thesis - P Wallace; McMaster University - Anthropology

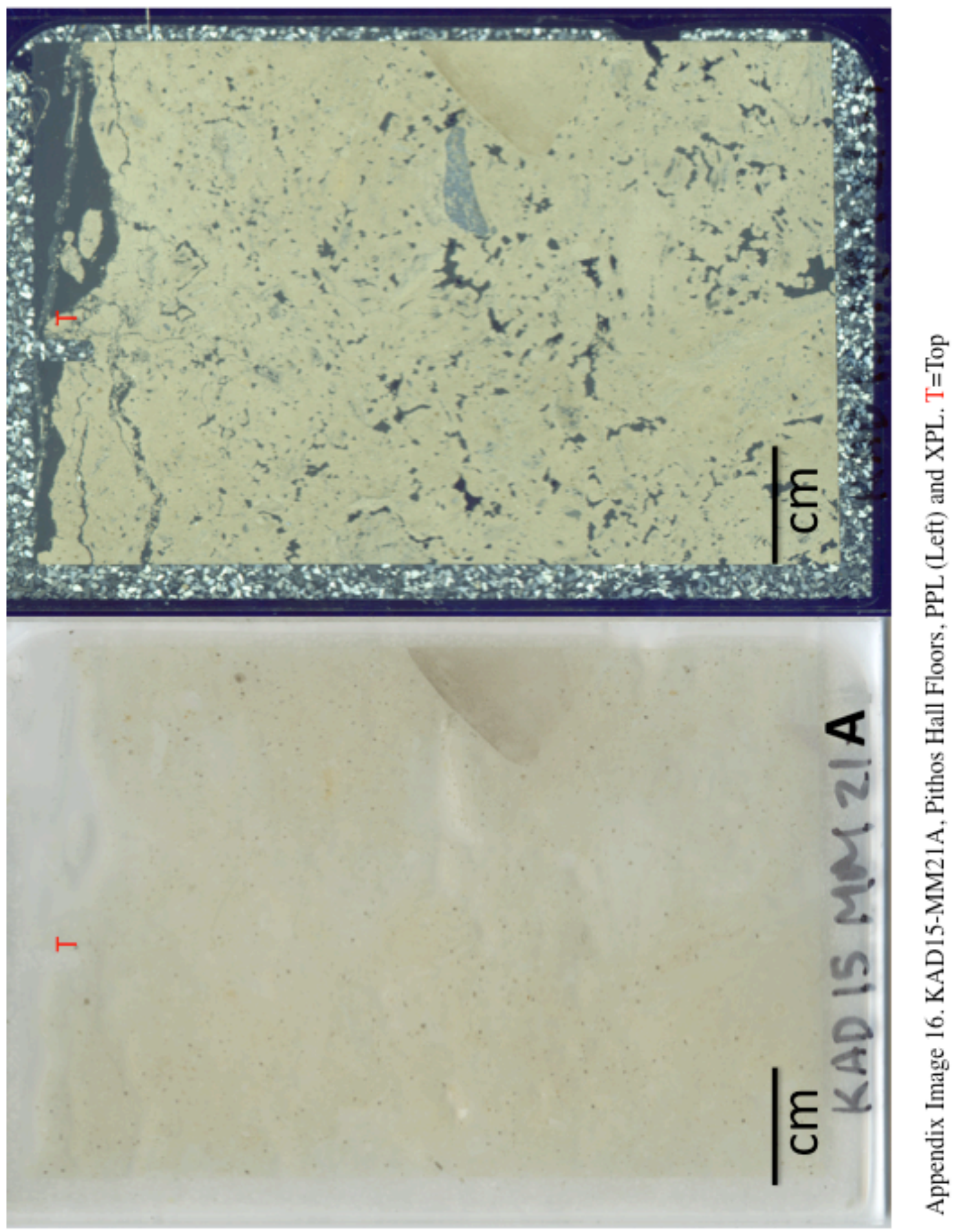


Master's Thesis - P Wallace; McMaster University - Anthropology

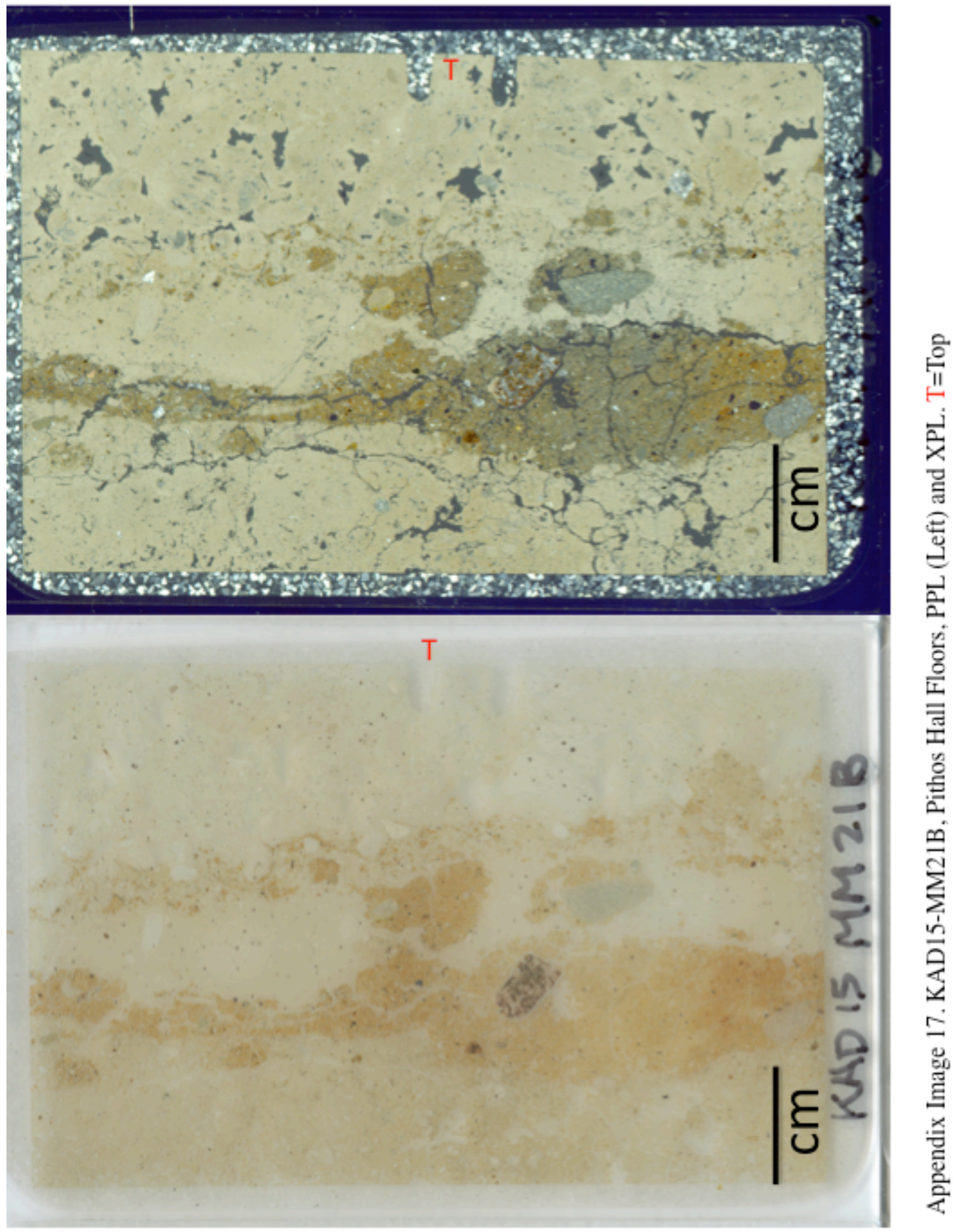


Master's Thesis - P Wallace; McMaster University - Anthropology

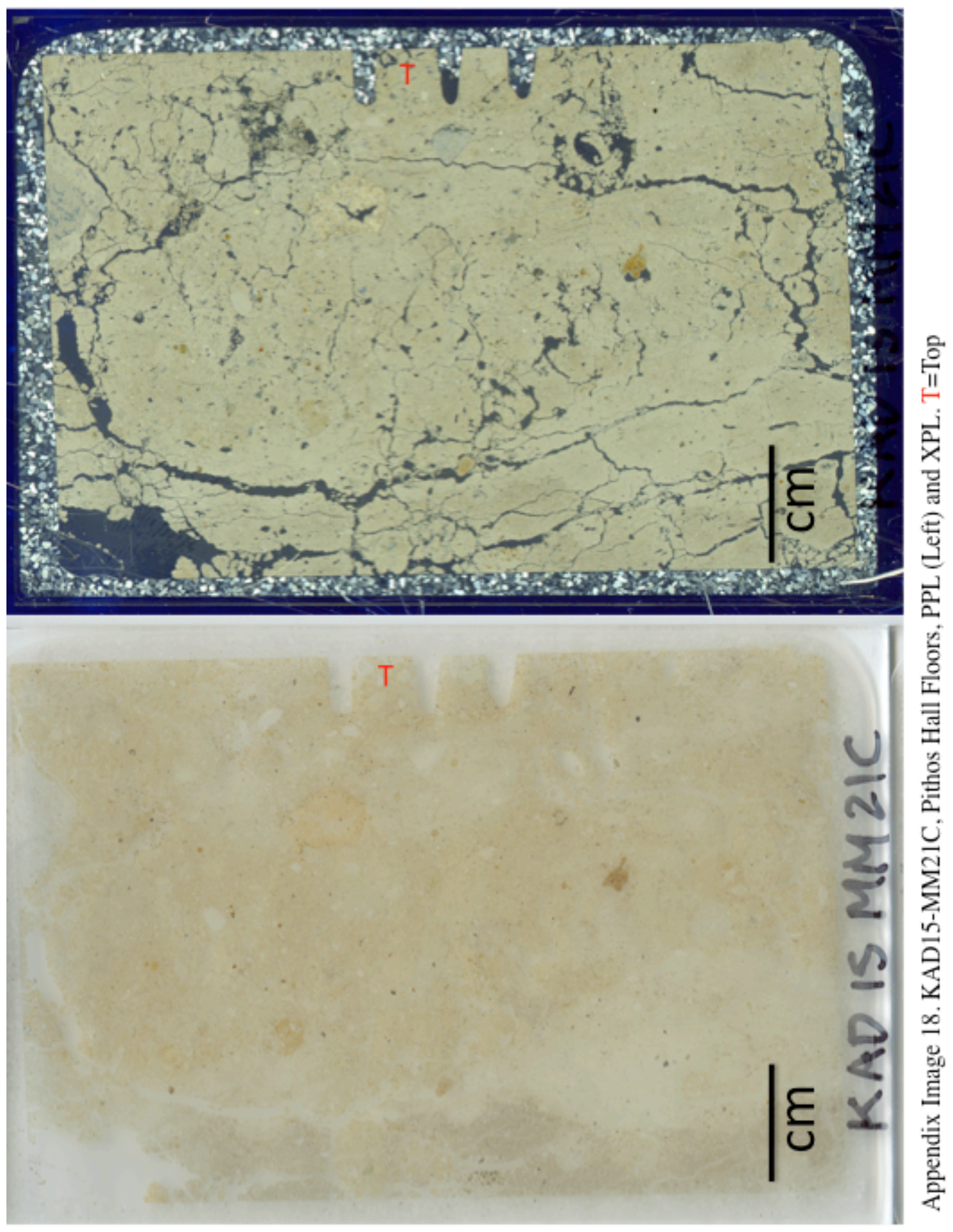


Master's Thesis - P Wallace; McMaster University - Anthropology

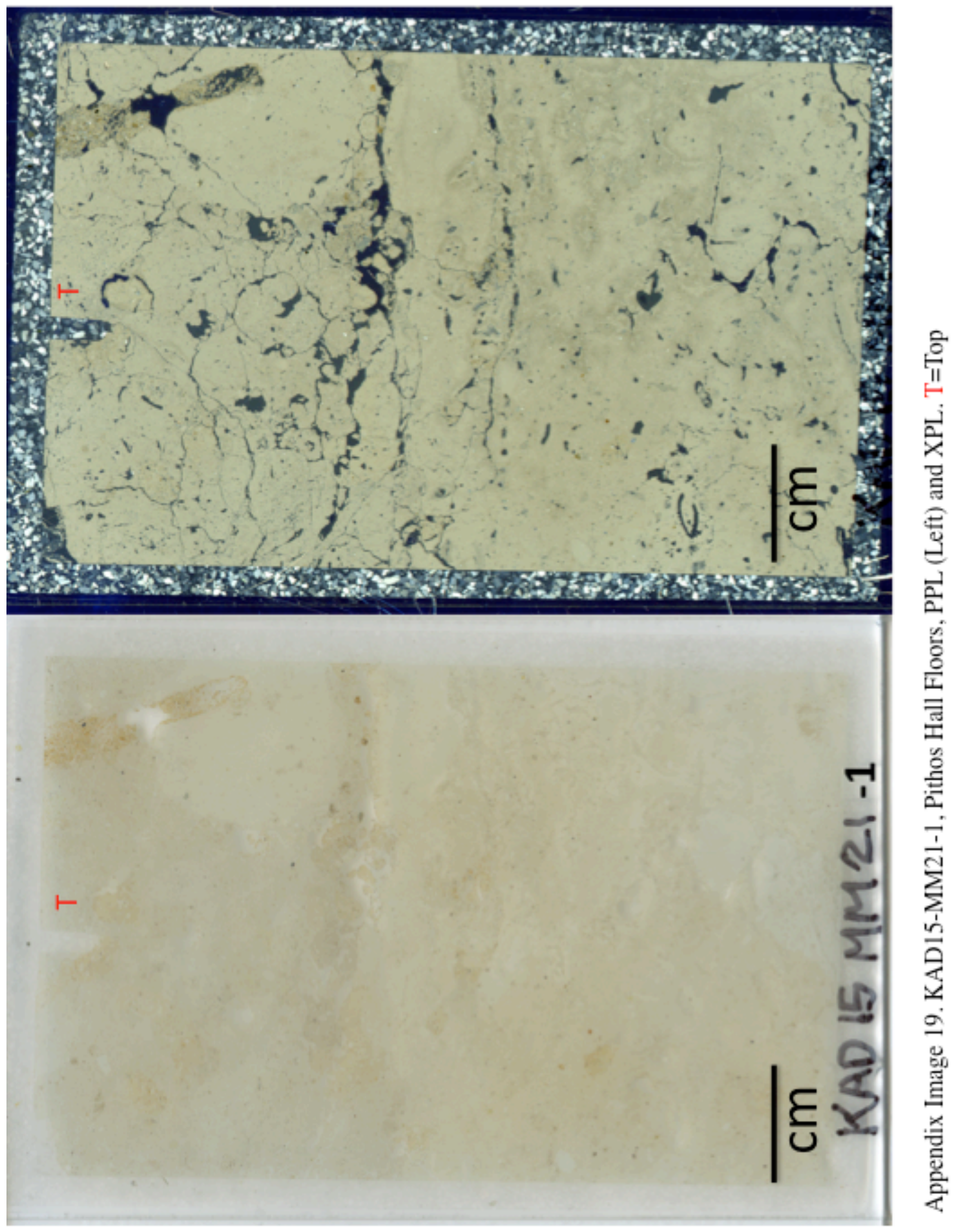


Master's Thesis - P Wallace; McMaster University - Anthropology

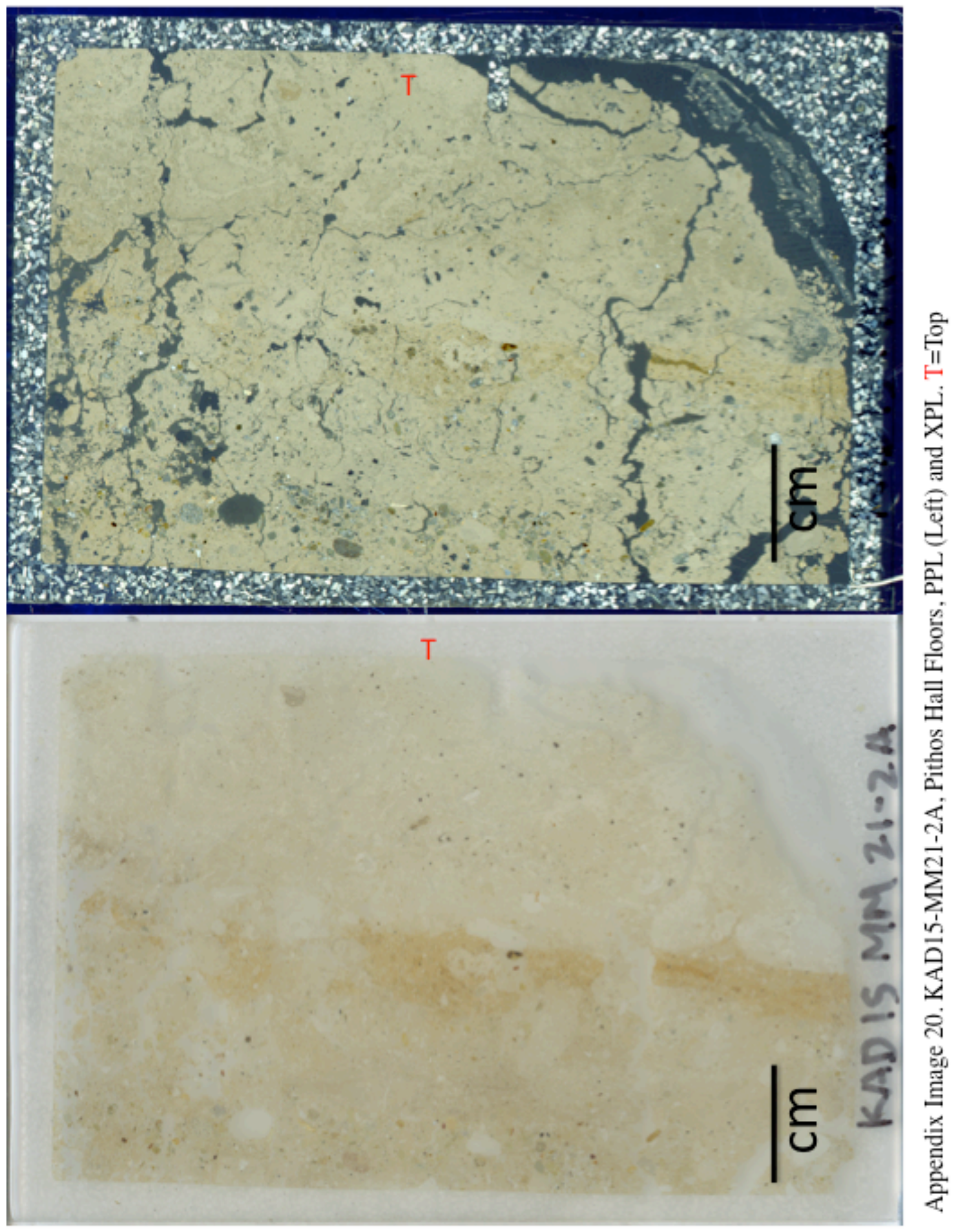


Master's Thesis - P Wallace; McMaster University - Anthropology

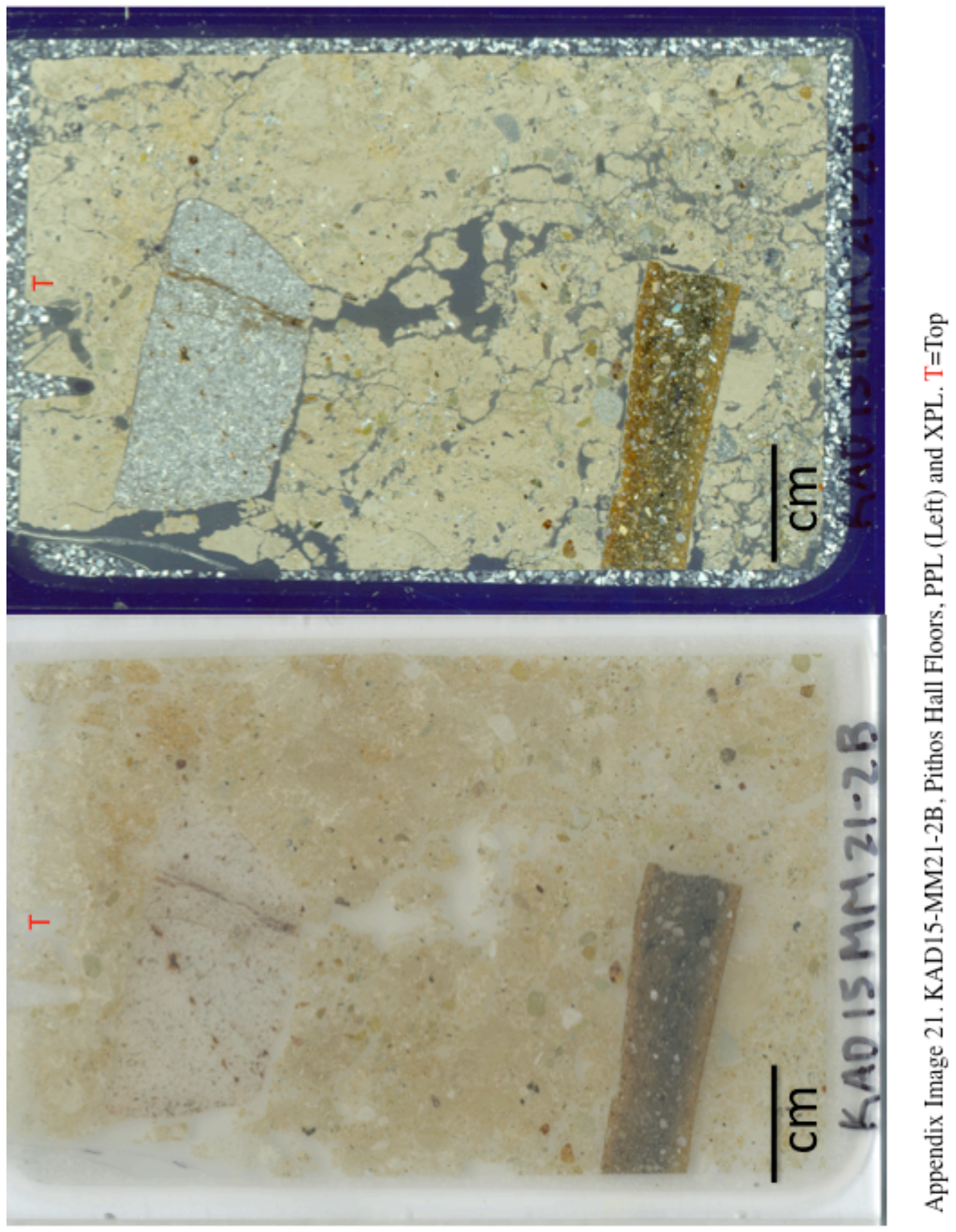


Master's Thesis - P Wallace; McMaster University - Anthropology

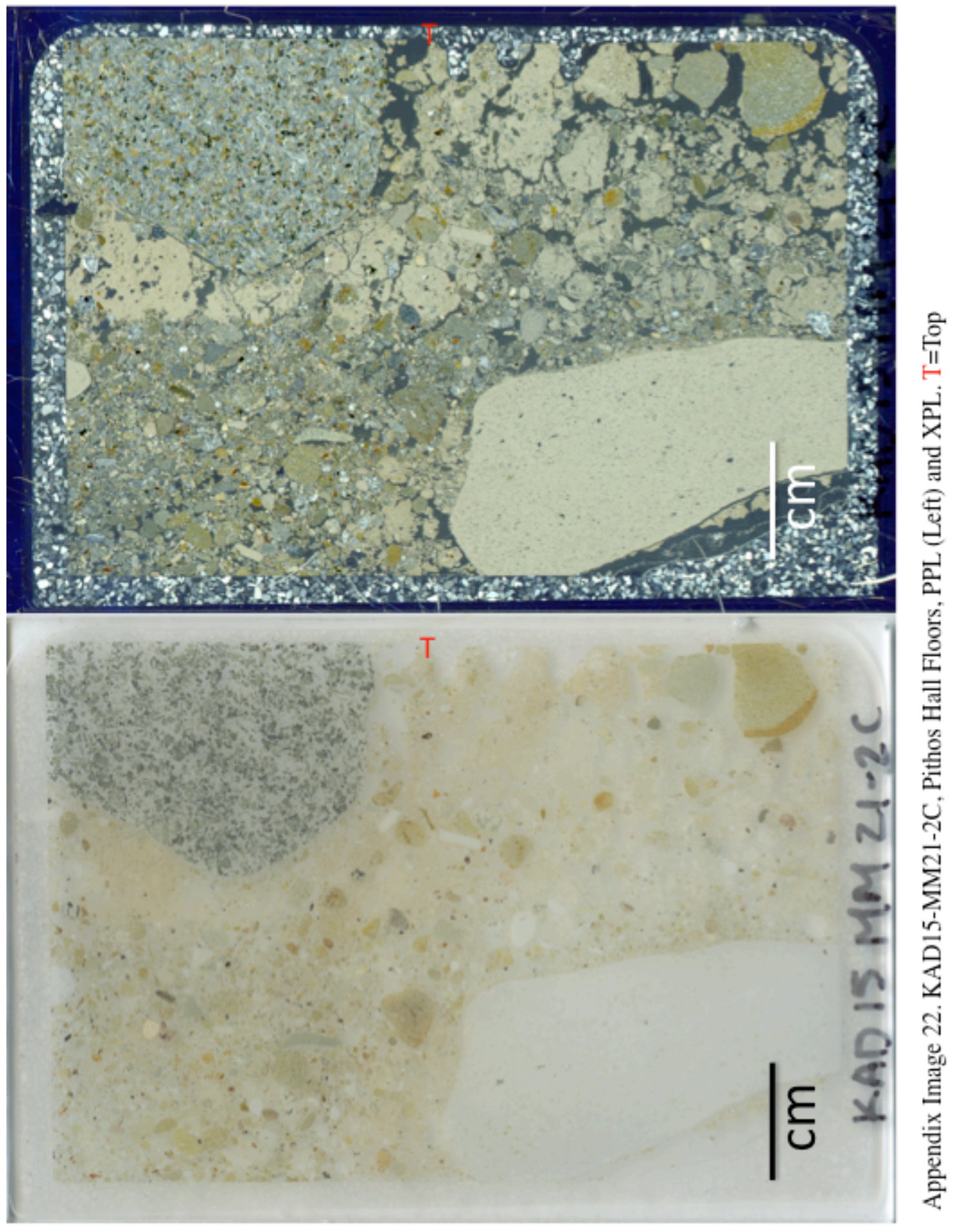


Master's Thesis - P Wallace; McMaster University - Anthropology

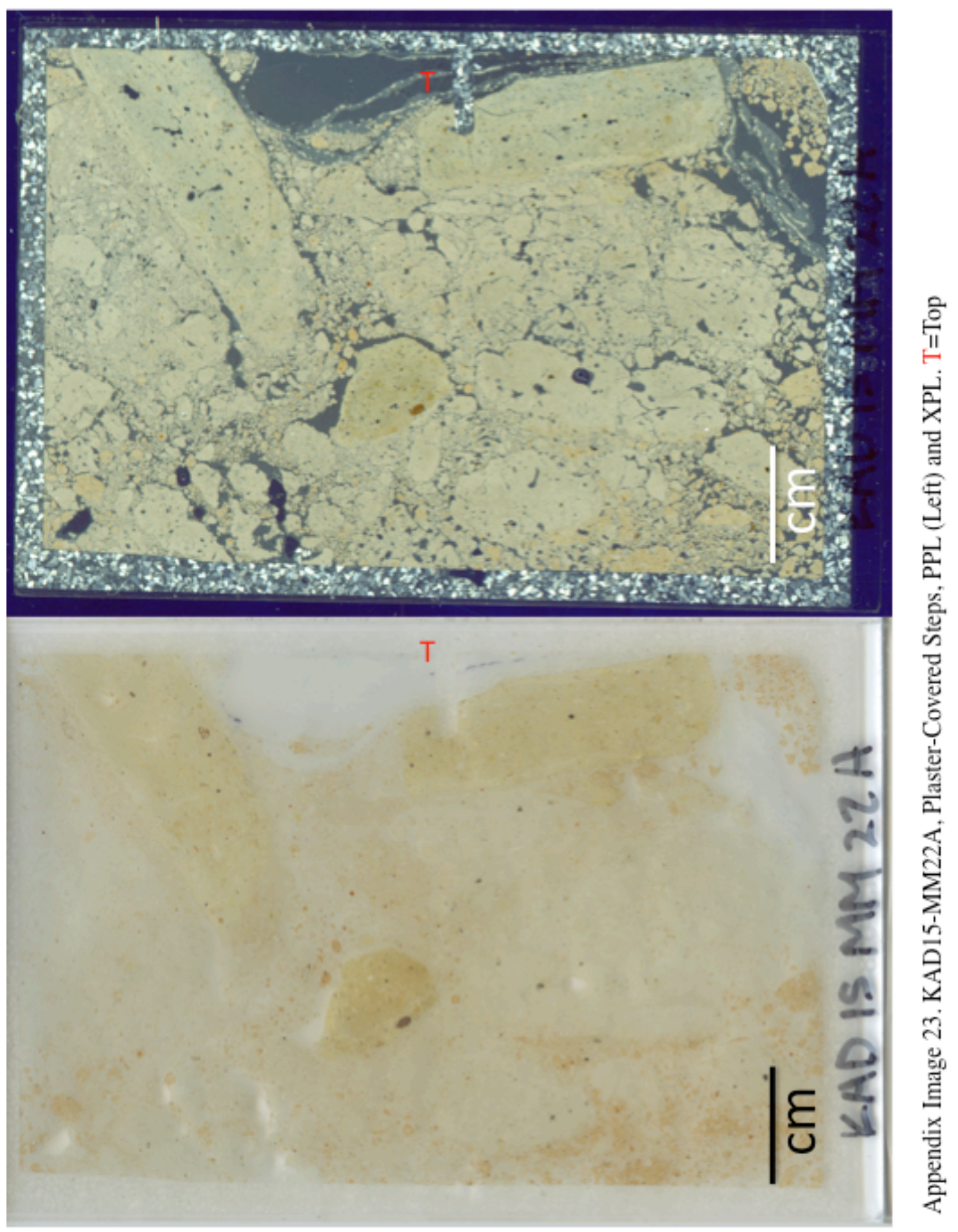


Master's Thesis - P Wallace; McMaster University - Anthropology

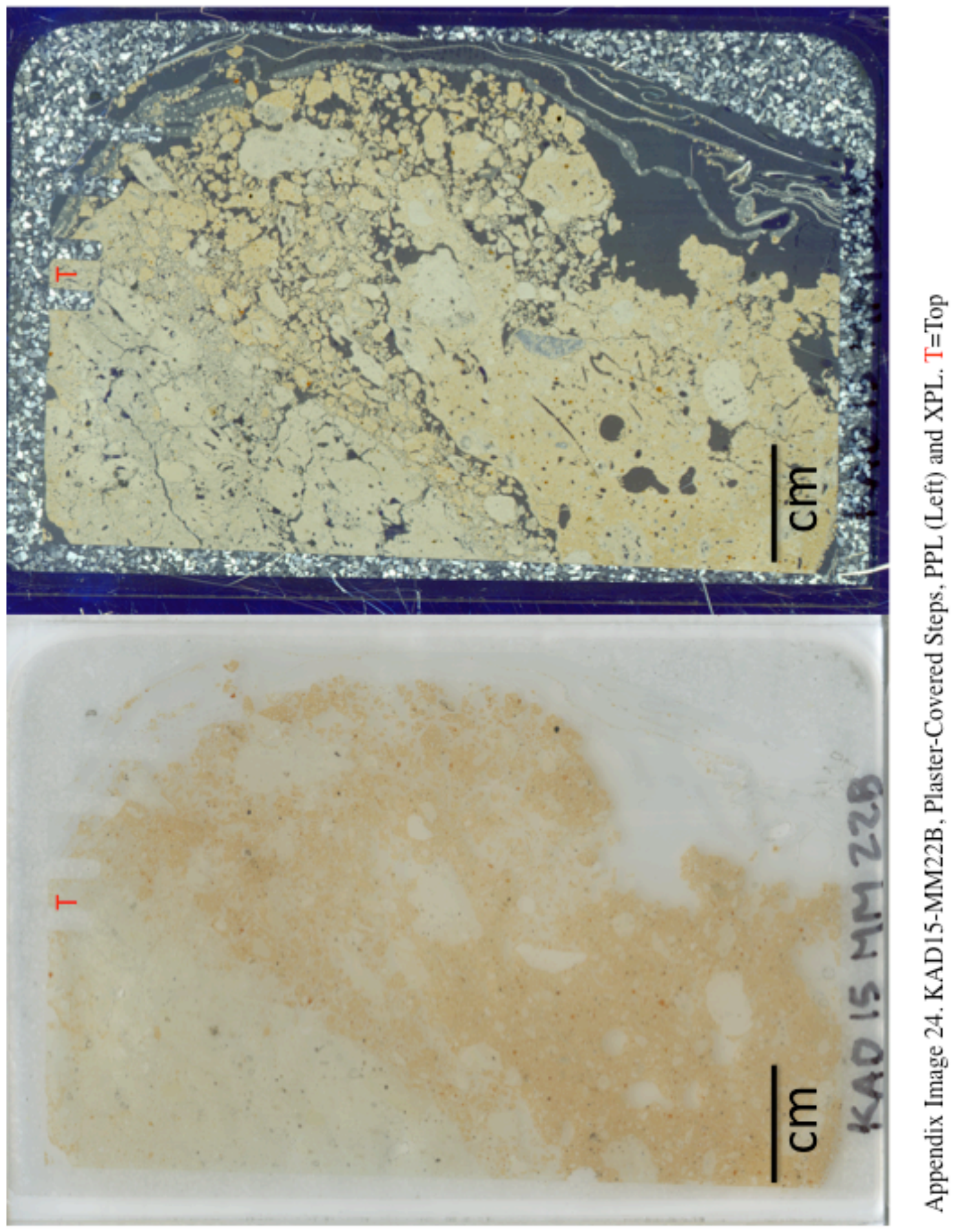


Master's Thesis - P Wallace; McMaster University - Anthropology

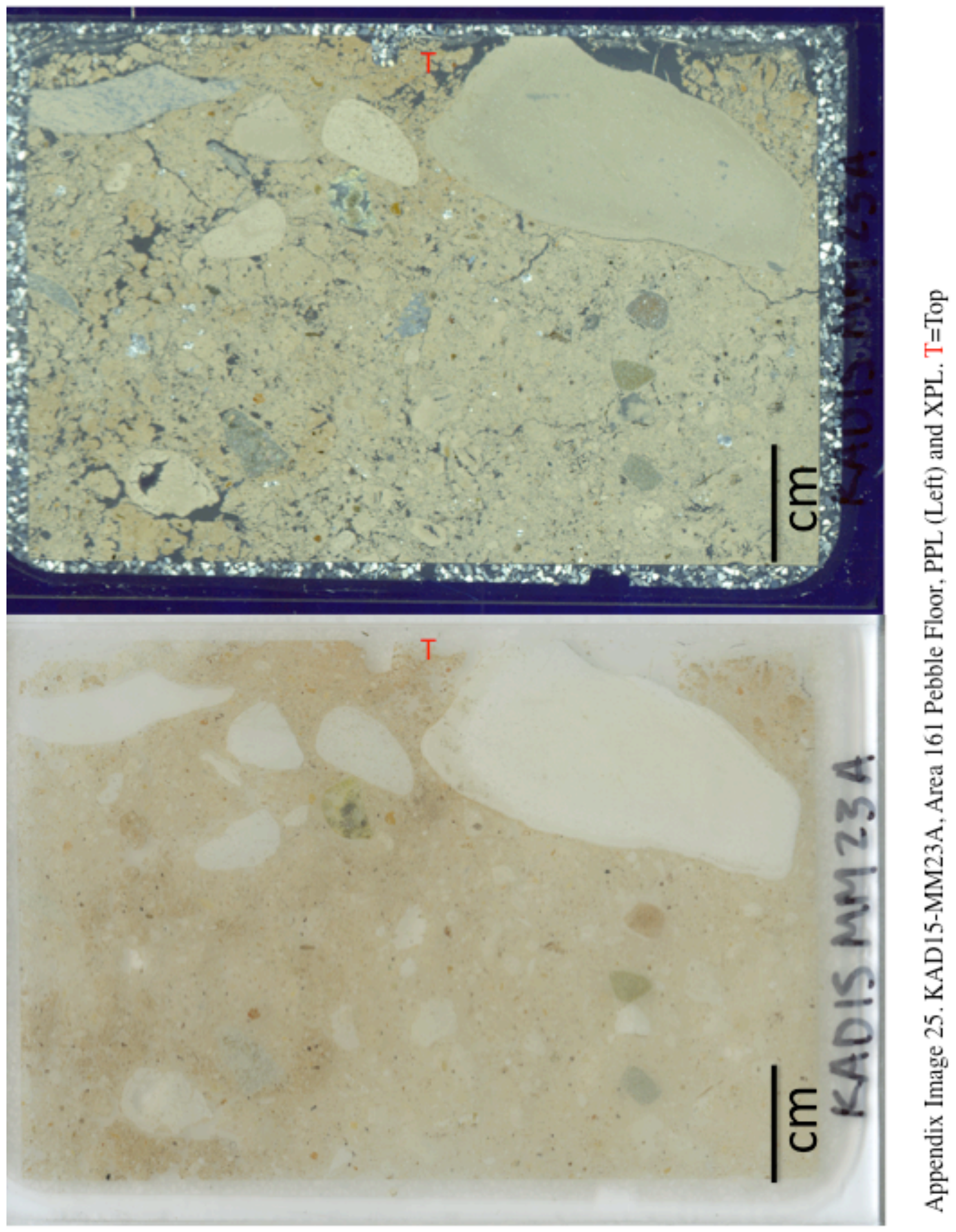


Master's Thesis - P Wallace; McMaster University - Anthropology

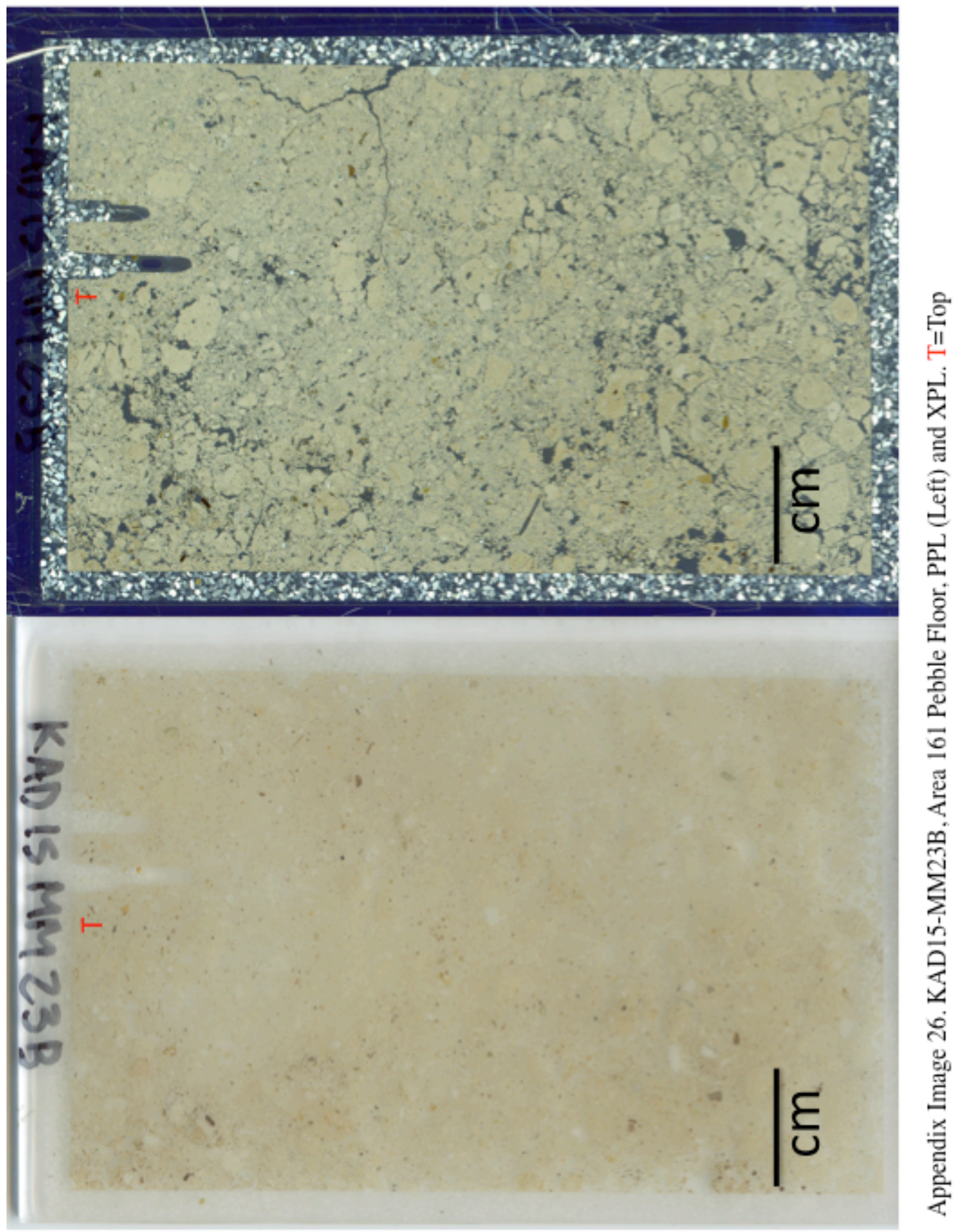


Master's Thesis - P Wallace; McMaster University - Anthropology

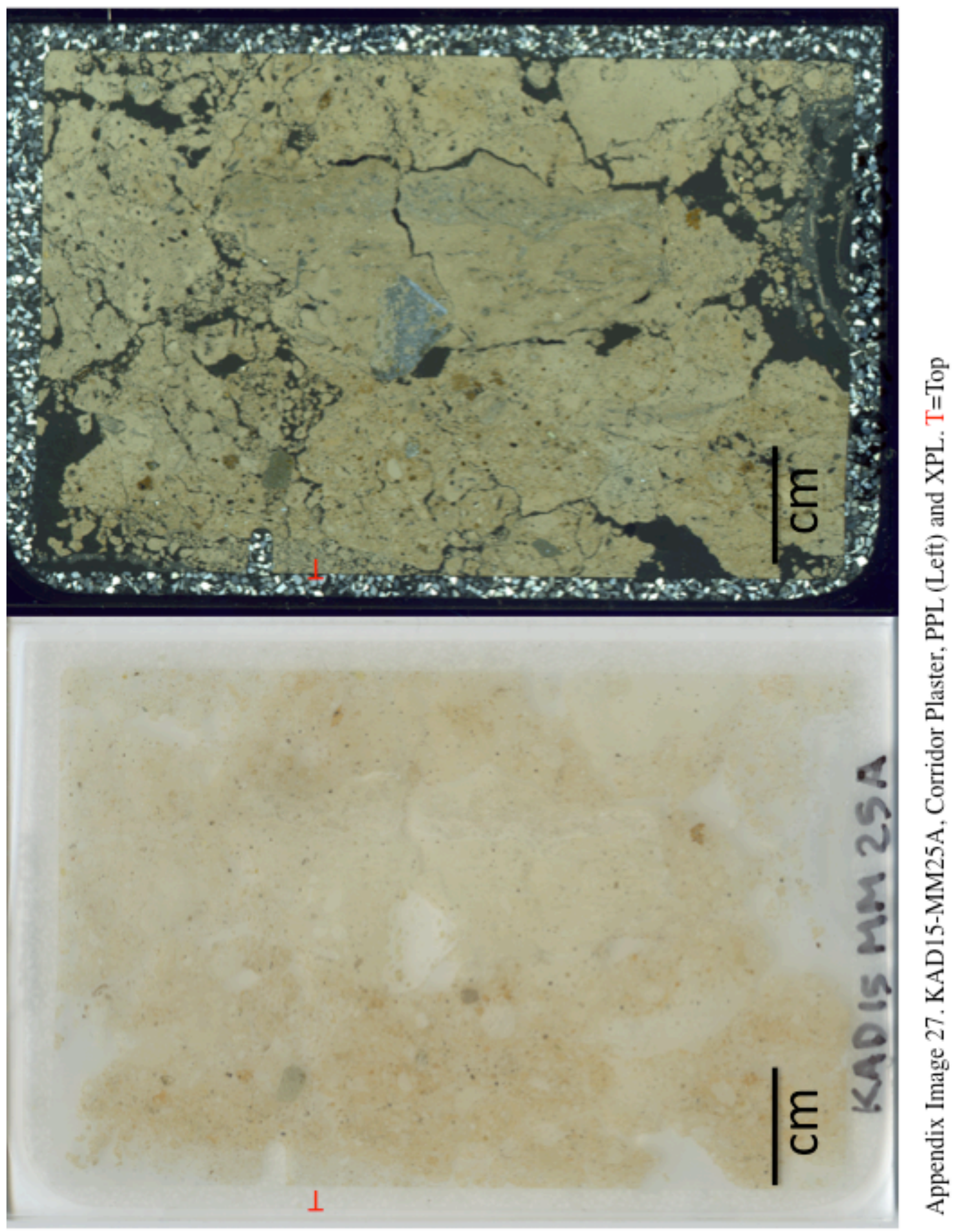


Master's Thesis - P Wallace; McMaster University - Anthropology

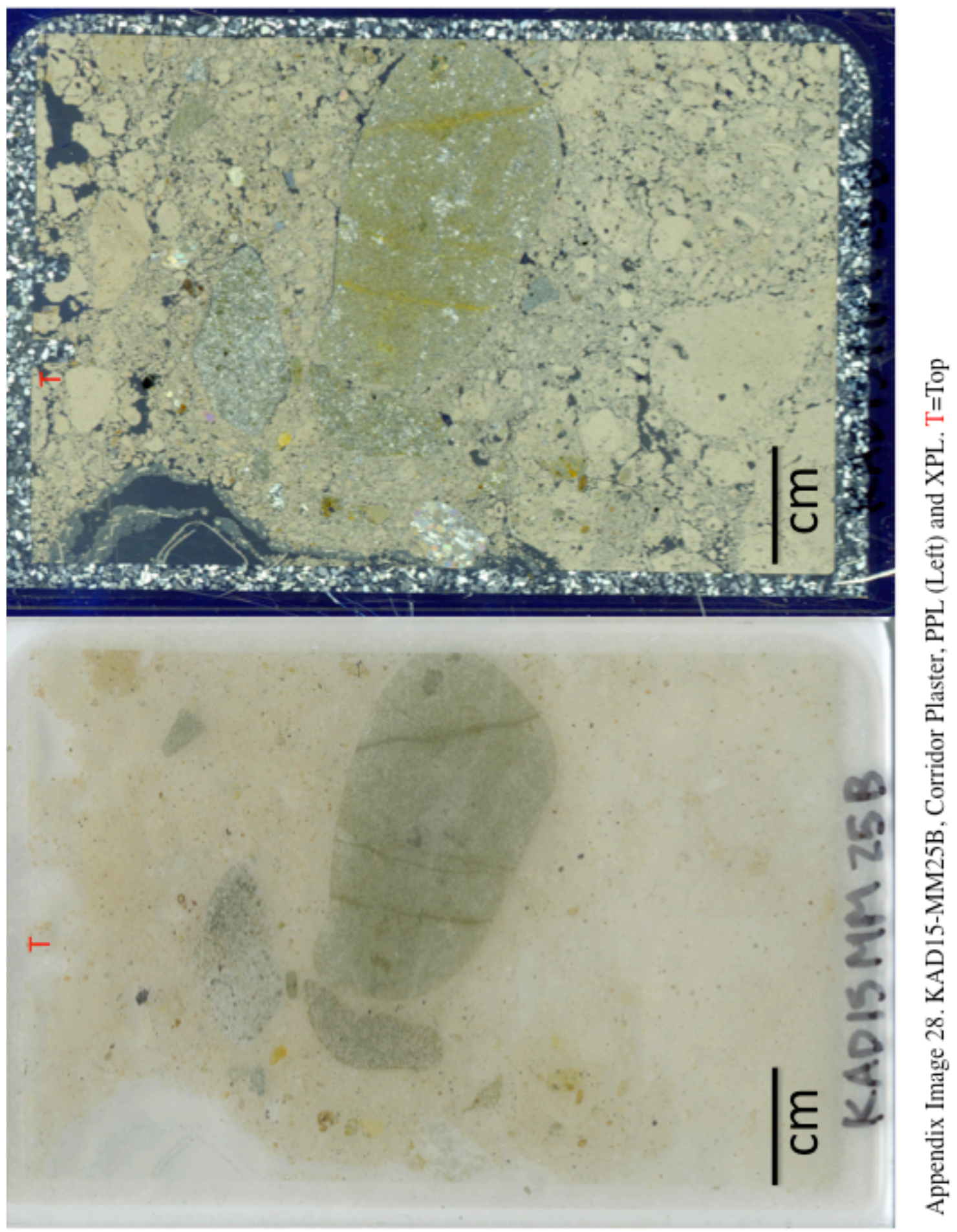


Master's Thesis - P Wallace; McMaster University - Anthropology

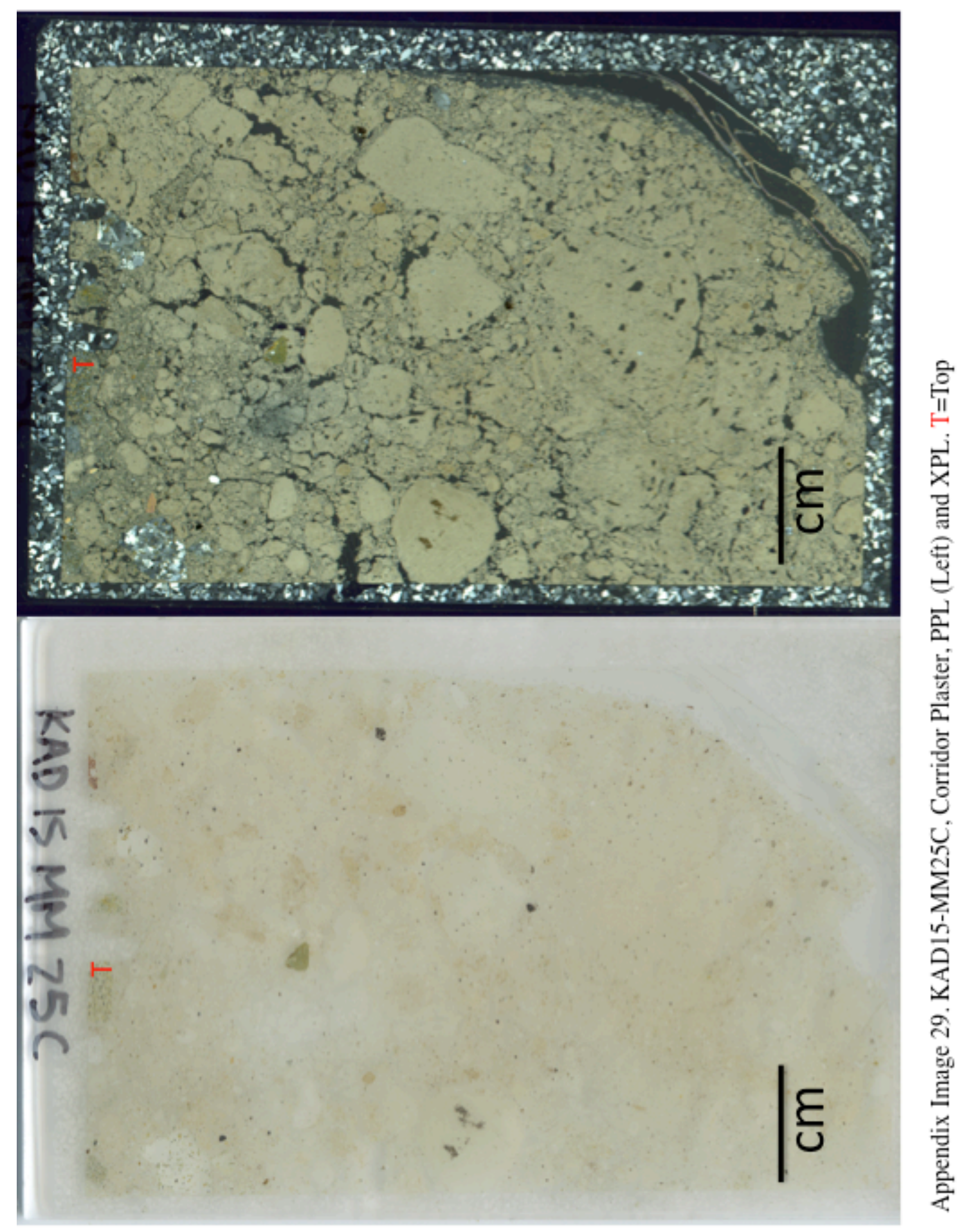


Master's Thesis - P Wallace; McMaster University - Anthropology
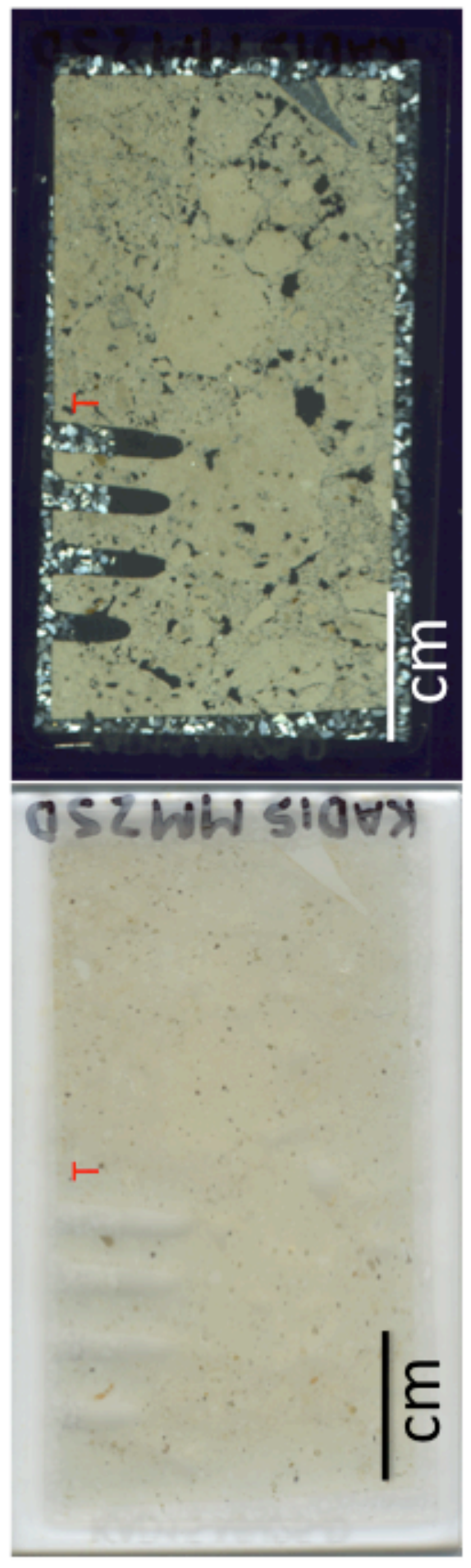

年 
Master's Thesis - P Wallace; McMaster University - Anthropology

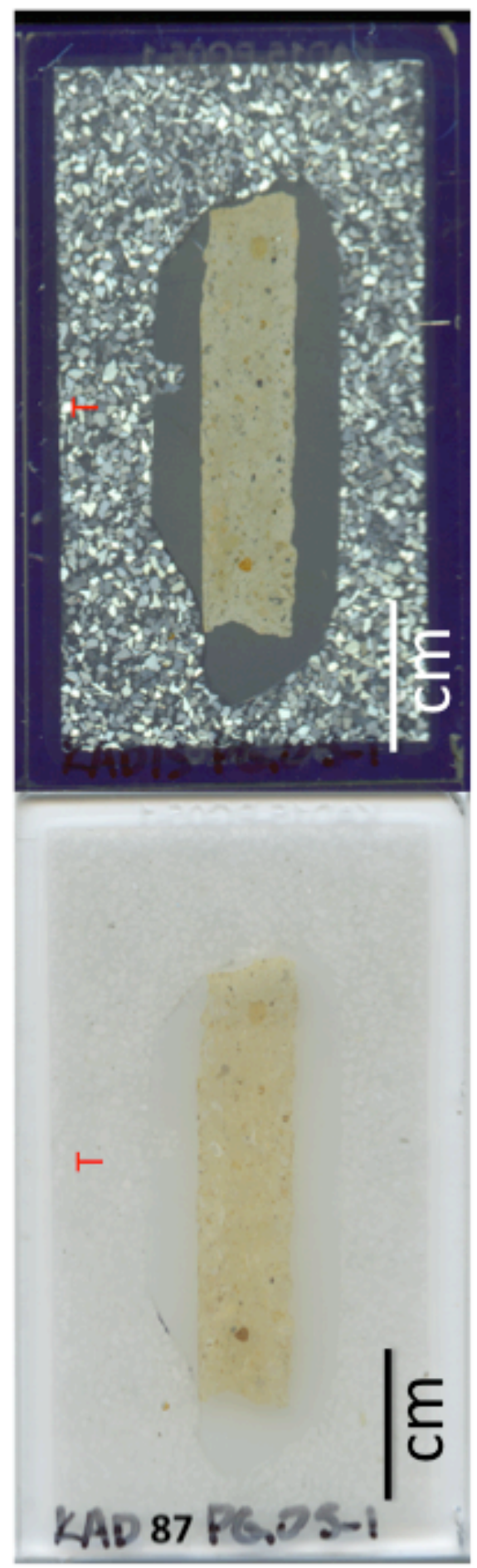

年 
Master's Thesis - P Wallace; McMaster University - Anthropology

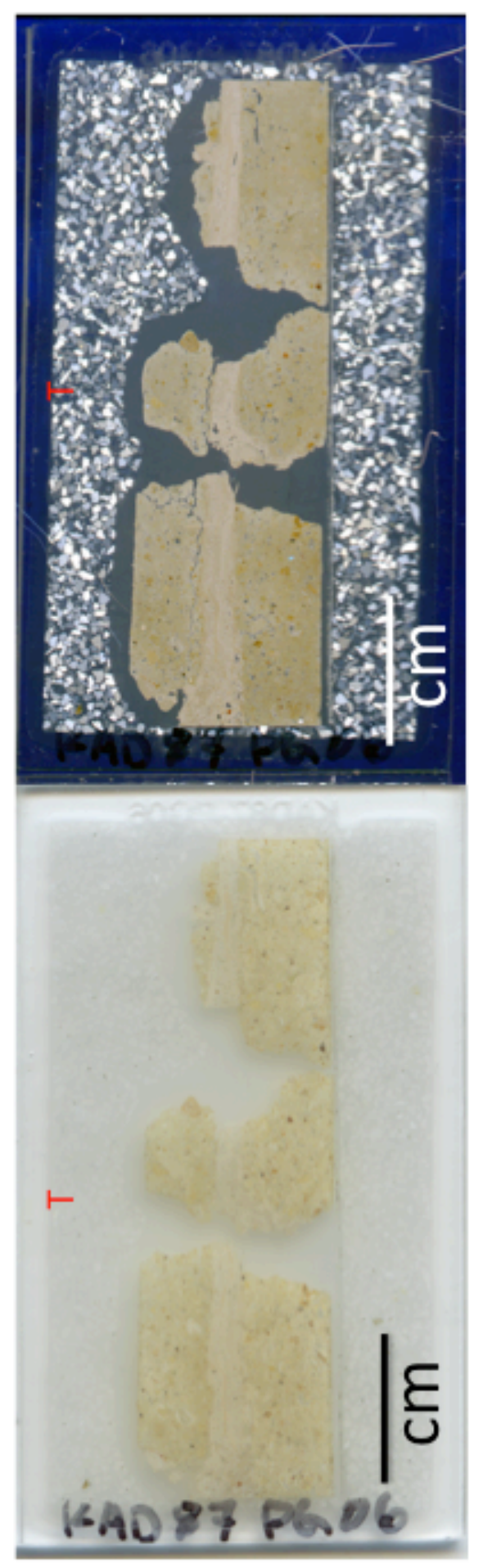

告 
Master's Thesis - P Wallace; McMaster University - Anthropology

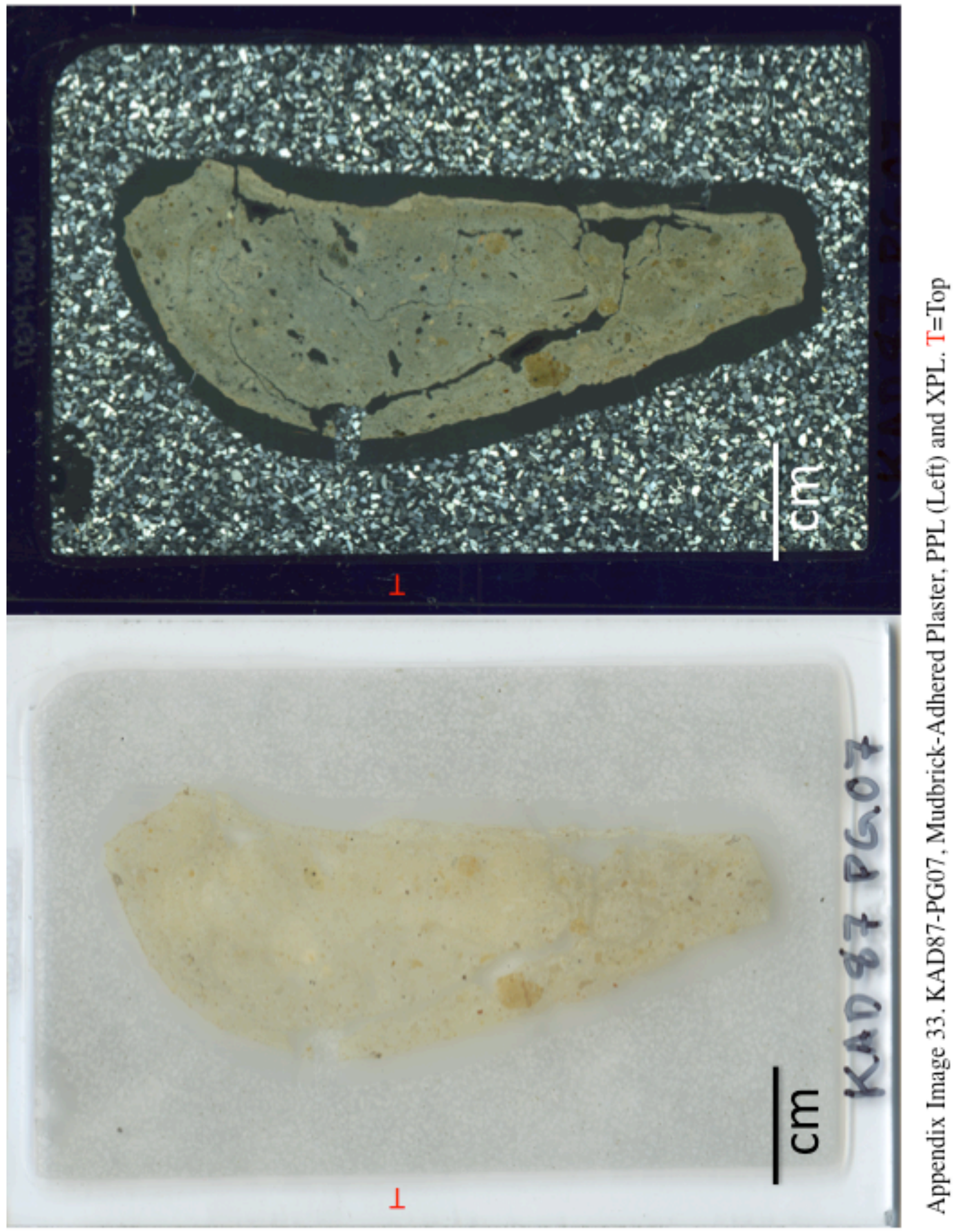


Master's Thesis - P Wallace; McMaster University - Anthropology

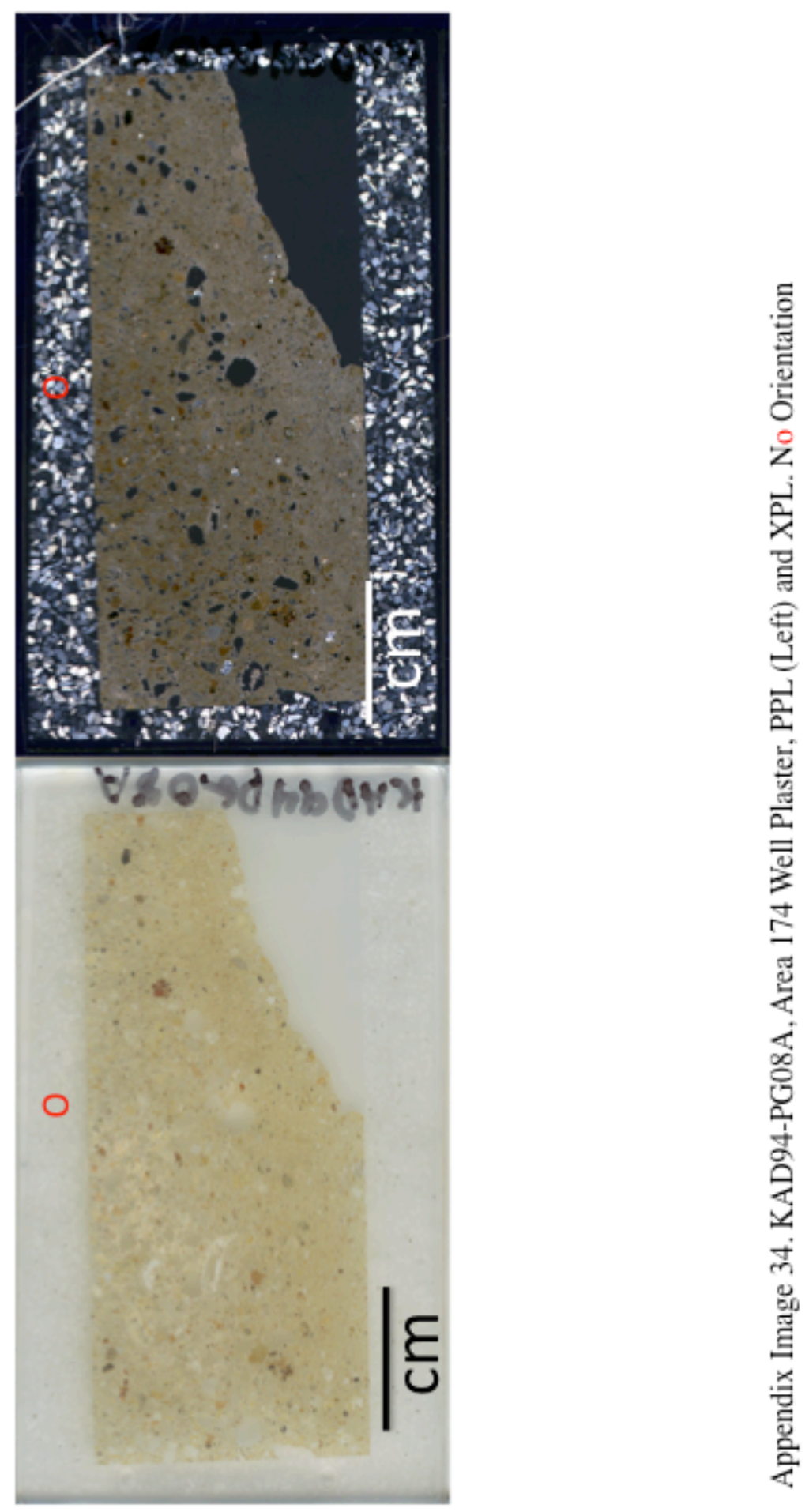


Master's Thesis - P Wallace; McMaster University - Anthropology

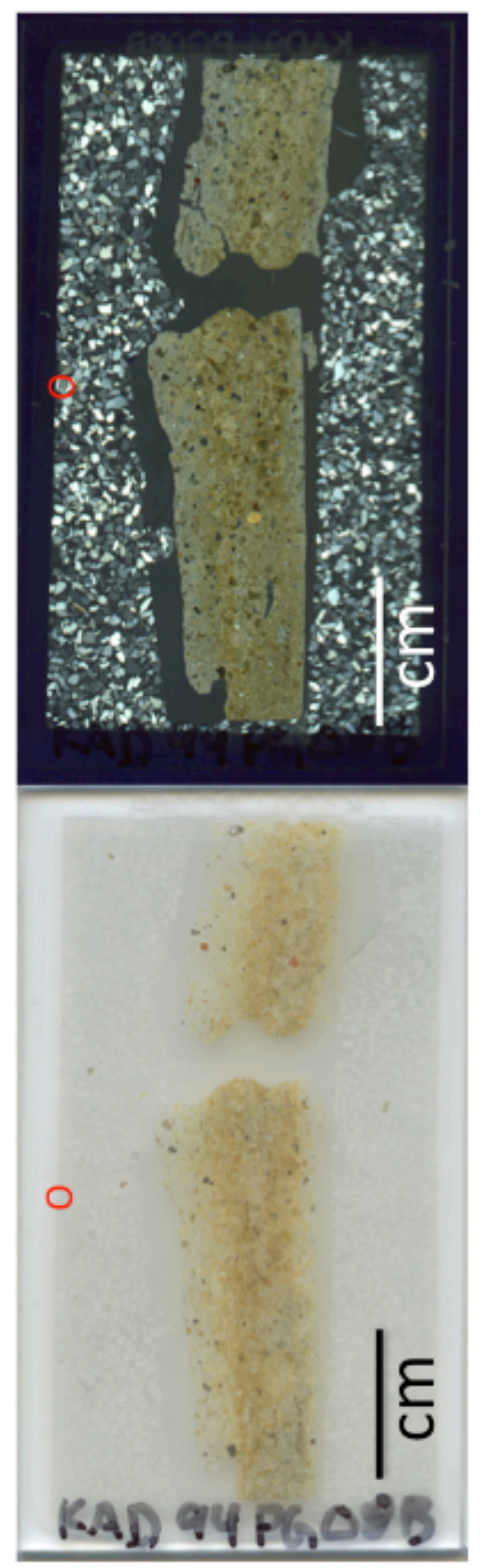

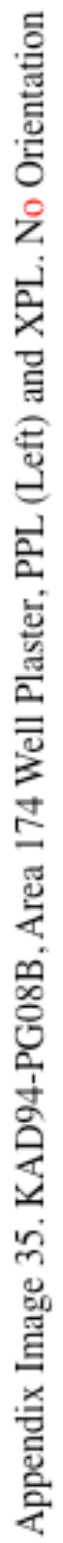


Master's Thesis - P Wallace; McMaster University - Anthropology

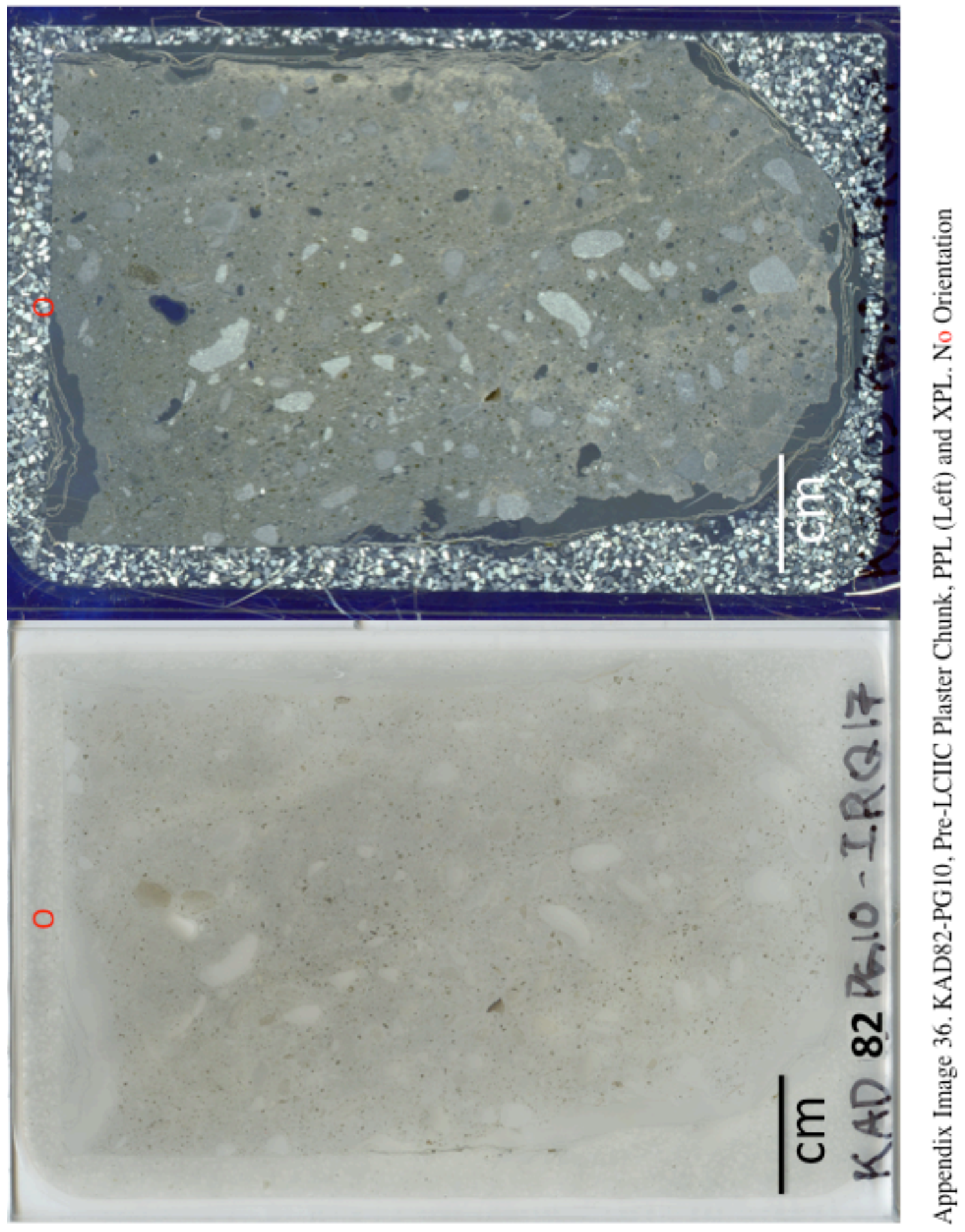


Master's Thesis - P Wallace; McMaster University - Anthropology

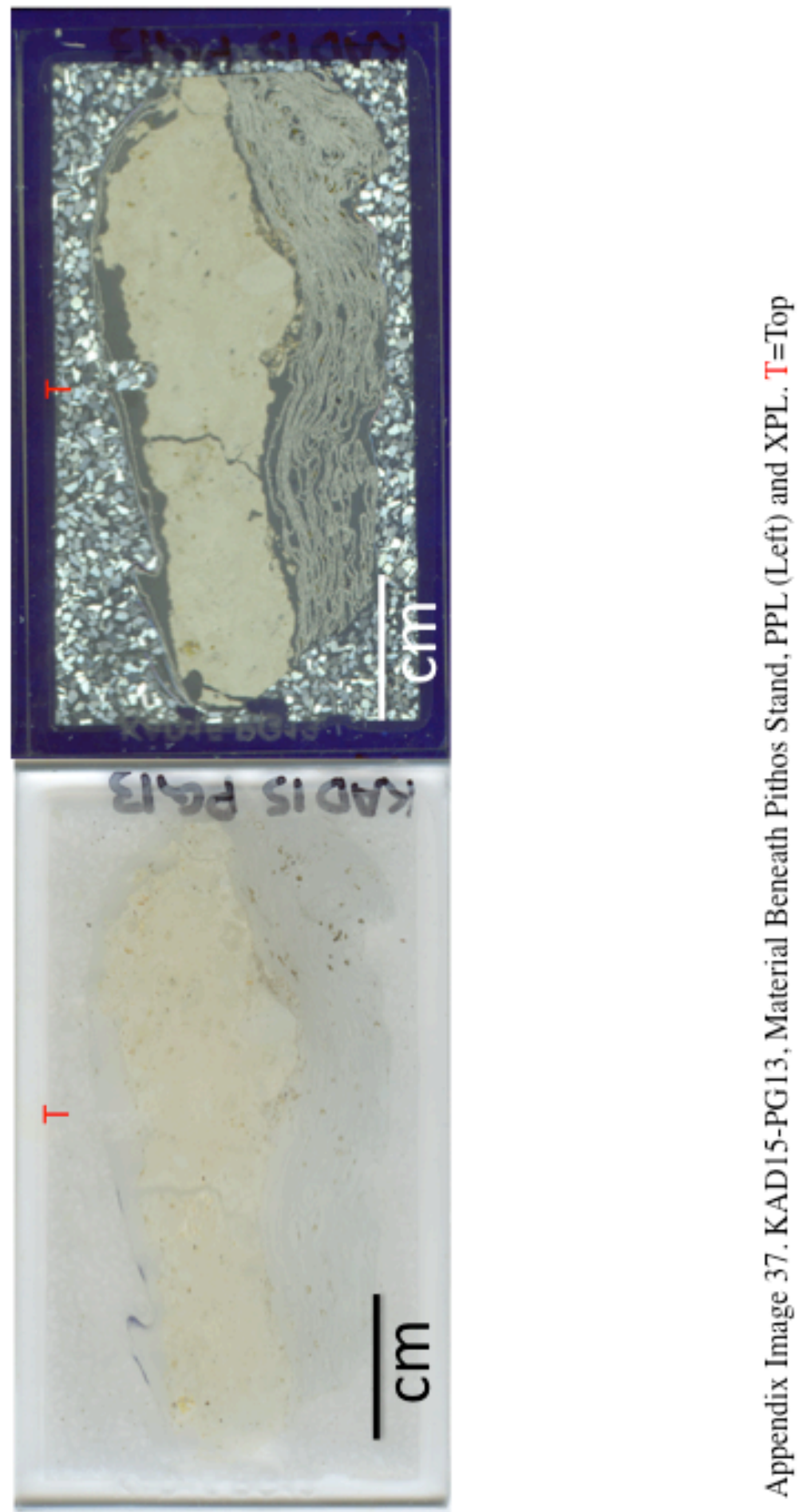


Master's Thesis - P Wallace; McMaster University - Anthropology

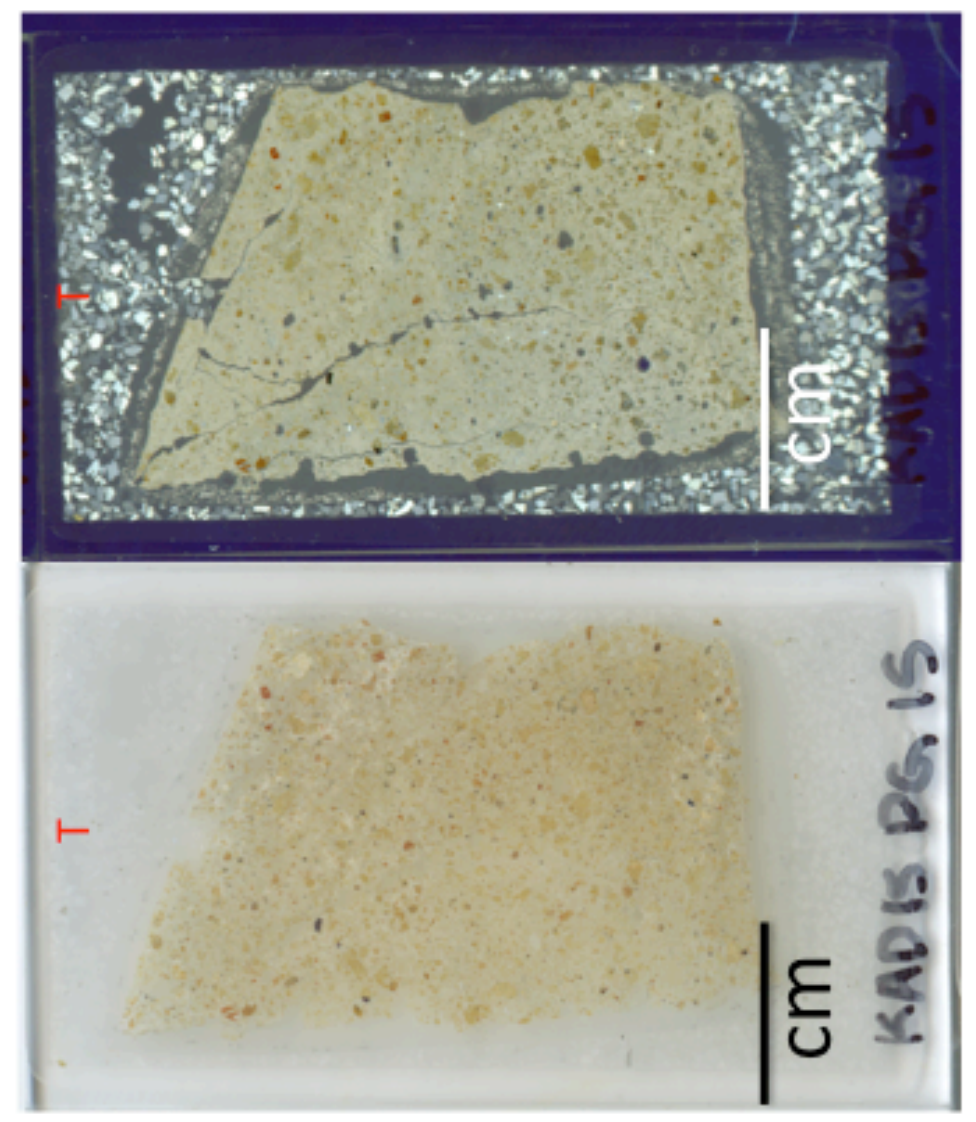

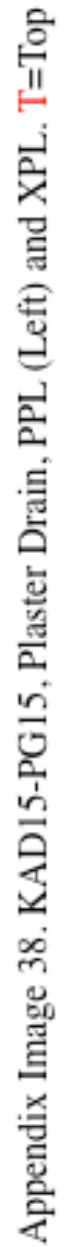


Master's Thesis - P Wallace; McMaster University - Anthropology

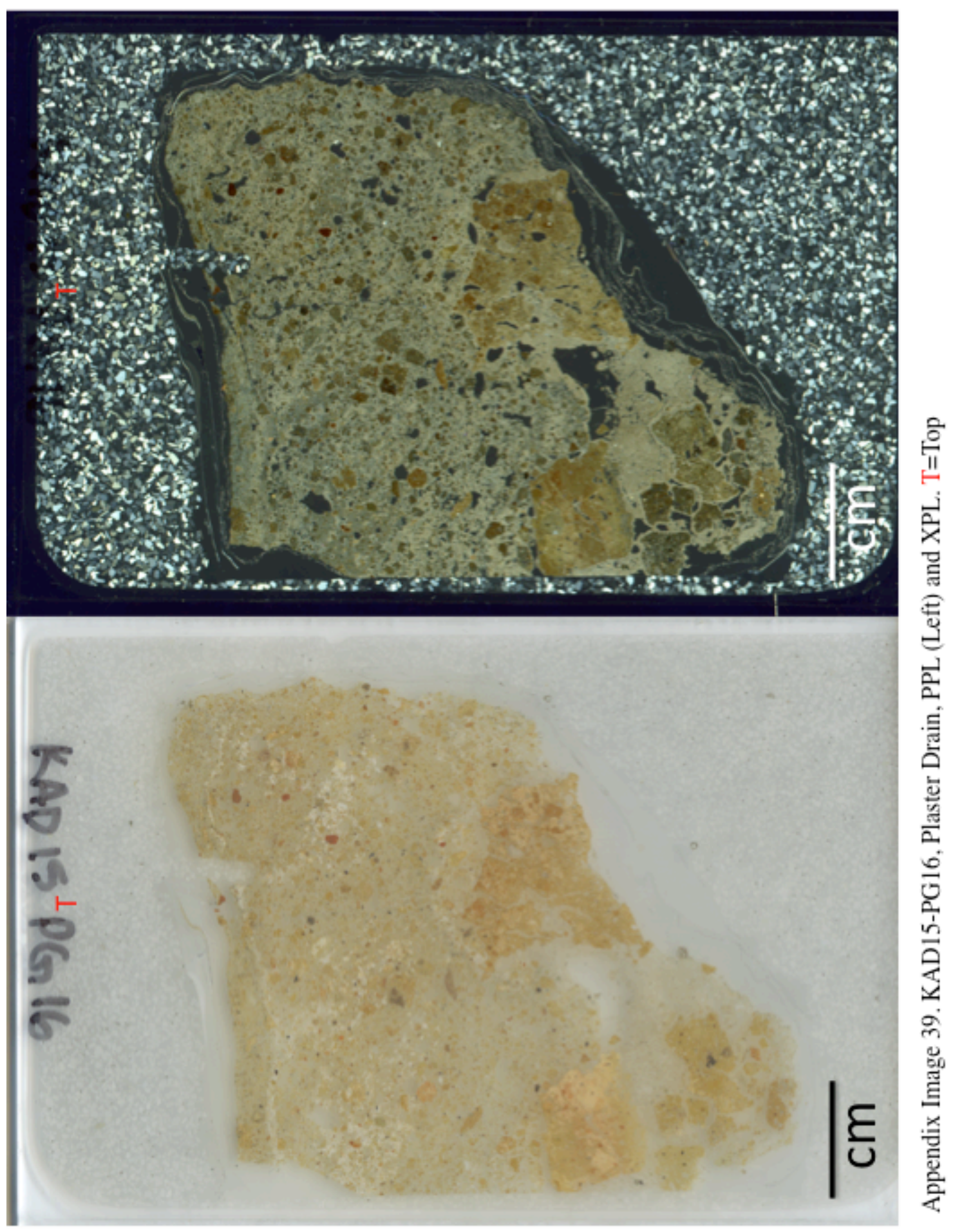


Master's Thesis - P Wallace; McMaster University - Anthropology

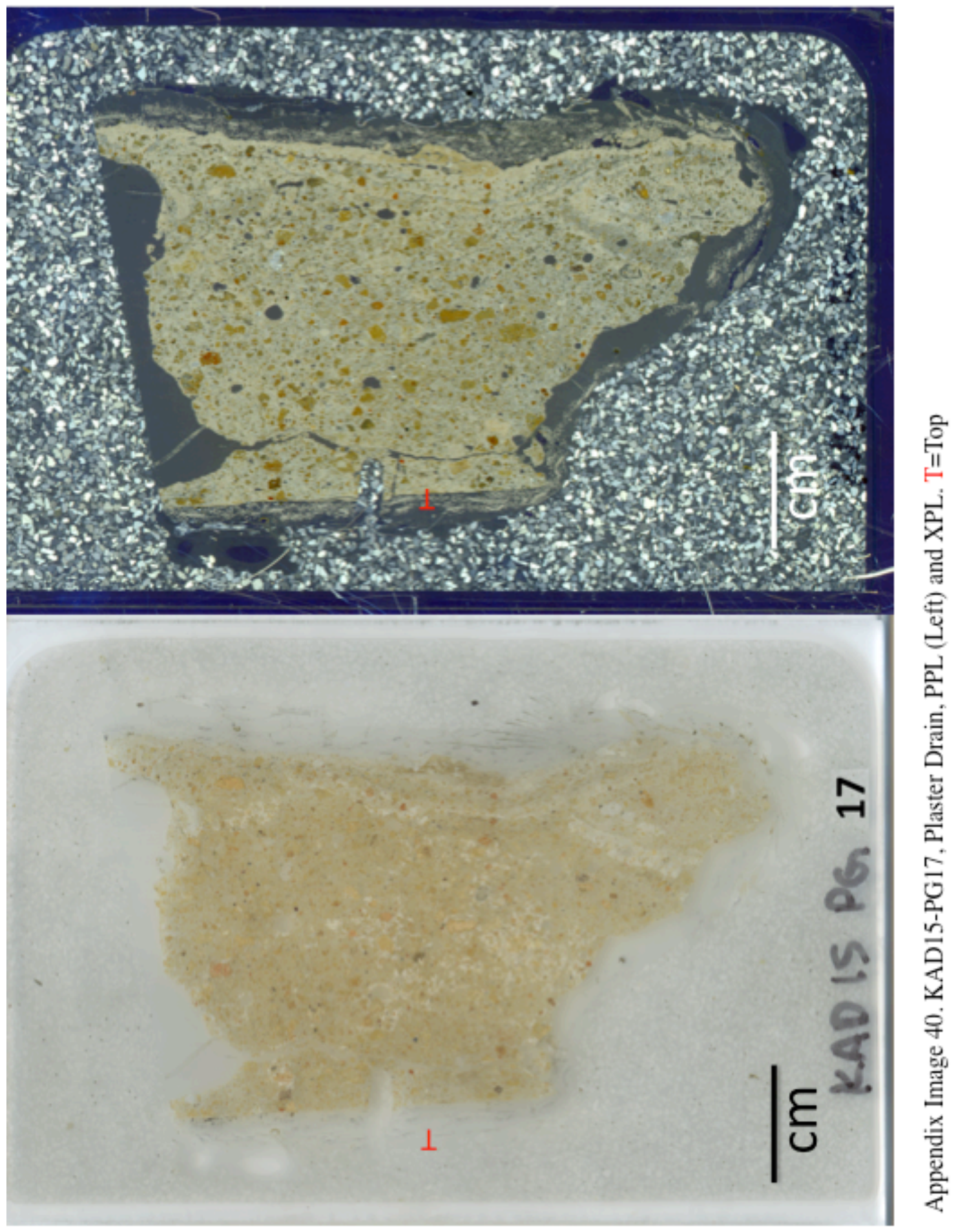


Master's Thesis - P Wallace; McMaster University - Anthropology

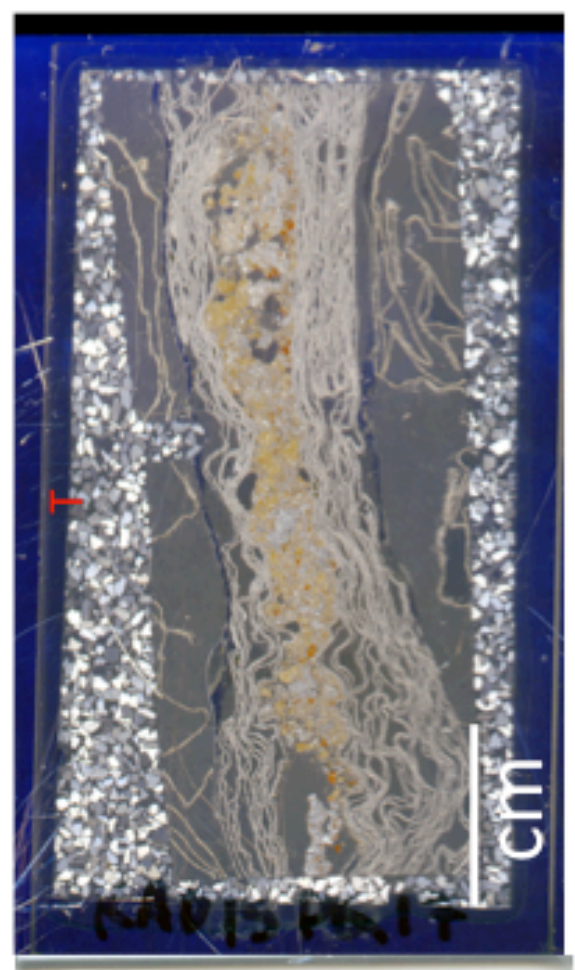

응

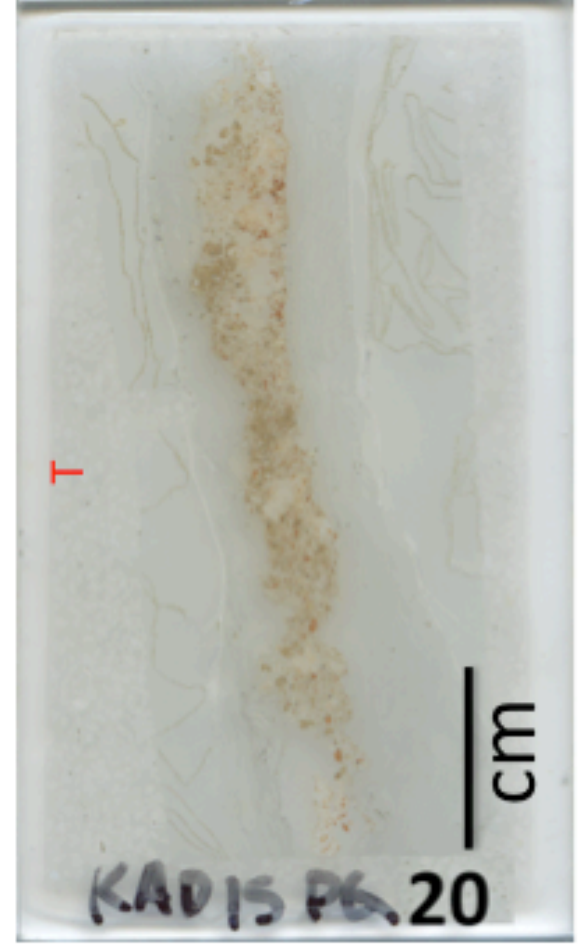

을 
Master's Thesis - P Wallace; McMaster University - Anthropology

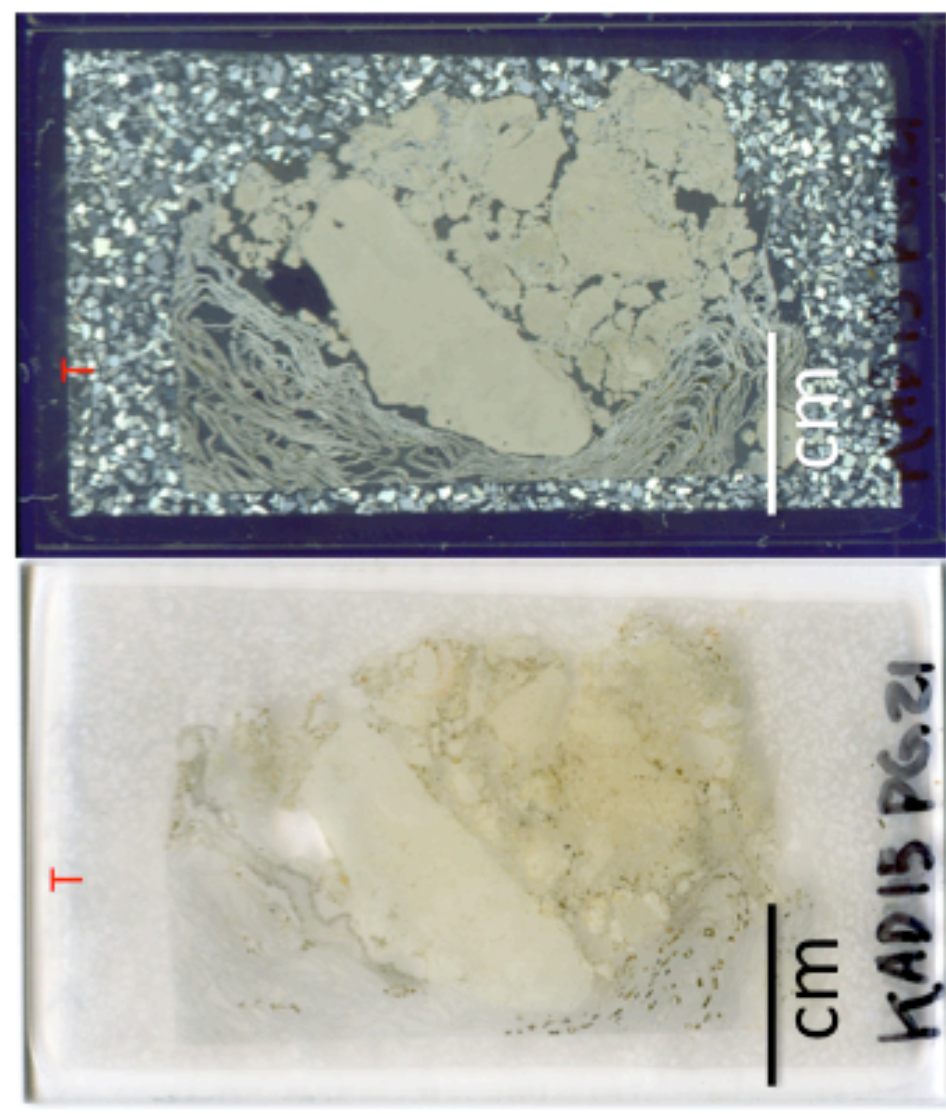

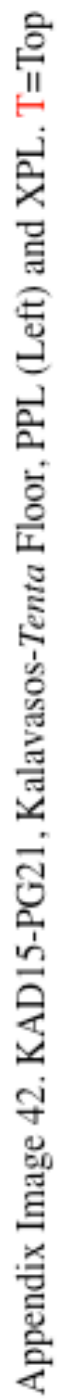


Master's Thesis - P Wallace; McMaster University - Anthropology

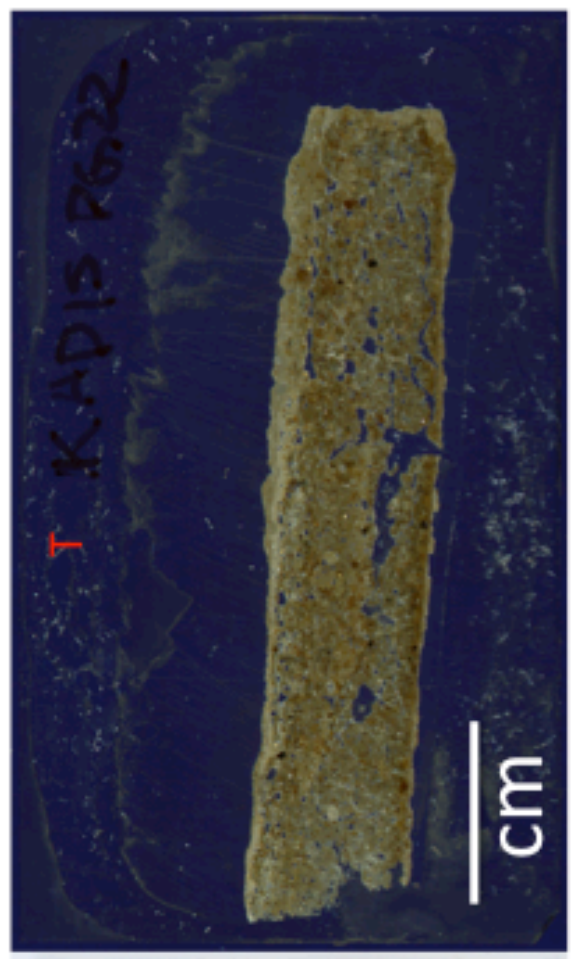

을

$\ddot{\theta}$

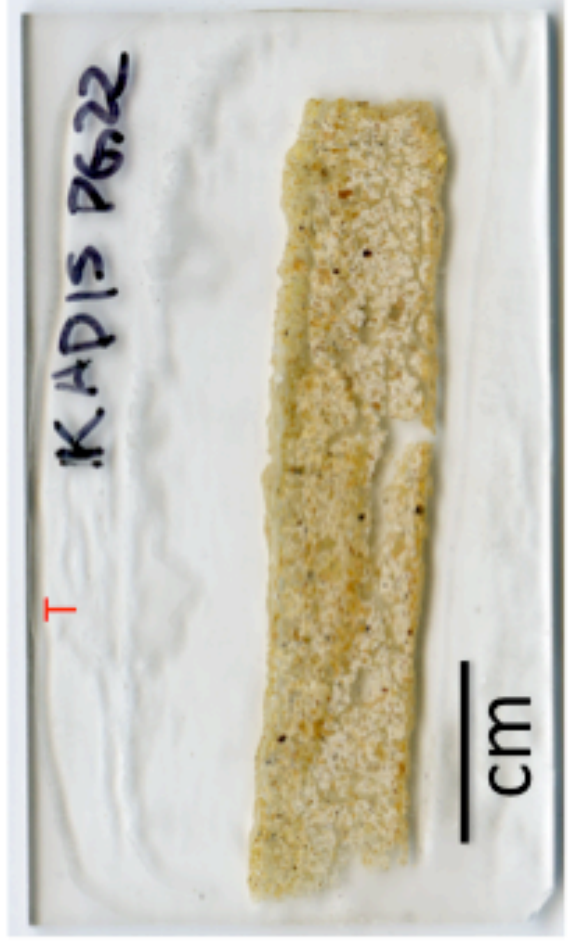

㤩

i

0

年

$\dot{7}$

욤

晋

츰 
Master's Thesis - P Wallace; McMaster University - Anthropology

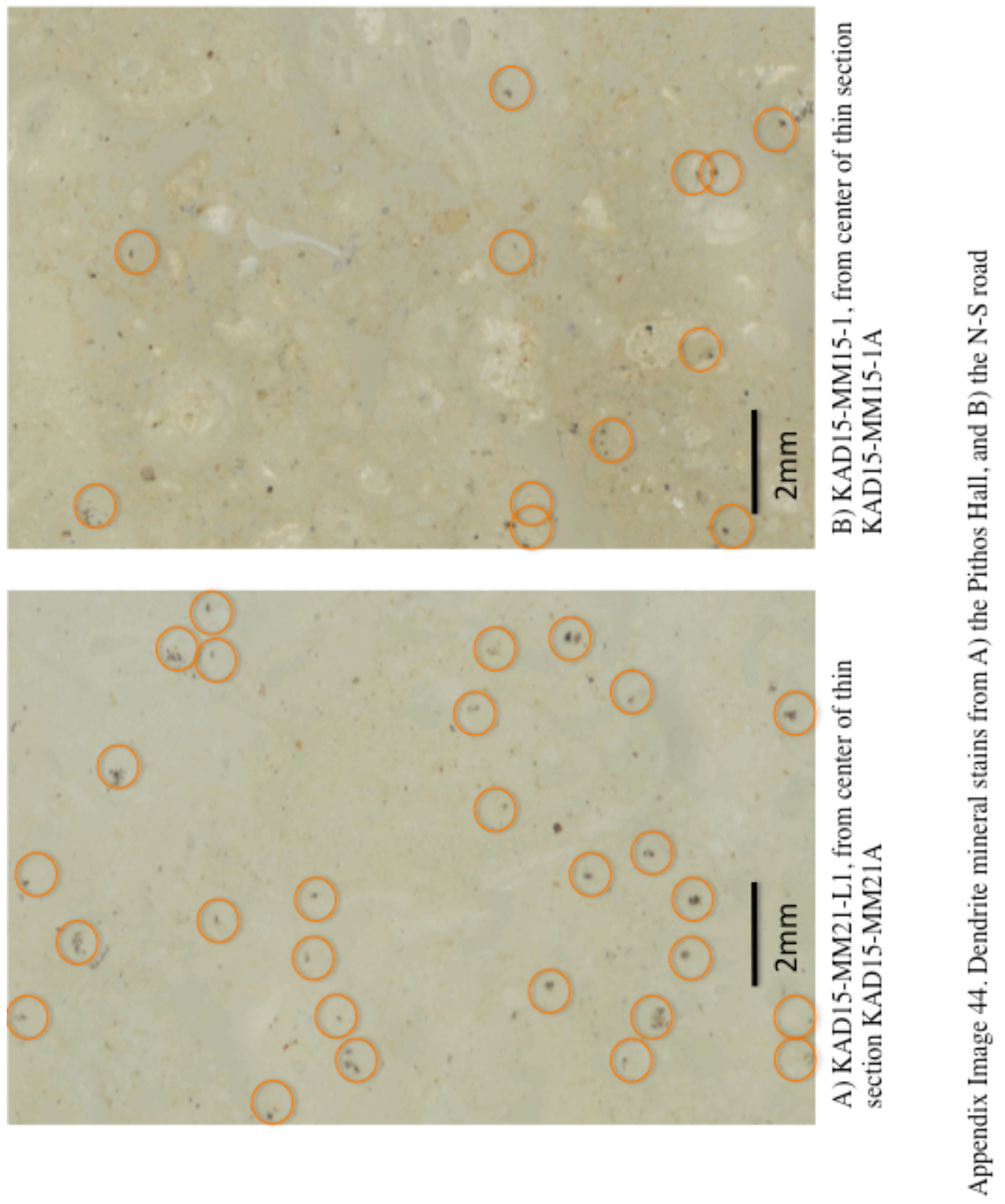


Master's Thesis - P Wallace; McMaster University - Anthropology

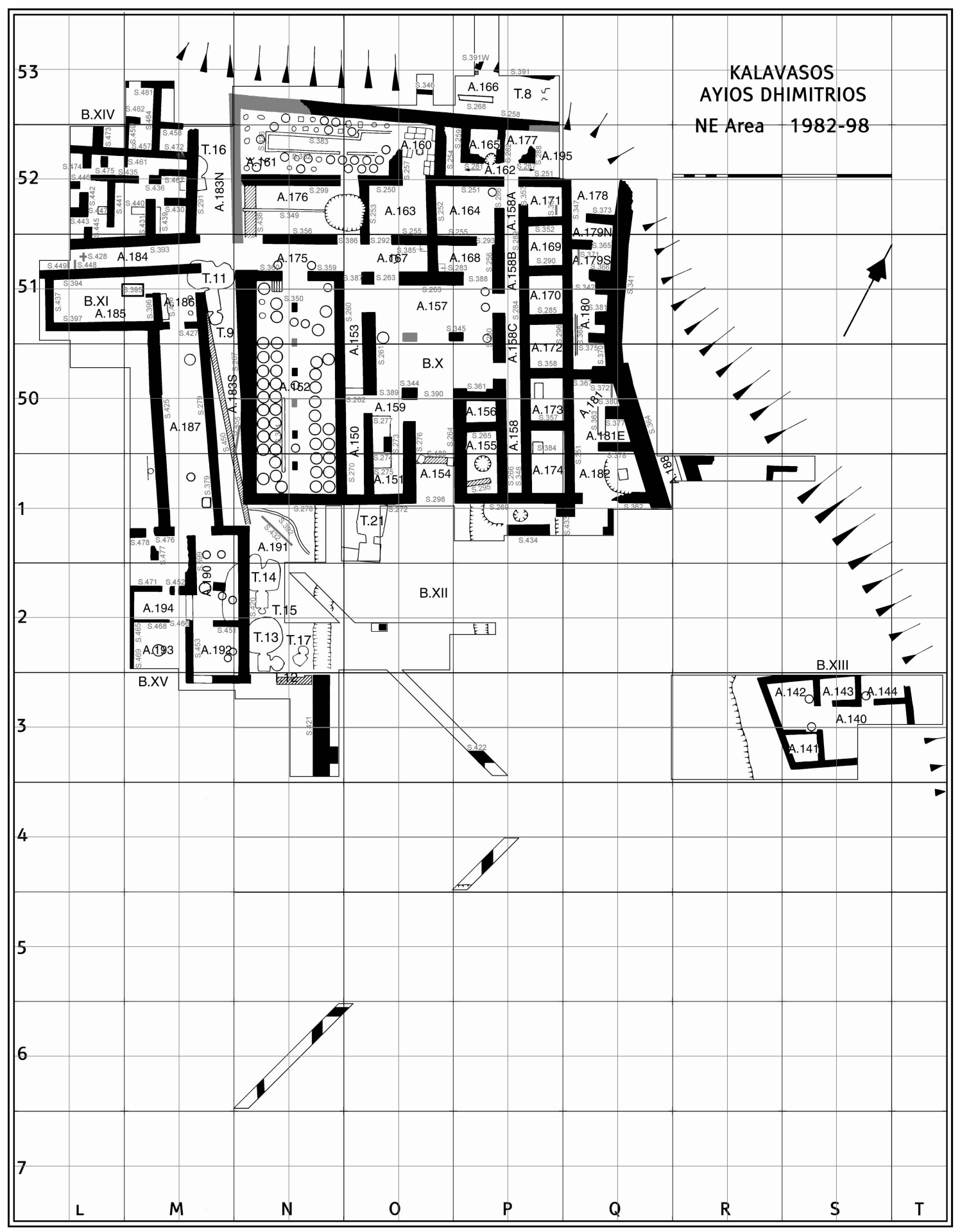

Appendix Image 45. 1982-98 site plan of K-AD with room numbers. Credit: Alison South. 